\title{
Guide to NIST
}

National Institute of Standards and Technology
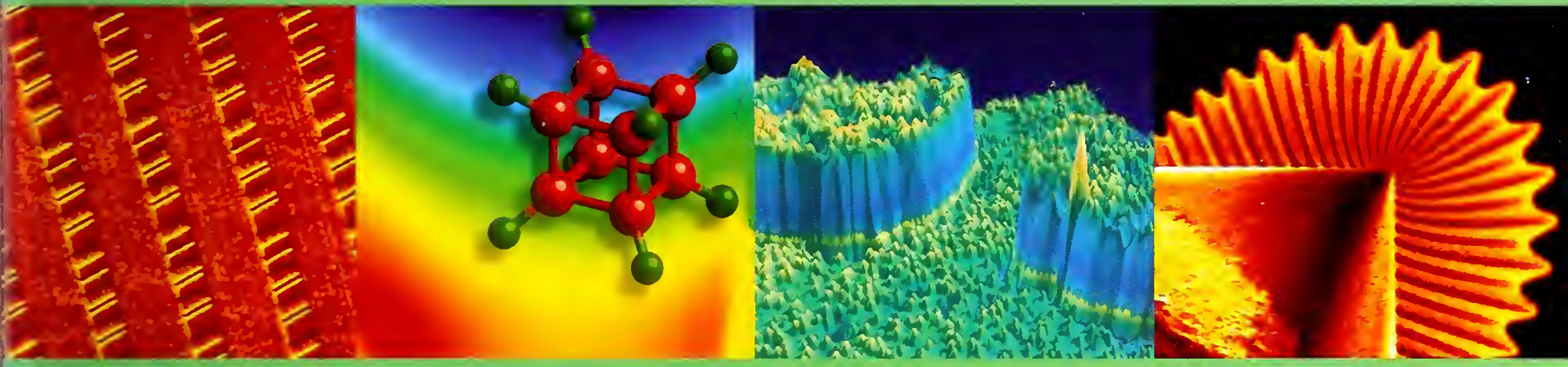

QC

100

.457

N0. 358

1998
U.S. DEPARTMENT OF COMMERCE

Technology Administration

www.nist.gov 
On the cover:

Graphics of scientific and engineering data or calculations often are used by NIST researchers to improve understanding of production processes, measurement methods, or scientific experiments. Shown on the cover from right to left are computer-generated graphics of:

- a scanning electron micrograph of a negatively charged diamond tip used in mealsuring surface roughness;

- an atomic-level image of chromium atoms (bumps) alloved in iron (flat areas) made ats part of a study of new matgnetic recording and storage materials;

- a cubane molecule superimposed on a plot used to describe how these unusual cube-shaped molecules stack together in a solid;

- magnetic data "tracks" encoded on a prototype reference sample that can be used to help improve the quality of computer disks;

- tree-like crystals growing als a pure metal solidifies;

- the microstructure of a tin-oxide film used in arrays of tiny sensors for detecting gases;

- the extent of chemical degradation on a biosensor film exposed to an electron beam-heights of raised areas correspond to the degree of damage in those areas; and

- the movement of smoke particulates and combustion products from burning of a crude oil spill as predicted by the NIST software program, ALOFT. 
Success in business these days is about specialties and partnerships - knowing what you're good at and teaming with others to do everything else. At the National Institute of Standards and Technology, our specialty is technology and business infrastructureputting in place key ingredients that industry needs to thrive and help the economy grow. Partnerships are central to everything we do. Infrastructure has no value if it is not used.

This Guide to NIST is designed to help make forming partnerships with NIST a little easier. Here you will find descriptions for more than 300 different programs and projects along with contact names, phone numbers, addresses, and World Wide Web sites.

An agency of the U.S. Department of Commerce's Technology Administration, NIST's mission is to promote U.S. economic growth by working with industry to develop and apply technology, measurements, and standards. It carries out this mission through four major programs, each one addressing different components of the technology pipeline.

NIST's seven disciplinary Measurement and Standards Laboratories work at all stages of the pipeline from advancing basic science and pioneering new measurement methods to the development of standard test methods, materials, and data to ensure the quality of commercial products.

The Advanced Technology Program helps fill the gaps that often exist between basic research advances and commercialization by providing cost-shared funding to industry for development of high-risk, "enabling" technologies with broad commercial potential.

The Manufacturing Extension Partnership uses a nationwide network of centers to help smaller manufacturers adopt technologies and business practices that can improve their competitiveness in the global marketplace.
Finally, the Baldrige National Quality Program provides information to companies of all sizes on how to continuously improve their products, services, and processes through effective business and quality management.

I see several challenges ahead for NIST's future. Shortening of product cycles, globalization of standards, the next generation Internet, continuous education and training - these are trends that will profoundly affect the business of U.S. industry. NIST is responding with a number of new initiatives including the construction of new world-class research facilities, support for a comprehensive national standards strategy, increased emphasis by the ATP on joint ventures and participation by small to midsized firms, improved access for smaller manufacturers to MEP centers, and promotion of quality management concepts for the healthcare and education sectors.

And as we anticipate both the new millennium and NIST's 100th anniversary in 2001, we're confident that some things will stay the same — namely our commitment to accuracy, fairness, and scientific excellence. NIST's vision is to be the best in the world at what we do. We hope you'll take a moment now to stroll through these pages and see how your organization might benefit by joining us in that quest.

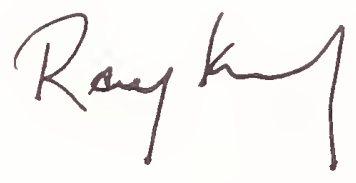

Raymond Kammer, Director email: director@nist.gov

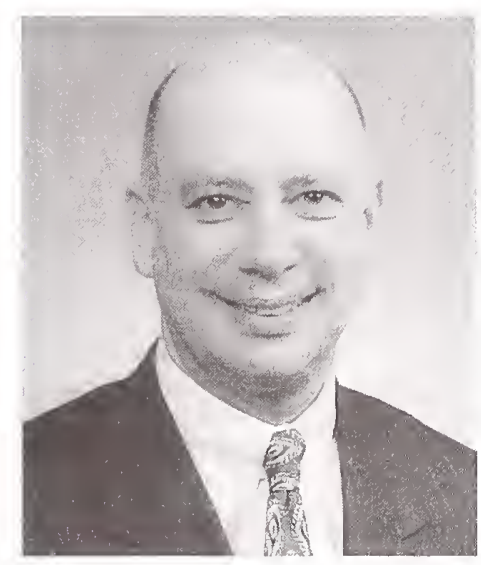




\section{HOW TO USE THIS GUIDE}

This guide is designed to make finding out about programs and contacts at the National Institute of Standards and Technology a little easier.

The pages that follow describe hundreds of NIST projects, grants, industry outreach programs, services, and facilities, followed by contact names; phone numbers; and mail, electronic mail, and, in some cases, World Wide Web addresses for further information. Unless otherwise noted, all addresses listed are at NIST, Gaithersburg, Md. 208990001.

This guide is divided into chapters covering each of NIST's major operating units. In addition, each chapter on the Measurement and Standards Laboratories' programs includes subheadings for NIST organizational divisions or subject areas.

NIST's Measurement and Standards Laboratories deliver essential public goods to companies, universities, and government agencies. The reach of NIST's high-quality measurement tools, data, and services extends from science and medicine to industry and commerce and from health and the environment to law enforcement and national defense.

Researchers in the NIST Measurement and Standards Laboratories actively seek out industrial and other collaborators to work on well-defined, cooperative research projects of mutual interest. In addition, NIST researchers collaborate informally with industrial and academic researchers to solve shorter-term technical problems. For an overview of the many different ways NIST may be able to work with your organization, see a description of the NIST Measurement and Standards Laboratories beginning on page 35.
The Advanced Technology Program provides multiyear, cost-shared funding for highrisk, high-payoff development of technologies by individual companies or industry-led joint ventures. ATP accelerates development of technologies that otherwise are unlikely to be available in time to compete in rapidly changing markets without such a partnership of industry and government. See description on page 6 .

The Manufacturing Extension Partnership operates a nationwide network of regionally based extension centers that help smaller manufacturers adopt modern technologies and business practices. Through MEP even the smallest firms have access to more than 2,000 knowledgeable manufacturing and business specialists. See description on page 25 .

The Malcolm Baldrige National Quality Award has become both the U.S. standard of performance excellence in business and a comprehensive guide to quality improvement. The Baldrige National Quality Program, which manages the Baldrige Award, develops and disseminates evaluation criteria and provides global leadership in promoting quality awareness and in the sharing of successful quality practices, principles, and strategies. See description on page 33 .
A detailed subject index begins on page 170 . Due to the interdisciplinary nature of NIST's work, many topic areas appear in more than one chapter. For example, research involving polymers is described in different chapters: polymer processing and structure investigations within the Materials Science and Engineering Laboratory and polymer combustion studies within the Building and Fire Research Laboratory.

This guide attempts to include all major NIST program areas. However, no single report can be completely comprehensive. Institute programs change constantly as new research results and technologies become available. If you don't find a topic area that specifically matches your needs, contact the office for the research area closest to your field of interest.

If you review this guide and you're still not sure which office to call, the NIST General Inquiries unit probably can help you.

Contact:

General Inquiries

(301) 975-NIST

email: inquiries@nist.gov

fax: (301) 926-1630

A903 Administration Building

NIST

Gaithersburg, Md. 20899-0001 


\section{CONTENTS}

4 NIST at a Glance

6 Advanced Technology Program

25 Manufacturing Extension Partnership

33 Baldrige National Quality Program

35 Measurement and Standards Laboratories

$40 \quad$ Building and Fire Research Laboratory

51 Chemical Science and Technology Laboratory

$76 \quad$ Electronics and Electrical Engineering Laboratory

$99 \quad$ Information Technology Laboratory

109 Manufacturing Engineering Laboratory

126 Materials Science and Engineering Laboratory

144 Physics Laboratory

164 Technology Services

170 Facilities Index

170 Subject Index 
The National Institute of Standards and Technology was established by Congress "to assist industry in the development of technology ... needed to improve product quality, to modernize manufacturing processes, to ensure product reliability ... and to facilitate rapid commercialization ... of products based on new scientific discoveries."

An agency of the U.S. Department of Commerce's Technology Administration, NIST's primary mission is to promote U.S. economic growth by working with industry to develop and apply technology, measurements, and standards. It carries out this mission through four interwoven programs:

- the Measurement and Standards Laboratories, providing vital components of the nation's technology infrastructure needed by U.S. industry to continually improve products and services;

- the Advanced Technology Program, providing cost-shared awards to industry for development of high risk, enabling technologies with broad economic potential;

- a grassroots Manufacturing Extension Partnership with a nationwide network of local centers offering technical and business assistance to smaller manufacturers; and

- a highly visible quality outreach program associated with the Malcolm Baldrige National Quality Award that recognizes business performance excellence and quality achievement by U.S. manufacturers and service companies.

\section{BUDGET}

$\$ 790$ million

(FY 1998 estimated operating resources from all sources)

\section{STAFF}

About 3,300 scientists, engineers, technicians, and support personnel, plus some 1,250 visiting researchers each year

\section{SITES}

Gaithersburg, Md. (headquarters-

234-hectare campus) and

Boulder, Colo. (84-hectare campus)

\section{MAIN RESEARCH AREAS IN NIST LABORATORIES}

Building and fire research

Chemical science and technology

Electronics and electrical engineering

Information technology

Manufacturing engineering

Materials science and engineering

Physics

\section{ADDITIONAL SOURCES OF INFORMATION}

NIST issues more than 400 publications each year, such as reports on research results and standards, catalogs of products and services, and technical handbooks.

NIST staff also author about 1,650 technical journal papers. To locate current and past Institute publications, call General Inquiries at (301) 975-NIST (6478).
The Institute also publishes serial publications. The Joumal of Research of the National Institute of Standards and Technology reports NIST research and development results in physics, chemistry, engineering, mathematics, and information technology, with major emphasis on measurement methodology and basic technology underlying standardization. Issued bimonthly. Subscription price: domestic$\$ 34$ per year, foreign $-\$ 42.50$ per year. Contact: (202) 512-1800.

Tecbnology at a Glance is a four-page, lay language newsletter providing brief updates on NIST research, grants, and other program activities, with a contact name for each topic covered. Issued quarterly. Free subscription. Contact: Gail Porter, (301) 975-3392.

News and general information about NIST programs and services are available on the World Wide Web at www.nist.gov. Links to homepages for NIST major programsLaboratories, ATP, MEP, and Baldrige—are available through the NIST homepage. The homepage also links to NIST Time, a staff locator, and events calendar. The site has information on Standard Reference Materials, Standard Reference Data, calibrations, standards services, and facilities. In addition, the site provides tour information; press releases; budget updates; congressional testimony; maps of NIST's Gaithersburg, Md., and Boulder, Colo., facilities; and answers to some frequently asked questions. 
Click on "NIST in Your House" and "NIST and Your City" to find out where NIST research has had an unseen role in your everyday life. To find the NIST connection, you can click on items such as a smoke detector, watt-hour meter, car, hospital, and a factory.

\section{FREQUENTLY REQUESTED NIST CONTACTS}

\section{General Inquiries}

(301) 975-NIST (301-975-6478)

email: inquiries@nist.gov

A903 Administration Building

NIST

Gaithersburg, Md. 20899-0001

Advanced Technology Program

(800) ATP-FUND

(800-287-3863)

\section{Manufacturing Extension Partnership}

(301) 975-5020

(800) MEP-4MFG for center serving you
Baldrige National Quality Program

(Malcolm Baldrige National Quality Award)

(301) 975-2036

Measurement and Standards Laboratories

Building and Fire Research

(301) $975-5900$

Chemical Science and Technology

(301) 975-3143

Electronics and Electric Engineering

(301) 975-2220

Information Technology

(301) $975-2900$

Manufacturing Engineering

(301) $975-3407$

Materials Science and Engineering

(301) $975-5658$

Physics

(301) 975-4200

\section{Technology Services}

Calibrations

(301) 975-2002

Industrial Partnerships

(301) 975-3084

Laboratory Accreditation

(301) $975-4016$

Metric Program

(301) $975-3690$

Small Business Innovation Research Program

(301) 975-3085

Standard Reference Data

(301) 975-2208

Standard Reference Materials

(301) $975-6776$

Standards Information Center

(301) 975-4040

Weights and Measures

(301) 975-4004

\section{NIST Organization}

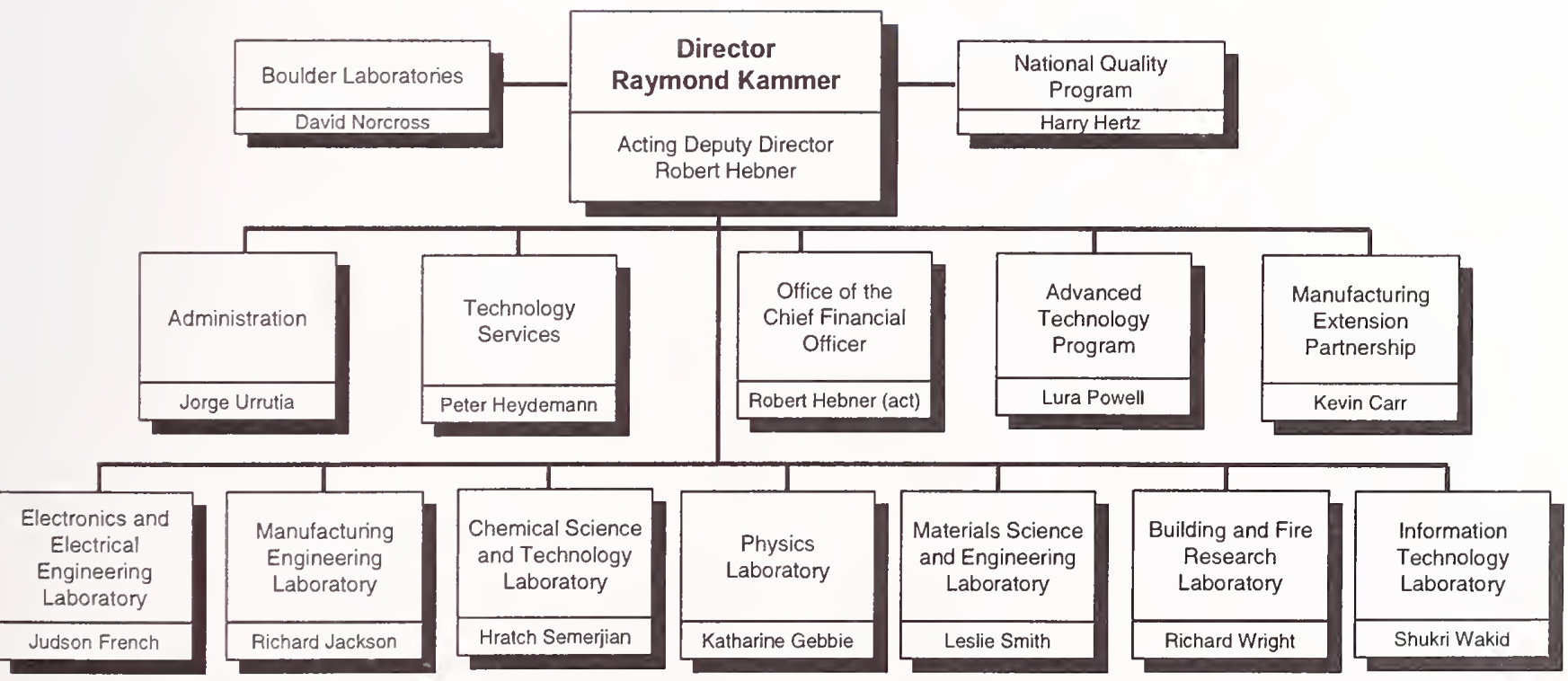




\section{Overview}

Not-yet-possible technologies are the domain of the NIST Advanced Technology Program (ATP). A new synthetic materials technology that might revolutionize the auto industry - if the process variables can be identified and controlled. A new polymer that can be used as a drug, ensnaring and neutralizing dangerous pathogens - if the design and manufacturing issues can be overcome. A new concept in distributed information systems that could both cut costs and potentially save lives in the nation's hospitals - if the proper software tools can be developed to make it cost effective on a large scale.

The ATP is a unique partnership between government and private industry to conduct high-risk research to develop enabling technologies that promise significant commercial payoffs and widespread benefits for the economy. The ATP provides a mechanism for industry to extend its technological reach and push the envelope of what can be attempted.

\section{Lowering the Barriers to High-Risk Research}

Technology research in the private sector is driven by today's economic realities. Markets are global - your competitors can be anywhere in the world. The pace of technological change is faster than ever before, and victory goes to the swift. These realities force companies to make narrower, shorterterm investments in R\&D that maximize returns to the company quickly. A project may offer the possibility of important benefits to American industry or the public, but in hard-nosed business calculations, those benefits are worth only as much as the innovating company can recoup in profits.
The ATP views R\&D projects from a broader perspective - its bottom line is how the project can benefit the nation. In sharing the relatively high development risks of technologies that potentially make feasible a broad range of new commercial opportunities, possibly across several industries, the ATP fosters projects with a high payoff for the nation as a whole-in addition to a direct return to an innovation. The goal of the ATP is economic growth and the good jobs and quality of life that come with economic growth-opening new opportunities for U.S. business and industry in the world's markets by fostering enabling technologies that will lead to new, innovative products, services, and industrial processes.

The ATP has several critical features that set it apart from other government R\&D programs:

- ATP projects focus on the technology needs of U.S. industry, not those of government. The ATP is industry driven, which keeps the program grounded in real-world needs. Research priorities for the ATP are set by industry: for-profit companies conceive, propose, co-fund, and execute ATP projects and programs based on their understanding of the marketplace and research opportunities.

- The ATP has strict cost-sharing rules. Joint ventures (two or more companies working together) must pay at least half of the project costs. Large, "Fortune-500" companies participating as a single firm must pay at least 60 percent of total project costs.

Smaller companies working on single firm ATP projects must pay a minimum of all indirect costs associated with the project. (This provision encourages small companies, particularly start-ups, that often have limited R\&D budgets and much lower overhead rates than large firms.)
- The ATP does not fund product development. It supports technologies that are essential to the development of new products, processes, and services across diverse application areas. Private industry bears the costs of product development, production, marketing, sales, and distribution.

- ATP awards are made strictly on the basis of rigorous competitions designed to select the proposals that are best in terms of innovation, technical risk, the potential economic benefits to the nation (not just the applicant), and the strength of the plan for eventual commercialization of the results. Expert reviewers (without conflicts of interest) drawn from the economic community, government, and academe carefully examine and rate each proposal according to published selection criteria that focus on both economic and technical potential. Proprietary information is protected carefully.

ATP support does not become a perpetual subsidy or entitlement-each project has goals, specific funding allocations, and completion dates established at the outset. Projects are monitored and can be terminated for cause before completion.

The ATP partners with companies of all sizes, encouraging them to take on greater technical challenges with potentially large benefits that extend well beyond the innovators - challenges they could not or would not do alone. For smaller, start-up firms, early support from the ATP can spell the difference between success and failure. To date, more than half of the ATP awards have gone to individual small businesses or to joint ventures led by a small business. Large firms can work with the ATP, especially in joint ventures, to develop critical, high-risk technologies that would be difficult for any one company to justify because, for example, the benefits spread across the industry as a whole. 


\section{An ATP Project Sampler}

The ATP portfolio is highly diversified. The 352 projects selected in the first 30 competitions span a broad array of key technologies, with particular concentrations in information technology, biotechnology, electronics, advanced materials, and manufacturing. These awards represent an investment of $\$ 2.3$ billion shared almost equally by industry and ATP. More than 800 companies, universities, independent non-profit research organizations, and government laboratories have participated in ATP projects. Several hundred additional organizations have participated as subcontractors and strategic partners. Over half of the awards were made to small businesses or to joint ventures led by a small business.

Representative projects include:

- A new DNA sequencing technology developed by GeneTrace Systems, Inc. (Menlo Park, Calif.), under the ATP gets results hundreds of times faster than current methods at a fraction of the cost. The system identifies the sequence of base chemicals in a given DNA strand in as little as five seconds rather than the three hours required for conventional DNA separation methods. This research is expected to lead to inexpensive yet highly effective new drugs and widely available tests for disease diagnosis and identification, such as forensic and paternity testing. The company expects its technology to lead to genetic screening tests for as little as a few dollars, compared with the $\$ 300$ to $\$ 5,000$ required today.

- A wide range of U.S. manufacturers could save substantially if they adopt the new spindle designs developed in a joint venture co-funded by ATP. Spindles (the rotating parts that hold cutting instruments in machine tools) are critical in manufacturing because they strongly influence production rates and parts quality. A team led by the National Center for Manufacturing Sciences (Ann Arbor, Mich.) designed and currently is testing three prototype spindles that are smaller, faster, and more flexible that conventional designs and offer new capabilities as well. For example, one design could save the auto industry more than 100,000 hours in annual machining time for a single part.

- Nanophase Technologies (Burr Ridge, Ill.) used ATP co-funding to develop a novel process for producing uniform, nanometer-scale ceramic powders. The original target for such ultrafine powder was the manufacture of highperformance ceramic components for the automotive and aerospace industries, but along the way Nanophase discovered several other applications, including wafer polishing agents for the semiconductor industry and cosmetic and skin-care products (the tiny iron oxide particles have good sunscreen properties). The market potential for the company's powder products could reach $\$ 80$ million by the turn of the century. Since the beginning of the company's participation in the ATP as a tiny start-up, total employment has increased from 5 to 68 people; annual revenues have increased 10 -fold.

- A new type of "molecular recognition" technology developed by IBC Advanced Technologies of American Fork, Utah, may help crack one of the $\$ 1.2$ trillion world chemical-processing industry's most intractable problems: how to selectively remove economically important or environmentally hazardous molecules from industrial fluids and waste. With ATP co-funding, the company is combining computer modeling expertise and some Nobel Prize-winning research into a highly efficient chemical separation technology with broad applications, from extracting and refining base and precious metals to creating ultrapure substances for pharmaceuticals. Several major chemical processors have licensed the technology, and IBC has begun to market separation systems to the metals industry.

- With assistance from the ATP, a small company called Aastrom Biosciences Inc. (Ann Arbor, Mich.) has developed the first device to successfully grow functional, therapeutic human cells outside the body. The desktop bioreactor developed by Aastrom-now in clinical trials-successfully induces the growth and replication of stem cells, precursor cells normally found in bone marrow that mature into blood and immune system cells. If approved (and initial results are promising), the Aastrom technology could mean the end of a painful procedure of harvesting bone marrow for transplantation (often part of cancer therapy). Some studies also indicate that the cultured cells may be safer-less likely to be contaminated with tumor cells.

- Vastly more powerful computers and cellular telephones are among the products that could result from an ATP project that developed new materials for integrated circuits (ICs). Texas Instruments (Dallas, Texas) incorporated xerogel, a near-perfect insulator consisting of tiny glass bubbles, into ICs for the first time. The material now is being commercialized by a major materials supplier for the electronics industry. Xerogel could fuel at least 10-fold increases in the speed of microprocessors and digital signal processors. 
Universities and non-profit independent research organizations also play significant roles as participants in ATP projects. Out of the more than 350 projects selected by the ATP since its inception, well over half of the projects included plans to involve one or more universities as either subcontractors or joint-venture members. In many of these cases, more than one academic institution was involved. There are more than 300 individual instances of university participation in ATP projects all told.

\section{Programs and Competitions}

The ATP conducts two types of competitions for new R\&D projects, each with its own advantages. General competitions, open to proposals from any field, ensure that all good ideas receive consideration, no matter what the technology area, and result in some of the ATP's most innovative projects. At least one general competition is held every year.

Focused program competitions were created to provide a critical mass of support for high-risk, enabling technologies in particular technology areas that have been identified by U.S. industry as offering especially important opportunities for economic growth. An ATP focused program identifies a specific set of research and business goals that require the parallel development of a suite of synergistic R\&D projects. By managing groups of projects that complement and reinforce each other, the ATP reaps the benefits of synergy and, in the long run, can have a stronger impact on U.S. technology and the economy.

Focused programs are developed in response to specific suggestions received from industry and academia. The proposals outline a specific technology area and describe the potential for U.S. economic benefit, the technical ideas available to be exploited, the strength of industry commitment to the work, and the reasons why ATP funding is necessary to achieve well-defined research and business goals. Areas that attract particularly strong interest then are developed further through discussions with industry, meetings, workshops, and other interactions.

Within a focused program, the ATP holds special competitions open only to project proposals that would advance the goals of the specific program. Individual projects are selected through the normal ATP competitive review process. The ATP has established 17 focused programs to date.

\section{Focused Program Descriptions}

\section{Information Technology and Electronics}

Adaptive Learning Systems. To develop new enabling technologies for flexible, network-based (including web-based) learning systems, including intelligent authoring systems to reduce the cost and time to develop educational content; knowledge management and interface technologies to improve the delivery of instructional content; and large-scale modular components, instructional frameworks, and middleware to support a highly usable, reliable networked learning environment that makes training and education more accessible than ever before.

Contact:

Richard Morris

(301) 975-4695

email: richard.morris@nist.gov

A426 Administration Building
Component-Based Software. To develop the technologies necessary to enable systematically reusable software components—small, carefully engineered software elements suitable for automated assembly in a broad array of applications.

Contact:

Barbara Cuthill

(301) $975-3273$

email: barbara.cuthill@nist.gov

A426 Administration Building

Digital Data Storage. To support U.S. companies in exploiting the revolution in digital storage by producing dramatic improvements in data storage technology in six key areas: tape and disk storage density, higher performance magnetic recording heads, new lubricants and surface finishes, more reliable tracking devices, improved signal-processing electronics, and data storage and retrieval software.

\section{Contact:}

Philip Perconti

(301) 975-4263

email:philip.perconti@nist.gov

A426 Administration Building

\section{Digital Video in Information Net-}

works. To develop interoperable digital video capabilities for emerging information networks through techniques for encoding, converting, and transcribing video data into the various forms required by the network. The program will help U.S. firms to take commercial advantage of the information network to allow any video-based information product to travel via wire, optical fiber, satellite, or broadcast seamlessly into regular televisions and other information appliances.

\section{Contact:}

David Hermreck

(301) $975-4328$

email: david.hermreck@nist.gov A426 Administration Building 
Information Infrastructure for

Healthcare. To develop critical information infrastructure technologies to enable enhanced, more fully integrated medical information systems across the healthcare industry, increasing accessibility and uniformity while greatly reducing costs and errors in handling medical information.

\section{Contact:}

Bettijoyce Lide

(301) 975-2218

email: bettijoyce.lide@nist.gov

A\{26 Administration Building

Photonics Manufacturing. To develop critical tools-packaging technologies, simulation and modeling tools, processing methods, equipment, and instrumentation-needed by U.S. manufacturers to develop innovative photonics-based products quickly and manufacture them efficiently in large volume at low cost, improving their competitiveness in global markets.

\section{Contact:}

Philip Perconti

(301) 975-4263

email: philip.perconti@nist.gov

A426 Administration Building

Technologies for the Integration of Manufacturing Applications. To

develop and demonstrate the technologies needed to create affordable manufacturing software applications that can be integrated rapidly, reconfigured, and, in the long run, automatically adjust their performance in response to changing conditions and requirements.

Contact:

Selden Stewart

(301) $975-3833$

email: selden.stewart@nist.gov

A426 Administration Building

\section{Chemistry and Life Sciences}

Catalysis and Biocatalysis Technologies. To develop the tools, abilities, and theoretical insight to identify, design, and implement new catalytic and biocatalytic processes and catalyst manufacturing techniques of major economic importance to chemical producers and other catalyst users.

Contact:

Robert Bloksberg-Fireovid

(301) $975-5457$

email: robert.b-f@nist.gov

A225 Administration Building

Manufacturing Composite Structures. To reduce the high initial costs of using advanced composite materials, traditionally found in military and sports applications, through cost-effective manufacturing processes to enable the use of these highperformance, lightweight, durable materials in large-scale commercial structural applications such as surface transportation, civil infrastructure, and offshore oil production.

\section{Contact:}

Felix Wu

(301) 975-4685

email: felix.wu@nist.gov

A225 Administration Building

Selective-Membrane Platforms. To develop the combination of materials science and manufacturing technology advances needed to create new families of membrane materials and process technologies for advanced high-selectivity, highthroughput chemical separations (including concentration and purification), producing feedstocks for areas as diverse as pharmaceuticals and medical diagnostics, automobile parts, consumer electronics, clothing, and alternative fuels.

\section{Contact:}

David King

(301) 975-2369

email: david.king@nist.gov

A426 Administration Building
Tissue Engineering. To enable dramatic advances in the development and use of biocompatible materials, with or without a cellular component, to replace damaged or defective tissues and organs. The program concentrates on four key areas: biomaterials, cellular components (including largescale culturing techniques and genetic or environmental manipulation), manufacturing processes, and implantation and transplantation technologies.

\section{Contact:}

Rosemarie Hunziker

(301) 975-5324

email: rosemarie.hunziker@nist.gov A225 Administration Building

Tools for DNA Diagnostics. To develop compact, low-cost, automated DNA analysis technologies and equipment to enable fast, inexpensive detection and diagnosis of human, animal, and plant diseases. Other applications include personal identification, toxicology, environmental monitoring, and bioprocessing.

\section{Contact:}

Stanley Abramowitz

(301) 975-2587

email:stanley.abramowitz@nist.gov

A225 Administration Building

\section{Materials and Manufacturing}

\section{Materials Processing for Heavy}

Manufacturing. To develop and demonstrate innovative materials-processing technologies that will help U.S. heavy manufacturing companies make longer lasting, more reliable, and more efficient products. The program concentrates on three major commercial markets: engines, power trains, and chassis for surface vehicles; heavy equipment for construction, agriculture, mining, and oil fields; and engines, 
turbines, rotors, and related components for power generators.

\section{Contact:}

Clare Allocca

(301) 975-4359

email: clare.allocca@nist.gov

A225 Administration Building

\section{Microelectronics Manufacturing}

Infrastructure. To develop new infrastructure technologies in materials, design, manufacturing, and testing and to enable strategic advances in semiconductor chips, processes, packaging, and board interconnections. These technologies have been identified in several industry roadmaps as potentially serious barriers to developing the smaller, lighter, faster, and more costeffective microelectronic products demanded by world markets.

\section{Contact:}

Michael Schen

(301) 975-6741

email: michael.schen@nist.gov

A225 Administration Building

Purabi Mazumdar

(301) $975-4891$

email: purabi.mazumdar@nist.gov

A426 Administration Building

Motor Vehicle Manufacturing Technology. To foster innovations in manufacturing technologies that can strengthen capabilities and lead to dramatic advances along the entire automotive production chain, including more versatile equipment, better control and integration of processes, and greater operational flexibility at all levels. Automotive suppliers are key partners and players in this program.

Contact:

Jack Boudreaux

(301) 975-3560

email: jack.boudreaux@nist.gov

A225 Administration Building
Premium Power. To develop advanced electric power technologies, including photovoltaic solar arrays, integrated fuel cell systems, advanced batteries, ultracapacitors, and flywheels, to support modular, highquality, highly distributed power sources required for developing technologies in broadband wireless telecommunications, portable electronics, and power-qualitysensitive industries.

\section{Contact:}

Gerald Ceasar

(301) 975-5069

email: gerald.ceasar@nist.gov

A225 Administration Building

\section{Vapor Compression Refrigeration}

Technology. To develop more efficient, quiet, and compact air-conditioning and refrigeration systems with the lowest achievable environmental impact. The projects selected focus on improving the vapor compression cycle, the principle of operation for most current cooling equipment. The overall technical goals are to increase system efficiency, reduce noise levels, and reduce refrigeration components' sizes---each by 25 percent - and to design and manufacture systems in which no refrigerant leaks.

Contact:

John Gudas

(301) 975-3214

email: john.gudas@nist.gov

A225 Administration Building

\section{Proposing a Focused Program}

The ATP reviews its portfolio of focused programs annually and encourages interested groups in industry, academia, and government to submit ideas suggesting new focused program areas. Potential focused programs are evaluated against four basic criteria:
- The potential for broad economic benefits to the nation. How would the proposed technological developments lead to significant economic benefits for the nation? How would this be reflected in integrated research and business strategies? What would be the likely effect on the U.S. workforce if the program succeeds and is carried forward to commercialization-taking into account national and international trends? How important to the economy are the industrial sectors that would be most affected by the program area? Would the proposed program create new industries or cause a leap forward in a well-established industry?

- Good technical ideas. The ATP emphasizes revolutionary changes, not incremental advances. What is the technology baseline for the proposed program? Given current research trends in government and industry, where would that technology be in the next 5 years to 10 years without an ATP program? How will this be accelerated or changed by establishing an ATP program? What are the major technical barriers to be overcome? Which innovative technologies will erase those barriers? Where are the technology risks that require ATP support?

- Strong industry commitment. The ATP is a partnership between industry and government and cannot succeed without industry's whole-hearted support. What is the evidence that industry is ready and willing to work with the ATP and with one another as needed to achieve the program's goals? Would the program require horizontal alliances? Vertical alliances? Both? Are the industry players prepared to build these relationships? What resources would the industry be willing to commit to the program? Are the potential industry partners willing to share the costs of the R\&D? 
- The opportunity for ATP funding to make a significant difference. In other words, why the ATP? What related efforts are under way, either by industry or government? How would the ATP program complement these efforts? Why is federal funding in general, and ATP funding in particular, needed to achieve the large potential economic benefit to the nation? What is the international competition? Is time of the essence? Can we realistically hope to meet the program goals? Will the combined industry and government funding be adequate to exploit the technological opportunity in the critical time frame? If the program is successful, will our relatively small investment lead to far greater investment by industry in subsequent development and commercialization?

For more information on submitting focused program ideas, visit the ATP web site (www.atp.nist.gov) or use one of the other contact points listed in this chapter.

\section{Delivering Results}

From a remarkable new microcircuit soldering system based on the same principles as the ink-jet printer, to power-transmission towers made of durable, high-performance composites, to the dramatic DNA "chips" that enable rapid, low-cost, DNA analyses, the ATP already is having an impact, delivering new technologies that would not exist here and now without the ATP (see An ATP Project Sampler on page 7).

But the true impacts of the ATP will be felt in the long run as ATP-fostered technologies enter the market. Long-term evaluation of the ATP must take into account the "downstream" effects of these technologies: higher productivity and lower reject rates for manufacturers using new processes and equipment based on ATP technologies; better medical care at lower costs from hospitals and clinics that benefit from ATP biotechnology projects or the ATP focused programs on Tools for DNA Diagnostics and Information Infrastructure for Healthcare; and longerlived, lower-maintenance structures and equipment made possible by ATP focused programs in advanced composites. The value of such long-range effects, though real, are difficult to measure accurately.

Since its inception, the ATP has made economic evaluation of the outcomes of ATP projects a central element of its operations. The ATP has developed and implemented a thorough measurement program that pushes the state of the art in evaluating the long-term outcomes of R\&D investment.

This is a lengthy process. ATP projects typically run from 2 years to 5 years; the technology commercialization and diffusion phase easily can add several more years. The full economic impact may not be realized for some years after commercial introduction. It also is costly—companies must spend additional time, effort, and money on their own to pursue product development and marketing. Because of the risks involved - commercial as well as technical_-some ATP projects will fail. Others may proceed faster than anticipated, and intermediate results may lead to marketable products even before the ATP project ends. Regardless of whether initial commercialization takes place before an ATP project ends or long after, the company must invest its own money to design specific products incorporating the technology and pay any other costs associated with commercialization.
The ATP is contributing a new element to the R\&D culture of U.S. business - one that emphasizes more high-risk, high-payoff, enabling R\&D and greater use of cooperative research ventures and industrial alliances. Studies conducted both by the ATP and by private contractors have documented several important near-term results of the program:

- Successful ATP technologies represent not simply incremental advances but rather significant innovations that have broad application. A study of more than 200 ATP projects-most still in progress- found that the companies surveyed had identified more than 1,000 potential applications of the ATP-supported technologies. Thirty-five percent of those are considered by project participants to be "new-to-the-world" solutions to a market need or problem with the potential to create totally new markets. Another 29 percent were expected to result in performance improvements of 100 percent to 500 percent over the state of the art.

- The ATP successfully catalyzes high-risk research. Surveys of ATP participants consistently find that a substantial percentage70 percent in one study - would not have attempted the ATP project without the ATP. Those that would have gone forward anyway report significantly increased levels of effort and an often dramatic acceleration in progress due to the ATP. In one study, 86 percent of project respondents reported that the ATP support cut their estimated development time by one-half or more - which translated to economic impacts ranging from a million to several billions of dollars for each year gained according to some respondents- and a similar percentage reported that they had adopted ATP practices to other research projects to capitalize on these gains. The bottom line: U.S. industry today has important new technical capabilities that would not exist without the A'TP. 
- The ATP contributes to a valuable new culture of cooperation in U.S. industrial R\&D. In one study of more than 400 organizations working on ATP projects, nearly 80 percent reported that they were working on the project in collaboration with other companies, universities, or federal labs, and 85 percent of these reported that the ATP played a significant role in bringing the collaborative relationship together. In another study, of 115 companies working collaboratively on ATP projects, 95 percent reported a "significant benefit" from the ATP-inspired collaboration - some companies even participating without funding for the sake of the benefits-and 96 percent of joint venture participants reported that the ATP experience encouraged them to seek other joint ventures in the future.

The results of ATP-sponsored research, commercialized by private industry, are starting to emerge from laboratories and enter the marketplace — potential impacts becoming actual.

- One of the earliest ATP projects, a collaborative effort to develop a suite of advanced manufacturing technologies for the printed wiring board (PWB) industry, resulted in new materials, testing, imaging, and production techniques that have been credited by the National Center for Manufacturing Sciences, a participant, with "quite literally saving" the roughly $\$ 7$ billion U.S. PWB industry, with its approximately 200,000 jobs.

- An ATP joint venture in the auto industry that included several small and mid-sized manufacturers and universities resulted in manufacturing monitoring and control technologies that led to significantly improved dimensional tolerances, improving vehicle quality and customer satisfaction. One theoretical economic analysis of the project projected that a market-share boost for U.S. auto manufacturers as a result of the ATPsponsored work could lead ultimately to thousands of new jobs and a $\$ 3$ billion increase to the U.S. industrial output by the year 2000 .

- The ATP was instrumental in promoting the research that led to today's "DNA chips," miniaturized genetics labs that offer fastup to 1000 times faster than conventional methods - accurate, low-cost genetic analysis. Early spin-offs of ATP projects in this area already are being used in agriculture and food and cosmetics testing as well as the obvious applications in drug discovery, human-genome research, and biomedical research.

Charged with monitoring and analyzing both the short-term performance and longrange impacts of the program, the ATP's Economic Assessment Office employs a variety of research tools. Third-party surveys and in-depth case studies of individual projects look at such issues as the near-term impact of the ATP on participating companies and efficiencies from collaborative research and development. An innovative computerized business reporting system facilitates statistical analysis by researchers and supplements site visits and annual reviews to track project progress toward future applications of the ATP technologies.

Other studies attempt to measure "spillover" benefits and costs-those that accrue to users of the technology beyond the ATP participating companies. The ATP also sponsors studies to increase the understanding of spillover mechanisms in the economy and to develop improved methods for measuring the long-term impact of the program. ATP periodically holds workshops with the nation's leading economists to discuss evaluation models, results, and opportunities. A variety of ATP economic reports may be read online at www.atp.nist.gov/atp/pubs.htm.

\section{Contacting the ATP}

The ATP accepts project proposals only in response to specific, published solicitations. Notices of ATP competitions are published in Commerce Business Daily. You also may request to be placed on a mailing list (or emailing list) to receive notification of ATP competitions and other events by calling the ATP automated hotline (1-800-ATPFUND or 1-800-287-3863) or by sending email to atp@nist.gov.

The ATP Proposal Preparation Kit may be requested at any time. In addition to the necessary application forms, the kit includes a thorough discussion of ATP goals and procedures as well as useful guidance in the preparation of a proposal. Notices of ongoing competitions, upcoming events, ATP research papers, and descriptions of ongoing and completed ATP projects may be found on the program's web site.

\section{Contact:}

Advanced Technology Program 1-800-ATP-FUND (1-800-287-3863) email: atp@nist.gov fax: (301) 926-9524 or (301) 590-3053 A407 Administration Building www.atp.nist.gov 


\section{ATP Projects}

Ongoing and completed ATP projects and their participants are listed below, sorted into related technical categories. The ATP manages projects through three technical offices: Information Technology and Electronics Office, Chemistry and Life Sciences Office, and Materials and Manufacturing office.

The focused programs for which each office is responsible are listed under each office's heading. Projects selected in focused program competitions are listed under the corresponding focused program. Projects closely related to the subject of a focused program but selected in our general competitions are included in the focused program listing. When the ATP selects a number of projects in one particular area, such a cluster of projects is managed for synergy as a "virtual focused program" even though there has not been a formal competition in that technical area.

General competition projects that do not fit within a focused program category are listed separately, grouped in appropriate technical categories. For information, contact the office under which the project is listed.

\section{Information Technology and Electronics Office}

Contact:

Cita Furlani

(301) 975-3543

email: cita.furlani@nist.gov

A426 Administration Building

Component-Based Software

Contact:

Barbara Cuthill

(301) $975-3273$

email: barbara.cuthill@nist.gov

A426 Administration Building
Creating New Software Development Paradigms

- A Plausible Dependability Model for Component-Based Software-Reliable Software Technologies

- A Programmable Framework Based on Semantic Modeling Components-Synquiry Technologies, Ltd.

- Component Integration: An ArchitectureDriven Approach—Andersen Consulting, Center for Strategic Technology Research

- Cost-Based Generation of Scalable, Reliable, Real-Time Software ComponentsHyBrithms Corp. (formerly Sagent Corp.)

- Design Maintenance System-Semantic Designs, Inc.

- MirrorBall: A Component Infrastructure Initiative—Sterling Software, Inc.

- Reusable Performance-Critical Software Components Using Separation of Implementation Issues-Xerox Corp., Palo Alto Research Center

\section{Enbancing the Capabilities of Application} Experts

- A Component Technology for Virtual Reality Based Applications-Aesthetic Solutions

- A Component-Based Software Approach to Analog and Mixed Signal Model Development-Analogy, Inc.

- Automatic Generation of Mathematical Modeling Components—SciComp, Inc.

- Automation of Dependable Software Generation with Reusable Components - Lucent Technologies, Inc.

- Component-Based Software for Advanced Interactive Systems in Entertainment and Education-Extempo Systems, Inc.

\section{Automating the Software Development Process}

- Business Object Component Specification, Generation and Assembly—Data Access Technologies, Inc.
- Component-Based Re-engineering Technology—Reasoning Systems, Inc.

- Component-Based Software System for Parallel Processing Systems-Applied Parallel Technologies, Inc.

- Component-Based Software Tools for Real-Time Systems - Real-Time Innovations, Inc.

- Debugging Component-Based Software for Enterprise Systems - Intermetrics, Inc.

- Graph Visualization Technology-Tom Sawyer Software

- Scalable Business Application Development Components and Tools - Continuum Systems

\section{Digital Data Storage}

Contact:

Philip Perconti

(301) 975-4263

email: philip.perconti@nist.gov

A426 Administration Building

Optical Recording Technology

- A High-Density and High-Speed Read-

Only Optical Data Storage System-

Calimetrics

- A Novel Flying-Optical-Head Disk DriveQuinta Corp.* and SDL, Inc.

- Continuous Low-Cost Manufacturing System for DVD—Energy Conversion Devices, Inc.

- Digital Data Storage Technology via Ultrahigh-Performance Optical Tape Drive Using a Short-Wavelength Laser-LOTS Technology, Inc.

- Enabling Technology for a Digital Video Optical Tape Recorder of High-Resolution Motion Imagery — Avid Technology, Inc.; EMC Corp.; LOTS Technology, Inc.*; Lucent Technologies; and Polaroid Corp.

- Multiple Optical Recording Enhancements - Calimetrics, Inc.; Energy Conversion Devices, Inc.; National Storage Industry Consortium*; and Polaroid Corp. 
- Short-Wavelength Sources for Optical Recording — Carnegie Mellon University, ECE Department; Eastman Kodak Co., Mass Memory Division, Research Labs; IBM Corp., Almaden Research Center; National Storage Industry Consortium*; Uniphase; and University of Arizona, Optical Science Center

- Technology Development for OpticalTape-Based Rapid Access Affordable Mass Storage-Carnegie Mellon University; Energy Conversion Devices, Inc.; Moterola, Inc., Phoenix Applied Research Center; NASA Goddard Space Flight Center; Polaroid Corp.; Science Applications International Corp.; Terabank Systems, Inc. *; University of Arizona, Optical Sciences Center; and Xerox Corp.

\section{Magnetic Recording Tecbnology}

- High-Performance, Variable-Data-Rate, Multimedia Magnetic Tape RecorderAdvanced Research Corp.; Imation Corp.*; Seagate Recording Head, Tape Head Operations; and Storage Technology Corp.

- Integrated Vacuum Lubrication System for Hard Disks—Intevac, Inc.

- Trainable Digital Logic: A New Approach to Increasing Data Storage Density on Magnetic Media-Neural Systems Corp.

- Ultra-High Density Magnetic Recording Heads-Applied Magnetics Corp.; Carnegie Mellon University, ECE Department, Data Storage Systems Center; Eastman Kodak Co.; George Washington University, Department of Electrical Engineering and Computer Science; Hewlett-Packard Co.; IBM Corp., Almaden Research Center; National Storage Industry Consortium*; Quantum Corp.; Read-Rite Corp.; Seagate Technology; Stanford University, Department of Materials Science and Engineering; Storage Technology Corp.; University of Alabama at Tuscaloosa, Center for Materials Information Technology; University of California at San Diego, Center for Magnetic Recording; University of Minnesota, Electrical Engineering and Computer Science; and Washington University, Department of Electrical Engineering

\section{Digital Video in Information Networks}

\section{Contact:}

David Hermreck

(30I) 975-4328

email: david.hermreck@nist.gov

A426 Administration Building

\section{Information Capacity Improvements for Transmission and Distribution}

- Adaptive Video Codec for Information Networks - Cubic VideoComm, Inc.

- Mobile Information Infrastructure for Digital Video and Multimedia ApplicationsLucent Technologies, Inc.* and Sun Microsystems Federal, Inc.

- Perceptual-Based Video Encoding and Quality Measurement-Bell Atlantic; Sarnoff Corp.*; Sun Microsystems Computer Corp.; and Texas Instruments, Inc.

\section{Interoperable System Components}

- HDTV Broadcast Technology—Comark Communications, Inc.; IBM Corp., T.J. Watson Research Center; MCI; Philips Research; Sarnoff Corp.*; Sun Microsystems Computer Corp.; and Thomson Consumer Electronics, Inc.

- Interoperability Tools for Digital Video Systems-Bell Communications Research, Inc.

\section{Digital Video Tools and Management Capabilities}

- Advanced Distributed Video ATM Network for Creation, Editing, and DistributionTektronix, Video and Networking Division

\section{Information Infrastructure for Healthcare}

Contact:

Bettijoyce B. Lide

(301) $975-2218$

email: bettijoyce.lide@nist.gov

A426 Administration Building

Infrastructure Development Technologies (Enterprise Integration)

- An Evolvable, Distributed Information Infrastructure for Interoperation of the Healthcare Delivery System-Andersen
Consulting, Center For Strategic Technology Research*; Enigma Logic, Inc.; Expersoft Corp.; MedicaLogic; Medical Records Corp.; and University of Texas at Arlington, Automation Engineering

- An Expert Knowledge Server With a General Vocabulary Server Interface-Mosby Consumer Health (formerly Applied Medical)

- Development of a Seamless Clinical Management System for Behavioral Health Organizations-InStream Corp.

- Enterprise Tools for the Continuously Available Medical Care Home Healthcare System-Intermetrics, Inc., Microcomputer Systems Division

- Healthcare Lifetime Data Repository Infrastructure-3M Co., Health Information Systems

- A Master Patient Index for Massively Distributed Records Across a U.S. National Backbone-Sequoia Software Corp.

- "MEDencode": A Technology to Populate a Clinical Data Repository as a Byproduct of Producing the Clinical Note-Clinical Information Advantages, Inc.

- Patient-Oriented Management System: An Integration Infrastructure for Health Care-Benchmarking Partners, Inc.

- Voyager: Browsing and Automatically Extracting Healthcare Data from Scattered Databases - Belmont Research, Inc.

Infrastructure Development Technologies (Domain Analysis and Business Process Re-engineering)

- An Information Infrastructure to Redefine Caregiver Roles: A New Approach to Integration-Health Data Sciences Corp. * and New York City Health and Hospitals Corp.

- Health Informatics Initiative-Beth Israel Hospital; Booz-Allen and Hamilton, Inc.; Corporation for Studies and Analysis; D. Appleton Company, Inc.; International Cancer Alliance; Koop Foundation, Inc.*; 
Meta Software Corp.; Oracle Corp.; and Wizdom Systems, Inc.

- Healthcare Information Infrastructure Technology Proposal—BellSouth Telecommunications; Coleman Information Services, Health Technology Group; Connecticut Healthcare Research and Education; Danbury Health Systems, Inc.; General Electric Corporate R\&D; Liberty Health Systems; Medical University of South Carolina, Center for Computing and Info. Tech.; Microelectronics \& Computer Technology Corp.; New Jersey Institute of Technology; South Carolina Research Authority, Trident Research Center*; Statewide Health Information Network, Inc. (SHINE); Unitron Medical Communications, Inc.; and University of Georgia, Sponsored Programs Program Office

Infrastructure Development Tecbnologies (Total Quality Management)

- Automated Care Plans and Practice Guidelines-American Healthware Systems

- Development of an Episode Grouper-3M Co., Health Information Systems* and Actuarial Sciences Associates

- MEDassist: A Generalized ComponentBased Technology to Serve as a Foundation for Decision Support Systems - Datamedic

- Methodologies for Automating Clinical Practice Guidelines-Cerner Corp.

- RxInfo: Data Mining Tools for Assessing the Impact of Pharmaceutical Therapies on Population-Based Healthcare OutcomesCHIME, Inc.

User Interface and Efficiency-

Enbancement Tecbnologies (Information Access, Transmission, Storage, and Retrieval)

- Computer Aided Medical Planning: A New Paradigm in Vascular InterventionCentric Engineering Systems, Inc.

- Decision Support Technology for LDR Infrastructure-3M Co.
- Development of National Medical Practice Knowledge Banks—AT\&T Corp., Business Markets Division; Allegheny-Singer Research Institute*; and NCR Corp., Parallel Systems (formerly AT\&T)

- Health Object Library ON-line ProjectAgora, Inc.; At Home Network; Beth Israel Hospital Deaconess Medical Center; Concept Five Technologies; Forefront Group, Inc;; George Washington University, School of Engineering; IntelliTek, Inc.; Koop Foundation, Inc.*; Lumina Decision Systems; Meta Software Corp.; Norwalk Hospital, Center for Health Informatics; Oracle Corp.; Windom Health Enterprises; and Wizdom Systems, Inc.

- Healthcare Information Technology Enabling Community Care—Advanced Radiology; BellSouth Telecommunications; Charleston Area Medical Center, Inc.; Connecticut Healthcare Research and Education; General Electric Corporate R\&D; Lockheed Martin Energy Systems, Inc.; Shared Medical Systems Corp.; South Carolina Research Authority*; Technology 2020; University of Florida at Gainesville, Department of Anesthesiology; and University of Maryland at Baltimore, Diagnostic and Radiology

- Physician's Assistant for Continuous Transcription and Structure-Kurzweil Applied Intelligence

- Pre 0p: The Pre-0perative Decision Support System-HT Medical Systems, Inc.

User Interface and EfficiencyEnbancement Tecbnologies (Multimedia Information)

- A Multimedia Medical Dialog System for Home Healthcare—Dragon Systems, Inc.

- A Three-Dimensional Database for Visualization of Human Physiology - Engineering Animation, Inc., and Iowa State University Research Park

- Automating Disease Surveillance from Structured and Text Data--Sunquest Information Systems
- Intelligent Spoken Medical Records_Berdy Medical Systems

- Open, Voice-Enabled, Structured Medical Information-Kurzweil Applied Intelligence, Inc.

- TELEOSTM: An Authoring System for Virtual Reality Surgical SimulationsHT Medical, Inc. (formerly High Techsplanations)

- Wellnet ${ }^{\mathrm{TM}}$ : An Interactive Multimedia Consumer Health Management ToolCareSoft, Inc.

\section{Technologies for the Integration of Manufacturing Applications}

Contact:

Selden Stewart

(301) 975-3833

email: selden.stewart@nist.gov

A426 Administration Building

- A Product-Family-Based Framework for Computer Integrated Manufacturing - IBM Corp.

- ANTS Scheduling and Execution System-Deneb Robotics, Inc.

- Advanced Process Control Framework Initiative-Advanced Micro Devices and Honeywell, Inc., Technology Center*

- Agent-Enhanced Manufacturing System Initiative-Advanced Micro Devices* and Object Space, Inc.

- An Agent-Based Framework for Integrated Intelligent Planning-Execution-Berclain USA Ltd.; EnVisionIt Software Corp.; IBM Manufacturing Solutions Unit, CIIMPLEX*; Ingersoll-Rand Co.; Intercim Corp.; and $\mathrm{QAD}$, Inc., Americas Regional office

- Distributed Factory System FrameworkConsilium, Inc.

- EECOMS: Extended Enterprise Coalition for Integrated Collaborative Manufacturing Systems-Berclain USA Ltd.; Enterprise Engines, Inc.; Envisionit Software Corp.; IBM Corp., CIIMPLEX*; Ingersoll-Rand Co.; Intercim Corp.; QAD, Inc.; Scandura; The 
Haley Enterprise, Inc.; and Vitria Technology, Inc.

- Model-Driven Application \& Integration Components for MES - Vitria Technology, Inc.

- Process Integration Using Model-Driven Engines-Vitria Technology, Inc.

- Solutions for MES-Adaptable Replicable Technology_AMP, Inc.; Applied Automation Techniques, Inc.; CIMLINC; Concentus Technology Group; IBM Corp. (NIIIP Consortium Project Office)*; Industrial Computer Corp.; International TechneGroup, Inc.; MESA International; Pilot Industries, Inc.; STEP Tools, Inc.; SynQuest; and University of Florida at Gainesville, Database Systems R\&D Center

- Virtual Reality Telecollaborative Integrated Manufacturing Environment-Searle

\section{General Projects Related to Information Technology}

Contact:

Cita Furlani

(301) $975-3543$

email:cita.furlani@nist.gov

A426 Administration Building

- A National Knowledge InfrastructureCycorp, Inc.

- Advanced Spoken Language User Interfaces for Computer Applications-Kurzweil Applied Intelligence, Inc.

- Building a Future Database-Continuum Software, Inc.

- High-Fidelity Digital Image Compression-Iterated Systems, Inc.

- New User Interface for Computers Based on Online Recognition of Natural Handwriting - Communication Intelligence Corp.

- Optical Maximum Entropy Verification Technology for Anti-Counterfeiting Physical Optics Corp.

- Pen-Based User Interface for the Emerging Chinese Computer Market-Communication Intelligence Corp.

\section{General Projects Related to Electronics and Photonics}

Contact:

Cita Furlani

(301) 975-3543

email: citafurlani@nist.gov

A426 Administration Building

Displays and Graphic Image Manipulation

- Advanced Manufacturing Technology for Low-Cost Flat-Panel Display-ElectroPlasma, Inc.; Kent Display, Inc.; Photonics Imaging, Inc. (American Display Consortium)*; Planar America, Inc., Division of Planar Systems; and Westinghouse Norden Systems, Inc., Division of United Technologies

- Color Sequential Imaging - ColorLink, Inc.

- Diamond Diode Field Emission Display Process Technology Development-SI Diamond Technology, Inc., * and Supertex, Inc.

- FLC/VLSI High-Definition Image Generators-Displaytech, Inc.

- High Information Content Display Technology — Kopin Corp.* and Philips Consumer Electronics North America

- High Resolution Multimedia Laser

Projection Display_-Laser Power Corp.* and Proxima Corp.

- Large Area Digital HDTV Field Emitter Display Development-FED Corp.

- Mathematical Algorithms and Software for the Restoration and Reformatting of Moving Pictures-Mathematical Technologies, Inc.

- Optically Controlled Alignment Materials for Liquid-Crystal Displays—Alliant Techsystems, Research Center (technology transferred to Elsicon, Inc.)

- Patterning Technology for Color FlatPanel Displays-Electro-Plasma, Inc.; Kent Display, Inc.; Photonics Imaging, Inc.; and Planar America, Inc., Division of Planar Systems (American Display Consortium)*
- Scalable High-Density Electronics Based on MultiFilm Modules-Kopin Corp.* and Microelectronics \& Computer Technology Corp.

- Technology Development for the Smart Display: A Versatile High-Performance Video Display Integrated with Electronics-

B.F. Goodrich Avionics Systems; FED Corp.*; InfiMed, Inc.; and Kaiser Electronics

Semiconductor Devices, Materials, and Fabrication

- A Feedback-Controlled Metalorganic Chemical Vapor Deposition Reactor-Spire Corp.

- Advancement of Monocrystalline Silicon Carbide Growth Processes - Cree Research, Inc.

- Critical Components for Process Control in Microelectronics Manufacturing-ADE Corp.; Advanced Fuel Research, Inc.; Applied Materials, Inc.; Massachusetts Institute of Technology; and On-Line Technologies, Inc.*

- Development of Blue/Green Emitters Utilizing Homoepitaxial ZnSe-Based Heterostructures-Eagle-Picher Research Laboratory

- Dry Gas-Phase Cleaning Technology for Single-Wafer Surface Conditioning-FSI International, Inc.

- Fabrication and Testing of Precision Optics for Soft X-ray Projection Lithography-Lucent Technologies, Inc. (formerly AT\&T Bell Laboratories)

- Flip Chip Monolithic Microwave Integrated Circuit Manufacturing TechnologyHughes Aircraft Co., Microelectronic Circuits Division

- GaAs Super Microprocessor Technology Development—Vitesse Semiconductor Corp.

- Manufacturing Technology for High Performance Optoelectronic Devices Based on Liquid Phase Electro-Epitaxy-AstroPower, Inc. 
- New Technology for High-Current, Parallel, Broad-Beam Implanters for Microelectronics Fabrication-Diamond Semiconductor Group, Inc.

- Nonvolatile Magnetoresistive Semiconductor Technology-Nonvolatile Electronics, Inc.

- Solid-State Laser Technology for PointSource X-ray Lithography-Hampshire Instruments, Inc.*, and McDonnell Douglas Electronic Systems Co.

Optical/Electro-optical Components and Systems (Including Lasers)

- A Novel Microminiature Light Source Technology_Philips Laboratories

- Advanced Technology for Microchannel Plates-Galileo Electro-Optics Corp.

- Fiber Fabry-Perot Tunable Filters for AllOptical Networks-Micron Optics, Inc.

- Holographic Graded-Index NonLambertian Scattering Screens and Components with Light-Shaping CapabilityPhysical Optics Corp.

- Incoherent Combining of Radiation from a Two-Dimensional Array of Semiconductor Lasers-Cynosure, Inc.

- Jitney: A Low-Cost, High-Performance Optical Bus-3M Co.; IB.I Corp., T.J. Watson Research Center*; and Lexmark International, Inc.

- Monolithic Multivavelength Laser Diode Array Spanning 430 to $1100 \mathrm{~nm}$-SDL, Inc.* and Xerox Corp., Palo Alto Research Center

- Precision Optoelectronics AssemblyAdept Technology, Inc.; Boeing Co., Information, Space \& Defense Systems; Dresser Industries, Inc., Instrument Division; MultiLifecycle Engineering Research Center, New Jersey Institute of Technology; Precision Optoelectronics Assembly Consortium (c/o NCMS)*; and SDL, Inc.

- Tunable Deep UV and VuV Solid-State Laser Source—Light Age, Inc.
- Wavelength Division Multiplexing for Optical Telecommunications SystemsAccuwave Corp.

- X-ray and Neutron Focusing and Collimating Optics-X-ray Optical Systems, Inc.

New Waterials/Manufacturing for Electronics and Electrical Systems

- Integrated Force Array-Microelectronics Center at North Carolina

- Printed Wiring Board Interconnect Systems—AlliedSignal Laminate Systems; Hughes Aircraft Co.; IBM Corp.; Lucent Technologies, Inc. (formerly AT\&T); National Center For Manufacturing Sciences, Inc.*; Sandia National Laboratories; Texas Instruments, Inc.; and United Technologies Corp., Hamilton Standard Division

Superconducting Systems and Devices

- Advanced Thallium Superconductor Technology—DuPont

- High-Temperature Superconducting Racetrack Magnets for Electric Motor Applications-American Superconductor Corp.

- Hybrid Superconducting Digital SystemConductus, Inc. *; National Institute of Standards and Technology; Stanford University, Department of Applied Physics; TRW Applied Technology Divison, Space and Technology Group; and University of California at Berkeley, Department of Electrical Engineering and Computer Science

- Technologies for HTS Components for Magnetic Resonance Applications-DuPont, Superconductivity Group and Intermagnetics General Corp.*

- Thick-Film Superconducting Materials for Radiofrequency CommunicationsIllinois Superconductor Corp.

Other Electronics, Electrical, and Photonics Projects

- Advanced Cathode for Flat Fluorescent Light Sources-Thomas Electronics, Inc.
- High Performance ASIC Technology for Digital Signal Processing-The Athena Group, Inc.

- Low Dielectric Foams for Microelectronics Applications-IBM Corp., Almaden Research Center

- Polymeric Switches for Optical Interconnects-IBM Corp., Almaden Research Center

\section{Chemistry and Life Sciences Office}

Contact:

Linda Beth Schilling

(301) 975-2887

email: linda.schilling@nist.gov

A225 Administration Building

\section{Catalysis and Biocatalysis}

Contact:

Robert Bloksberg-Fireovid

(301) $975-5457$

email: robert.b-f@nist.gov

A225 Administration Building

- A Process for Biocatalytic Desulfurization of Crude Oil-Energy BioSystems Corp.

- Biosynthesis of Monomers - General Electric Corporate R\&D

- Breakthrough Process for Direct Oxidation of Propylene to Propylene Oxide-Dow Chemical Co.

- Breakthrough Technology for Oxidation of Alkanes-Rohm and Haas Company, Inc., Research Laboratories and Sun Company, Inc. (R\&M)*

- Computational Methods for Catalyst Design-Phillips Petroleum Co., Corporate Technology

- Continuous Biocatalytic Systems for the Production of Chemicals from Renewable Resources-Argonne National Laboratory; Eastman Chemical Co.; Electrosynthesis Company, Inc.; Genencor International, Inc.*; and MicroGenomics, Inc. 
- Development of Improved Catalysts using Nanometer-Scale Technology — Catalytica, Inc." and Microfluidics International Corp.

- Direct Oxidation of Natural Gas to Methanol and Transportation Fuels-Catalytica, Inc.

- Elastomeric Polypropylene and Elastic Non-wovens Venture-Amoco Corp., Resource Center" and Fiberweb North America, Inc.

- New Zeolite Synthesis TechnologyChevron Research and Technology Co.

- Polar-Tolerant Organometallic Catalytic Technology for Functionalized Linear Polyolefins — Grace Packaging (formerly W.R. Grace)

- Tailored Optical Polymers Through a Novel Catalyst System-3M Co. and B.F. Goodrich*

- Thin-Film Solid Acid Catalyst for Refinery Alkylation-ABB Lummus Global, Inc.

- Three-Phase Circulatory Flow Reactor Technology for Vapor-Phase Organic 0xidations - Praxair, Inc., Applications for R\&D

\section{Manufacturing Composite Structures}

Contact:

Felix Wu

(301) $975-4685$

email: felix.wu@nist.gov

A225 Administration Building

Technologies for Vehicles

- Automotive Composite Structures: Development of High-Volume Manufacturing Technology — Chrysler Corp., Organic Materials Engineering; Ford Motor Co., Scientific Research Labs; General Motors (Automotive Composites Consortium)*; and General Motors Corp., Polymers Department

- Cyclic Thermoplastic Liquid Composite Molding for Automotive Structures-Ford Motor Co., Scientific Research Labs* and General Electric Corporate R\&D
- Development of Manufacturing Methodologies for Vehicle Composite FramesBudd Co., Design Center

- Engineering Design with InjectionMolded Thermoplastics-General Electric Corporate R\&D and General Motors Corp., Research and Enviromental Staff*

- Integrated Agile Manufacturing for Advanced Composite Electric VehiclesAdvanced Product Development, Inc.; Black Emerald Group; Boston Edison Co.; Design Evolution 4, Inc.; IBIS Associates; Lightbody Technology, Inc.; Massachusetts Division of Energy Resources; Northeast Alternative Vehicle Consortium*; Pepin Associates, Inc.; Solectria Corp.; TPI, Inc.; and Thermal Wave Imaging, Inc.

- Low-Cost Advanced Composite Process for Light Transit Vehicle ManufacturingAdvance USA*; Dow Chemical Co.; Ford Motor $\mathrm{C}$.; and General Electric Co.

- Low-Cost Elastomeric Composites with Application to Vehicle Tires-AlliedSignal, Inc.

- Manufacturing Composite Flywheel Structures-Dow-United Technologies Composite Products, Inc.

- Manufacturing Methodologies for Automated Thermoset Transfer/Injection Molding-Budd Co., Design Center

- Vapor-Grown Carbon-Fiber Composites for Automotive Applications-Applied Sciences, Inc. *; General Motors Corp., North American Operations R\&D Center, Environmental; General Motors Delphi Chassis Systems, Advanced Composite Engineering; and Goodyear Tire \& Rubber Co., Goodyear Technical Center

\section{Technologies for Offshore Oil Production}

- Composite Production Risers-Amoco Corp.; Brown \& Root USA, Inc.; Conoco, Inc.; Cullen Engineering Research Foundation (Composite Production Risers Joint Venture) ${ }^{*}$; Hexcel Corp.; Hydril Co.; Lincoln Composites; Shell Exploration and Production Technology Co.; Stress Engineering
Services, Inc.; and University of HoustonCEAC

- Innovative Joining/Fitting Technology for Advanced Composite Piping SystemsSpecialty Plastics, Inc.

- Light-Weight/High-Strength Composite Intelligent Flexible Pipe DevelopmentWellstream Corp.

- Manufacturing Composite Structures for the Offshore Oil Industry — ABB Vetco Gray, Inc.; Hexcel Corp.; Northrop Grumman Corp., Marine Systems Division*; Reading \& Bates Development Co.; Texaco, Inc./Deep Star Project; and Texas Engineering Experiment Station, Offshore Tech. Res. Ctr. (University of Texas and Texas A\&M)

- Spoolable Composite Tubing-Amoco Corp., Resource Center; Cullen Engineering Research Foundation (Spoolable Composite Tubing Joint Venture)*; Elf Atochem North America, Inc.; Hydril Co.; Phillips Petroleum Co.; Shell Exploration and Production Technology $\mathrm{Co}_{\text {.; }}$ and University of Houston-CEAC

Technologies for Bridges and Other Large Structures

- High-Performance Composites for Large Commercial Structures-Brunswick Technologies, Inc.; Dow Chemical Co.; Hardcore DuPont Composites, L.L.C.*; and Johns Hopkins University, Whiting School of Engineering

- Innovative Manufacturing Techniques to Produce Large Phenolic Composite Shapes-Strongwell Corp. (formerly Morrison Molded Fiberglass)

- Low Cost Manufacturing and Design/ Sensor Technologies for Seismic Upgrade of Bridge Columns - Composite Retrofit Corp./Xxsys*; Hexcel Corp.; and TransScience Corp.

- Polymer Matrix Composite Power Transmission Devices - Hexcel Corp.; New Venture Gear, Inc.*; Quantum Composites of Midland; and Quantum Consultants, Inc. 
- Synchronous In-line CNC Machining of Pultruded Lineals—Ebert Composites Corp.

\section{Tissue Engineering}

Contact:

Rosemarie Hunziker

(301) $975-5324$

email: rosemarie.hunziker@nist.gov

A225 Administration Building

- Advanced Transgenic Model Systems for Biomedical Research and DevelopmentGenencor International, Inc.

- Application of Gene Therapy to Treatment of Cardiovascular Diseases-Progenitor, Inc.

- Biocompatible Resorbable Polymers Designed for Tissue Engineering - Integra LifeSciences Corp.

- Cardiac Muscle Regeneration Using Mesenchymal Stem Cells— Osiris Therapeutics, Inc.

- Combinatorial Cell Culture: Tool Development and Application to Human Stem Cell Growth-Automated Cell Technologies, Inc.

- Computer-Integrated Revision Total Hip Replacement Surgery-IBM Corp., T.J. Watson Research Center; Integrated Surgical Systems, Inc.*; and Johns Hopkins University

- Development of Immortalized Human Hepatocytes for Therapeutic PurposesMulti-Cell Associates, Inc.

- Development of Tissue-Engineered Vascular Grafts Based on Quantitative Cell and Tissue Biomechanics-Advanced Tissue Sciences, Inc.

- Disease Treatment Using Living Implantable Microreactors - BioHybrid Technologies, Inc. " and Synergy Research Corp.

- Ex Vivo Production of Universal Red Blood Cells and Platelets in a Biocompatible 3-D Tissue Scaffold-Cytomatrix

- Fabrication of Clinical Prosthesis from Biomaterials_-Tissue Engineering, Inc.
- Generation of Neural Stem Cell Implants for Neurodegenerative Disease TherapiesCytoTherapeutics, Inc.

- High-Throughput Screening of Hardy Cells for Encapsulation and Implantation Therapies-CytoTherapeutics, Inc.

- Human Stem Cell and Hematopoietic Expansion Systems-Aastrom Biosciences, Inc.

- Molecular Approaches to Ice Control for Engineered Tissue Storage - Life Resuscitation Technologies, Inc.

- Structurally New Biopolymers Derived from Alpha-L-Amino Acids-Integra LifeSciences Corp.

- Synthetic Nerve Fiber Guides Using Novel Biopolymers and Cellular Adhesion Molecules-Acorda Therapeutics, Inc.

- Three-Dimensional Fibrous Scaffolds for Tissue Engineering—Johnson \& Johnson

- Treatment of Diabetes by Proliferated Human Islets in Photocrosslinkable Alginate Capsules-VivoRx, Inc.

- Universal Donor Organs for Transplantation-Alexion Pharmaceuticals, Inc.

- Xenogeneic Cartilage TransplantationAlexion Pharmaceutical, Inc., ${ }^{*}$ and United States Surgical Corp.

\section{Tools for DNA Diagnostics}

Contact:

Stanley Abramowitz

(301) 975-2587

email:stanley.abramowitz@nist.gov A225 Administration Building

- A Portable Genetic Analysis SystemNanogen, Inc.

- An Integrated Microelectronic DNA Diagnostic System-Nanogen, Inc.

- Arrayed Primer Extension: The Next Generation DNA Analysis System for Sequencing in DNA Diagnosis - Amersham Pharmacia Biotech, Inc.*; Baylor College Of Medicine; Duke University, Department of Chemistry,
PM Gross Chemical Laboratory; and Identigene, Inc.

- Automated DNA Amplification and Fragment Size Analysis—DuPont, FQMS Group

- Compact Blue Laser for DiagnosticsPerkin-Elmer Corp., Applied Biosystems Division and Uniphase, Laser Division*

- DNA Diagnostic Systems Based on Novel Chem-jet Techniques - Combion, Inc./Incyte Pharmaceuticals, Inc.

- DNA Diagnostics Using Self-Detected Target-Cycling Reaction-NAVIX, Inc.

- Development and Commercial Application of Genosensor-Based Comparative Genome Hybridization—Vysis, Inc.

- Development of a Generic Technology for the Targeted Detection and Cleavage of DNA and RNA-Third Wave Technologies, Inc.

- Development of Bar Code Diagnostics for DNA Diagnostics—Vysis, Inc.

- Development of Rapid DNA Medical Diagnostics-GeneTrace Systems, Inc.

- Diagnostic Laser Desorption Mass Spectrometry Detection of Multiplex Electrophore Tagged DNA - Bruker Analytical Systems, Inc.*; Genome Therapeutics Corp.; and Northeastern University

- Generation and Development of Novel Nucleic Acid Binding Proteins and Their Use as DNA Diagnostics — Sangamo BioSciences

- Genosensor Technology DevelopmentBaylor College of Medicine, Center for Biotechnology; Beckman Instruments; Genometrix, Inc.; Genosensor Consortium, c/o Houston Advanced Research Center*; Genosys Biotechnologies, Inc.; Houston Advanced Research Center; Laboratories for Genetic Services, Inc.; Massachusetts Institute of Technology, USAF/Lincoln Laboratory; Microfab Technology, Inc.; and Triplex Pharmaceutical Corp.

- Hyperthermophilic Microorganisms in Molecular Biology and BiotechnologyUnited States Biochemical Corp. 
- Integrated Microfabricated Devices for DNA Typing-Molecular Tool, Inc., Alpha Center

- Integrated Microfabricated DNA Analysis Device for Diagnosis of Complex Genetic Disorders_CuraGen Corp. * and Soane BioSciences, Inc.

- MicroLab: A High-Throughput, Low-Cost Approach to DNA Diagnostics by Array Hybridization-Sarnoff Corp.

- Miniature Integrated Nucleic Acid Diagnostic (MIND ${ }^{\mathrm{TM}}$ ) DevelopmentAffymetrix, Inc.*, and Molecular Dynamics, Inc.

- Molecular Cytogenetics Using the GeneScope: An Ultrafast, Multicolor System for Automated FISH Analysis—-Bio-Rad Laboratories

- Programmable Nanoscale Engines for Molecular Separation - CuraGen Corp.

- Real-Time Micro-PCR Analysis SystemCornell University Medical College, Department of Microbiology; EG\&G IC Sensors; Louisiana State University, Department of Chemistry; Perkin-Elmer Corp., Applied Biosystems Division*; and University of Minnesota, Department of Chemistry

- SBH Format 3 Megabase Diagnostics Instrumentation-Hyseq, Inc.

- Self-Contained Cartridge Integrating Nucleic Acid Extraction, Specific Target Amplification, and "Dip Stick" Immediate Detection-Immunological Associates of Denver

- Simple, Generic, and Low-Cost GeneticBased Tools for Disease Detection, Monitoring, and Intervention-Third Wave Technologies, Inc.

\section{General Projects Related to Chemistry and Chemical Engineering}

Contact:

Linda Beth Schilling

(301) 975-2887

email: linda.schilling@nist.gov

A225 Administration Building

\section{Separations Technology}

- Advanced Sorbents for Reducing the Cost of Oxygen-Praxair, Inc.

- Development of New Technologies for Treating and Recycling Wastewater from Aquaculture Facilities—Aquatic Systems/ Kent SeaFarms Corp., Research Division

- Dual Purpose Ceramic Membranes--BP Chemical, Inc.*, and Praxair, Inc.

- Energy-Efficient Oxygen Production Using Novel Ion-Transport Membranes - Air Products and Chemicals, Inc.

- Facilitated Transport Process for LowCost Olefin-Paraffin Separations-Amoco Corp., Resource Center

- Non-Chromatographic Enantiomer Separation and Purification with High Separation Factors - IBC Advanced Technologies, Inc.

- Novel Anion-Selective Separations Using Molecular Recognition Technology - - IBC Advanced Technologies, Inc.

\section{Drug Design and Chemical Modeling}

- Crystallization and Structural Determination of G-Coupled Protein Receptors3-Dimensional Pharmaceuticals, Inc., Eagle View Corporate Center

- Development and Applications of Density Functional Software for Chemical and Biomolecular Modelings_-Biosym Technologies, Inc.

- Enhanced Molecular Dynamics Simulation Technology for Biotechnology Applications-Moldyn, Inc.
- Evolution of a Murine Model for AIDS: Applications to Discovery of Small Molecule and Vaccine Therapeutics-Maxygen

- Fundamental New Strategies to Discover Drugs_-Isis Pharmaceuticals

- Marine Microorganisms and Saline Fermentation: A New Industrial ResourceAphios Corp.

- Molecular Recognition Polymers as AntiInfectives - GelTex Pharmaceuticals, Inc.

- Molecular Recognition Technology for Precise Design of Protein-Specific DrugsCuraGen Corp.* and Wyeth-Ayerst Research, American Home Products

- RNA Binding Protein Technology for Identification of Novel TherapeuticsBearsden Bio, Inc. (formerly Symphony Pharmaceuticals)

Other Chemistry and Chemical Engineering Projects

- Development of Improved Functional Properties in Renewable-Resource-Based Biodegradable Plastics - Cargill, Inc., Research Center

- Enabling Large-Scale Recovery of Plastics from Durable Goods-MBA Polymers

- Film Technologies to Replace Paint on Aircraft_-3M Co.* and Lockheed Martin Corp., Aeronautical Systems

- Plasma and Phosphor Technology for Mercury-Free Fluorescent ApplicationsGeneral Electric Corporate R\&D

\section{General Projects Related to Biotechnology}

Contact:

Linda Beth Schilling

(301) 975-2887

email: linda.schilling@nist.gov

A225 Administration Building

\section{Health-Related Biotechnology}

- A Long-Term Pressure-Sensing System for Use in the Human Body and Harsh Environments—Apex Medical, Inc.* and East Development Group, Inc. 
- Development of Multi-Photon Detection Technique and its Application to Environmental and Biomedical DiagnosticsBioTraces, Inc.

- Development of Novel DNA Binding Proteins as Antiviral Therapeutics - Sangamo BioSciences, Inc.

- Low-Temperature Viral InactivationAphios Corp.

- Measurement Technology for Quantitation of the Complete Human ProteomeLarge Scale Biology Corp.

Industrial and Agricultural Biotechnology

- Enhanced Manufacturing Technologies for Bioactive Proteins and Peptides in Transgenic Tobacco-CropTech Development Corp.* and Dyax Corp.

- Oleaginous Yeast Fermentation as a Production Method for Squalene and Other Isoprenoids-Mycogen Corp.

- Standardization of 2-D Protein Analysis Using Manufacturable Gel Media_Large Scale Biology Corp.

- Transgenic Cotton Fiber with Polyester Qualities via Biopolymer Genes—Agracetus/ A Unit of Monsanto Co.

- U.S. Self-Sufficiency in High-Quality Pyrethrin Production-AgriDyne Technologies, Inc.

- Using Biotechnology to Control Fruit Ripening-Agritope, Inc.

\section{Materials and Manufacturing Office}

Contact:

John Gudas

(301) 975-3214

email: john.gudas@nist.gov

A225 Administration Building

\section{Materials Processing for Heavy Manufacturing}

Contact:

Clare Allocca

(301) $975-4359$

email:clare.allocca@nist.gov

A225 Administration Building

Advanced Materials Technologies

- Development of a High-Pressure 0xygen Generator Using a Solid Electrolyte Oxygen Separation Technology — Ceramatec, Inc.

- Rapid Solidification Powder Metallurgy for High-Nitrogen Stainless Steels_-Crucible, Compaction Metals Division

\section{Microelectronics Manufacturing Infrastructure}

- Conducting Polymers: ThreeDimensional Engineering for Advanced Applications-IBM Corp., T.J. Watson Research Center

- Novel Synthetic Fused Quartz for Semiconductor Manufacturing - General Electric Corporate R\&D

- Solder Jet Technology DevelopmentMicrofab Technology, Inc.

- Ultra-Low k Dielectric Materials for HighPerformance Interconnects-Texas Instruments, Inc.

\section{Net-Shape Manufacturing}

- Aqueous Injection Molding for Low-Cost Fabrication of Silicon Nitride ComponentsAlliedSignal, Inc., Ceramic Components

- Ceramic Technology for Broad Based Manufacturing-AlliedSignal, Inc.

- Cost-Effective Blade Manufacturing for Combustion Turbine Applications-PCC Airfoils, Inc., Manufacturing Technology Center and Westinghouse Power Generation, A Division of CBS Corp.*

- Cost-Effective, Near-Net-Shape, Superalloy Forgings for Power Generation Gas Turbines-Wyman-Gordon Co.

- Development of Casting Technology to Produce Large Superalloy Castings for Industrial Applications-PCC Structurals, Inc. (formerly Precision Castparts Corp.)

- Low-Cost, Near Net-Shape Aluminium Casting Processes for Automotive and Truck Components_AlliedSignal, Inc.*; Stahl Specialty Co.; and Top Die Casting Company, Inc.

- Novel Near-Net-Shape Processing of Engineered Ceramics - Garrett Ceramic Components (Division of AlliedSignal Aerospace)

Surface Modification

- Accelerated Commercialization of Diamond-Coated Round Tools and Wear Parts-Kennametal, Inc., Corporate Technology Center and Norton Diamond Film*

- Ceramic Coating Technology for the Internal Surfaces of Tubular/Cylindrical Components-Praxair Surface Technologies, Inc.

- CVD Diamond-Coated Rotating Tools for Machining Advanced Composite Materials Boeing Commerical Airplane Group; Crystallume, A Division of Advanced Refractory Technologies, Inc.*; Ford Motor Co., V-Engine Manufacturing Engineering; General Motors Corp., Technical Center; Hughes Aircraft Co.; and Rogers Tool Works, Inc. 
- Diamond-Like Nanocomposite Technology-Advanced Refractory Technologies, Inc.

- Engineered Surfaces for Rolling and Sliding Contacts-Caterpillar, Inc., Advanced Materials Technology*; General Motors Corp., Gear Center; and Timken Co.

- Functionally Gradient Materials - Synthesis, Process and Performance-Caterpillar, Inc.

- Plasma Technology for Low-Cost Diamond Production-SGS Tool Co. and Westinghouse Electric Co.*

\section{Joining, Cutting and Grinding}

- Fabrication of Advanced Structures Using Intelligent and Synergistic Materials Processing-Caterpillar, Inc., Fabricated Structures R\&D*; Lincoln Electric Co.; Tower Automotive (formerly A.0. Smith); and U.S. Steel

\section{Knowledge-Based Manufacturing}

- Intelligent Processing of Materials for Thermal Barrier Coatings-General Electric Corporate R\&D, Power Generation

\section{Motor Vehicle Manufacturing Technology} Contact:

Jack Boudreaux

(301) $975-3560$

email: jack.boudreaux@nist.gov

A225 Administration Building

\section{Advanced Materials Technologies}

- Nanocomposites: New Low-Cost, HighStrength Materials for Automotive PartsMagna International of America and The Dow Chemical Co."

\section{Net-Shape Manufacturing}

- Agile Precision Sheet-Metal StampingA. J. Rose Manufacturing Co.; Allen Bradley Co., Inc.; American Iron and Steel Institute; Atlas Technologies; Autodesk, Inc.; Autodie International, Inc.; Chrysler Corp.; Classic Design, Inc.; Data Instruments, Inc.; Deneb Robotics, Inc.; Ford Motor Co.; General Motors Corp., Flint Metal Fabricating Plant; HMS Co.; HMS Products Co.; Helm Instru- ment; Lamb Technicon; Near Zero Stamping, Inc. (c/o Auto Body Consortium)*; Ohio State University; Oxford Automotive (formerly Lobdell-Emery Manufacturing Co.); Perceptron, Inc.; Sekely Industries; Signature Technologies; Tecnomatix Technologies, Inc.; Tower Automotive; and Verson

- Low Cycle Time Liquid Molding Process for Automotive Structural ComponentsStewart Automotive Research, LLC

- Motor Vehicle Rapid ToolmakerSanders Prototype, Inc.

- Springback Predictability in Automotive Manufacturing-Alcoa Aluminum Co. of America; Budd Co., Technical Center; Chrysler Corp.; Environmental Research Institute of Michigan*; Ford Motor Co., Scientific Research Labs; General Motors Corp., North American Operations Research Analytics; and U.S. Steel

- The Next-Generation Industrial Production Process for High-Density Powder Metal Products-General Motors Corp., Powertrain Division; IAP Research, Inc.*; and Zenith Sintered Products, Inc.

Coatings, Diamond Deposition, and Multilayer Materials

- Cubic Boron Nitride Coatings for Cutting and Specialty Tools - Extrude Hone Corp. and Kennametal, Inc., Corporate Technology Center*

\section{Surface Modification}

- Plasma-Based Processing of Lightweight Materials for Motor-Vehicle Components and Manufacturing Applications-A.0. Smith Corp.; ABB High Power Semiconductors; Diversified Technologies, Inc.; Empire Hard Chrome, Inc.; Environmental Research Institute of Michigan*; General Motors Corp., Electrical and Electronics Department; Harley-Davidson Motor Co.; IONEX; Kwikset Corp.; Litton Electron Devices; NANO Instruments, Inc.; PVI; and University of Wisconsin at Madison, Engineering Research

\section{Joining, Cutting, and Grinding}

- Advanced Welding Technology for Structural Automotive Products—Dana Corp., Parish Light Vehicle Structures Division

- Flow-Control Machining-Extrude Hone Corp.*; Ford Motor Co., Scientific Research Labs; General Motors Corp., Powertrain Division; University of Nebraska at Lincoln; and University of Pittsburgh

- Intelligent Resistance Welding-Alcan Aluminum Corp.; Allen Bradley Co., Inc.; American Iron and Steel Institute; Ansys, Inc.; Battelle Memorial Institute; Chrysler Corp.; DuPont Central Research; Ford Motor Co., Manufacturing Development Center; General Motors Corp., NAO, Mid-Lux; Intelligent Resistance Welding Consortium ( $\mathrm{c} / 0$ Auto Body Consortium)*; Johnson Controls, Inc., Automotive Systems Group; Lamb Technicon; Medar, Inc.; Progressive (PICO); RoMan Manfacturing, Inc.; Robotron; Sensotec, Inc.; and Tower Automotive

- Sub-Micron Precision Grinding of Advanced Engineering MaterialsCincinnati Milacron; Cummins Engine Co.*; and Goldcrown Machinery

\section{Machine Tools}

- Agile Precision Line Boring-Lamb Technicon

- Development of the 3-D Printing Process for Direct Fabrication of Automotive Tooling for Lost Foam Castings - Extrude Hone Corp.* and General Motors Powertrain Group

- Flexible Low-Cost Laser Machining for Motor Vehicle Manufacturing - SDL, Inc.* and Utilase Systems, Inc.

- Machine Tool Process Monitoring Diagnostic System-Montronix, Inc.

- Non-Circular Turning Process for Camshaft Machining - Saginaw Machine Systems, Inc.

- Rapid Fabrication of Superabrasive Grinding Tools-Abrasive Technology Aerospace, Inc. 
- Real-Time Active Balancing for HighSpeed Machining-Balance Dynamics Corp.

\section{Imaging and Weasurement Technology}

- Fast, Volumetric X-ray Scanner for ThreeDimensional Characterization of Critical Objects--EG\&G Reticon; General Electric Aircraft Engines; General Electric Corporate R\&D; General Motors Corp., Technical Center; and Scientific Measurement Systems, Inc.*

- High Performance Sensor Arrays for Digital X-ray and Visible Light Imaging-TPL, Inc.; Thermotrex Corp.; and Xerox Corp., Palo Alto Research Center*

- Technology for Gear Performance Prediction Utilizing High-Speed Precision. Weasurement-M\&M Precision Systems Corp.

- Wet Paint Thickness Measurement System-Autospect, Inc.

\section{Knowledge-Based Manufacturing}

- Development of Advanced Technologies and Systems for Controlling Dimensional Variation in Automobile Body Manufacturing-2mm-Auto Body Consortium*; CDIModern Engineering; Chrysler Corp; Classic Design, Inc.; Detroit Center Tool, Inc.; General Motors Corp., Technical Center; ISI Robotics; Perceptron, Inc.; Pioneer Engineering \& Manufacturing; Progressive Tool \& Industries, Inc.; University of Michigan, Mechanical Engineering and Applied Mechanics; and Weber Technologies, LLC (formerly ASC, Inc.)

- Die Casting Technician's Digital Assistant-AI WARE; Doehler-Jarvis; and Edison Industrial Systems Center*

- Flexible Robotic Assembly for Powertrain Applications- -Automated Powertrain Assembly Consortium (c/o NCMS)*; Ford Motor Co.; MicroDexterity Systems; Perceptron, Inc.; and Progressive Tool \& Industries Co.

- Manufacturing Agility Server--Flavors Technology
- Next Generation Agile Fixturing SystemLamb Technicon

\section{Premium Power}

Contact:

Gerald Ceasar

(301) 975-5069

email: gerald.ceasar@nist.gov

A225 Administration Building

- Advanced Magnesium Alloys Production Process-Manufacturing Sciences Corp. and Ovonic Battery Co. (ECD)*

- Development of Rapid Thermal Processing to Produce Low Cost Solar Cells Solarex, A Business Unit of Amoco/Enron Solar

- Ultrathin Silicon Ribbon for HighEfficiency Solar Cells_Evergreen Solar, Inc.

\section{Vapor Compression Refrigeration Technology}

Contact:

John Gudas

(301) 975-3214

email: john.gudas@nist.gov

A225 Administration Building

- Development of Closed Cycle Air Refrigeration Technology for Refrigeration Markets-Air Products and Chemicals, Inc.* and Toromont Process Systems, Inc.

- Ejector Expansion Refrigeration CycleCalmac Manufacturing Corp.

- High- and Variable-Speed Co-Rotating Scroll-Copeland Corp.

- Innovative, Small, High-Speed, Centrifugal Compressor and Integrated HeatExchanger/Fan TechnologiesAlliedSignal, Inc.; Carrier Corp.; DuPont Fluoroproducts; General Electric Corporate R\&D; Lockheed Martin Corp. (formerly Martin-Marietta Corp.); SatCon Technology Corp.; and United Technologies Corp., Research Center*

- Novel Leak Detection Technology Development-Adaptive Optics Associates, Inc.; DeMaria Electroptics Systems, Inc.; and United Technologies Research Center*
- Photocatalytic Indoor Air Purification for Air Conditioning Systems-E. Heller \& Co.

- York Coil Technology Project-York International Corp.

\section{General Projects Related to Materials and Manufacturing}

Contact:

John Gudas

(301) 975-3214

email:john.gudas@nist.gov

A225 Administration Building

Machine Tools

- Advanced Compensation Techniques for Enhancing Machine-Tool AccuracySaginaw Machine Systems, Inc.

- Development of an Adaptive Compensation Technique for Enhancing CMM Accuracy_-Giddings \& Lewis, Inc., Sheffield Measurement Division

- Octahedral Hexapod Machine Development Program —-Ingersoll Milling Machine Co.

- Strategic Machine Tool Technologies: Spindles-Aesop, Inc.; Ford Motor Co., Alpha Development Center; General Motors Corp., NAO Technical Center; Giddings \& Lewis, Inc., Automation Technology; Manufacturing Laboratories, Inc.; National Center For Manufacturing Sciences, Inc.*; Olofsson Machine Tools, Inc.; Setco Sales Co.; and Torrington Co.

\section{Imaging and Measurement Technology}

- A Non-intrusive Method for Intelligent Process Control of the Densification of Powder Preforms During ElectroconsolidationSuperior Graphite Co., Inc.

- Low-Cost Amorphous Silicon Manufacturing Technology - EG\&G Reticon and General Electric Corporate R\&D*

- Robust, Fast 3-D Image Processing and Feature Extraction Tools for Industrial Automation Applications - Perceptron, Inc. 


\section{Knowledge-Based Manufacturing}

- Collaborative Decision Support for Industrial Process Control-Amoco Corp., Worldwide Engineering and Construction; Applied Training Resources; BP Oil; Chevron; Exxon Research and Engineering; Gensym Corp.; Honeywell, Inc., Technology Center*; Mobil; Shell Chemical Co.; and Texaco, Inc.

- NCMS Rapid Response ManufacturingCimplex Corp.; Ford Motor Co., Manufacturing Development Center; General Motors Corp., Technical Center; ICAD, Inc. (Concentra); MacNeal Schwendler Corp.; National Center for Manufacturing Sciences, Inc.*; Spatial Technology Inc.; Teknowledge Corp.; Texas Instruments, Inc.; and United Technologies Corp., Hamilton Standard Division, Research Div.

\section{Ceramics}

- Novel Cost-Effective Process to Fabricate Surface Feature Micro-Optics in Pure Silica-Geltech, Inc.

- Synthesis and Processing of Nanocrystalline Ceramics on a Commercial Scale-Nanophase Technologies Corp.

\section{Other Manufacturing and Materials Projects}

- A Software Technology for Optimizing On-time Performance in the Transportation Industry-Union Switch \& Signal, Inc.

- Advanced Gear Measurement Technologies to Achieve Submicron-Level Accuracies-M\&M Precision Systems Corp.
- Autonomous Navigation in QuasiStructured Environments-HelpMate Robotics (formerly Transitions Research Corp.)

- Development of Cost-Effective Routes to Compatibilize Polymers in a Commingled Waste Stream-Michigan Molecular Institute

- Development of TERFENOL-D HighPowered Ultrasonic Transducer Technology for Sonochemistry—ETREMA Products, Inc.

- Electrochromic Materials-3M Co., Industrial and Consumer Sector Research Laboratory* and SAGE Electrochromics

- Neural Network Control and Sensors for Complex Materials-3M Co., Engineering Systems and Technology; Alliant Techsystems (formerly Hercules Aerospace); Honeywell, Inc., Technology Center*; and Sheldahl

- Non-Contact Optical Metrology of Complex Surface Forms for Precision Industrial Manufacturing-Tropel Corp.

- Novel X-ray Source for CT ScannersTeledyne Electronic Technologies, Vacuum Technology Business Unit

- PREAMP: Pre-Competitive Advanced Manufacturing of Electrical ProductsBoeing Co., Defense and Space Group, Hughes Aircraft Co.; Martin Marietta Corp., Electronics Information and Missiles Group, a subsidiary of Lockheed Martin; Rensselear Polytechnic Institute; Rockwell International Corp., Collins Avionics and Communication Division; and South Carolina Research Authority*
- Rapid Agile Metrology for Manufacturing-Brown \& Sharpe Manufacturing Co.; Caterpillar, Inc., Technical Services Division; Central State University; Cleveland Advanced Manufacturing Program; Eaton Corp., Manufacturing Technologies Center; General Electric Aircraft Engines; General Electric Corporate R\&D; Industrial Technical Institute; Intelligent Automation Systems; NASA Lewis Research Center; Ohio Aerospace Institute (Consortium for Noncontact Gauging)*; and University of Cincinnati; Department of Electrical and Computer Engineering

- Thermal Insulation Materials-Morphology Control and Processes for the Next Generation of Performance-Armstrong World Industries, Inc., Innovation Center

- Thick Ductile Metallic Glass for Electric Power Applications-AlliedSignal, Inc. 


\section{Overview}

The NIST Mlanufacturing Extension Partnership (MEP) is a nationwide network of locally managed extension centers offering technical assistance and the latest business practices to help the nation's smaller manufacturers improve their competitiveness. At the heart of MEP is a network of more than 400 manufacturing extension centers and field offices located throughout the country. Started in 1989, today's network delivers services to manufacturers in all 50 states and Puerto Rico.

\section{Smaller Manufacturers: Critical to the U.S. Economy}

Numbering more than 380,000 , small and mid-sized manufacturers make vital contributions to the economy. About 98 percent of the nation's manufacturers are small to medium-sized, defined as having fewer than 500 employees. They supply more than 50 percent of the value added in U.S. manufacturing and employ nearly 12 million people. That accounts for 75 percent of all U.S. manufacturing workers with high-skilled, high-wage jobs, paying an average 89 percent more than the average retail salary.

As large manufacturers increase their dependence on suppliers for parts and services, the performance and capabilities of smaller manufacturers become even more critical to the competitiveness of the entire manufacturing sector and to the health of the U.S. economy. Yet, according to a National Research Council report, "Many of these small firms ... are operating far below their potential. Their use of modern manufacturing equipment, methodologies, and management practices is inadequate to ensure that American manufacturing will be globally competitive." Limited budgets, lack of in-house expertise, and lack of access to the newest technologies are but a few of the significant barriers faced by smaller manufacturers-barriers that MEP helps firms overcome.

\section{MEP Extension Centers}

MEP centers are local resources serving their local markets. Linked together through NIST's MEP, they are part of a national network of manufacturing and business experts. They exist as the result of a partnership among the federal government, state/ local governments, and industry to help local manufacturers. They are created through a competitive, merit-based process where funding is contingent upon successful annual reviews of each center. MEP centers are supported by contributions from public and private organizations that match federal funding.

While part of a national network, MEP centers are independent, non-profit organizations. They offer products and services that meet the specific needs of the region's local manufacturers. Each center works directly with area firms to provide expertise and services tailored to their most critical needs, which range from process improvements and worker training to business practices and applications of information technology. Solutions are offered through a combination of direct assistance from center staff and work with outside consultants. MEP centers are staffed by knowledgeable manufacturing engineers and business specialists who typically have years of practical experience gained from working on the manufacturing floor, managing plant operations, or both. MEP center staff also know the local business community and the available local resources and can access additional resources available through the MEP network. As a result, centers help small firms to overcome barriers in locating and obtaining private-sector resources.
MEP centers work with companies that are willing to invest in themselves. That means companies that are willing to invest time, money, and/or human resources to improve their businesses. Typical MEP clients include manufacturers who:

- have been unable to locate the proper resources or technologies they need;

- want expert, impartial advice in helping them evaluate alternative solutions;

- need help solving a specific problem, such as determining the cause of product defects, modifying plant layout to improve work flow, or establishing employee training;

- want assistance in reversing negative business situations - such as sales decreases, loss of market share, or cost increases;

- want to implement new technologies or processes that will help establish them as market leaders; or

- seek to improve their ongoing business operations for peak performance.

\section{How Centers Help}

\section{ASSESSMENTS}

Many firms begin their relationship with an MEP center through an assessment of the company's current operations and opportunities for improvement. As part of that assessment, field engineers may review the manufacturing process, the plant layout, the inventory and materials flow, and the policies and procedures. Field engineers, also known as manufacturing specialists, then prepare an evaluation of the firm and its operations. These findings are reviewed with management and other key personnel at the manufacturing company. 


\section{MEP Success Stories}

MEP's locally managed centers have worked with thousands of smaller manufacturers, providing the technical and business assistance the companies needed to improve their performance and become more competitive. The following examples show how companies have benefited by working with an MEP center.

- The Futon Shop, a client of the Bay area's MEP affiliate in California-The Corporation for Manufacturing Excellence or MANEX — was experiencing difficulties in meeting production demands in an efficient and cost-effective manner. MANEX provided the solution by designing a customized training program that used the manufacturer's own employees to resolve issues. In addition to identifying waste, production line personnel designed a new inventory and assembly system that met current production requirements and allowed the manufacturer to increase output systematically. These changes increased overall production by 30 percent, eliminated over $\$ 100,000$ in waste annually, saved an immediate $\$ 20,000$ per month in payroll costs, and reinvented the manufacturing culture.

- Southern Automation Inc., located in Shreveport, La., designs and builds automated material-handling equipment that is used by Fortune 500 companies for manufacturing operations. With engineering help from the MEP affiliate in Louisiana - the Louisiana Manufacturing Technical Extension Center or LAMTEC the company has been able to break into the robotics and custom automation field in a big way. Southern Automation needed engineering design help to produce more custom manufacturing equipment. LAMTEC industrial design experts helped the company open up new markets and increase business volume by roughly 20 percent. "When I heard of LAMTEC, I couldn't believe that such a program existed to help businesses," said company president Dennis Rimmer. "I am now a believer. It has been great for us."

- In 1995, the Plastics Group, a small company specializing in custom injection molding, engineering, testing, and tooling for plastic products, grew concerned about its lack of profitability. Management thought the firm had a production problem and considered expensive, company-wide production and accounting changes. Specialists with the MEP affiliate in Georgia-the Georgia Manufacturing Extension Alliance-determined costing and marketing issues were the culprits. Changes in quality procedures yielded some $\$ 30,000$ in material savings, and revamped marketing efforts generated more than $\$ 500,000$ in new sales. Its new base of business also enabled the company to hire 20 new employees. For the first time in two years, the firm was profitable.

- Lorrie Browning never dreamed she would be running a snack food manufacturing plant when she started making beef jerky in her kitchen in 1995. Testing a new food dehydrator, she tried out her own recipe on friends and relatives, who kept asking for more. Knowing she was onto something, Browning stepped up her process, contacted the U.S. Department of Agriculture (USDA), and launched her business. Next, she looked for help in financing a building, buying equipment, and improving process management. That's when she contacted the MEP affiliate in northeastern Pennsylvania, called the Northeastern Pennsylvania Industrial Resource Center (NEPIRC). Engineers with NEPIRC helped Browning set up and modify her processing systems, particularly the venting for dehydrators. The net effect was an increase in beef dehydrating throughputs and a USDA-approved manufacturing process. Experts also helped Browning secure the necessary funds for the manufacturing facility and process equipment. The result was an increase in staff to five employees and a 1,000 percent increase in production, from 25 to 250 pounds per day.

- Kansas-based Robbie Manufacturing was able to trim its costs and boost its profitability with help from the MEP affiliate in Kansas, known locally as the MidAmerica Manufacturing Technology Center. By videotaping employees using new techniques for setup reduction and quick changeover on one product line, employee team members were able to apply the same techniques and establish new standardized manufacturing processes, saving the company an estimated $\$ 150,000$.

- Efficiency increased by 295 percent as a result of a process redesign for Boozer Lumber Company located in Columbia, S.C. The South Carolina Manufacturing Extension Partnership (SCMEP) helped Boozer Lumber Company realize an impact of over $\$ 11.2$ million through inventory reduction, capital avoidance, savings in materials and labor, increased sales, and jobs created. After the South Carolina MEP evaluated existing industry tools and technologies, a prototype truss fabrication system was built. Benchmark studies then were used to evaluate the setup and build time of 16 specific trusses. "As a direct result of SCMEP's assistance, we have reinvented our company into a world-class operation," said Bob Jones, chief executive officer of Boozer Lumber Company. 
As a result of the assessment, MEP manufacturing specialists may recommend a few simple, quick solutions or a detailed plan of action. Both types of recommendations are designed to provide quantifiable, bottomline impact on performance-productivity, quality, profits, or sales.

For some firms, these assessments are enough to get started. The manufacturer may have the resources to implement the plan, or may incrementally pursue new initiatives or changes. For those manufacturers requiring assistance in implementing center-suggested actions, the MEP center can provide the solutions and the support.

\section{TECHNICAL AND BUSINESS SOLUTIONS}

The degree and type of assistance provided to each MEP customer firm is based on the particular need of that manufacturer. For a firm dealing with employee relations and human resource issues, for example, support may come through a management training program, a series of staff workshops, or revamping relevant policies and procedures-all services managed by the center staff either independently or through other experts. If the field engineers identify inefficiencies in the physical layout of the plant, they may provide a number of options for reconfiguration and may guide the process for testing these alternatives. Other services may focus on quality improvement, new product development, new equipment needs, marketing and sales support, or capital investments.

\section{ACCESS TO RESOURCES}

Sometimes, the technical guidance needed by a manufacturer is best found beyond the MEP center. That is when the value of MEP is most apparent. Through both its local and national network of partners, MEP staff can identify experts and resources from the region - or across the country - that can help improve a company's performance. In fact, the MEP network provides small manufacturers with access to over 2,000 partnerships with federal agencies, national associations, and other organizations. Pro- jects with the U.S. Department of Labor, U.S. Department of Energy, U.S. Environmental Protection Agency, U.S. Department of Defense, federal labs, and manufacturing associations are examples of how MEP leverages public and private resources to make a comprehensive range of technical services and assistance available to small manufacturers.

\section{SEMINARS AND TRAINING}

Every day, MEP centers deal with manufacturers who share common problems and seek similar assistance. Often, manufacturers may not be aware of available resources. To help manufacturers improve their knowledge and capabilities, centers provide a variety of seminars and training programs. These seminars may address issues unique to a specific community or information sought by many firms, such as preparing for ISO 9000 certification, implementing waste reduction programs, finding and hiring employees, or profiling the newest manufacturing technologies.

In addition, MEP centers help provide manufacturing firms with exposure to other manufacturers in the area- and the opportunity to share resources and information. Regular events, including tours of local manufacturing facilities, discussions, and demonstrations of the latest industry innovations, give company owners and managers the opportunity to see state-of-the-art processes and discuss common issues with their peers.

\section{MEP Results}

Evaluation is a key element of all MEP programs and activities. Results are used to assess the effectiveness of services and their impact on the performance of client firms, and to help guide planning at both the center and network levels. By measuring shortand long-term impacts, MEP also can assess economic returns on the federal investment in manufacturing extension services.
The U.S. Census Bureau surveyed 2,350 firms served by MEP centers in 1996. These companies reported an increase in sales of nearly $\$ 110$ million and showed savings of $\$ 16$ million in inventory and over $\$ 13$ million in labor and material. They also invested more than $\$ 85$ million in modernization. These companies directly attribute these benefits to the services provided by the NIST manufacturing extension centers.

Other independent studies also have yielded solid evidence of performance and economic benefits. An analysis by the U.S. General Accounting Office found that a substantial majority of firms using extension services, including those provided by the MEP, credited this assistance with helping them to improve productivity, product quality, customer satisfaction, profits, and other critical facets of their operations.

\section{Additional Information}

For additional information, contact:

Manufacturing Extension Partnership

(301) $975-5020$

email: MEPinfo@mep.nist.gov

fax: (301) 963-6556

C121 Building 301

www.mep.nist.gov

or see the list of centers below or phone (800) MEP-4MFG for direct access to your local Manufacturing Extension Partnership affiliate. 


\section{MEP Center Locations}

Most MEP centers are affiliated with state, local, and educational organizations. In the following listing, each center serves the entire state unless otherwise noted.

\section{ALABAMA}

Alabama Technology Network

1500 Resoulce Drive

Birmingham, Ala. 35242

(205) $943-4770$

\section{ALASKA}

Alaska Manufacturing Extension Partnership c/o Industry Network Corp.

155 University Blvd. S.E.

Albuquerque, N.M. 87106

(505) 843-4250 or (800) 716-6462

\section{ARIZONA}

Industry Network Corp.

1155 University Blvd. S.E.

Albuquerque, N.M. 87106

(505) 843-4250 or (800) 716-6462

\section{ARKANSAS}

Arkansas Manufacturing Extension Network 100 Main St., Suite 450

Little Rock, Ark. 72201

(501) 324-9006

\section{CALIFORNIA}

California Manufacturing Technology Center

13430 Hawthorne Blvd.

Hawthorne, Calif. 90250

(310) 355-3060

Serves the five-county Los Angeles basin, Fresno, and Sacramento through seven regional offices.

San Diego Manufacturing Extension

Center; Inc.

World Trade Center

1250 Sixth Ave., 5th Floor

San Diego, Calif. 92101-4301

(619) 515-9820, ext. 1201

Serves firms in San Diego County.
The Corporation for Manufacturing

Excellence

48001 Fremont Blvd.

Fremont, Calif. 94538

(510) 249-1480

Serves the nine counties of the Bay area.

\section{COLORADO}

Mid-America Manufacturing Technology

Center

10561 Barkley, Suite 602

Overland Park, Kan. 66212

(913) 649-4333

A regional organization that also operates in

Kansas, Missouri, and Wyoming.

\section{CONNECTICUT}

Connecticut State Technology Extension

Program

185 Main St., Suite 408

New Britain, Conn. 06051

(860) $832-4600$

\section{DELAWARE}

Delaware Manufacturing Alliance

Delaware Technology Park

One Innovation Way, Suite 301

Newark, Del. 19711

(302) 452-2520

\section{FLORIDA}

Florida Manufacturing Technology

Center, Inc.

390 N. Orange Ave., Suite 1300

Orlando, Fla. 32801

(407) 316-4633

\section{GEORGIA}

Georgia Manufacturing Extension Alliance Georgia Institute of Technology

2230 'Keefe Building

Atlanta, Ga. 30332-0640

(404) 894-8989

\section{HAWAII}

Hawaii Manufacturing Extension Center

c/o Industry Network Corp.

1155 University Blvd. S.E.

Albuquerque, N.M. 87106

(505) $843-4250$ or (800) 716-6462
IDAHO

Idaho TechHelp ${ }^{\mathrm{TM}}$

Boise State University

1910 University Drive

Boise, Idaho 83725

(208) 385-3689

\section{ILLINOIS}

Chicago Manufacturing Center

3333 West Arthington

Chicago, Ill. 60624

(773) 265-2020

Serves the six-county Chicago metropolitan area: Cook, DuPage, Kane, Lake, McHenry, and Will counties.

Illinois Manufacturing Extension Center

Bradley University

404 Jobst Hall

Peoria, Ill. 61625

(309) 677-4632

Serves manufacturers through 16 locations throughout northern, southern, and central Illinois.

\section{INDIANA}

Indiana Business Modernization and

Technology Corp.

One North Capitol Ave., Suite 925

Indianapolis, Ind. 46204-2242

(317) 635-3058 or (800) 877-5182

\section{IOWA}

Iowa Manufacturing Technology Center Des Moines Area Community College

ATC Bldg. 3E

2006 South Ankeny Blvd.

Ankeny, Iowa 50021

(515) $965-7125$

\section{KANSAS}

Mid-America Manufacturing Technology

Center

10561 Barkley, Suite 602

Overland Park, Kan. 66212

(913) 649-4333

A regional organization that also operates in Missouri, Colorado, and Wyoming. 


\section{KENTUCKY}

Kentucky Technology Service

167 West Main St., Suite 500

Lexington, Ky. 40507

(606) 252-7801

\section{LOUISIANA}

Louisiana Manufacturing Technical

Extension Center

P.0. Box 44172

241 East Lewis St.

Lafayette, La. 70504-4172

(318) $482-6767$

\section{MAINE}

Maine Manufacturing Extension Partnership

87 Winthrop St.

Augusta, Maine 04330

(207) 621-6350

\section{MARYLAND}

Maryland Technology Extension Service

University of Maryland Engineering

Research Center

Potomac Building 092, Room 2104

College Park, Md. 20742-3415

(301) 405-3883

\section{MASSACHUSETTS}

Massachusetts Manufacturing Partnership

Corporation for Business, Work, and Learning

The Schrafft Center

529 Main St.

Boston, Mass. 02129

(617) 727-8158 or (800) 667-6347

\section{MICHIGAN}

Michigan Manufacturing Technology Center

P.0. Box 1485

2901 Hubbard Road

Ann Arbor, Mich. 48106

(800) 292-4484

\section{MINNESOTA}

Minnesota Technology, Inc.

111 Third Ave. South

Minneapolis, Minn. 55401

(612) $338-7722$

\section{MISSISSIPPI}

Mississippi Technology Extension

Partnership

Building 1103, Suite 146K

Stennis Space Center, Miss. 39529

(228) 688-3535 or (800) 746-4699

Mississippi Polymer Institute and Pilot

Manufacturing Extension Center

P.0. Box 10003

Hattiesburg, Miss. 39406-5157

(601) 266-4607

Serves polymer and polymer-related firms

throughout Mississippi.

\section{MISSOURI}

Mid-America Manufacturing Technology

Center (MAMTC)

10561 Barkley, Suite 602

Overland Park, Kan. 66212

(913) 649-4333

Serves the seven-county St. Louis area.

A regional organization that also operates in

Kansas, Colorado, and Wyoming.

MAMTC Missouri Rolla Regional Office

800 W. 14th St., Suite 111

Rolla, Mo. 65401

(573) 364-8570 or (800) 95-MAMTC

(956-2682)

Serves rural Missouri through four regional offices.

\section{MONTANA}

Montana Manufacturing Extension Center

Montana State University

313 Roberts Hall

Bozeman, Mont. 59717

(406) 994-3812

\section{NEBRASKA}

Nebraska Industrial Competitiveness Service 301 Centennial Mall South, 4th Floor Lincoln, Neb. 68509-4666

(402) $471-6513$

\section{NEVADA}

Nevada Manufacturing Extension

Partnership

c/o Industry Network Corp.

1155 University Blvd. S.E.

Albuquerque, N.M. 87106

(505) $843-4250$ or (800) 716-6462

\section{NEW HAMPSHIRE}

Manufacturing Extension Partnership of

New Hampshire, Inc.

505 Amherst St.

Nashua, N.H. 03061-2052

(603) 594-1188

\section{NEW JERSEY}

New Jersey Manufacturing Extension

Program

New Jersey Institute of Technology

University Heights

G ITC Suite 3200

Newark, N.J. 07102-1982

(973) 642-7099

\section{NEW MEXICO}

Industry Network Corporation

1155 University Blvd. S.E.

Albuquerque, N.M. 87106

(505) 843-4250 or (800) 716-6462

\section{NEW YORK}

New York Manufacturing Extension

Partnership

New York Science and Technology

Foundation

99 Washington Ave., Suite 1730

Albany, N.Y, 12210

(518) 486-7384

Serves firms statewide through 10 regional offices listed below.

- Alliance for Manufacturing and

Technology

61 Court St., 6th Floor

Binghamton, N.Y. 13901

(607) 774-0022

Serving a nine-county area within New

York's southern tier. 
- Center for Economic Growth One Key Corp. Plaza, Suite 600 Albany, N.Y. 12207

(518) $465-8975$

Serves the 11-county Capital District in the Albany area.

- Central New York Technology Development Organization 1201 East Fayette St. Syracuse, N.Y. 13201 (315) $425-5144$ Serves the five counties in central New York in the Syracuse area.

- CI-TEC Box 8561, Peyton Hall Potsdam, N.Y. 13699-8561

(315) 268-3778

Serves six counties in the North Country area.

- High Technology of Rochester Five United Way Rochester, N.Y. 14604 (716) $327-7930$

Serves the nine-county Finger Lakes region, in and around Rochester.

- Hudson Valley Technology Development Center

300 Westage Business Center, Suite 130 Fishkill, N.Y. 12524

(914) 896-6934

Serves the seven-county mid-Hudson region.

- Industrial Technology Assistance Corp. 253 Broadway, Room 302

New York, N.Y. 10007

(212) 240-6920

Serves the five boroughs of New York City.

- Long Island Forum for Technology P.0. Box 170

Farmingdale, N.Y. 11735

(516) 755-3321

Serves Nassau and Suffolk counties.
- Mohawk Valley Applied Technology Commission

207 Genessee St., Room 1604

Utica, N.Y. 13501

(315) $793-8050$

Serves Oneida, Herkimer, Hamilton, Fulton, Montgomery, and Schohari counties.

- Western New York Technology Development Center 1576 Sweet Home Road Amherst, N.Y. 14228

(716) 636-3626

Serves New York's five western-most counties.

\section{NORTH CAROLINA}

North Carolina Manufacturing Extension Partnership

IES Technical Services

900 Capability Drive

Raleigh, N.C. 27695-7902

(919) $515-5408$

\section{NORTH DAKOTA}

North Dakota Manufacturing Technology Partnership

Institute for Business and lndustry Development

NDSU-Hastings Hall

P.0. Box 5256

Fargo, N.D. 58105-5256

(701) 231-1001

\section{OHIO}

Great Lakes Manufacturing Technology Center (GLMTC)

Prospect Park Building

4600 Prospect Ave.

Cleveland, Ohio 44103-4314

(216) $432-5300$

Serves northeastern Ohio.

Lake Erie Manufacturing Extension Partnership

1700 N. Westwood Ave.

Toledo, Ohio 43607

(419) 534-3705

Serves 26 counties of northwestern Ohio.
Miami Valley Manufacturing Extension Center

3155 Research Blvd., Suite 205

Kettering, Ohio 45420

(937) $258-6190$

Serves 23 counties of southwestern Ohio.

Plastics Technology Deployment Center GLMTC Manufacturing Outreach Program Prospect Park Building 4600 Prospect Ave.

Cleveland, Ohio 44103

(216) $432-5340$

Serves 10 counties in northeastern Ohio surrounding Cleveland.

\section{OKLAHOMA}

Oklahoma Alliance for Manufacturing

Excellence

525 South Main St., Suite 210

Tulsa, Okla. 74103

(918) 592-0722

\section{OREGON}

Oregon Manufacturing Extension

Partnership

29353 Town Center Loop East

Wilsonville, Ore. 97070

(503) 657-6958

\section{PENNSYLVANIA}

North/East Pennsylvania Manufacturing Extension Partnership:

- Manufacturers Resource Center 125 Goodman Drive Bethlehem, Pa. 18015 (610) 758-5599 or (800) 343-6732

- Northeastern Pennsylvania Industrial Resource Center

75 Young St.

Wilkes Barre, Pa. 18706-1471

(717) 819-8966 or (800) 343-6732 
Southeastern Pennsylvania Manufacturing Extension Partnership:

- Delaware Valley Industrial Resource Center

2905 South Hampton Road

Philadelphia, Pa. 19154-1286

(215) $464-8550$

Serves five counties surrounding

Philadelphia and greater southeastern

Pennsylvania.

- Manufacturers' Technology Center

227 W. Market St.

P.0. Box 5046

York, Pa. 17405

(717) $843-5054$ or (888) 843-5054

Serves nine counties in south-central

Pennsylvania.

- Industrial Modernization Center

Farm Complex

R.R. \#5, Box 220-62A

Montoursville, $\mathrm{Pa} .17754$

(717) 368-8361 or (800) 326-9467

Serves 12 counties in central Pennsylvania.

Western Pennsylvania Manufacturing

Extension Partnership:

- Southwestern Pennsylvania Industrial Resource Center/Northwest

Pennsylvania Industrial Resource Center

2000 Technology Drive

Pittsburgh, Pa. 15219

(412) 687-0200

Serves firms throughout southwestern

Pennsylvania.

- Northwestern Pennsylvania Industrial Resource Center

Uniflow Center

1525 East Lake Road

Erie, Pa. 16511-1031

(814) 456-6299

Serves firms throughout northwestern

Pennsylvania.
Plastics Technology Deployment Center

Penn State-Erie

Behrend College Station Road

Erie, Pa., 16563-0101

(814) 898-6132

Serves 14 counties in northwestern

Pennsylvania surrounding Erie.

\section{PUERTO RICO}

Puerto Rico Manufacturing Extension, Inc.

Mercantil Plaza Building

Suite 819, 2 Ponce de Leon Ave.

Hato Rey, P.R. 00918

(787) $756-0505$

\section{RHODE ISLAND}

Rhode Island Manufacturing Extension

Services

229 Waterman St.

Providence, R.I. 02906

(401) $621-5710$

\section{SOUTH CAROLINA}

South Carolina Manufacturing Extension

Partnership

1136 Washington Street, Suite 300

Columbia, S.C. 29202

(803) $252-6976$

\section{SOUTH DAKOTA}

South Dakota Manufacturing Extension

Partnership Center

South Dakota State University

Harding Hall

P. 0. Box 2220

Brookings, S.D. 57007-0199

(605) 688-4184

\section{TENNESSEE}

Tennessee Manufacturing Extension

Partnership

University of Tennessee Center for Industrial

Services

226 Capitol Blvd., Suite 606

Nashville, Tenn. 37219-1804

(615) $532-8657$
TEXAS

Texas Manufacturing Assistance Center 1700 Congress Ave., Suite 200

Austin, Texas 78701

(512) 936-0235 or (800) 488-TMAC (8622)

UTAH

Utah Manufacturing Extension Partnership Utah Valley State College

800 S. 1200 W.

Orem, Utah 84058

(801) 764-7221

\section{VERMONT}

Vermont Manufacturing Extension Center Box 500

Randolph Center, Vt. 05061

(802) $728-1421$

\section{VIRGINIA}

Virginia's A.L. Philpott Manufacturing Extension Partnership

645 Patriot Ave.

P.0. Box 5311

Martinsville, Va. 24112

(540) $666-8890$

\section{WASHINGTON}

Washington Manufacturing Services

2333 Seaway Blvd.

Everett, Wash. 98203

(425) 267-0173

\section{WEST VIRGINIA}

West Virginia Manufacturing Extension

Partnership

317 Mineral Resources Bldg.

P.0. Box 6070

Morgantown, W. Va. 26506

(304) 293-3800

\section{WISCONSIN}

Wisconsin Manufacturing Extension

Partnership

432 N. Lake St.

Room B121-B

Madison, Wis. 53706-1498

(608) 262-2224

Serves manufacturers in the northeastern, southeastern, and southwestern regions of the state. 
Northwest Wisconsin Manufacturing Outreach Center

University of Wisconsin-Stout

278 Jarvis Hall

Menomonie, Wis. 54751-1876

(715) $232-2397$

Serving 32 counties in northwestern Wisconsin.

\section{WYOMING}

Mid-America Manufacturing Technology Center

10561 Barkley, Suite 602

Overland Park, Kan. 66212

(913) 649-4333

A regional organization that also operates in

Missouri, Colorado, and Kansas.

\section{NATIONAL}

National Center for Printing, Publishing and Imaging

Rochester Institute of Technology

111 Lomb Memorial Drive

Rochester, N.Y. 14623-5608

(716) $475-2950$

Printing and publishing industry resource serving manufacturers nationwide through their local MEP affiliate. 


\section{BALDRIGE NATIONAL QUALITY PROGRAM}

First presented in 1988, the $\mathrm{Malcolm}$ Baldrige National Quality Award has become the nation's premier award for business performance excellence and quality achievement. The Baldrige Award program was established by Congress in 1987 not only to recognize individual U.S. companies for their achievement but also to promote quality awareness and to provide information on successful performance and competitiveness strategies. The award is not for specific products or services. Two awards may be given annually to companies in each of three categories: manufacturing, service, and small business. In conjunction with the private sector, NIST developed and manages the award program.

\section{Criteria for Performance Excellence}

The Baldrige National Quality Program. focuses on performance excellence as an integral part of today's business management practices. The award's criteria for performance excellence, used by thousands of organizations as a general performance and business excellence model, are designed to help companies deliver ever-improving value to customers and improve overall company performance and capabilities. More than 1.5 million copies of the criteria have been distributed since 1988. The criteria's seven categories focus on requirements that all businesses-especially those facing tough competitive challenges_-should understand. The criteria are:

- Leadership. How do the company's senior leaders set directions and build and sustain a leadership system conducive to high performance, individual development, initiative, organizational learning, and innovation? Does the company integrate its values and expectations regarding public responsibilities and citizenship into performance management practices?
- Strategic planning. How are strategic directions set? Are critical strategies and action plans developed to support the directions? Are appropriate resources committed to achieve the strategies?

- Customer and market focus. How does the company determine requirements, expectations, and preferences of customers and markets? How are relationships built with customers, and how is customer satisfaction determined?

- Information and analysis. Does the company effectively select, manage, and use information and data to support key company processes and action plans and to improve its overall performance and competitive position?

- Human resource focus. Does the company enable its employees to develop and use their full potential? How does the company build and maintain a work environment and climate that is conducive to performance excellence, full participation, and personal and organizational growth?

- Process management. How are products and services designed, introduced, produced, delivered, managed, and improved?

- Business results. How has the company performed in key business areas: customer satisfaction, financial and marketplace performance, human resource results, supplier and partner performance, and operational performance? Has the company shown improvements, and what is its performance compared to those of competitors and benchmarks?

Using the criteria as an assessment tool provides firms with a clear view of where they stand and of how far they must go to achieve world-class levels of performance.

\section{Rigorous Evaluation}

Applications for the award undergo a rigorous evaluation by an independent review board comprising more than 300 business and quality experts from many industries (along with a smaller contingent from universities and governments at all levels). These experts volunteer many hours reviewing applications for the award, conducting site visits at firms that receive high scores after an initial screening, and providing each applicant with an extensive feedback report citing strengths and opportunities to improve.

\section{Interactions}

The Baldrige National Quality Program has proven to be a remarkably successful government and industry team effort, starting in 1987 with industry's assistance in raising more than $\$ 10$ million to help launch the program. Since that time, NIST has worked closely with a wide variety of groups to extend the benefits of performance excellence and to stimulate activities nationwide. These organizations run the gamut from trade, professional, and business groups such as the National Association of Manufacturers and the U.S. Chamber of Commerce, to state and local government organizations such as the National Governors' Association, to broad-based interest groups like the National Education Association.

The cooperative nature of this joint government/private-sector team is perhaps best captured by the award's board of examiners. In addition to many hours spent during the award evaluation process, board members have given thousands of presentations on performance excellence and the Baldrige national quality program.

The award recipients, too, have taken seriously the charge to be quality advocates. One of the main purposes of the award is to pass on information about the Baldrige Award recipients' quality and business processes and results that other companies can tailor to their own needs. Representatives from the award recipients willingly have 
shared their companies' performance excellence strategies and methods with thousands of other firms. Their efforts to educate and inform other companies and organizations on the benefits of using the Baldrige framework and criteria have far exceeded expectations

\section{Award as Quality Model}

Private-sector reviews and surveys are showing that the award is having a profound effect on shaping how people and organizations operate and work. For example, a report on the Baldrige Award program by the private-sector Council on Competitiveness states, "More than any other program, the Baldrige Quality Award is responsible for making quality a national priority and disseminating best practices across the United States."

The program has helped to stimulate an amazing movement to improve performance in many U.S. organizations, including companies; academic institutions; and federal, state, and local government agencies. Nationwide, interest in the Baldrige model is growing steadily. In 1991, fewer than 10 state and local quality awards existed. Now, more than 50 state and local award programs have been established that are modeled after the Baldrige Award.

For many companies, these award programs are "proving grounds," helping them to better understand quality and performance excellence before they consider an application for the national Baldrige Award. In 1991, state programs received 110 applications; in 1997 that number climbed to over 970.

Internationally, more than 25 quality awards have been established, most within the past several years. Many of them are based on the Baldrige Award. Japan, home of the Deming Prize, recently launched an award that resembles the U.S. Baldrige Award.

Interest also is increasing in organizations other than for-profit businesses. Working

\section{Quality Award Recipients}

Companies that have received the Malcolm Baldrige National Quality Award:

1997-3M Dental Products Division, St. Paul, Minn. (manufacturing); Solectron Corp., Milpitas, Calif. (manufacturing); Merrill Lynch Credit Corp., Jacksonville, Fla. (service); Xerox Business Services, Rochester, N.Y. (service)

1996-ADAC Laboratories, Milpitas, Calif. (manufacturing); DANA Commercial Credit Corp., Toledo, Ohio (service); Custom Research Inc., Minneapolis, Minn. (small business); Trident Precision Manufacturing Inc., Webster, N.Y. (small business)

1995-Armstrong World Industries' Building Products Operation, Lancaster, Pa. (manufacturing) and Corning Telecommunications Products Division, Corning, N.Y. (manufacturing)

1994 - AT\&T Consumer Communications Services, Basking Ridge, N.J. (service); GTE Directories Corp., Dallas/Ft. Worth, Texas (service); and Wainwright Industries Inc., St. Peters, Mo. (small business)

1993-Eastman Chemical Co., Kingsport, Tenn. (manufacturing) and Ames Rubber Corp., Hamburg, N.J. (small business)

with experts from healthcare and education organizations, NIST tailored the Baldrige Award criteria and framework for these sectors and conducted a pilot application program in 1995.

Forty-six healthcare and 19 education organizations submitted applications. While funding to expand the Baldrige Award to include categories for non-profit healthcare and education organizations was not available in 1998, NIST did revise the criteria for these two sectors. NIST's fiscal year 1999 budget proposal includes $\$ 2.3$ million to establish Baldrige Award categories for
1992-AT\&T Network Systems Group/ Transmission Systems Business Unit, Morristown, N.J. (manufacturing); Texas Instruments Inc. Defense Systems \& Electronics Group, Dallas, Texas (manufacturing); AT\&T Universal Card Services, Jacksonville, Fla. (service); The RitzCarlton Hotel Co., Atlanta, Ga. (service); and Granite Rock Co., Watsonville, Calif. (small business)

1991-Solectron Corp., Milpitas, Calif. (manufacturing); Zytec Corp., Eden Prairie, Minn. (manufacturing); and Marlow Industries, Dallas, Texas (small business)

1990-Cadillac Motor Car Division, Detroit, Mich. (manufacturing); IBM Rochester, Rochester, Minn. (manufacturing); Federal Express Corp., Memphis, Tenn. (service); and Wallace Co. Inc., Houston, Texas (small business)

1989-Milliken \& Company, Spartanburg, S.C. (manufacturing) and Xerox Corp. Business Products and Systems, Rochester, N.Y. (manufacturing)

1988-Motorola Inc., Schaumburg, Ill. (manufacturing); Commercial Nuclear Fuel Division of Westinghouse Electric Corp., Pittsburgh, Pa. (manufacturing); and Globe Metallurgical Inc., Beverly, Ohio (small business)

non-profit healthcare and education organizations. In addition, the private Foundation for the Malcolm Baldrige National Quality Award has initiated a fund-raising effort to provide an endowment of $\$ 15$ million to help establish the awards, provided federal funding also is available.

\section{Contact:}

Baldrige National Quality Program

(301) 975-2036

email: nqp@nist.gov

fax: (301) 948-3716

A635 Administration Building

www.quality.nist.gov 
Higher quality products, more reliable and more flexible processes, fewer rejected parts, speedier product development, more efficient market transactions, higher levels of interoperability among machines, factories, and companies. These are some of the practical advantages that U.S. companies realize from the NIST Measurement and Standards Laboratories' research, services, and standards-related activities. The ultimate U.S. reference point for measurements with counterpart organizations throughout the world, the laboratories provide companies, entire industries, and the whole science and technology community with the equivalent of a common language needed in nearly every stage of technical activity. In furthering the technical aims and capabilities of U.S. industry, the NIST laboratory program serves as an impartial source of expertise, developing highly leveraged measurement capabilities and other infrastructural technologies.

Several hundred laboratory projects are under way at NIST during a single year. Some relate to the evolving needs of mature industries such as steel, machine tools, automobiles, and chemical processing. Others concentrate on the technical challenges conf ronting emerging industries such as those sprouting from advances in nanotechnology or the ones facing established high-technology sectors undergoing rapid technology change such as microwave communications.

\section{Collaborative Research}

NIST actively seeks industrial, academic, and non-profit research partners to work collaboratively on projects of mutual benefit. Many mechanisms are available for carrying out these research collaborations. Special efforts are made to tailor collaborations to specific needs.

Most research collaborations start with one-to-one interactions between industry or other researchers and NIST scientists and engineers. To locate NIST researchers in specific fields of interest, see the project listings on pages 40 to I63. For further information about the process for implementing specific types of research agreements, contact the Industrial Partnerships Program,

(301) 975-3084.

The most common types of arrangements include the following:

\section{Cooperative Research and Development} Agreements (CRADAs) - Typically cover joint research efforts in which both NIST and the cooperating company provide staff, equipment, facilities, and/or funds, in any number of possible combinations, for a project of mutual interest. NIST currently is working with nearly 200 research partners on more than 200 CRADAs in nearly 130 different areas of research. NIST's CRADA partners are predominantly U.S. businesses, with about equal numbers from large and small companies.

When companies conduct joint research with the Institute under a CRADA, NIST can protect confidential or proprietary information exchanged during the project, keep research results confidential, and provide exclusive rights for intellectual property developed during the course of the project. Each CRADA is negotiated separately between NIST and prospective partners. Most CRADAs take 3 to 4 weeks to implement.
Copies of a model NIST CRADA agreement are available from the NIST Industrial Partnership Program, (30I) 975-5073.

Guest Researcher Agreements-Typically used when an industrial or other researcher wishes to join an ongoing NIST research effort. The researcher gains access to NIST research staff and facilities and, in return, results from the collaboration are made available publicly. Such agreements cannot protect proprietary information and do not allow cooperating companies to receive exclusive intellectual property rights. Each year NIST hosts about 1,250 guest scientists and engineers at its Gaithersburg, Md., and Boulder, Colo., laboratories. Contact: domestic guest researchers, (30I) 975-3084; international guest researchers, (30I) 975-4119.

\section{Research and Development Contracts-} Used when external organizations contract with NIST researchers to receive specific technical services or results uniquely available at the Institute. The cooperating organization funds the NIST effort on a costreimbursable basis. Individual contracts may provide protection of proprietary information under certain circumstances.

Research results are made publicly available, and any intellectual property rights are retained by NIST. Preparation of contracts for such agreements typically takes about 4 weeks.

\section{Informal Collaborations-Informal} one-to-one collaborations between Institute and other researchers. Such collaborations often involve exchange of research results, publicly available technical know-how, and/or samples between NIST and other researchers. 


\section{Examples of NIST Lab Projects}

The examples of recent accomplishments described below are a small sampling of laboratory activities. They illustrate the ways in which NIST is carrying out its mission to provide infrastructural support to U.S. industry.

- NIST measurements are vital to the functioning of the entire economy, helping to ensure fairness and efficiency in the sale of more than $\$ 3$ trillion worth of goods and services. Accurate and uniform measurements of weight, size, volume, and other quantities maximize efficiency and promote customer confidence in the sale of goods ranging from slices of lunch meat at the deli counter to millions of cubic meters of natural gas transported through transnational pipelines.

- NIST measurements and standards are woven into the technical infrastructure underpinning the performance of companies in scores of established industriesfrom machine tools to photographic film to medical devices. For example, the accuracy of coordinate measuring machines in thousands of factories is checked with measurement standards traceable to NIST and applied according to industrystandardized procedures developed with NIST's technical assistance. In the automotive industry alone, more than 350 NIST-developed measurement tools and services are embedded in the process- and quality-control systems of companies.

- U.S. taxpayers are getting more than they pay for from the NIST program designed to ensure accuracy in measurements of radioactive drugs used to diagnose or treat disease, according to a recent evaluation of NIST's radiopharmaceutical research. The study conservatively estimated that, since 1990 , the program has cost taxpayers $\$ 2.4$ million and yielded benefits worth $\$ 236.2$ million, a benefit-to-cost ratio of 97 to 1 . The benefits represent money saved by patients and drug manufacturers.

- NIST research on alternative refrigerants has generated a social rate of return of 433 percent, the result of cost savings realized by companies during the race to meet the international deadline for phasing out ozone-depleting chlorofluorocarbons (CFCs). NIST expenditures of about $\$ 2.7$ million translated into savings totaling about $\$ 14.2$ million for a sample of 11 firms. Timely delivery of reliable data on alternative refrigerants, along with analytical software, made the search for CFC replacements more efficient.

\section{- NIST and partners from Sandia} National Laboratories and the consortium SEMATECH recently developed a new reference material that has potential to leapfrog several generations of measurement needs forecast by semiconductor manufacturers. This reference material, evaluated by a consortium of 18 companies, is being proposed as a tool for calibrating equipment that measures integrated-circuit features as tiny as 100 nanometers-about a thousandth of the width of a fine strand of human hair.

- A NIST-led effort involving more than 25 companies has resulted in a standard interface for integrating "smart" transducers--combinations of digital sensors and actuators - into the more than 50 different types of proprietary computer networks deployed throughout industry. The standard, officially adopted by the Institute of Electrical and Electronics Engineers (IEEE 1451.2), will broaden the choices available to manufacturers who use sensors to monitor and control processes, and it will expand markets for the estimated 3,000 sensor and actuator manufacturers in the United States.
- A recently begun NIST calibration service is helping U.S. industry to improve wireless telephone systems. A unique indoor testing range is used to deterinine the accuracy of specialized trumpetshaped antennas, which companies then use to check the performance of communications antennas designed for low Earth orbit satellites.

- Working with a consortium of 22 partners, NIST is helping companies evaluate prototype products for adherance to the BACnet standard, which allows interoperability of heating, ventilating, and air conditioning control systems in buildings, enhancing energy efficiency, safety, and comfort. By developing conformance testing tools and procedures, the effort aims to enable an industry-run certification program.

- The U.S. ceramics industy derives substantial economic benefits from the NIST Ceramic Phase Equilibria Program, according to an independent study. The program's benefit-to-cost ratio is estimated at 10 to 1 , and the internal rate of return is estimated to be at least 33.5 percent. Phase equilibria diagrams help ceramic component manufacturers understand the effects of temperature, pressure, and material concentrations on the processing and properties of ceramic products.

- NIST developed the original computerized system the Federal Bureau of Investigation uses to match fingerprint evidence against 38 million records, so that local police can identify suspects. NIST researchers now are working to link fingerprint biometrics with digital signatures, an accomplishment that would enable law enforcement agencies - as well as corporations and consumers-to make secure electronic transactions. 


\section{Research Consortia}

On research topics of broad interest to a number of different research partners, NIST may sponsor research consortia. Research consortia usually are structured through NIST CRADAs and involve groups of companies and other organizations that exchange data, ideas, researchers, and/or materials among themselves and with NIST to meet agreed-upon research goals. Most consortia require payment of membership fees in exchange for advance knowledge of research results produced by the consortia effort. Currently active NIST-centered consortia include the following:

Flowmeter Installation Effects-Supports research in fluid flow measurements to help industry understand, evaluate, and assess flowmeter performance under non-ideal installation conditions. Contact: George Mattingly, (301) 975-5939.

North American Integrated Services Digital Network Users' Forum-Promotes the implementation and use of ISDN standards and the development of interoperable systems for the simultaneous transmission of voice, data, and images over high-speed digital networks. Contact: Leslie Collica, (301) 975-4856.

Monolithic Microwave Integrated Circuits-Develops metrology for design and manufacture of microwave monolithic integrated circuits, especially measurement methods and standards to reduce testing costs. Contact: Dennis Friday, (303) 497-3131.
Ceramic Machining Consortium-Develops cost-effective production processes for grinding components made from advanced structural ceramics, such as silicon nitride and silicon carbide. Contact: Said Jahanmir, (301) 975-4525.

BACnet Interoperability Testing-Works to overcome communication barriers among building control systems from different manufacturers, making it possible to design truly "smart" buildings where all systems work together and are controlled from a central location. Contact: Steven Bushby, (301) 975-5873.

\section{Coatings Service Life Prediction-Devel-} ops test methods to quickly and reliably predict the service life of painted products exposed to the elements in order to help the paint industry get better products to market more quickly. Contact: Jonathan Martin, (301) 975-6707.

\section{Computer-Aided Manufacturing Engineer-}

ing-Develops standards and interfaces for a manufacturing engineering tool kit designed to allow software tools made by different vendors with different engineering functions to work together. Contact:

Swee Leong, (301) 975-5426.

Enhanced Machine Controller-Develops interface standards needed to produce an open architecture controller for manufacturing equipment that would allow machine builders, users, and systems integrators to customize equipment more effectively, reduce training and maintenance costs, and make retrofitting of existing equipment with new capabilities more practical. Contact: Fred Proctor, (301) 975-3425.

\section{Orthopedic Accelerated Wear Resis-} tance-Helps shorten development and approval time for new orthopedic implants by identifying test methods with the greatest promise for accelerated screening of materials for wear resistance. Contact: John Tesk, (301) 975-6799.

\section{Environmentally Friendly New Flame}

Retardants-Works to replace current fire retardants with environmentally friendly additives that reduce heat release rates of polymers used in carpets, upholstery, and other products without increasing smoke or carbon monoxide production. Contact: Jeff Gilman, (301) 975-6573.

\section{NIST-EPRI Ultrasonic Flow Meter Testing}

Program-Provides guidelines to improve flow measurements in industrial environments. NIST will assess ultrasonic flow meters from the consortium members by testing their commercially available, clampon type, time-of-travel ultrasonic flow meters in both ideal and non-ideal pipe flows. Contact: George Mattingly,

(301) 975-5939.

Optical Properties of Materials-Develops new standards and critically evaluated data on the optical properties of materials that are important for evolving optical industries and manufacturing processes. Contact: Raju Datla, (301) 975-2131. 
Machine Tool Performance Models and Machine Data Repository-Develops tools to replace actual machining and inspection of parts during prototyping with virtual machining and virtual inspection modules incorporated into a $\mathrm{CAD} / \mathrm{CAM}$ system. These tools include data structures and low-order machine models that represent actual machine behavior; mathematical representations of actual part geometry, including dimension and form errors; virtual machining algorithms; virtual inspection algorithms; standardized data formats; and remotely accessible machine data repositories. Contact: Alkan Donmez, (301) 975-6618.

\section{Ceramic Processing Characterization} Consortium-Develops new measurementbased strategies for ensuring reliable manufacturing by working with the U.S. ceramics industry in the development of a measurements and standards infrastructure for ceramic particulate systems. Contact: George Onoda, (301) 975-4489.

\section{Technical Assistance}

NIST provides without charge informal technical advice to U.S. companies and others seeking assistance in specific areas. Often NIST experts can help a company solve a technical problem through one or several phone conversations or a brief visit to the Institute's Gaithersburg, Md., or Boulder, Colo, laboratories. (Institute researchers are not permitted to consult on their own behalf or to receive personal payments for technical advice in areas within NIST's mission.) See project descriptions on pages 40 to 163 to locate a NIST expert in a specific research field or call General Inquiries for assistance, (301) 975-NIST.

\section{Technology Services and Products}

NIST provides many different technology services and products to help U.S. industry improve the quality, reduce the cost, and increase the competitiveness of its products. Summaries of the NIST programs providing these services and products appear on pages 164 to 169 . Examples include Standard Reference Materials, Standard Reference Data, and calibration and laboratory accreditation services.

\section{Use of NIST Facilities}

The Institute operates more than 40 different research facilities that are accessible to outside researchers for collaborative or independent research. Several one-of-a-kind facilities are available for proprietary measurements.

Access to NIST facilities generally occurs through one of four mechanisms: under the provisions of a NIST CRADA or consortium agreement; through a guest researcher agreement; through contract R\&D in which Institute staff members conduct specific experiments or tests at NIST and are reimbursed for their time and supplies; and, for a limited number of facilities, through scheduled appointments for qualified researchers wishing to conduct proprietary measurements.

Scheduling and priorities for NIST facilities use are determined by the relevant director for each NIST disciplinary laboratory, in some cases assisted by designated user group committees.

An index of NIST facilities appears on page 170. For detailed information on capabilities and availability of individual facilities, call the contact person listed for that facility. For general information on typical facility use agreements, contact the Industrial Partnerships Program, (301) 975-3084. 


\section{Technology Licenses}

NIST seeks patents for its product and process inventions when a patent will enhance the invention's commercialization or use. Individuals or companies may obtain a license to use, make, or sell NIST patented inventions, on either an exclusive, co-exclusive, or non-exclusive basis. Normally licenses are granted only in cases where the licensee agrees that resulting products will be manufactured substantially in the United States.

The goal of NIST's licensing process is to encourage commercial use of NISTdeveloped technologies. For a current listing of the more than 100 NIST inventions available for licensing, contact the NIST Industrial Partnerships Program, (301) 975-4188.

\section{Research Grants}

Grants supporting research at industrial, academic, and other organizations are available on a competitive basis through several different Institute offices. For general information on NIST grants programs, contact Joyce Brigham, (301) 975-6329.

\section{Small Business Innovation Research Pro-} gram-Funds proposals by small businesses for research and development efforts that fall within areas recommended yearly by the U.S. Department of Commerce. See description on page 165.

Precision Measurement Grants-Supports researchers in U.S. colleges and universities for experimental and theoretical studies of fundamental physical phenomena. Contact: (301) 975-4220.
Fire Research Grants-Sponsors research by academic institutions, non-federal government agencies, and independent and industrial laboratories that supports NIST's fire research laboratory programs. Contact: (301) 975-6854.

Standard Reference Data Grants-Supports research at academic, industrial, and other non-federal institutions to critically evaluate data in chemistry, physics, and materials properties. Contact:

(301) 975-2200.

\section{Materials Science and Engineering}

Grants-Supports work in polymers, ceramics, metallurgy, and neutron scattering and spectroscopy research at academic, industrial, and other non-federal institutions. Contact: (301) 975-5731. 
The Building and Fire Research Laboratory (BFRL) enhances the competitiveness of U.S. industry and public safety through performance prediction methods, measurement technologies, and technical advances that improve the lifecycle quality and economy of constructed facilities. BFRL's efforts are closely coordinated with industry, professional and trade organizations, academe, and other agencies of government.

Major BFRL goals are to improve the productivity of U.S. construction industries, which now face stiff competition from overseas firms, and to reduce the human and economic losses resulting from fires, earthquakes, winds, and other hazards. The laboratory conducts research in fire science and fire safety engineering; building materials; computer-integrated construction practices; structural, mechanical, and environmental engineering; and building economics. Products of the laboratory's research include measurements and test methods, performance criteria, and technical data that are incorporated into building and fire standards and codes. Staff members are involved in more than 100 activities to develop voluntary standards.

The laboratory conducts investigations at the scene of major fires and structural failures due to earthquakes, hurricanes, or other causes. The knowledge gained from these investigations guides research and is applied to recommendations for design and construction practices to reduce hazards.

\section{Contact:}

Richard N. Wright, Director

(301) 975-5900

email: richard.wright@nist.gov

fax: (301) 975-4032

B216 Building Research Building www.bfrl.nist.gov

\section{COOPERATIVE RESEARCH OPPORTUNITIES}

\section{Siructures}

40 Earthquake Engineering

41 Structural Control

\section{Building Materials}

41 Cement and Concrete

41 Organic Building Materials

42 High-Performance Construction Materials and Systems

42 Construction Materials Reference Laboratories

\section{Building Environment}

43 Indoor Air Quality and Ventilation

43 Refrigeration Machinery

43 Heat Transfer

44 Building Controls

44 Computer-Integrated Construction

\section{Fire Safety Engineering}

45 Fire Detection and Alarm

45 Large Fires

45 Fire Dynamics

\section{Fire Science}

46 Advanced Fire Sensing

46 Advanced Fire Suppression

46 Measuring Fire Accurately

47 Polymer Combustion Research

\section{Applied Economics}

47 Microeconomic Analysis

\section{RESEARCH FACILITIES}

48 Large-Scale Structures Testing Facility

48 Tri-Directional Test Facility

48 Large Environmental Chamber

49 Calibrated Hot Box

49 Line Heat-Source Guarded Hot Plate

50 Advanced Insulation Facility
COOPERATIVE RESEARCH OPPORTUNITIES

\section{STRUCTURES}

Division Contact:

Shyam Sunder

(301) $975-6713$

email: sunder@nist.gov

fax: (301) 869-6275

B166 Building Research Building www.bfrl.nist.gov/861/structd.html

\section{EARTHQUAKE ENGINEERING}

The National Earthquake Hazards Reduction Program mandates NIST to conduct research and development in earthquake engineering. These efforts improve building codes and standards and advance seismic practices for structures and lifelines.

Research is carried out to improve seismic design and construction standards. Results are applied to improve construction practices for both new and existing buildings, structures, and lifelines. Post-earthquake investigations are performed to study the performance of structures and lifeline systems during major seismic events. The findings are vital for improvement of design and construction practices. Guidance and technical support are provided to the Interagency Committee on Seismic Safety in Construction of the National Earthquake Hazards Reduction Program in support of its efforts to develop recommended practices for federal agency use. Current research addresses these topics:

- strength and ductility of connections in precast concrete structures;

- evaluation criteria for structural control systems and test procedures for evaluating the response of structures subjected to seismic loading; 
- a rational procedure to determine the ultimate shear strength of partially reinforced masonry walls;

- techniques for assessing the performance properties of strengthened existing structures;

- strengthening methodologies for concrete frame structures;

- developing technical criteria and methodologies for strengthening and repairing existing structural members and systems; and

- techniques for determining liquefaction and ground deformation potential of soil deposits.

\section{Contact:}

Riley Chung

(301) 975-6062

email: riley.chung@nist.gov

B158 Building Research Building

\section{STRUCTURAL CONTROL}

NIST carries out research that provides the technical basis for criteria that ensure structural safety and serviceability of buildings and other structures. Studies are performed to develop the technical basis for removing barriers to the use of new high-performance construction materials and systems. Research in construction automation seeks to develop, integrate, and implement new technologies that will permit generalized automation at the construction job site. Work in wind research is aimed at developing key elements of a knowledge-based wind load design standard that will use site- and building-specific databases and state-of-theart computational methods to establish realistic, consistent, and economical steady and fluctuating structural loads. Current research addresses the following areas:

- studies of structural performance measurement standards and test methods for high-performance concrete for construction applications;
- establishment of design wind loads for low-rise structures;

- non-destructive testing methods to detect internal flaws and discontinuities in structural members; and

- response measurements of full-scale structures.

Contact:

Nicholas Carino

(301) 975-6063

email: nicholas.carino@nist.gov

B158 Building Research Building

\section{BUILDING MATERIALS}

Division Contact:

Geoffrey J. Frohnsdorff

(301) 975-6706

email: geoffrey.frohnsdorff@nist.gov

fax: (301) 990-6891

B368 Building Research Building

www.bfrl.nist.gov/862/bmd.html

\section{CEMENT AND CONCRETE}

NIST researchers are developing a fundamental understanding of the relationship between chemistry, microstructure, performance, and service life of conventional and high-performance concrete and other inorganic building materials. Their goal is to develop tools for predicting the behavior of these materials and their service lifetimes. Because the service life of concrete largely depends on the transport of water, dissolved salts, and gases in the pore system of the concrete, researchers are developing mathematical representations of the microstructure of concrete and models for use in predicting its diffusivity and permeability.

Models are being developed to consider service conditions, including the chemistry of the environment; the transport rate of reactants by diffusion, convection, and capillarity; and reaction mechanisms.
Research projects include development and validation of models for simulating microstructure development in cement pastes as the cement hydrates and the degradation of concrete. Artificial intelligence systems are being developed for optimizing the selection of materials and for diagnosing the causes of material degradation. Experimental studies are being performed on the rheology of concrete aimed at improving the design of mixture proportions. The research is performed using a variety of techniques, including scanning electron microscopy, computerized image analysis, X-ray diffraction, and thermal analysis.

This work helps the U.S. construction industry to be competitive by providing a strong technical basis for standards for concrete and concrete materials. The research is coordinated with industry, voluntary standards organizations, trade associations, the National Science Foundation's Center for Advanced Cement-Based Materials, and federal and state government agencies.

\section{Contact:}

James R. Clifton

(301) 975-6767

email: james.clifton@nist.gov

B350 Building Research Building

\section{ORGANIC BUILDING MATERIALS}

NIST is conducting basic and applied research to develop methods for predicting the performance and service life of organic building materials such as protective coatings for steel, polymer-matrix composites, and roofing materials. In addition, researchers are developing a systems approach to advancing the science of appearance measurements for coated objects.

Researchers are investigating degradation mechanisms, improving characterization methods, and developing mathematical models of the degradation processes. Stochastic models, which are based in reliability theory and life-testing analysis, are 
included in the modeling efforts for all three of these materials.

To help understand the mechanisms of degradation and to provide data for models, materials are characterized in many ways, including Fourier transform infrared spectroscopy, thermal analysis, scanning electron microscopy/energy dispersive $\mathrm{X}$-ray, and visual and infrared imaging. Researchers also are developing improved ways to characterize atmospheric environments to which these materials are exposed. Characterization of environmental parameters that cause degradation is needed to link material properties with service life.

Researchers are using a systems approach to advance appearance metrology by applying optical metrology, mathematical modeling, and computer rendering, which have been developed over the last decade, to the development of new methods for appearance characterization and more accurate methods of modeling the appearance of coatings and coated objects. Application of advanced optical technologies, such as goniophotometric detectors, light scattering, and imaging, coupled with advanced computational technology, will result in more comprehensive understanding of appearance parameters. New detector technologies offer the potential of making low-cost, image-based measurement devices for characterizing appearance, rather than the commonly used simple wide-angle, source/ detector-based measurement devices. Parameterized mathematical models and computer rendering, when coupled with advanced measurements, will allow researchers and engineers to assess the contribution of a coating's constituents and microstructure to its appearance and help them design coatings with appropriate initial appearance and durability properties.
The NIST research strengthens the scientific and technical basis for engineering standards for organic building materials developed by voluntary consensus standards organizations. Sometimes, as is the case in the Coatings Service Life Prediction Consortium, the research is supported by and carried out in close collaboration with industry and other federal agencies.

\section{Contact:}

Jonathan W. Martin

(301) 975-6707

email: jonathan.martin@nist.gov

B350 Building Research Building

\section{HIGH-PERFORMANCE CONSTRUCTION MATERIALS AND SYSTEMS}

NIST's High-Performance Construction Materials and Systems Program is a BFRLwide research program. It supports the national High-Performance Construction Materials and Systems Program (CONMAT), which the Civil Engineering Research Foundation and 10 industry groups established "to develop the high-performance construction materials and systems necessary for America's well-being and international competitiveness in the 21st Century." The NIST program involves four of BFRL's divisionsStructures, Building Materials, Fire Sciences, and Fire Safety Engineering - and its Office of Applied Economics. The program encompasses high-performance concrete, steel, polymer-matrix composites, organic coatings, and roofing materials. Researchers are developing rational methods for evaluating, by measurement or prediction, all major aspects of performance-structural, durability, and fire resistance. The program is providing a testbed for collaboration with industry in development of a computerintegrated knowledge system for high-performance construction materials and systems. The results of the NIST program will facilitate acceptance of new and improved construction materials by the construction industry.

\section{Contact:}

Geoffrey J. Frohnsdorff

(301) 975-6706

email: geoffrey.frohnsdorff@nist.gov

B368 Building Research Building

\section{CONSTRUCTION MATERIALS REFERENCE LABORATORIES}

NIST's Construction Materials Reference Laboratories (CMRL), managed by BFRL, comprise the ASTM-sponsored Cement and Concrete Reference Laboratory (CCRL) founded in 1929 and the AASHTO (American Association of State Highway Transportation Officials)-sponsored AASHTO Materials Reference Laboratory (AMRL) founded in 1965. The laboratories provide a reimbursable, voluntary, quality assurance service for more than 1,200 commercial and other laboratories that test construction materials for compliance with standards — ASTM standards for cements and other concrete materials in the case of CCRL, and AASHTO standards for almost the full range of highway construction materials in the case of AMRL. The services of both laboratories comprise laboratory inspections by CMRL's staff of inspectors and operation of large proficiency sample programs. CMRL has been described as "an outstanding example of governmentindustry collaboration" for its contributions to the quality of construction.

Contact:

James H. Pielert (301) 975-6746 email: james.pielert@nist.gov A365 Building Research Building 


\section{BUILDING ENVIRONMENT}

Division Contact:

James E. Hill

(301) $975-5851$

email: james.hill@nist.gov

fax: (301) 975-5433

B306 Building Research Building

www.bfrl.nist.gov/863/bed.html

\section{INDOOR AIR QUALITY AND VENTILATION}

Computer simulation programs and measurement procedures are being developed and applied by NIST researchers to better understand the phenomena of air and contaminant transport in buildings and to support industry efforts to improve environmental conditions in buildings in a cost-effective manner. The results of this research are providing reliable methods to design buildings and heating, ventilating, and airconditioning (HVAC) systems and to evaluate ventilation characteristics and indoor pollutant concentrations in buildings.

The modeling efforts include the development and application of multizone airflow and indoor air quality models, specifically the CONTAM series, which predicts airflows and contaminant concentrations in multizone building systems. CONTAM has been used at NIST to study the indoor air quality impacts of HVAC systems in single-family residential buildings, ventilation in large mechanically ventilated office buildings, and radon entry and transport in large residential, office, and school buildings.
Measurement procedures are being developed and demonstrated to evaluate building ventilation and indoor pollutant concentrations. These procedures range from sophisticated tracer gas methods used predominantly in building research efforts to less involved procedures that can be employed by building operators. NIST researchers are developing new test procedures and demonstrating them in the field to evaluate their feasibility and reliability. These efforts have resulted in the development of an important database of building ventilation and indoor air quality performance.

Contact:

Andrew K. Persily

(301) $975-6418$

email: andrew.persily@nist.gov

A313 Building Research Building

\section{REFRIGERATION MACHINERY}

NIST researchers identify and characterize refrigerant and refrigerant mixtures to improve the efficiency of refrigeration cycles and replace harmful chlorine-containing refrigerants that were implicated in the destruction of the upper-atmosphere ozone laver. The researchers evaluate alternative refrigerant cycles, systems, and components that will operate efficiently with new refrigerants. Working with industry, they improve capabilities in determining the performance of alternative refrigerants and help refrigeration equipment manufacturers in designing refrigeration systems.

The researchers evaluate alternative refrigerants and a wide variety of refrigeration cycles by using a breadboard heat pump into which different components and circuits can be "plugged" and "unplugged." These breadboard modifications are based on theoretical and simulation studies conducted to find the optimal combination of mixtures and appropriate refrigeration cycle for the best and most versatile performance. Fluorocarbon and hydrocarbon refrigerants are studied in novel applications like a waterto-water heat pump or a heat pump with evaporative cooling of the high-pressure refrigerant. In addition to simulation and laboratory studies, pool-boiling and flowboiling heat-transfer coefficients are measured for alternative refrigerants and refrigerant mixtures, including tests with pool-boiling additives.

\section{Contact:}

Piotr A. Domanski

(301) 975-5877

email: piotr.domanski@nist.gov

B114 Building Research Building

\section{HEAT TRANSFER}

In the United States, buildings account for over 60 percent of all electricity used and almost 40 percent of all natural gas consumed, at an annual cost that exceeds $\$ 170$ billion. A significant portion of this energy is used to provide space heating and cooling. Researchers at NIST are developing basic data and simulation models for heat, air, and moisture transfer through building envelope components. They developed MOIST, a widely used computer model for predicting moisture transfer within the building envelope. They are developing a Standard Reference Material (SRM) that will be used to calibrate private-sector facilities for measuring thermal performance of windows while maintaining the supply of three other SRMs used to calibrate insulation manufacturers' "in-house" instrumentation. In addition to conducting measurements for industry on conventional building insulation products, researchers within the heat transfer group are developing measurement techniques to assess the thermal performance of new insulation products with superior thermal performance. A study currently is being conducted to determine the energy-savings potential of reflective roofing materials. 
A 1-meter guarded hot plate is used to develop SRMs; to determine thermal conductivity values for various materials, such as chlorofluorocarbon-blown insulation; and to provide measurement services to manufacturers and researchers. A calibrated hot box is used to measure the steady-state and dynamic performance of full-scale wall systems. A calorimeter and finite-element models are used to characterize the performance of advanced insulation systems such as gasfilled and vacuum insulation panels.

This work provides the national "meter bar" for the thermal insulation industry. All advertised thermal insulation product performance is traceable to measurements made in this program.

Contact:

A. Hunter Fanney

(301) $975-5864$

email: hunter.fanney@nist.gov

B320 Building Research Building

\section{BUILDING CONTROLS}

NIST research is fostering the development of more intelligent, integrated, and optimized building mechanical systems. A dynamic building heating, ventilating, and air-conditioning (HVAC) control system simulation program is used to study HVAC control system dynamics and interactions. An expanded building management and controls laboratory is used to assist the building controls industry in the development, evaluation, and testing of communication protocol standards for the open exchange of information. NIST technologies serve as a basis for American Society of Heating, Refrigerating and Air-Conditioning Engineers standards to assist the control system manufacturers in developing interoperable systems and methods for testing conformance to the standard.
The application of "smart" control systems to buildings is a relatively new area of research. Plans call for exploring how realtime models, on-line system identification, optimal control, and fault detection and diagnostics can be combined to improve control system performance, make control strategy decisions that optimize building operations, and advise the building operator or manager on building operations, equipment problems, or maintenance requirements. Research on smart building control systems will be performed by simulation and emulation studies, laboratory testing, and field studies in real buildings.

Contact:

George E. Kelly

(301) 975-5870

email: george.kelly@nist.gov

B114 Building Research Building

\section{COMPUTER-INTEGRATED CONSTRUCTION}

NIST researchers are working collaboratively with the U.S. construction and building industries to establish an exemplary computer-integrated construction environment, based on open standards for the representation, access, exchange, use, and archiving of information. With these standards implemented in software systems, industry will be able to achieve its goal of seamlessly circulating information throughout its life-cycle work processes, all taking place in a loosely coupled, distributed, heterogeneous environment.

Current research is concentrated in three areas: the integration of project information, the integration and automation of activities on the construction site, and the electronic commerce of technical information between supplier and project. The output of this research is prototype standards and protocols, measurement technologies, and testing procedures. Experiments to evaluate and demonstrate these outputs are conducted in a testbed that is open to industry and academia.
The near-term focus of the research has been in support of the heavy industrial construction sector, dealing with capital projects such as chemical process plants. To ensure that its research is addressing industrial needs, NIST participates in industrial consortia such as PlantSTEP, Inc., and the pdXi (Process Data Exchange Institute) of the American Institute of Chemical Engineers and in committees of the Construction Industry Institute. The focus is being broadened to other industry sectors as the research matures and industrial partnerships are established.

NIST researchers are exploring current and emerging information technologies in this program, including traditional dataoriented and emerging object-oriented technologies, and new communication and collaboration technologies made possible by the Internet. A major theme of NIST research is the harmonization of different technologies to allow industry maximum flexibility in choosing technologies to meet its needs. The computer-integrated construction program draws on researchers throughout BFRL and works cooperatively with other NIST programs, including the Systems Integration for Manufacturing Applications program managed by the Manufacturing Engineering Laboratory.

\section{Contact:}

Kent A. Reed

(301) 975-5852

email: kent.reed@nist.gov

B306 Building Research Building 


\section{FIRE SAFETY ENGINEERING}

Division Contact:

David D. Evans

(301) 975-6897

email: dave.evans@nist.gov

fax: (301) 975-4052

B250 Polymer Building

www.bfrl.nist.gov/864/fsed.html

\section{FIRE DETECTION AND ALARM}

The United States has one of the worst fire records in the industrialized world. NIST researchers are helping to reduce the losses and the cost of fire safety by providing scientific and engineering bases needed by manufacturers and the fire safety community. This work involves the development of predictive, analytical methods that permit the quantitative assessment of fire condition in structures. To ensure widespread use, the necessary input data must be readily available and results must be readily understood by the user. This research includes strong emphasis on numerical modeling, databases, state-of-the-art computer graphics, and computer-aided design techniques. The results of this work help manufacturers, purchasers, designers, code officials, fire investigators, and practitioners evaluate the fire hazard implications of the products and fire protection strategies they use.

The expedient transfer of scientifically based technology from NIST to the professional user community and the creation of a link between NIST computer-based activities and others doing similar or complementary work can enhance fire safety and reduce its costs. Over the past decade, NIST researchers developed many computer models of various aspects of fire. These researchers develop engineering systems for design application and fire investigation, collect supporting data and programs, and operate training programs and user workshops.
NIST' is developing fire data management systems and databases to facilitate the transfer and availability of fire data. The emphasis is on reducing the loss of life and property through innovative use of detection and control of fires and fire service response. As part of the mission of the group, the collection and exchange of data for fire science and engineering is promulgated through activities such as the Fire Research Information Service.

\section{Contact:}

Walter W. Jones

(301) $975-6887$

email:wwj@nist.gov

A249 Polymer Building

\section{LARGE FIRES}

Large fires result from industrial or transportation accidents, natural disasters, arson, or when fire protection systems in constructed facilities fail to perform adequately. While these fires present a hazard to building occupants, firefighters, and the surrounding area, little is known about their characteristics, their growth and control, and methods of mitigating their impact. NIST is performing research and developing techniques to measure and predict the behavior of large fires and the action of building fire protection systems. Large building fires involve the interaction of strongly buoyant gas flows and thermal radiation with complex structures and, in some cases, automatic fire suppression systems. Experiments to evaluate industrial fire behavior and the performance of fire suppression systems are being conducted to provide information that can be used to reduce vulnerability to large fires.
NIST is a leader in field fire measurement. Information from these studies, performed at sites of opportunity in cooperation with industry and fire service organizations, provides valuable data not obtainable in laboratory experiments. The development of robust field measurement techniques and equipment is a continuing activity. Data are used to develop and evaluate predictive models and standard test methods. As an example, NIST measures smoke plumes from large, open-air oil-spill fires to help develop and evaluate computer models for smoke movement.

\section{Contact: \\ Daniel Madrzykowski \\ (301) 975-6677 \\ email:madrzy@nist.gov \\ A345 Polymer Building}

\section{FIRE DYNAMICS}

The ability to make quantitative predictions of the hazards associated with fires in industrial, commercial, and residential facilities rests on an understanding of fire dynamics and the underlying physical principles that control these phenomena. The understanding of fire dynamics is gained from computer simulations based on advanced large eddy simulation techniques in computational fluid dynamics and laboratory experiments. The result is a system of analysis that relies on sophisticated computational and measurement tools to predict the impact of fires.

These techniques have been applied at NIST to study a variety of diverse fire response issues such as the dispersion of smoke plumes from oil-spill fires and the control of warehouse storage-rack fires using draft curtains, sprinklers, and vents. The unique NIST contribution has been the quantitative prediction of critical parameters such as the ground-level deposition of smoke particulate from oil fires and the time sequence of sprinkler activation in storage-rack fires. NIST is developing a system to predict the spread of fires in urban areas following earthquakes 
and other natural disasters. This system will involve both a computational wind engineering capability and an enhanced fire prediction methodology. The resulting methodology will be used to assist in disaster response planning in both industry and government.

\section{Contact:}

Daniel Madrzykowski

(301) 975-6677

email: madrzy@nist.gov

A345 Polymer Building

\section{FIRE SCIENCE}

\section{Division Contact:}

Richard Gann

(301) 975-6866

email: richard.gann@nist.gov

fax: (301) 975-4052

B250 Polymer Building

www.bfrl.nist.gov/865/fsd.html

\section{ADVANCED FIRE SENSING}

The damage from fires that are detected quickly can be kept small. NIST researchers are studying new "fire signatures" that would enable the development of a new generation of detectors. The signals from these detectors would be analyzed electronically to alert occupants or suppression devices, perhaps even before flames exist. The research also is intended to provide an understanding of technology for avoiding the high falsealarm rate of current detectors. In addition, advanced concepts for fire suppression chemicals, reduced explosion potential, and minimizing collateral damage from the application of the suppressant are being explored.
NIST also is developing a first-generation, fire-emulator/detector-evaluator. Identified by industry as a principal stimulant to the development and commercialization of new fire alert devices, the emulator will provide a well-controlled environment in which fire sensors can be exposed to highly reproducible, time-varying concentrations of combustion products at predetermined temperatures and flow velocities. This will provide accurate determination of the sensitivity and utility of new detector designs.

Using this device will demonstrate the response of discriminating detector systems to early fire events and will enable improved fire protection with reduced cost and losses.

Contact:

William Grosshandler

(301) $975-2310$

email:william.grosshandler@nist.gov

B356 Polymer Building

\section{ADVANCED FIRE SUPPRESSION}

Rapid, effective response to a fire is essential to improve life safety and avert major property loss. Halon fire suppressants have long been used to protect the most important, sensitive, and irreplaceable facilities. Production of these chemicals now has been halted due to their deleterious effect on stratospheric ozone.

In performing leading research into replacements for the halons, NIST is working closely with the industries and federal agencies that need alternative suppression capability, the potential manufacturers of advanced fire suppression technologies, and other researchers in the field. NIST researchers are studying the mechanisms of highly efficient flame extinguishants to help identify new chemicals for practical use, investigating the transport properties of gaseous and liquid suppressants to optimize their effectiveness, and developing performance measures for new fire suppression technologies.

\section{Contact:}

William Grosshandler

(301) 975-2310

email: william.grosshandler@nist.gov

B356 Polymer Building

\section{MEASURING FIRE ACCURATELYY}

The modern fire-safety professional has become dependent on quantitative measures of fire performance, whether in terms of specifying commercial products or in presuming the validity of the ever more pervasive fire models. This requires that the measurement methods themselves be of reliable accuracy and known precision. However, nearly all the current firecharacterization techniques have been in use for decades and have not incorporated the great strides made in instrumentation and data acquisition abilities. In addition, these techniques carry systematic and random errors that have not been adequately characterized, making questionable their reliability in safety assessments. 
NIST research is directed at modernizing fire measurements. The focus is on several areas:

- determining the needs of the fire community and analyzing the capability of current measurement approaches to meeting those needs;

- improving standard procedures for measuring temperatures in fire environments using thermocouples;

- developing a new and universal method for measuring smoke production in fullscale fire tests; and

- assessing the potential for new laser optical techniques for temperature and concentration measurements in harsh fire environments.

The results will enable the development of more accurate fire models and will enhance confidence in the ability of fire-modeldependent, performance-based fire codes to provide an ensured level of safety.

Contact:

William Pitts

(301) $975-6486$

email: william.pitts@nist.gov

B258 Polymer Building

\section{POLYMER COMBUSTION RESEARCH}

The materials industry is seeking products with low flammability that will not pose environmental hazards over their life cycles. NIST is working on several key research areas needed to produce natural and synthetic polymer and composite materials that can meet these goals. One area is the measurement of flammability properties by benchscale methods directly relevant to real fires. Also important is the development of mathematical models that use the measured flammability properties as inputs to predict fire performance of materials in the conditions of actual use.
Another research area concerns approaches to environmentally acceptable, charforming flame retardant treatments for flaming and smoldering combustion. This effort includes studying the physical and chemical nature of char and how its properties can be enhanced. Theoretical modeling using molecular dynamics and quantum mechanics complement the experimental work to develop a technical basis for the design of a new generation of fire-resistant materials, which, while retaining their intended-use properties, will be low in combustion toxicity and safe for the environment.

\section{Contact:}

Takashi Kashiwagi

(301) 975-6699

email: takashi.kashiwagi@nist.gov

B258 Polymer Building

\section{APPLIED ECONOMICS}

\author{
Office Contact: \\ Harold Marshall \\ (301) 975-6131 \\ email: harold.marshall@nist.gov \\ fax: (301) 208-6936 \\ B226 Building Research Building
}

\section{MICROECONOMIC ANALYSIS}

The Office of Applied Economics (OAE) conducts research and provides technical assistance in the field of microeconomic analysis. It provides information to decision makers in the public and private sectors who are faced with choices among new technologies and policies relating to manufacturing, industrial processes, the environment, energy conservation, construction, law enforcement, and safety. The OAE also develops and conducts prototype training programs in applied economics for scientists and engineers.
Benefit-cost analysis, life-cycle costing, multicriteria decision analysis, risk analysis, and econometrics are techniques the $\mathrm{OAE}$ uses to evaluate new technologies, processes, governmental programs, legislation, and codes and standards to determine efficient alternatives. Research areas include energy conservation in buildings, fire safety, automation, seismic design, and building economics. Products include reports of research findings, standard methods and guidelines for making economic evaluations, audiovisuals that teach and illustrate methods in practice, and decision-support software with documentation.

Currently researchers are developing and automating a decision-support system, BEES, for evaluating the environmental and economic performance of buildings; developing models and software for evaluating the life-cycle cost effectiveness of composites and other new technology materials in construction; constructing an optimization model for determining the appropriate prices and levels of production for NIST"s Standard Reference Materials; and providing economic software tools for evaluating the long-term cost effectiveness of capital investments in buildings and building components.

\section{Contact:}

Harold Marshall

(301) 975-6131

email:harold.marshall@nist.gov

fax: (301) 208-6936

B226 Building Research Building 


\section{RESEARCH} FACILITIES

\section{LARGE-SCALE STRUCTURES TESTING FACILITY}

The NIST large-scale structures testing facility consists of a universal testing machine (UTM) that may be used with a 13.7 -meterhigh reaction buttress equipped with a horizontal hydraulic ram of 4.5 MN capacity. A combination of horizontal and vertical forces may be applied to large-scale specimens.

\section{CAPABILITIES}

The UTM portion of the facility is a servocontrolled, hydraulically operated machine of 53.4 MN capacity and is one of the largest in the world. It can be programmed by function generator or computer to create any desired loading function using force, strain, or displacement as the variable. It tests large structural components and subassemblies and applies the forces needed to calibrate very large capacity force-measuring devices. It can apply compression forces to test sections up to $18 \mathrm{~m}$ in height. The reaction buttress will resist horizontal forces to $4.5 \mathrm{MN}$ from floor level to $12.2 \mathrm{~m}$ high. Flexure and tension specimens may be subjected to forces up to $18 \mathrm{MN}$ and $26 \mathrm{MN}$, respectively. Two-meter-thick test floors may be used to tie specimens in place.

\section{APPLICATIONS}

A testing program was conducted to evaluate the performance of concrete columns $1.5 \mathrm{~m}$ in diameter and up to $9.1 \mathrm{~m}$ high. Another test series evaluated fracture propagation in steel plates $1 \mathrm{~m}$ wide and $0.1 \mathrm{~m}$ and $0.15 \mathrm{~m}$ thick. A third experiment used the servocontrol system, programming repeated loads applied to composite specimens.
Low-cycle fatigue tests, destructive or ultimate loads, earthquake simulation in two dimensions, and complex loading of components may all be accomplished in this facility. Servo operation of this machine creates a unique potential for applying precisely controlled very large forces to test components.

\section{AVAILABILITY}

This facility, which NIST staff must operate, is available for cooperative or independent research. Tests should be arranged as far in advance as possible as special hardware may be needed for attaching specimens.

Contact:

Shyam Sunder

(301) $975-6713$

email:sunder@nist.gov

B166 Building Research Building

\section{TRI-DIRECTIONAL TEST FACILITY}

The tri-directional test facility at NIST is a computer-controlled apparatus capable of applying cyclic loads simultaneously in three directions. It is used to examine the strength and deformation characteristics of structural components or assemblages under the application of a variety of loadings, such as earthquake or wind. This is one of the largest facilities in the United States, in terms of both its high load capacity and its capability to handle large, fullscale specimens.

\section{CAPABILITIES}

The facility can apply forces or displacements or both in six directions. Specimens up to $3.3 \mathrm{~m}$ high $\times 3 \mathrm{~m}$ in length or width may be tested. The six degrees of freedom are translations and rotations in and about three orthogonal axes. Six closed-loop, servo-controlled hydraulic actuators apply forces or displacements. Loads may be applied up to 2,000 $\mathrm{kN}$ in the vertical and about $890 \mathrm{kN}$ in each of the two horizontal directions.

\section{APPLICATIONS}

The test facility is limited only by the size of the test specimen. Loads may be cyclic or monotonic depending on the type of loading condition being simulated. The facility is used to study masonry shear walls subjected to reverse cyclic lateral loading and precast concrete beam-column and wall connections, also subjected to reversed cyclic lateral loading. This facility supports NIST's role in conducting research for the development of seismic design and construction standards in the National Earthquake Hażards Reduction Program.

\section{AVAILABILITY}

The tri-directional test facility is used by NIST staff in a variety of NIST research projects and in collaborative projects with other agencies. It also is available for independent research but must be operated by NIST staff.

Contact:

Shyam Sunder

(301) 975-6713

email: sunder@nist.gov

B166 Building Research Building

\section{LARGE ENVIRONMENTAL CHAMBER}

The large environmental chamber is $14.9 \mathrm{~m} \times 12.8 \mathrm{~m} \times 9.5 \mathrm{~m}$ high. It has an earth floor and may be excavated as needed for building construction. The chamber is one of the largest of its kind, capable of accommodating two-story houses under simulated environmental conditions. This chamber has been used for thermal performance, heating and cooling load measurements, and energy consumption studies of buildings of different kinds. 


\section{CAPABILITIES}

The chamber is capable of automatically maintaining steady and/or dynamic temperature profiles from $-45^{\circ} \mathrm{C}$ to $65^{\circ} \mathrm{C}$ and humidity from 50 percent relative humidity (rh) at $1.7^{\circ} \mathrm{C}$ up to $35^{\circ} \mathrm{C}$ dewpoint at $49^{\circ} \mathrm{C}$. A wider range of rh ( 15 percent to 80 percent) may be obtained manually. Air circulation maintains the temperature variation within the chamber to within $\pm 1^{\circ} \mathrm{C}$. Damper-control return ducts in all four corners of the chamber permit good air distribution. Supply air is furnished by ceiling diffusers.

\section{APPLICATIONS}

The chamber is used to measure indoor temperature fluctuation, heat loss and heat gain through building envelopes, energy conservation and moisture condensation studies, and air infiltration under simulated and dynamically fluctuating outdoor temperature cycles. The chamber has been used to test a variety of conventional and special structures and equipment, including military hardware (such as inflatable life rafts, relocatable air-inflatable hospital units, and portable walk-in coolers) under extreme climatic conditions.

\section{AVALABILITY}

This facility, along with several smaller chambers (including one designed for vehicles), has substantial potential for use by researchers in industry and universities. Collaborative programs and proprietary research can be arranged.

\section{Contact:}

Piotr A. Domanski

(301) 975-5877

email: piotr.domanski@nist.gov

B114 Building Research Building

\section{CALIBRATED HOT BOX}

The NIST calibrated hot box measures the heat transfer coefficient of full-scale building wall sections. Designed according to ASTM Standard C976, it consists of two large, heavily insulated chambers - an environmental chamber and a climatic chamber- each with one open side. Indoor and outdoor conditions are simulated in the chambers. The open test section measures $3 \mathrm{~m} \times 4.6 \mathrm{~m}$. A well-insulated frame supports the wall specimen clamped between the open sides of the two chambers.

\section{CAPABILITIES}

This facility is the only one of its kind designed to perform simultaneous dynamic transfer measurements of air, moisture, and heat during simulated winter and summer conditions under steady-state and dynamic climatic conditions. While the environmental chamber temperature and humidity are maintained to simulate a relatively steady and narrow range of indoor conditions, the climatic chamber can attain temperatures ranging from $-40{ }^{\circ} \mathrm{C}$ to $65^{\circ} \mathrm{C}$. The apparatus measures the performance of homogeneous or composite walls having a range of thermal resistance from $0.35 \mathrm{~m}^{2}$ to $8.8 \mathrm{~m}^{2} \cdot \mathrm{C} / \mathrm{W}$. It accommodates wall specimens up to $0.6 \mathrm{~m}$ thick and up to $700 \mathrm{~kg} / \mathrm{m}^{2}$ in weight per unit area.

\section{APPLICATIONS}

NIST researchers use the facility to develop standard test methods to evaluate dynamic thermal performance of full-scale walls under cyclic temperature conditions. The building industry and government agencies are seeking reliable evaluation techniques for wall thermal mass, especially to predict energy consumption of buildings with heavy mass effects in comparison to standard wood-frame buildings.

NIST has participated in round-robin test activities with domestic and overseas thermal insulation laboratories.

\section{AVAILABILITY}

The facility provides a unique opportunity to measure simultaneous transfer of air, moisture, and heat through wall and roof specimens with openings for windows and doors. While available for use by those outside NIST, this apparatus must be operated by NIST staff.

Contact:

A. Hunter Fanney

(301) 975-5864

email: hunter.fanney@nist.gov

B320 Building Research Building

\section{LINE HEAT-SOURCE GUARDED HOT PLATE}

The $1 \mathrm{~m}$ guarded hot-plate apparatus measures thermal conductivity of building insulation materials. The thermal resistance of all insulation products sold in the United States is traceable to this apparatus. This facility is the only one of its kind in the world that will permit low-density thick insulation to be measured with an uncertainty of less than 0.5 percent.

\section{CAPABILITIES}

This apparatus has a test temperature range of $80^{\circ} \mathrm{C}$ for the hot plate and $-20^{\circ} \mathrm{C}$ for the cold plates. The apparatus permits measurement of vertical and horizontal heat flow to simulate heat transfer through ceilings and walls, respectively. This apparatus operates within its own carefully controlled temperature and humidity environment shielded by an insulated enclosure. This facility provides for absolute measurement of thermal resistance of thick and low-density test specimens used as transfer standards. These standards are used to calibrate or verify heat flowmeter (ASTM C518) or guarded hotplate (ASTM C177) equipment. 


\section{APPLICATIONS}

NIST researchers use the hot plate to provide calibration specimens for guarded hot plates in other laboratories. The hot plate also is used to investigate edge heat loss from thick thermal insulation materials.

\section{AVAILABILITY}

This apparatus is available for use by those outside NIST, but it must be operated by NIST staff. Collaborative programs may be arranged.

Contact:

A. Hunter Fanney

(301) 975-5864

email: hunter.fanney@nist.gov

B320 Building Research Building

\section{ADVANCED INSULATION FACILITY}

The advanced insulation facility consists of experimental apparatus and analytical tools to assess the thermal performance of advanced insulation systems. These systems include gas-filled, powder-filled, and metalclad vacuum panels. The facility consists of a calorimeter facility to measure the thermal resistance of advanced insulation panels, a state-of-the-art infrared thermography system to characterize thermal anomalies, and finite element software.

\section{CAPABILITIES}

The maximum panel size that can be accommodated by the calorimeter facility is $0.9 \mathrm{~m} \times 0.9 \mathrm{~m}$. The maximum thickness that can be accommodated is $0.1 \mathrm{~m}$. The temperature of one side of the panel may be varied from $-15^{\circ} \mathrm{C}$ to $10^{\circ} \mathrm{C}$. The other side of the panel, encased by a calorimeter, is maintained at laboratory ambient temperature. The infrared thermography system consists of both short-wave and long-wave scanners and advanced software that permits analysis of both real-time and stored images. The finite element software is applicable to all classes of advanced insulation systems.

\section{APPLICATIONS}

The facility is used to measure the thermal resistance of advanced insulation systems including, but not limited to, gas-filled, metal-clad vacuum, and powder-filled panels. The facility is well suited to measure non-homogeneous insulation systems but could be utilized to measure the thermal performance of conventional insulation materials.

\section{AVAILABILITY}

This facility has substantial potential for developers of advanced insulation systems in industry and academia. Cooperative research and development agreements are used to establish research projects within this facility.

Contact:

A. Hunter Fanney

(301) $975-5864$

email: hunter.fanney@nist.gov B320 Building Research Building 


\section{CHEMICAL SCIENCE AND \\ TECHNOLOGY LABORATORY}

The Chemical Science and Technology Laboratory (CSTL) performs cutting-edge research in measurement science; develops and maintains measurement methods, standards, and reference data; and develops models for chemical, biochemi$\mathrm{cal}$, and physical properties and processes. CSTL provides these capabilities to enhance U.S. industry's productivity and competitiveness; ensure equity in trade; and improve public health, safety, and environmental quality.

The technologies and services provided by CSTL help the U.S. chemical manufacturing, energy, healthcare, biotechnology, food-processing, and materials-processing industries to meet the broad range of international measurement requirements and compete in global markets.

One of CSTL's goals is to anticipate the measurement needs of new technologies so that a measurement infrastructure is available by the time a new technology is implemented. Needs are expanding for accurate, quantitative measurements at everdecreasing detection limits, in harsher environments, and for a wider range of chemical species.

In addition, the development of novel and improved processing techniques and new approaches to pollution prevention and control are critical to the economic success of U.S. industry. Through a strong commitment to basic research, and by leading the advancement of measurement science in critical areas, CSTL is poised to meet emerging national needs.

\section{Contact:}

Hratch G. Semeriian, Director

(301) $975-3145$

email: hratch.semerjian@nist.gov

fax: (301) 975-3845

A317 Chemistry Building www.cstl.nist.gov

\section{COOPERATIVE RESEARCH OPPORTUNITIES}

\section{Biotechnology}

52 DNA Chemistry

52 Nuclear Magnetic Resonance

52 Bioprocess Engineering Measurements

53 Biomolecular Materials

53 Center for Advanced Research in Biotechnology

\section{Process Measurements}

54 Flow Measurement Research and Standards

54 Measurement Technology for Benchmark Spray Combustion Data

55 Engineering Measurements for Near- and Super-Critical Processes

55 Vapor-Phase Synthesis of Nanostructures

55 Chemistry of Materials Processing

56 Flow and Chemistry in Thermal Reactors

56 Plasma Processing of Semiconductors

56 Applied Computational Chemistry

57 Reacting Flow Simulation

57 Solid-State Chemical Microsensors

58 Self-Assembled Monolayers

58 High-Temperature Thermocouples

59 Pressure, Vacuum, and Low-Flow Standards

59 Quantitative Optical Measurements of Partial Pressures and Moisture

60 Standards for Raman Spectroscopy

\section{Surface and Microanalysis Science}

60 Microbeam Analysis

61 Atmospheric and Chemometric Research

61 Surface Dynamical Processes

\section{Physical and Chemical Properties}

62 Fundamental Properties of Trace Components of Natural Gas

62 Fundamental and Applied Properties of Adsorbents

62 Thermophysical Properties of Supercritical Fluid Mixtures

63 Fundamental Properties for Membrane Separations

63 Thermophysical Properties of Gases

63 Thermophysical Properties of Semiconductor Processing Gases

64 Chemical Thermodynamics
64 Chemical Kinetics

64 Computational Chemistry

65 Pressure-Dependent Chemical Reactions

65 Information for Modern Chemists

66 NIST/EPA/NIH Mass Spectral Database

66 Properties of Alternative Refrigerants

66 Thermophysical Properties of Natural Gas Systems

67 Properties of Fluids and Fluid Mixtures

67 Properties of Gels, Micelles, and Clays

68 Dilute-Solution Thermodynamics

68 Finite-Element Modeling of Complex Physical and Chemical Processes

68 Advanced Low-Temperature Refrigeration

\section{Analytical Chemistry}

69 Inorganic and Elemental Isotopic Metrology

69 Fundamental Studies of Atomic Spectroscopy

70 Accuracy of Spectrochemical Analysis

70 Analytical Mass Spectrometry for Organics and Biomolecules

70 Chromatography and Electromigration Techniques

71 Novel Analytical Separation Science Methodology

71 Separation Science Techniques for Trace Organic Analysis

72 High-Accuracy Coulometry

72 Inorganic Electroanalytical Chemistry

72 Trace-Gas Analysis

72 Optical Techniques for Trace-Gas Analysis

72 Spectroscopy Standards and Process Analysis

73 Laboratory Automation Technology and Standards

73 Automated Sample Preparation and Sensing

73 Analytical Infometrics

74 Chemical Analysis with Neutron Beams

74 Neutron Activation Analysis

74 Focusing of Cold Neutrons for Analytical Measurements

\section{RESEARCH FACILITIES}

75 Fluid Flow Measurement and Research Facilities

75 Liquid-Nitrogen Flow Measurements 


\section{COOPERATIVE RESEARCH OPPORTUNITIES}

\section{BIOTECHNOLOGY}

Division Contact:

Gary L. Gilliland

(301) 975-2629

email: gary.gilliland@nist.gov

fax: (301) 330-3447

A345 Chemistry Building

http://indigo15.carb.nist.gov/biotech/

biotech.html

\section{DNA CHEMISTRY}

Working in several areas of DNA chemistry,

NIST scientists are actively manipulating

DNA to produce proteins, developing methods for measuring DNA damage at the molecular level, and developing methods for characterizing DNA, including mutation detection and human identity profiling.

NIST scientists are developing experimental methods to measure DNA damage in mammalian cells exposed to free radicals, generated by ionizing radiation, elevated oxygen pressure, redox-cycling drugs, or carcinogenic compounds. Free radicals produced in vivo are thought to be mutagenic and carcinogenic. Measurement of DNA damage at the molecular level in mammalian cells is a prerequisite to understanding the chemical mechanisms of damage by free radicals. Techniques used for measuring DNA damage include gas chromatography, mass spectrometry, high-performance liquid chromatography, and nuclear magnetic resonance spectroscopy.

NIST scientists are working on new methods for DNA profiling, ranging from developing well-characterized DNA standards for restriction fragment length polymorphisms to performing research for rapid determination of DNA profiles by polymerase chain reaction amplification and automated detection of fragments. In addition, NIST researchers are interested in cooperative development of short-tandem repeat technology, mitochondrial DNA sequencing, and attendant standards. Techniques for DNA detection include sensitive staining of electrophoretic gels, use of chemiluminescence, and enhanced applications of capillary electrophoresis.

NIST is investigating methods and standards for mutation detection, a burgeoning area of testing in genetic and clinical laboratories. At this time, no national standards are available for genetic testing protocols. Work is delineating the characteristics of a set of materials intended for use in the standardization of DNA-based mutation detection systems for diagnostic testing and as research tools for determining parameters that affect the quality of measurements that are produced by various assay systems.

\section{Contact:}

Dennis J. Reeder

(301) 975-3128

email: dennis.reeder@nist.gov

A353 Chemistry Building

\section{NUCLEAR MAGNETIC RESONANCE}

Detailed knowledge of the structures and dynamics of macromolecules is critical for a complete understanding of biochemical reaction mechanisms and molecular recognition processes. Such an understanding can impact bioengineering efforts in the areas of biomaterials, "designer" enzymes, and pharmaceuticals. Programs are under way in which NIST scientists are developing measurement methods, models, and databases needed to study macromolecular structure and dynamics using nuclear magnetic resonance (NMR) spectroscopy. NIST and the Center for Advanced Research in Biotechnology maintain a state-of-the-art NMR facility, which includes superconducting magnets operating at 400,500, and 600 megahertz proton resonance frequency.
Research projects include investigations into the structure and dynamics of carbohydrates, glycoproteins, redox proteins, DNA enzyme-ligand complexes, RNA and DNA oligonucleotides, nucleic acid binding proteins, nucleic acid-protein complexes, and signal transduction proteins. Studies that utilize NMR measurements to study protein folding are also under way.

Contacts:

John P. Marino

(301) 738-6160

email: john.marino@nist.gov

9600 Gudelsky Drive

Rockville, Md. 20850

Bruce Coxon

(301) $975-3135$

email: bruce.coxon@nist.gov

A353 Chemistry Building

\section{BIOPROCESS \\ ENGINEERING MEASUREMENTS}

NIST scientists are focused on the development of measurement methods, databases, and generic technologies related to the use of biomolecules and biomaterials in manufacturing. Measurement methods and data have been developed in the protein spectroelectrochemistry area that will lead to improved understanding of intra- and interprotein electron transfer processes. This understanding helps industrial biocatalyst development by allowing for more efficient utilization of carbon sources (e.g., renewable resources) and nutrients, and in developing new ways to drive organic syntheses such as the stereospecific hydroxylation of pharmaceutical precursors. In the biothermodynamics of enzyme-catalyzed reaction project, chromatography and microcalorimetry measurements have been combined with chemical equilibrium analysis to develop thermodynamic data for several industrially important biotransformations. 
The metabolic pathway by which microorganisms and plants convert glucose to aromatic amino acids is a current focus of the biothermodynamic measurements. This chorismate metabolic pathway is under current investigation by several large chemical companies as an environmentally friendly source of aromatic hydrocarbons.

In the preparative bioseparations project, electrochromatographic/electrophoretic separation equipment and methodology are being applied to the separation of different physical forms of DNA (supercoiled plasmid. relaxed circular plasmid, and linear genomic). Large-scale purification of these materials is an emerging need in industries developing gene therapies and diagnostic materials. New biocatalytic systems projects in enzyme characterization by nitrogen- 15 NMR spectroscopy, X-ray diffraction of protein crystals, and computational chemistry have been initiated. These techniques will be used to address focused, industrially important biotransformation problems such as those found in hydroxylation and aromatic amino acid metabolic pathways.

\section{Contact:}

Vincent L. Vilker

(301) 975-5066

email: vincent.vilker@nist.gov

A353 Chemistry Building

\section{BIOMOLECULAR MATERIALS}

A current trend in materials development is to employ biological molecules, principles that are inspired by biology, or both. Such materials are sometimes referred to as "biomimetic," indicating they have characteristics such as self assembly, molecular recognition, specific chemical responses, and complex molecular architecture, which lead to unique structural or functional characteristics or both. Chemically controlled biomimetic surfaces are essential components of biosensors, bioelectronics, biocatalytic systems, and many diagnostic devices. Biomolecular materials thus influence diverse applications such as healthcare, environmental pollution monitoring, agriculture, and chemical manufacturing. An underlying need for these applications of biotechnology is the characterization and control of biomolecules at interfaces.

Fundamental studies are being conducted to better understand the structure and function of natural and biomimetic materials that self assemble. Lipid membranes are one such class of self-assembling materials. They organize and control the structure of proteins that naturally reside within them, many of which have commercially important functions. Project staff members also study models of cell membranes as tools for achieving better quantification of therapeutic agents, which are likely to act at the level of the cell membrane via cell surface receptors or which have to pass through the cell membrane to be effective.

Interactions among biological molecules and between biological molecules and surfaces occur during sensor operation, diagnostic tests, cellular recognition events and mobility, and in the formation of modified surfaces as organized biomolecular materials. In some of these applications, it is desirable to enhance strong molecular specific interactions while minimizing weaker non-specific interactions. In other cases, many simultaneous weak interactions are needed to effect the appropriate dynamic response. NIST develops both the experimental tools, such as chemically controlled surfaces and techniques for monitoring reactions at surfaces, and the theoretical tools to improve understanding of dynamic biomolecular processes and permit predictions and optimization of reactions of biomolecules. Methods for kinetic analysis, current noise analysis, and stochastic models of processes at surfaces are under development in the biomolecular materials group.
Macromolecules including bacteriorhodopsin, DNA, and enzymes are examined in various configurations as potential components of electrochemical, electronic, and optical devices. This effort is closely coupled with the more fundamental studies within the group, with the intention of bringing the knowledge gained from basic science studies closer to potential applications such as environmental sensing or optical storage. Engineering prototype devices allows consideration of real world issues such as fabrication and adaptation of instrumentation and methodology to field conditions.

\section{Contact:}

Anne Plant

(301) 975-3124

email: anne.plant@nist.gov

A353 Chemistry Building

\section{CENTER FOR ADVANCED RESEARCH IN BIOTECHNOLOGY}

At the Center for Advanced Research in Biotechnology (CARB) in Rockville, Md., jointly established by NIST, the University of Maryland, and Montgomery County, Md., researchers study structure and function relationships of biological macromolecules. They are focusing on the measurement of structure by X-ray crystallography and nuclear magnetic resonance spectroscopy (NMR) as well as the manipulation of structure by molecular biological techniques, including site-directed mutagenesis. Scientists use modeling, molecular dynamics, and computational chemistry to understand protein structure and to predict the effects of specific structural modifications on the properties of proteins and enzymes. A variety of physical chemistry methods are used to measure and analyze structural changes, activities, and thermodynamic behavior of biological macromolecules. CARB maintains state-of-the-art facilities for X-ray crystallography, NMR spectroscopy, molecular biology, and physical biochemistry. Its computer facilities include a variety of 
computational and high-resolution graphics workstations as well as access to the NIST supercomputer resources.

Contacts:

Roberto J. Poljak

(301) 738-6232

email: roberto.poljak@nist.gov

Edward Eisenstein

(301) 738-6272

email: edward.eisenstein@nist.gov

9600 Gudelsky Drive

Rockville, Md. 20850

\section{PROCESS}

MEASUREMENTS

Division Contact:

Gregory J. Rosasco

(301) 975-2609

email: gregory.rosasco@nist.gov

fax: (301) 869-5924

B312 Physics Building

www.cstl.nist.gov/div836

\section{FLOW MEASUREMENT RESEARCH AND STANDARDS}

The accelerating costs of scarce fluid resources and valuable fluid products - particularly petrochemical fluids — are causing increased concerns about the performance of flow meters. Additionally, the role of flow meters in controlling and optimizing critical industrial processes is pushing performance limits and extending the required fluid and flow conditions. To attain these goals, improved flow traceability to NIST standards is essential.

Improved flow measurement traceability needs to be established and maintained so that realistic, quantified data are generated on a continuing basis to ensure practical fluid measurements at satisfactory performance. To achieve the desired flow measurement traceability, NIST is conducting several flow measurement proficiency testing programs for a range of fluid and flow conditions. NIST also is designing new transfer standards to link the performance of calibration facilities having special conditions and capabilities to appropriate national reference standards.

Because of the importance of critical flow measurements, transfer standards need to be designed and used so that high levels of confidence can be placed in the measurements from critical flow meters. New transfer standards are evaluated rigorously against NIST fluid flow calibration standards. As part of these evaluations, the appropriate range of calibrations will be done on the developed standards so performance can be ensured at specified levels. Current fluid metering research programs use computational fluid dynamics (CFD) with validation using laser Doppler velocimetry (LDV) techniques to focus on flows that are critical to U.S. industry. Currently, the two areas of metering research are the assessment of acoustic technology for making improved flow measurements and the description of flow meter installation effects. CFD and LDV are applied in both of these areas.

Contact:

George E. Mattingly

(301) 975-5939

email: george.mattingly@nist.gov

105 Fluid Mechanics Building

\section{MEASUREMENT TECHNOLOGY FOR BENCHMARK SPRAY COMBUSTION DATA}

Control of process efficiency and the formation of species byproducts from industrial thermal oxidation systems (e.g., power generation and treatment of process liquid chemical wastes) generally are based on a priori knowledge of the input stream global physical and chemical properties, desired stoichiometric conditions, and monitoring of a few major chemical species in the exhaust. Optimization of the performance of these systems is relying increasingly on computational models and simulations that help provide relevant process information in a cost-effective manner. In general, there is a dearth of reliable data for specifying model initial/boundary conditions and a need for experimental/numerical comparative analysis of conditions within the reactor. The reactor volume is precisely the region that requires a better knowledge base to enable optimization of the chemical and thermal processes and control of particulate and gaseous emissions. There is a need to provide in-situ, real-time data on the characteristics of the droplet field and flame structure and its interrelationship with the system operating conditions (e.g., desired stoichiometry), heat transfer, and particulate/gaseous byproducts. These data are crucial for the development and calibration of advanced computational models, diagnostics, and instrumentation and the efficient operation of high-temperature process systems.

Experiments are being carried out in a spray combustion test bed, with a movable-vane swirl burner enclosed in a refractory chamber. The well-characterized and controlled facility has evolved to handle different process liquid fuels and wastes, atomizer designs, and combustor configurations. A unique array of intrusive probes, nonintrusive diagnostics, and flow visualization techniques are being employed to obtain comprehensive data on spray combustion characteristics. Current research involves measurement of the input fuel stream (fuel composition), spray flame (droplet size, velocity, number density, and temperature), and combustor exhaust (particulate size and volume fraction and toxic gas concentrations). NIST researchers are developing the measurement technology to provide benchmark experimental data that completely characterize the facility for input/validation/calibration of multiphase combustion models, calibration of instrument/sensors, and development of advanced 
diagnostics. These databases will be used to establish correlations between operating conditions and the resultant spray flame characteristics, thermal gradients, and level of chemical byproducts in combustion systems.

Contact:

Cary Presser

(301) $975-2612$

email: cary.presser@nist.gov

B312 Physics Building

\section{ENGINEERING MEASUREMENTS FOR NEAR-AND SUPER- CRITICAL PROCESSES}

A variety of promising new chemical technologies takes advantage of the unique properties of near-and super-critical fluids. For example, supercritical water oxidation can destroy hazardous materials mixed in a water stream, producing benign endproducts in a self-contained process. Development of robust designs is hampered by an inadequate understanding of crucial processes in the near- and super-critical fluids, such as reaction chemistry, heat transfer, fluid mechanics, and phase separation, as well as lack of thermodynamic and transport data. Investigations have been limited by a lack of in-situ measurements due to the high-pressure, high-temperature, and often chemically harsh environment. This work focuses on application of in-situ measurement techniques and acquisition of vital process data to model and understand these processes.

Several of these important issues are being addressed by NIST researchers with a complete range of unique experimental facilities and diagnostic capabilities. Experiments utilize unique optical cells that provide access for in-situ measurements of temperature, pressure, density, chemical species and concentrations, and phase discrimination.
Corrosion detection and characterization is performed with in-situ Raman spectroscopy for flowing solutions with temperatures up to 900 kelvin and pressures to 35 megapascals. Precipitation and deposition of "salts" in sodium sulphate and potassium sulphate solutions are studied in an optical cell, which can operate at 900 kelvin and 35 megapascals. A bench-scale chemical reactor is used to study ammonia and acetic acid destruction as functions of reactor geometry, temperature, residence time, and oxidant. Heat transfer experiments are conducted in a supercritical carbon dioxide flow loop, which matches conditions of pilotscale process heat exchangers. Modeling work is integrated with the experiments; predictions are made of thermodynamic phase boundaries and other properties of supercritical systems, as well as computations of flow fields, temperatures, and mass transfer. The experimental measurements and models will support process simulation and design efforts that are currently under way.

\section{Contact:}

Douglas Olson

(301) $975-2956$

email: douglas.olson@nist.gov

B312 Physics Building

\section{VAPOR-PHASE SYNTHESIS OF NANOSTRUCTURES}

Nanostructured materials have demon-

strated novel magnetic, optical, and mechanical properties. However, practical application of these materials requires the development of economical synthesis and processing methods. NIST researchers have focused their efforts in two important areas. The first is the development of gas-phase synthesis techniques for bulk production of nanoparticles and nanostructured thin films (e.g., superconductors, magnetic nanocomposites, metals, and ceramics). This work includes the use of gas-phase combustion and thermal flow reactors with emphasis on the use of in-situ optical diagnostics, such as planar laser-induced fluorescence and light scattering, for characterization. Current activities are focusing on the growth of composite particles with enhanced magnetic and structural properties and the production of nanostructured titanium thin films. Secondly, researchers are studying the application of molecular dynamics and quantum chemistry methods to describe particle nucleation and growth. Available facilities include excimer, neodymium-yttrium aluminum garnet, and tunable dye laser systems; continuous-wave-ion lasers; and graphics workstations. Expected results from this work are a better understanding of the mechanisms of particle nucleation and growth and strategies necessary to obtain desirable end-products such as commercially important thin films.

Contacts:

Michael R. Zachariah

(301) 975-2063

email: michael.zachariah@nist.gov

Donald R. Burgess, Jr.

(301) 975-2614

email: donald.burgess@nist.gov

B312 Physics Building

\section{CHEMISTRY OF MATERIALS PROCESSING}

This work focuses on both quantitative and qualitative measurements of the principal reacting species and the kinetics of the chemistry relevant to thermal chemical vapor deposition and plasma processing. NIST researchers conduct experiments using either a high-temperature flow reactor or a low-pressure plasma coupled to a modulated molecular-beam mass-spectrometer sampling system. The current focus has been on the thermal and oxidation chemistry of precursors used in the deposition of $\mathrm{SiO}_{2}$ films 
and the chemistry of fluorocarbons relevant to low-pressure plasma etching processes. Experiments are supported with a strong modeling effort involving extensive use of modern computational chemistry methods as well as detailed reactor models.

\section{Contacts:}

Michael R. Zachariah

(301) 975-2063

email: michael.zachariah@nist.gov

Donald R. Burgess Jr.

(301) 975-2614

email: donald.burgess@nist.gov

B312 Physics Building

\section{FLOW AND CHEMISTRY IN THERMAL REACTORS}

This project is aimed at providing measurements suitable for development and testing of models that may be used as design tools for development of next-generation process equipment used in the manufacture of microelectronic components. Research focuses on the characterization of both flow and chemistry in thermal reactors. These are under investigation using a new optically accessible rotating disk reactor. A major focus of this work is on the detection of the early stages of contaminant particle formation. Additionally, both chemical species and thermal fields will be measured under various operating conditions. This work is in conjunction with a substantial modeling effort in this type of reactor. Available facilities include excimer, neodymiumyttrium aluminum garnet, and tunable dye laser systems; continuous-wave-ion lasers; mass spectrometers; and high-performance graphics workstations. The results of this research are expected to aid in the development of industrial process reactor simulations and on-line diagnostics for process control, as well as to increase fundamental understanding of these important processes.

\section{Contacts:}

James E. Maslar

(301) 975-4182

email: james.maslar@nist.gov

Ronald W. Davis

(301) 975-2739

email: ronald.davis@nist.gov

B312 Physics Building

\section{PLASMA PROCESSING OF SEMICONDUCTORS}

Plasmas are widely used by the semiconductor industry to etch and deposit films. Plasma processing reactors have historically been designed and operated using empirical methods alone, but continued evolution of these tools requires a much greater reliance on process and reactor modeling. Such models would be used as design tools for nextgeneration processes and equipment. Also, because most existing plasma diagnostic techniques are incompatible with the manufacturing environment, a need exists to develop sensors for that environment, models to interpret the sensor readings, and new schemes of closed-loop control based on these sensors and models.

The goal of this project is to develop advanced chemical and electrical measurement methods for characterizing plasmas, use these measurements to test and develop models, and apply the models to the development of new types of sensors and new design strategies. Measurements of high-density and low-density plasmas are made in a standard plasma reactor known as the Gaseous Electronics Conference reference cell. Also under construction is a new platform, similar to state-of-the-art industrial reactors designed for 300-millimeter wafers. Measurement techniques to probe gas and surface chemistry include optical emission, mass spectrometry, spectroscopic ellipsometry, absorption spectroscopy, and planar laserinduced fluorescence (PLIF). PLIF provides two-dimensional maps of gas phase species concentrations, enabling investigation of plasma spatial uniformity and rigorous testing of plasma simulations. Present PLIF studies focus on the fluorocarbon plasmas used for etching and chamber-cleaning.

Electric probe and radio-frequency voltage and current waveform measurements provide electrical characterization of plasma parameters and reactor conditions. These electrical measurements, as well as ion energy measurements, are used to characterize and model plasma sheath dynamics. Sheath models developed and verified by this work have been used to optimize the efficiency of power utilization in chambercleaning plasmas and to develop a new technique for measuring the ion current at wafers during high-density plasma processing.

Contacts:

Mark A. Sobolewski

(301) 975-2980

email: mark.sobolewski@nist.gov

A303 Physics Building

Kristen L. Steffens

(301) 975-2656

email: kristen.steffens@nist.gov

B312 Physics Building

\section{APPLIED COMPUTATIONAL CHEMISTRY}

Improvements in process design and control, which can be realized from increasingly sophisticated process models, are not occurring because of the lack of highquality data. New computational chemistry methods offer the potential to revolutionize the manner in which fundamental thermochemical, physical, and kinetic data are obtained. Research focuses on the development and application of robust methods for data estimation. NIST scientists are investigating the application of empirical correction schemes to ab-initio molecular orbital calculations as a means to obtain highaccuracy data at low computational cost. 
Such methods have been used to predict the thermochemistry of more than 110 hydrofluorocarbons and oxidized hydrofluorocarbons. These results when compared to available literature data showed excellent agreement.

Thermochemistry data on the $\mathrm{Si}-\mathrm{O}-\mathrm{H}$ and Si-P-H system also have been generated for application to the chemistry of microelectronics processing. A user-friendly reaction rate theory program has been developed that will enable the estimation of rate constants. This program, which currently is being tested, is applicable to any arbitrary reaction manifold and should find wide application by those interested in large-scale chemistry simulations. Molecular dynamic simulations are being used to simulate the structure, properties, and kinetics of clusterto-cluster growth kinetics relevant to nanoparticle formation. These results are finding application in the development of aerosol models and in improving understanding of nanoparticle growth. Calculations are conducted using the NIST supercomputer facility and are processed using high-performance graphic workstations.

Contacts:

Michael R. Zachariah

(301) $975-2063$

email:michael.zachariah@nist.gov

Donald R. Burgess, Jr.

(301) $975-2614$

email: donald.burgess@nist.gov

B312 Physics Building

\section{REACTING FLOW SIMULATION}

This research focuses on the chemical process industry's need to understand reacting systems. The primary emphasis is on systems that involve complex chemistry in such environments as plasma and thermal processing of microelectronics, combustion, and two-phase flows. Researchers are simulating high-temperature reacting flows to understand the complex coupling between the fluid flow, heat release, multiple phases, and chemical reactions. Most recently, simulation of contaminant particle nucleation and growth in materials processing reactors in support of ongoing experimental efforts have been stressed.

Scientists are developing large, detailed chemical kinetic mechanisms relevant to combustion and plasma etching as well as materials processing chemistries. In addition, researchers are pursuing automated methods for mechanism generation, analysis, and reduction, which rely heavily on interactive graphics. These approaches increasingly rely on the use of advanced methods for thermochemical and kinetic data estimation. Calculations are conducted using the NIST supercomputer facility and are processed using high-performance graphic workstations.

\section{Contacts:}

Ronald W. Davis

(301) 975-2739

email: ronald.davis@nist.gov

Michael R. Zachariah

(301) 975- 2063

email: michael.zachariah@nist.gov

B312 Physics Building

\section{SOLID-STATE CHEMICAL MICROSENSORS}

The increasing demand for reliable chemical sensors is being driven by wide-ranging measurement needs. The chemical process industry, for example, now faces new demands for more efficient use of materials, better process reproducibility, and environmental safety. Similar concerns are encountered in the automotive field, where researchers are challenged to optimize engine performance while reducing emissions. To address such measurement needs, this program concentrates on developing generic sensor platforms, as well as fabrication and operational techniques, that allow sensors to be tuned (with active materials and temperature control) for detecting differing target gases and vapors within varied environments.

Fundamental work on sensing materials is done to create the understanding necessary to optimize performance characteristics such as sensitivity, selectivity, speed, and stability. Microsensors are based on a "microhotplate" design developed and patented at NIST. These Si-based, surfacemicromachined devices, which have nominal lateral dimensions of between 30 micrometers and 200 micrometers and masses of approximately 0.25 microgram, provide microplatforms with localized, measurable, and rapidly variable thermal control. The microhotplate structure can be repeated easily to form integrated arrays of multiple, individually addressable, and thermally isolated elements. Rapid heating (to 500 degrees Celsius and higher) and cooling characteristics of the devices allow dynamic temperature programming to be 
used in producing response signatures for identifying detected species. In this work, neural network methods are employed with response training sets to develop heating schedules for high information content operation and recognition. Localized heating of the devices has been combined with chemical vapor deposition to directly define different active films on array elements. To date, most efforts have been connected to conductometric gas sensing with semiconducting oxide films ( $\mathrm{SnO}_{2}, \mathrm{ZnO}$, and $\left.\mathrm{TiO}_{2}\right)$ that have been modified with catalytic metal additives (Pt and Pd). However, modified versions of the microhotplate are being developed for sensing by calorimetric, capacitance, and other transduction principles. NIST researchers now are examining the use of organic films, epitaxial films, and high-area metal dispersions for incorporation into the microsensor platforms. Thermally controlled array structures also are being used in efficient studies on materials suites for new applications.

There is continuing interest in cooperative research that would assist this interdisciplinary program in its efforts to understand and advance sensing mechanisms, sensor materials, and sensing platforms. Dedicated facilities for multitechnique surface analysis, device design and micromachining, and response testing can be utilized for investigating new concepts and prototype structures, and for evaluating sensor performance in specific application sectors. NIST researchers also have a growing interest in algorithm development for signal processing.

\section{Contacts:}

Stephen Semancik

(301) 975-2606

email: stephen.semancik@nist.gov

Richard E. Cavicchi

(301) 975-3970

email: richard.cavicchi@nist.gov

A303 Physics Building

\section{SELF-ASSEMBLED MONOLAYERS}

Future sensors and diagnostics are being developed to perform multianalyte measurements rapidly, accurately, and at low cost. A promising approach is to use large-scale solid-phase arrays of molecular recognition elements. One such example is DNA microchip technology, which has the potential for revolutionizing genetic diagnostic and analysis applications including disease detection, toxicology, forensics, industrial processing, and environmental monitoring. Although considerable effort is focused on applications of DNA and peptide arrays, relatively little research is directed toward understanding the molecular-scale structure and mechanisms that govern the surface reactions of these monolayer systems. To investigate many of these issues, NIST researchers are studying alkanethiol self-assembled monolayers (SAMs) formed on gold substrates as a model system. SAMs are robust, reproducibly prepared structures with highly tunable surface properties useful in sensing applications. Fully functional biomolecular films are readily prepared by derivatizing a biological molecule (protein or nucleic acid) of interest with a thiol group and then self-assembling the modified biomolecule on gold.

Current studies are focused on determining the structure/function properties of thiolderivatized, single-stranded (ss) DNA monolayers on gold and their associated hybridization reactions. DNA monolayer films are prepared with high hybridization activities and precisely controlled probe coverages using a two-component film of thiolderivatized ssDNA and a passivating thiol to limit non-specific adsorption of test DNA. optical, electrochemical, and neutron measurement methods are being developed and applied to these monolayers for in situ determination of surface DNA density, hybridization activity, and molecular orientation. The goal of these studies is to ascertain the optimal film structure and composition for promoting hybridization of surface-bound probes. In addition, scanning tunneling microscopy is being used to elucidate the molecular packing of the alkanethiol monolayers. The goal of this work is to correlate the nanometer-scale structure of the SAMs with the macroscopic chemical and physical properties important in sensing and diagnostic applications.

Contacts:

Michael J. Tarlov

(301) 975-2058

email:michael.tarlov@nist.gov

Tonya M. Herne

(301) $975-5153$

email: tonya.herne@nist.gov

A303 Physics Building

\section{HIGH-TEMPERATURE THERMOCOUPLES}

Industrial high-temperature processes and scientific research at high temperatures require stable thermometers that cover wider temperature ranges with better accuracy than previously required. Problems with thermocouples at high temperatures result primarily from unstable compositions (impurities, defects, and chemical reactions), causing their electromotive force, and thus their temperature indication, to drift with use and rapidly become highly uncertain. A second problem in process measurements is the unreliable measurement of surface temperatures resulting from the use of traditional contact and noncontact (radiation) thermometers. Accurate, high-speed measurements of temperatures of surfaces are especially critical in semiconductor wafer preparation by rapid thermal processing because accurate control of temperature during short high-temperature exposures is critical to product quality and device performance. 
NIST is developing new wire and thin-film thermocouples as reference thermometers for secondary calibration laboratories and as high-accuracy, high-stability, hightemperature thermometers for industrial use, including use in surface-temperature measurements. Scientists are investigating noble metal thermocouples of exceptionally high purity and generally resistant to oxidation in high-temperature environments. They also are investigating thin-film thermocouples for accurate surface temperature measurements. These devices become a part of the surface and thereby obviate the uncertainties associated with conventional contact thermometers (uncertainty of the correlation between measured temperature and surface temperature) and with radiation thermometers (uncertainty with respect to the time-dependent, effective emissivity of the surface).

Contact:

Billy W. Mangum

(301) $975-4808$

email: billy.mangum@nist.gov

B128 Physics Building

\section{PRESSURE, VACUUM, AND LOW-FLOW STANDARDS}

Many industries depend on accurate pressure, vacuum, and low-flow measurements for research and development and for process and quality control. NIST develops and maintains pressure and vacuum standards from 200 megapascals to $10^{-7}$ pascal; flow standards are operated from $10^{-3} \mathrm{~mol} / \mathrm{s}$ to $10^{-14} \mathrm{~mol} / \mathrm{s}$. Facilities include five ultrahigh vacuum systems, two low-range flowmeters, a mid-range flowmeter, high-accuracy mercury and oil manometers, oil and gas piston gauges, apparatuses for measuring gas densities using optical techniques, and the necessary pressure and vacuum control systems. These facilities are used to provide calibration support for industrial, academic, and government entities and for research in the areas where these capabilities can be used to improve the fundamental understanding of physical phenomena.

These measurement capabilities enable researchers to develop improved measurement techniques and equipment and to investigate the performance of vacuum and pressure equipment, specifically piston gauges, mechanical pressure gauges, momentum transfer gauges, ionization gauges, thermal mass flowmeters, standard leaks, and residual gas analyzers. In addition, NIST uses this measurement capability to investigate properties of materials and physical phenomena of fundamental interest. Among current projects are the development of an optical adsorption-based standard for measuring low gas densities, development of a high-precision laminar flowmeter, modeling of primary pressure standards to reduce their uncertainties, development of a low-gas flow acoustic flowmeter, characterization of thermal mass flowmeters, and characterization and modeling of residual gas analyzers for semiconductor process control. NIST researchers also are developing molecular drag gauges that operate in high-vacuum conditions and precise isotopic reference standards for pure gases.

Contact:

Stuart A. Tison

(301) $975-2857$

email: stuart.tison@nist.gov

A55 Metrology Building

\section{QUANTITATIVE OPTICAL MEASUREMENTS OF PARTIAL PRESSURES AND MOISTURE}

Low-level gaseous contaminants cause deleterious effects in chemical and materials processing such as semiconductor manufacturing systems. Many commercially available instruments either are not species specific, are not sufficiently sensitive, or utilize detection techniques that perturb the chemical composition and, therefore, com- promise the measurement of contaminant composition. This research seeks to develop quantitative optical measurement techniques that have high species selectivity and sensitivity. This effort strives to produce a new generation of species-specific, partial pressure measurement standards with a particular emphasis on low-density measurement of $\mathrm{H}_{2} \mathrm{O}, \mathrm{CO}_{2}, \mathrm{CO}_{2} \mathrm{O}_{2}, \mathrm{H}_{2}$, and $\mathrm{CH}_{4}$. optical measurement techniques of primary interest include photon-induced ionization spectroscopies for partial pressures less than $10^{-2}$ pascal and absorption spectroscopy in the range of 1 kilopascal to $10^{-6}$ pascal. Initial efforts are emphasizing the use of cavity-ring-down-spectroscopy, an absorption technique for the measurement of $\mathrm{H}_{2} \mathrm{O}$, which should enable quantitative determinations in the range from approximately 1 kilopascal to approximately $10^{6}$ pascals and resonant enhanced multiphoton ionization techniques with $\mathrm{CO}$ in the range of $10^{-4}$ pascal to $10^{-8}$ pascal. In addition to providing non-intrusive measurement techniques for measuring partial pressure of contaminant gases, this research may lead to a new generation of humidity measurement techniques and primary standards for concentrations as low as 1 in $10^{9}$.

Contacts:

J. Patrick Looney

(301) 975-4806

email: john.looney@nist.gov

A55 Metrology Building

Joseph Hodges

(301) 975-2605

email: joseph.hodges@nist.gov

A303 Physics Building 


\section{STANDARDS FOR RAMAN SPECTROSCOPY}

A new program has been implemented that draws on the expertise and resources in Raman spectroscopy of the Process Measurements Division, the Analytical Chemistry Division, and the Surface and Microanalysis Science Division of CSTL to respond to the Raman community's request for NIST to provide much-needed practical standards for analytical Raman spectroscopy. It is widely acknowledged that major advances in analytical Raman instrumentation have virtually revolutionized Raman spectroscopic measurements, and Raman spectroscopy now is finding its place in the industrial environment for process measurements and quality control. Unlike in infrared spectroscopy, in Raman spectroscopy the intensity of the analytical signal is not calibrated as part of the measurement. Consequently, relatively few published spectra have been corrected for the typical variations in the instrument response function, and there are no widely available standardized Raman spectral libraries. The lack of accepted practices, standards, and spectral libraries has been a main obstacle to the acceptance of Raman in industrial settings and is a barrier to its use in the regulated industries.

The new research undertaken here is concerned with critically evaluating presently existing approaches to the standardization of Raman measurements and aims to develop new methods and techniques so that calibration of Raman spectrometers can be reliably accomplished for both the signal intensity and for the Raman shift frequency. One approach will consist of the evaluation of the laser-excited fluorescence spectra of rare-earth doped glasses to provide broadband and narrow-band emissions over the common Raman spectral domains. These results will lead to the certification of a set of Standard Reference Materials traceable to NIST primary radiometric standards. While fluorescence can be exploited for intensity calibration, a more fundamental approach will rest upon the determination of absolute Raman cross-sections, which can provide an absolute intensity calibration that is verifiably instrument independent. Work is planned to develop a Raman gain spectrometer for the measurement of the Raman crosssections of judiciously chosen liquids and solids that may serve as absolute Raman intensity standards. One thrust of the program is the close coordination of this standards work with the objectives of various organizations outside of NIST including the ASTM Committee for Raman Spectroscopy, which has adopted a set of Raman standards initiatives. Close contacts are maintained with the Raman community of major chemical industries and several regulatory agencies. These liaisons are intended to provide opportunities for collaborative work through appropriate cooperative agreements.

\section{Contacts:}

Wilbur S. Hurst

(301) 975-4814

email: wilbur.hurst@nist.gov

B312 Physics Building

Steven J. Choquette

(301) 975-3096

email: steven.choquette@nist.gov

A213 Chemistry Building

\section{SURFACE AND MICROANALYSIS SCIENCE}

\section{Division Contact:}

Rance A. Velapoldi

(301) 975-3917

email: rance.velapoldi@nist.gov

fax: (301) 216-1134

B364 Chemistry Building

www-sims.nist.gov/Division/837home.html

\section{MICROBEAM ANALYSIS}

The macroscopic properties and behavior of a wide variety of physical, biological, and technological phenomena are controlled by chemical events that occur on the microscale. Microbeam analysis techniques based on beams of electrons, ions, and photons can achieve lateral and depth resolution ranging from the micrometer to the nanometer scale, which is equivalent to a sample mass of picograms down to zeptograms. NIST performs research in many aspects of the measurement science of microbeam analysis. This research develops standards, data, and standard methods to meet the critical need for chemical measurements that can provide quantitative information on small variations in composition or structure. The role of trace constituents distributed in microstructures (often at levels of 1 part in $10^{6}$ to 1 part in $10^{9}$ ) in controlling, for example, device properties is studied through techniques that can achieve trace nanoanalysis, which combines trace fractional sensitivity with nanometer-scale resolution. Measurement of the atoms (elements) present in a microstructure is complemented by techniques that determine the molecular (chemical) forms present, as well as the arrangement of atoms and molecules into crystallographic forms. 
The need to visualize lateral compositional distributions quantitatively has been the subject of an extensive effort to develop compositional mapping, in which the result is in the form of an image where the gray or color level is directly related to numerical concentration. Initially developed for picture elements (pixels) in two lateral dimensions, current efforts seek to extend compositional mapping to threedimensional volume elements (voxels), a capability needed to meet the challenges posed by advanced technologies such as giga-scale electronics and microelectromechanical systems (MEMS).

Instrument resources available in the NIST microanalysis research and analytical microscopy groups include scanning electron microscopes (conventional, electron probe X-ray microanalysis, environmental, and field emission), high-voltage transmission analytical electron microscopes (conventional and field emission, with $\mathrm{X}$-ray and electron energy loss analytical spectrometries), an electron-optical/X-ray optical bench, and secondary ion mass spectrometers (ion microprobe, ion microscope, and laser microprobe with magnetic sector or time-of-flight mass spectrometers). Also available are conventional and Fouriertransform Raman optical microprobes; Fourier-transform infrared microscopy; $\mathrm{X}$-ray diffraction, including capillary optic $\mathrm{X}$-ray microfocusing facilities from conventional X-ray tube and high-brightness rotating anode X-ray sources; and extensive facilities for computer-aided microscopy and analysis, sample synthesis, and sample preparation.

\section{Contacts:}

David S. Simons

(301) 975-3903

email: david.simons@nist.gov

Eric B. Steel

(301) $975-3902$

email: eric.steel@nist.gov

A113 Chemistry Building

\section{ATMOSPHERIC AND CHEMOMETRIC RESEARCH PROCESSES}

Concern is mounting worldwide over environmental contamination and wastes, atmospheric pollution, and potential effects on health and climate. It is imperative to determine with a high degree of accuracy the individual sources of pollutant species. State-of-the art research, pioneered at NIST', makes possible unique source identification by application of the most advanced microchemical and isotopic analytical techniques, including accelerator mass spectrometry and high-precision gas isotope ratio mass spectrometry. The data obtained provide city, state, and national governments with a unique opportunity to develop and test control strategies to reduce emissions of the identified pollutant sources.

Complementing advanced isotopic-chemical characterization of atmospheric gases and particles is basic research in chemometrics, which represents the synthesis of chemical knowledge and measurement with modern statistical and computational methods. Work in this area is directed toward improving the quality of chemical measurements generally through advanced design, measurement and data analysis quality assurance, and graphical multivariate data exploration.

Contacts:

R. Michael Verkouteren

(301) 975-3933

email: michael.verkouteren@nist.gov

Lloyd A. Currie

(301) 975-3919

email:1loyd.currie@nist.gov

B364 Chemistry Building
Understanding the processes that occur at surfaces and interfaces, such as the interactions of adsorbates with substrates, is critical for describing and controlling reactions at these locations. This understanding can lead to new procedures that are fundamental in tailoring surfaces to produce nanoscale structures, decrease wear and corrosion, or to develop new electronic devices, catalysts, or layered materials with improved properties. To address these important technological areas, NIST scientists are utilizing laser radiation, proximal probes, chemical radicals, and charged particles to study the fundamental atomic and molecular processes that are characteristic of a broad spectrum of surfaces and interfaces. These studies provide information on electronic structure, topography, chemical reactivity, and the mechanisms of energy transfer. These techniques are applied in experiments with substrates of metals, semiconductors, insulators, and oxides as well as with selected deposited films of polymers, oxides, and biomimetic systems.

The investigations of these processes have progressed from large spatial scales using femtosecond laser spectroscopy and other surface interrogative techniques to spatial scales on the order of tens of nanometers with the current development of infrared, near-field optical spectroscopic techniques. These experimental techniques are complemented by the development of theories that pull together diverse ideas to provide comprehensive, focused explanations of the processes, which, in turn, lead to new experimental designs and research.

\section{Contact:}

Richard R. Cavanagh

(301) 975-2368

email: richard.cavanagh@nist.gov

B248 Chemistry Building 


\section{PHYSICAL AND CHEMICAL PROPERTIES}

Division Contacts:

Richard F. Kayser

(301) 975-2483

email: richard.kayser@nist.gov

fax: (301) 869-4020

A111 Physics Building

William M. Haynes

(303) 497-3247

email: haynes@boulder.nist.gov

fax: (303) 497-5044

Mailcode 838.00

Boulder, Colo. 80303-3328

http://properties.nist.gov

\section{FUNDAMENTAL}

PROPERTIES OF TRACE COMPONENTS OF NATURAL GAS

Natural gas is a complex mixture that can consist of between 300 and 400 organic and inorganic components, many of which are present at relatively low (trace) concentrations. Most of these materials are naturally occurring, while some are intentionally added during processing. The properties of many of these trace constituents are important since they can strongly affect the overall behavior of the natural gas. NIST researchers recently have completed measurements on the vapor pressure and the enthalpy of adsorption (on pipeline surfaces) of a family of chlorinated trace constituents. The vapor pressure studies were done on three pieces of equipment that were specifically constructed for measurements on involatile compounds. The enthalpic measurements were carried out on a modified gas chromatographic apparatus.
Current work is concerned with standardizing the extended analysis of natural gas through the use of measured chromatographic retention indices. The researchers have constructed dedicated chromatographic instrumentation specifically to provide the accuracy required for these measurements. This will facilitate component identification for custody transfer and calorific value calculations. They also are measuring the diffusion of odorants (strongsmelling sulfur compounds added to aid in detection) in natural gas. These measurements are performed on a Taylor-Aris apparatus that was constructed for high-pressure fluids. This work will provide a fundamental understanding of odorant fading, a problem that often occurs during winter months.

\section{Contact:}

Thomas J. Bruno

(303) 497-5158

email: bruno@boulder.nist.gov

Mailcode 838.01

Boulder, Colo. 80303-3328

\section{FUNDAMENTAL AND APPLIED PROPERTIES OF ADSORBENTS}

The industrial consumption of adsorbents for separation processes is in the range of a megaton per year. These adsorbents include silicas, aluminas, carbons, and zeolites, and their uses range from commodity chemical separations to small-scale environmental applications. An understanding of the properties of these materials is vital to efficient separation process design and operation. A NIST research program is focused on the measurement and modeling of fundamental parameters such as the enthalpy of adsorption and adsorption isotherms (which are measures of the attraction of a chemical on an adsorbent) and the skeletal density (a measure of the ultimate capacity) of adsorbents. NIST has designed and constructed apparatus for these measurements and has applied them to clay and carbon adsorbents.
The techniques also allow the study of the effects of surface modifications of adsorbents that are produced by compounds such as surfactants. These measurements are combined with surface observations obtained from neutron scattering and dynamic light scattering to elucidate the surface structure. This will permit design of novel special-purpose adsorbents, since the researchers will have a clear idea of what components or areas of an adsorbent structure are important for the separation process.

Contact:

Thomas J. Bruno

(303) 497-5158

email: bruno@boulder.nist.gov

Mailcode 838.01

Boulder, Colo. 80303-3328

\section{THERMOPHYSICAL PROPERTIES OF SUPERCRITICAL FLUID MIXTURES}

All facets of chemical process technology require an accurate knowledge (or reliable predictive capability) of various thermophysical and chemical properties of pure chemicals and their mixtures. This is especially true of separations because of the great diversity of chemicals involved, with widely varying molecular sizes, shapes, and polarity. In addition to this inherent complexity, industry now is exploring the application of alternative solvents for separation processes because many traditional solvents have environmental and health risks associated with their use. This project explores the modeling of processes using alternative solvents through multivariate statistical analysis incorporating a number of empirical and semi-empirical chemical and thermophysical variables as input. 
Work is in progress to extend significantly the Kamlet-Taft solvatochromic chemical parameters to the alternative solvents in the subcritical and supercritical phases. Both chemical and thermophysical variables are incorporated into a multivariate statistical model to better predict solution processes of industrially relevant compounds in the alternative solvents. This requires the experimental determination of acidity, basicity, polarity, polarizability, and density of potential solvents. These measurements are performed spectroscopically. In addition to providing a predictive approach to solvent behavior, this work provides insight into understanding of the solution process itself. In addition to the spectroscopic-based techniques mentioned earlier, a magnetic levitation solubility instrument is being developed to measure phase equilibria of mixtures not amenable to spectroscopic measurement.

\section{Contact:}

Thomas J. Bruno

(303) 497-5158

email: bruno@boulder.nist.gov

Mailcode 838.01

Boulder, Colo. 80303-3328

\section{FUNDAMENTAL PROPERTIES FOR MEMBRANE SEPARATIONS}

Membranes are used increasingly in separation and novel synthesis processes and as components of process sensors. To add to the science and engineering base of membrane technology, NIST is working on methods of measuring and correlating chemical and morphological structure with gas and vapor transport-property relationships in both phase-separated polymers and homopolymers. Ionomers, interpenetrating polymer networks, and polymer blends are examples of the former. The linchpin of this effort is obtaining consistent and accurate measurements of solubility and permeability for a variety of gases and gas mixtures in novel polymers that can be chemically or morphologically altered in a systematic way. These data then can be used as starting points for developing molecular-level prediction of transport properties.

\section{Contact:}

John Pellegrino

(303) 497-3416

email: jjp@boulder.nist.gov

Mailcode 838.01

Boulder, Colo. 80303-3328

\section{THERMOPHYSICAL} PROPERTIES OF GASES

Thermophysical properties of gases are required to design heat transfer machinery and chemical processes. NIST obtains very accurate values for these properties (equation of state, heat capacity, thermal conductivity, viscosity, and speed of sound) by exploiting high-Q acoustic resonators developed and modeled at NIST.

NIST routinely measures the speed of sound in gases with uncertainties of less than \pm 0.01 percent. NIST data were used to determine the thermodynamic properties of more than 20 environmentally benign, candidate replacement refrigerants and of heliumxenon mixtures used in thermoacoustic refrigerators. To extend these measurements to corrosive gases and gases at very high temperatures, NIST developed acoustic wave guides to conduct sound from remote transducers into and out of resonators through corrosion-resistant metal diaphragms. NIST also developed novel acoustic resonators for measuring the viscosity and thermal conductivity of gases with an imprecision of 0.1 percent.
NIST is using acoustic measurements of the highest possible accuracy to measure the imperfections in the internationally accepted temperature scale (ITS-90) in the range 200 kelvin to 700 kelvin. For this work, the speed of sound in argon is measured with an imprecision of 0.0001 percent in a spherical resonator. The thermal expansion of the resonator is measured using microwaves. To maintain the purity of the argon at 700 kelvin, clean argon continuously flows through the resonator with a pressure that is controlled to 1 part in $10^{6}$.

\section{Contact:}

Michael R. Moldover

(301) 975-2459

email: michael.moldover@nist.gov

A105 Physics Building

\section{THERMOPHYSICAL PROPERTIES OF SEMICONDUCTOR PROCESSING GASES}

Mass flow controllers (MFCs) deliver process gases for plasma etching, chemical vapor deposition, and other processes used throughout the semiconductor industry. The operation of the most widely used kind of MFC depends upon heat transfer through the process gas; thus, the sensitivity of these MFCs depends upon the thermophysical properties of the process gas, and each gas requires a different MFC calibration. However, many process gases are toxic, corrosive, and/or pyrophoric, making it impractical to calibrate directly all MFCs for all 50 or so process gases.

An alternative to direct calibration is based upon flowing benign "surrogate" gases (such as $\mathrm{N}_{2}, \mathrm{CF}_{4}$, $\mathrm{SF}_{6}$, or $\mathrm{C}_{2} \mathrm{~F}_{6}$ ) through the MFCs and scaling the MFCs' response to account for the differences between the thermophysical properties of the surrogate gas 
and those of the process gas. The relevant gas properties are density, heat capacity, thermal conductivity, and viscosity. These should be known throughout the temperature and pressure ranges in which MFCs operate. NIST is exploiting its expertise in acoustic technologies to measure the thermophysical properties of the four process gases $\left(\mathrm{Cl}_{2}, \mathrm{HBr}, \mathrm{BCl}_{3}\right.$, and $\left.\mathrm{WF}_{6}\right)$ and the three surrogate gases ( $\mathrm{CF}_{4}, \mathrm{SF}_{6}$, and $\mathrm{C}_{2} \mathrm{~F}_{6}$ ) that were identified by the semiconductor industry as having the highest priority.

Contact:

Michael R. Moldover

(301) 975-2459

email: michael.moldover@nist.gov

A105 Physics Building

\section{CHEMICAL}

\section{THERMODYNAMICS}

The Chemical Thermodynamics Data Center carries out expert evaluations of thermodynamic data on organic and inorganic compounds. In addition to the Joint Army/ Navy/Air Force Tables, current interests include comprehensive evaluations of thermodynamic data related to atmospheric chemistry, such as the destruction of the stratospheric ozone layer, and of data for organic compounds important to the chemical and related industries. The latter work has the long-range goal of producing reliable estimation schemes for predicting the properties of species for which measurements are not available or would be difficult or impossible to perform. In planning and executing its programs, NIST maintains close contact with industrial organizations such as the Design Institute for Physical Properties Data.

NIST researchers use precision oxygenbomb and fluorine-bomb calorimeters to determine data on enthalpies of combustion, from which enthalpies of formation can be derived. The addition of a new lowtemperature heat capacity calorimetry facility now gives the NIST thermodynamics laboratories the capacity to carry out the full range of measurements necessary to determine chemical equilibrium constants for systems of interest. The focus is on the determination of thermodynamic properties of materials important to modern technologies such as chemical process modeling and simulation and semiconductor processing, as well as on the certification of calorimetric Standard Reference Materials.

\section{Contacts:}

Robert Huie

(301) 975-2559

email: robert.huie@nist.gov

A261 Chemistry Building

$$
\begin{aligned}
& \text { Gary Mallard } \\
& \text { (301) 975-2564 } \\
& \text { email: gary.mallard@nist.gov } \\
& \text { A111 Physics Building }
\end{aligned}
$$

\section{CHEMICAL KINETICS}

The chemical kinetics program at NIST provides reliable measurement methods, chemical kinetics data, and theoretical models. Applications of this research include combustion, plasma processing, new chemical and energy-related technologies, environmental chemistry, effects of ionizing radiation on materials, and analytical applications of kinetics. Among the experimental projects under way are high-pressure mass spectrometric studies of the kinetics and thermochemistry of ion/molecule reactions and clustering processes and pulse radiolysis of aqueous solutions. Researchers also are studying free-radical kinetics using heated single-pulse shock tubes and flashphotolysis kinetic-absorption and resonancefluorescence techniques.
At present, there is significant emphasis on developing and using cavity-ring-down laser absorption spectroscopy to study chemical kinetics in the gas phase and at surfaces. In addition, this group uses resonanceenhanced multiphoton ionization spectroscopy to provide very sensitive and selective schemes for the optical detection of free radicals and to acquire new, previously unobtainable data about their electronic structures. An important focus of the kinetics program is the production of databases of evaluated chemical data, including kinetic data and spectral data for analytical chemistry, as well as the design of databases and relevant software.

Contacts:

Robert Huie

(301) 975-2559

email: robert.huie@nist.gov

A261 Chemistry Building

Gary Mallard

(301) 975-2564

email: gary.mallard@nist.gov

A11 Physics Building

\section{COMPUTATIONAL CHEMISTRY}

The quality and efficiency of chemical processing, including shrinking the timelines for industrial process scale-up and optimizing processes to maximize yields and minimize unwanted wastes and byproducts, can be greatly enhanced through computer simulation.

However, reliable simulation of chemical processes often is inhibited by the lack of accurate chemical and physical property data for individual molecular species, mixtures, and reactions. Industrial scientists and engineers are beginning to look to quantum chemistry as a source of timely and cost-effective estimates of needed property data. This has generated an intense need for systematic testing, evaluation, and benchmarking of quantum chemistry methods in 
order to establish the accuracy, reliability, applicability, and relative merits of different computational tools or approaches for different problems.

The computational chemistry group is developing databases and computational archives that will function as a resource for scientists and engineers who want to compare the economics and accuracy of various computational methods for estimating properties. Current efforts are focused on thermochemical and kinetic properties. State-ofthe-art computational methods are developed, tested, and evaluated. Benchmark comparisons are made against accurate experimental data for classes of chemical compounds and reactions. Databases of computational and experimental comparisons are developed in order to provide reliable estimates of the accuracy and precision of well-defined computational methods.

Long-range interests include the development of computational methods for predicting reaction mechanisms and reaction rates in solution; the development of more accurate methods for determining the structures and thermodynamic properties of large molecules; the development of new hybrid quantum chemistry methods with empirical corrections for predicting thermochemical properties; the development of robust density functional methods that are applicable to transition states; and the development and testing of quantum chemistry methods for molecules containing heavy atoms.

Contact:

Walter J. Stevens

(301) 975-5968

email:walter.stevens@nist.gov

A111 Physics Building

\section{PRESSURE-DEPENDENT CHEMICAL REACTIONS}

While many chemical reactions proceed at rates that are independent of pressure, there is a group of important reactions that have pressure-dependent rate constants. A number of theories have been used to explain and predict the rates of these reactions, but none has been successful for some of the most complex reactions. It is often these very complex reactions, with multiple pathways, that are important in understanding how complex mixtures such as gasoline react at high temperatures.

Work at NIST has provided a new way to calculate these rate constants so that the many pathways that are observed in these reactions can be predicted. This work is important in the analysis of the experimental data from these complex reactions as well as in providing the fundamental understanding of how to use modern quantum mechanical calculations to predict the pressure dependence of these reactions. These calculations have been used to reinterpret older experimental data to derive fundamental thermochemical information. More importantly, the work has led to a better understanding of the role of highly energetic species formed in recombinations.

The theoretical results are being applied in a number of practical reacting systems. The destruction of chemical weapons, the decomposition of hydrocarbons in complex mixtures, and the reactions involved in chemical vapor deposition have been studied using these new techniques. In each case, better and more consistent models have been created using these new tools.

Contacts:

Wing Tsang

(301) 975-2507

email: wing.tsang@nist.gov

Gary Mallard

(301) 975-2564

email: gary.mallard@nist.gov

A111 Physics Building

\section{INFORMATION FOR MODERN CHEMISTS}

The amount of information available in chemistry has grown steadily. The tools needed to access this information have not evolved as rapidly as the technical community's need to find the larger amounts of data. NIST has developed a tool to provide access to the chemical data over the Internet. Using the conventions of the World Wide Web, the NIST Chemistry WebBook (http://webbook.nist.gov) is providing a growing audience with thermochemical, thermophysical, and spectral data for a large set of substances.

The goal of the WebBook is to provide a single point of access to all NIST chemical data. The current edition contains data for more than 20,000 molecules. Data from NIST archival collections used in developing evaluated data, NIST evaluated data, archival data from non-NIST sources, and evaluated data from non-NIST sources are provided. Every data item is individually referenced, and cross-references by author, research paper, and other molecules are provided. The WebBook is designed to be easy to use, even for novice users. For example, users can search for molecules by name, molecular formula, and partial molecular formula, as well as by property values. Data can be graphed and the resulting graphs expanded for more detail. This is especially useful for complex spectral data such as infrared spectra.

\section{Contacts:}

Peter Linstrom

(301) 975-5422

email: peter.linstrom@nist.gov

Gary Mallard

(301) 975-2564

email: gary.mallard@nist.gov

A111 Physics Building 


\section{NIST/EPA/NIH MASS SPECTRAL DATABASE}

One of the most widely used techniques for identifying organic compounds is gas chromatography/mass spectrometry. In this technique, complex mixtures of chemicals are separated using gas chromatography, and then each compound is "fingerprinted" using the mass spectrometer. The resulting spectra are analyzed and compared to a library of known spectra. To be successful, the library of known spectra must have only high-quality, complete spectra, and the algorithms used to compare the library and unknown spectra must be robust and well tested.

NIST programs develop and test algorithms for matching and predicting, evaluate spectra from other contributors, and fill in missing data with an ongoing experimental effort. The goal is to develop a mass spectral database containing every compound in commerce. The result of these efforts is an increasing acceptance of the NIST database and algorithms as the standard. In addition to the experimental, evaluation, and algorithmic development work, NIST promotes the use of high-quality tools within the mass spectrometry instrument community.

\section{Contacts:}

Stephen E. Stein

(301) 975-2505

email: stephen.stein@nist.gov

Gary Mallard

(301) 975-2564

email: gary.mallard@nist.gov

A111 Physics Building

\section{PROPERTIES OF ALTERNATIVE REFRIGERANTS}

Chlorofluorocarbons (CFCs) and hydrochlorofluorocarbons (HCFCs) have been used widely for the past 50 years as refrigerants, as foam-blowing agents, and in many other applications. Recent evidence has shown, however, that CFCs and, to a lesser extent, HCFCs, are breaking down the stratospheric ozone layer that protects the Earth from harmful levels of ultraviolet radiation. These fluids also contribute to greenhouse warming. Alternative chemicals must be found to replace the existing fluids as quickly as possible. To replace the CFCs and HCFCs, accurate knowledge of the thermophysical properties of the substitutes is required.

NIST provides these data to industry. Research includes extensive experimental measurements on pure fluids and mixtures, including saturation and single-phase densities, vapor pressure, heat capacity, thermal conductivity, viscosity, sound speed, and surface tension. The program includes a substantial effort in modeling fluid properties and in developing equations of state. NIST also leads efforts to arrive at international standards for refrigerant properties.

Contacts:

William M. Haynes

(303) 497-3247

email: haynes@boulder.nist.gov

Mailcode 838.00

Mark 0. McLinden

(303) 497-3580

email: mark.mclinden@nist.gov

Mailcode 838.07

Boulder, Colo. 80303-3328

\section{THERMOPHYSICAL PROPERTIES OF NATURAL GAS SYSTEMS}

A comprehensive experimental and modeling research program is focused on the thermophysical properties of natural gas systems needed by the gas industry for custodytransfer operations, for energy optimization in gas industry operations, and for the design and control of gas processes. Major goals of the program are to develop the means to accurately model and predict the thermodynamic, phase equilibrium, and transport properties of complex fluid mixtures that contain hydrocarbons to $\mathrm{C}_{20+}$; other constituents such as carbon dioxide, nitrogen, and hydrogen sulfide; and trace constituents such as water, helium, hydrogen, carbon monoxide, argon, oxygen, and others. The program is designed to provide state-of-the-art measurements on selected systems needed to support the modeling efforts. These models and data cover the ranges of temperature ( 90 kelvin to $700 \mathrm{kel}-$ vin), pressure ( 70 megapascals), and composition (full range) necessary for efficient operation of the gas industry, with emphasis on the major region for custody transfer operations. The models cover all fluid states (gas, vapor, and liquid), including properties along phase boundaries, and can be used to calculate the properties of natural gas; liquefied natural gas; natural gas liquids; substitute/synthetic natural gas; compressed natural gas, and wet, dry, and sour gases.

Research includes extensive experimental measurements on both pure fluids and mixtures, including saturation and single-phase densities, vapor pressures, heat capacities, sound speeds, thermal conductivities, and viscosities. Vapor-liquid and solid-fluid 
phase boundaries also are studied. A substantial modeling effort involves the development of highly accurate mixture models and pure fluid equations of state. A new generalized mixture model, based on the excess Helmholtz energy and standard reference quality formulations for the constituents, shows promise to be the most accurate model available for mixture properties. These models are incorporated in computer databases that serve as the major mechanisms for technology transfer of the data to industry. NIST also participates in efforts to arrive at national and international standards for natural gas properties.

Contact:

William M. Haynes

(303) $497-3247$

email: haynes@boulder.nist.gov

Hailcode 838.00

Boulder, Colo. 80303-3328

\section{PROPERTIES OF FLUIDS AND FLUID MIXTURES}

The thermophysical properties of fluids and fluid mixtures are essential for process design and control in the chemical, natural gas, aerospace, environmental, and energyrelated industries. The research program in fluid properties involves experiniental and theoretical research and computer simulation studies on the thermodynamic and transport properties of pure fluids and fluid mixtures. A primary goal of this program is to develop highly accurate predictive models for the thermophysical properties of fluids and fluid mixtures. This is accomplished through an integrated program of measurement, theory, and correlation. Apparatus are available for state-of-the-art measurements of the thermodynamic and transport properties of pure fluids and mixtures, including pressure-volume-temperature relations, speed of sound, heat capacity, dielectric constant, viscosity, phase equilibria, and thermal conductivity over wide ranges of temperature and pressure. Included in this work are measurements in the critical and extended critical region. In concert with the experimental work, NIST researchers conduct theoretical studies to develop widerange predictive models and computer codes.

A wide variety of research, both experimental and theoretical, is directed toward the understanding of complex fluid behavior, the microscopic structure of fluids, and the liquid-solid phase boundary. Included are studies of non-Newtonian fluids, colloidal suspensions, shear-induced chemical reactions, supercooled fluids and melting phenomena, and macromolecules. A unique shearing cell is available for neutron scattering studies at the NIST Center for Neutron Research.

Molecular-level computer simulation has proved an essential technique for utilizing statistical mechanics-based models of condensed matter. Molecular dynamics studies, involving both equilibrium and nonequilibrium systems, have been conducted. Computer simulation studies are important in interpreting and understanding the results of experimental studies in fluids and in developing predictive models of fluid properties. Other theoretical studies include dynamic and static critical region models (emphasizing mixtures), extended corresponding states, equations of state, kinetic theory of gases and dense fluids, theory of the glassy state, properties of mixtures of dissimilar compounds, phase transitions, and structure-based modeling.

Contacts:

Daniel G. Friend

(303) $497-5424$

email: friend@boulder.nist.gov

Mailcode 838.08

Richard A. Perkins

(303) $497-5499$

email:perkins@boulder.nist.gov

Mailcode 838.07

Boulder, Colo. 80303-3328

\section{PROPERTIES OF GELS, MICELLES, AND CLAYS}

NIST researchers are using small-angle neutron diffraction, static visible laser-light scattering, dynamic time-correlation spectroscopy, and computer simulation to study the structure and properties of systems containing particles with sizes in the range of 10 nanometers to 1000 nanometers. In addition to the fundamental information being obtained about complex fluids, these suspensions are interesting in their own right. For example, sol/gel technology is being used increasingly in the production of ultrahighpurity optical glasses. Using neutron diffraction and computer simulation, NIST scientists are improving understanding of the formation dynamics and structure of the precursor gel (a state of matter intermediate to liquid and solid). Dynamic light scattering studies, coupled with experiments using neutron scattering, also are being used to better understand the interaction between surfactant micelles and clay platelets. This will improve understanding of how organic pollutants interact with clay. Current activities include the study of colloidal silica solutions, gelation of silica at high volume fraction, cationic surfactant micelles, and adsorption of large organic molecules on suspended and dispersed clay platelets. 
Much of this research is directed toward understanding complex fluids. The characteristic time scales governing the dynamics of colloidal solutions are many orders of magnitude slower than in molecular fluids. Colloidal solutions thus provide NIST scientists with experimentally accessible models for the study of complex fluid behavior. Non-Newtonian fluid behavior is being studjed using the NIST Couette-flow shearing cell at the small-angle neutron scattering beam lines of the NIST Center for Neutron Research.

\section{Contacts:}

Howard J.M. Hanley

(303) 497-3320

email: hanley@boulder.nist.gov

Mailcode 838.00

Brent D. Butler

(303) 497-3952

email: bbutler@boulder.nist.gov

Mailcode 838.08

Boulder, Colo. 80303-3328

\section{DILUTE-SOLUTION} THERMODYNAMICS

Much chemical technology, particularly in the environmental area, involves solutions where the concentration of the substance of interest is near zero. The thermodynamics of these dilute solutions presents special challenges and opportunities. One area of interest is the solubility of substances in liquid solvents. Water is the most important solvent, but dilute-solution thermodynamics (usually in the form of Henry's law) is used in many different applications.
Recently, new theoretical understanding of the high-temperature behavior of Henry's constant has been exploited to produce an improved model for correlating Henry's constants over a wide temperature range and for extrapolation of existing data to higher temperatures. This project works toward using structural and other data to predict Henry's constants of organic compounds in water at conditions characteristic of air stripping and steam stripping operations. Dilute-solution thermodynamics also can be used to analyze the solubility of solids in vapors and supercritical fluids, which is important for a variety of processes, including extraction using $\mathrm{CO}_{2}$ and deposition of minerals in steam power plants. Modeling efforts focus on using the density of the solvent as the key variable. Molecular computer simulation is used to test the validity of modeling approaches.

Contact:

Allan H. Harvey

(303) 497-3555

email: aharvey@boulder.nist.gov

Mailcode 838.08

Boulder, Colo. 80303-3328

FINITE-ELEMENT MODELING OF COMPLEX PHYSICAL AND CHEMICAL PROCESSES

This group's objective is to elucidate the physicochemical details of industrial methodologies to provide a basis for improved processes, to provide quantitative information for selection among processing alternatives, and to uncover limiting factors in current approaches such as uncertainties in available property data or geometrically caused flow instabilities. The group is using the finite-element technique to simulate and analyze fluid flow with associated heat transfer, mass transfer, and chemistry. Two areas of current modeling research are organometallic vapor-phase epitaxy and fluid/solid-particle systems.

Contacts:

Adele P. Peskin

(303) 497-3466

email: adele@boulder.nist.gov

Gary R. Hardin

(303) $497-5168$

email: hardin@boulder.nist.gov

Mailcode 838.08

Boulder, Colo. 80303-3328

\section{ADVANCED \\ LOW-TEMPERATURE REFRIGERATION}

Many new and developing technologies rely on the use of cryogenic temperatures. Some of these technologies include the cooling of infrared sensors for night vision, atmospheric studies, and process monitoring; semiconducting and superconducting electronics for increased speed and reduced noise; cryopumps for the production of clean vacuums in semiconductor processing; magnetic-resonance imaging superconducting magnets; some medical catheters; and the liquefaction of natural gas for a clean-burning transportation fuel. Specialized refrigerators known as cryocoolers are required to reach cryogenic temperatures. Significant research and development of cryocoolers has occurred in the last 15 years to meet the reliability, cost, and efficiency requirements of many different applications.

NIST has been a world leader in this advanced refrigeration field and has led the development of a new type of cryocooler, known as the orifice pulse tube refrigerator (OPTR), that is being considered for all of the applications discussed above. In its normal configuration, it has only one moving part at room temperature and can reach temperatures below 40 kelvin in a single stage. Using thermoacoustic drivers in place 
of mechanical compressors, NIST and Los Alamos National Laboratory scientists developed an OPTR that became the first cryogenic refrigerator with no moving parts. A patent, a Strategic Defense Initiative Office innovative technology award, and an R\&D 100 award have been received for this device, called a TADOPTR. NIST has collaborated with dozens of companies and other government laboratories to transfer this and other new cryocooler technologies into specific application areas. NIST computer models on regenerator performance are used extensively in the field to aid in the optimization of regenerative cryocoolers.

NIST researchers have done substantial research on many types of cryocoolers to improve their technologies so they may be useful for various applications. In the area of Joule-Thomson refrigerators, NIST scientists have performed adsorption isotherm measurements for many different gases on various carbons. This extensive database is used by government and private laboratories in the design of adsorption compressors for cryocoolers.

\section{Contact:}

Ray Radebaugh

(303) $497-3710$

email: radebaugh@boulder.nist.gor

Mailcode 838.09

Boulder, Colo. 80303-3328

\section{ANALYTICAL CHEMISTRY}

Division Contact:

Willie E. May

(301) 975-3108

email:willie.may@nist.gov

fax: (301) 926-8671

B158 Chemistry Building

www.cstl.nist.gov/nist839

\section{INORGANIC AND ELEMENTAL ISOTOPIC METROLOGY}

NIST researchers are improving and apply-

ing high-accuracy and precision isotope ratio measurements for isotope dilution mass spectrometry (IDMS), as well as identifying and tracking species with unique isotopic signatures. Available instrumentsinductively coupled plasma (ICP-MS), thermal ionization, and laser resonance ionization mass spectrometers - have diverse capabilities. Research programs are possible in elemental, isotopic, and speciation measurement. Stable and radioisotopes can be applied to study environmental and health problems, materials, and processes.

Research can be directed to innovative development of instrumentation and methods, the characterization and interpretation of unique samples, or the determination of natural, absolute isotopic abundances.
Researchers are studying chemical separation schemes to eliminate ionization and isobaric interferences and to increase the speed and reliability of sample introduction. They also are investigating various schemes for quantitative analysis using ICP-MS for non-IDMS applications.

Contacts:

John D. Fassett

(301) 975-4109

email: john.fassett@nist.gov

A21 Physics Building

Gregory C. Turk

(301) $975-4118$

email: gregory.turk@nist.gov

B24 Physics Building

\section{FUNDAMENTAL STUDIES OF ATOMIC SPECTROSCOPY}

The continued development and improvement of analytical atomic spectrometry requires understanding of fundamental processes that occur in flames and plasmas. Researchers are investigating sampling, excitation, emission, and absorption phenomena in all types of flames, glow discharges, and other plasma sources useful in chemical analysis. Advanced approaches used in these studies include laser probes and mass spectrometry for enhanced ionization and resonance ionization studies, as well as ultrahigh resolution spectroscopic investigations using one of the few ultraviolet Fourier transform spectrometer systems in the world. Research opportunities include spectral characterization such as hyperfine structure and isotopic shifts, application of advanced computational methodologies, and energy transfer mechanism studies.

Contact:

Gregory C. Turk

(301) $975-4118$

email: gregory.turk@nist.gov

B24 Physics Building 


\section{ACCURACY OF SPECTROCHEMICAL ANALYSIS}

Instrumental methods of analysis require the control of a complex list of parameters to ensure accuracy. Furthermore, such methods of chemical analysis produce large quantities of multidimensional data that challenge the analyst's ability to interpret the results. Using both advanced approaches in automation to control experimental parameters and mathematical tools to optimize, sort, and summarize complex data sets, NIST researchers are designing studies to improve the accuracy of all forms of atomic spectrometry. Research is directed toward developing optimized and automated sample treatments and separation chemistries using microwave-digestion and flowinjection technologies. Automated approaches for instrument control, drift, and interference corrections also are employed. Multidimensional data generated by both rapid scanning and array detector spectrometers are analyzed using personal computers and NIST central computing facilities.

Contacts:

Marc L. Salit

(301) $975-3646$

email: marc.salit@nist.gov

Gregory C. Turk

(301) $975-4118$

email: gregory.turk@nist.gov

B24 Physics Building

\section{ANALYTICAL MASS SPECTROMETRY FOR ORGANICS AND BIOMIOLECULES}

Researchers are developing advanced techniques in mass spectrometry and applying them to the detection, identification, and accurate quantitation of trace levels of organic compounds. Available instrumentation includes a triple quadruple mass spec trometer with electrospray, cesium ion bombardment, positive- and negative-ion chemical ionization, and electron ionizafion; a magnetic mass spectrometer with capabilities for high resolution, fast atom bombardment, and linked scanning; and a liquid chromatograph/mass spectrometer with electrospray and atmospheric pressure chemical ionization.

The group encourages research that is related to electrospray and other techniques suitable for coupling liquid chromatography or capillary electrophoresis to mass spectrometry, particularly if the work may lead to developing techniques for the quantitation of polar and non-volatile analytes in complex matrices. of particular interest are biomolecules that are markers for health status.

Research in understanding and applying ion trap technology to quantitative gas chromatography/mass spectrometry/mass specfrometry also is encouraged as is research into understanding and applying collisioninduced and surface-induced dissociation to analytical problems.

Contacts:

Michael J. Welch

(301) 975-3100

email: michael.welch@nist.gov

Edward White $V$

(301) 975-3101

email: edward.white@nist.gov

B208 Chemistry Building

\section{CHROMATOGRAPHY AND ELECTROMIGRATION TECHNIQUES}

Solute retention in chromatography and electromigration systems is the result of a complex assortment of molecular interactions between the solute, the stationary phase, and the mobile phase. The diversity of these interactions can be utilized to optimize separations by varying separation parameters such as stationary phase and/or mobile phase composition and column temperature. An understanding of these fundamental retention and selectivity mechanisms facilitates the optimization of separations in gas chromatography (GC), liquid chromatography (LC), supercritical fluid chromatography and extraction (SFC and SFE), and capillary electrophoresis (CE)

Recent research interests have focused on the synthesis and characterization of bonded stationary phases in LC and GC (e.g., monomeric/polymeric $\mathrm{C}_{18}$ phases and charge transfer phases in LC and liquid crystalline phases in GC), which offer unique capabilities for the separation of isomeric compounds or compound classes. Researchers are investigating solutestationary phase interactions using chromatographic and spectroscopic techniques and chiral interactions in LC, GC, SFC, and CE. In addition, NIST scientists are studying molecular modeling of solutes and stationary phases to investigate retention mechanisms and to correlate molecular descriptors with retention. They also are investigating solutematrix interactions in SFE.

\section{Contacts:}

Lane C. Sander

(301) $975-3117$

email: lane.sander@nist.gov

Stephen A. Wise

(301) 975-3112

email: stephen.wise@nist.gov

B208 Chemistry Building 


\section{NOVEL ANALYTICAL SEPARATION SCIENCE METHODOLOGY}

Researchers are developing new, innovative approaches to separate and detect trace-level organic species in complex natural matrices. One priority is the design, synthesis, and characterization of bonded stationary phases for liquid chromatography (LC), gas chromatography (GC), and supercritical fluid chromatography (SFC). They also are developing novel separation media/modes for electromigration separation techniques, e.g., capillary electrophoresis (CE), capillary gel electrophoresis, micellar electrokinetic capillary chromatography, and capillary electrochromatography. In another effort. they are developing on-line multidimensional separation techniques based on orthogonal methodologies (such as LC-GC, LC-CE, LC-LC, and GC-GC) and fast separation technology in GC, LC, SFC, and CE. They also seek application of existing separation modes in novel combinations (e.g., chiral separations in SFC and CE), design of new separation systems based on micellar and liposomal phases, antibody/antigen associations, and size-selective networks.

Research is under way on sensitive and/or selective detection systems for microcolumn separations, e.g., mass spectrometry, laser-excited fluorescence, thermal-lens absorbance, chemical reaction, and chemiluminescence approaches. They also are developing supercritical fluid extraction systems for probing the interactions of analytes and matrices and for on-line coupled extraction and chromatography. Researchers are investigating chromatographic and electrophoretic approaches for the measurement of physico-chemical properties such as octanol/water partition coefficients, aqueous solubilities, and vapor pressures. Another effort involves designing micro-fluidic systems for capillary flow injection analysis, electrophoresis, and electrochromatography. Research will emphasize applications to environmental, clinical, nutritional, and forensic disciplines.

\section{Contacts:}

Stephen A. Wise

(301) 975-3112

email: stephen.wise@nist.gov

Lane C. Sander

(301) 975-3117

email: lane.sander@nist.gov

B208 Chemistry Building

\section{SEPARATION SCIENCE TECHNIQUES FOR TRACE ORGANIC ANALYSIS}

Researchers are developing and applying separation techniques such as gas chromatography (GC), liquid chromatography (LC), supercritical fluid chromatography (SFC), and capillary electrophoresis (CE) for trace-level determination of organic and organometallic compounds. Researchers are developing extraction systems for selective removal of analytes from natural matrices, e.g., supercritical fluid extraction (SFE), pressurized fluid extraction (PFE), and microwave-assisted extraction. They also are developing chromatographic and electrophoretic approaches for sample preparation and clean-up and analyte preconcentration prior to analysis by $\mathrm{LC}, \mathrm{GC}, \mathrm{SFC}$, or $\mathrm{CE}$.
Another project seeks to develop off-line and on-line multidimensional separation procedures (e.g., LC-GC, LC-LC, SFE-GC, and LC-CE) to measure individual species in complex mixtures. NIST researchers are developing and using simuitaneous multiple and/or selective chromatographic and electrophoretic detection systems (e.g., mass spectrometric, electron capture, atomic emission, flame photometric, infrared, UV-visible diode array, fluorescence, electrochemical, and chemical reaction detectors) to enhance measurement selectivity or sensitivity or both. Recent activities have emphasized applications in environmental, clinical, and forensic areas, including the determination of environmental contaminants such as polychlorinated biphenyls, polycyclic aromatic hydrocarbons, pesticides, and organometallic species in natural matrices such as sediment, tissue, and air particulate material; nutrients such as vitamins and carotenoids in food and serum; drugs of abuse in urine and hair; and biomolecules such as proteins, peptides, and DNA fragments. Researcl opportunities exist within the division for the application of these separation techniques to trace inorganic analysis problems.

\section{Contacts:}

Stephen A. Wise

(301) 975-3112

email: stephen.wise@nist.gov

Michele M. Schantz

(301) 975-3106

email:michele.schantz@nist.gov

B208 Chemistry Building 


\section{HIGH-ACCURACY COULOMETRY}

The coulometry program entails a broad spectrum of research interests and activities, including improving the precision and accuracy of coulometric methods, determining chemical stoichiometry, redetermining physical constants (such as atomic weights, and the Faraday constant), and developing new methods and instrumentation including microcoulometry. The application of absolute coulometric methods to the standardization of primary chemical standards and to the calibration of other analytical techniques is also a prime concern. Instrumentation is available for constant-current and controlled potential coulometric measurements.

Contact:

Kenneth W. Pratt

(30I) $975-413 I$

email: kenneth.pratt@nist.gov

B324 Chemistry Building

\section{INORGANIC \\ ELECTROANALYTICAL CHEMISTRY}

Research interests encompass all areas of inorganic electroanalytical chemistry, with specific interests in fundamental studies of $\mathrm{pH}$, such as modeling the liquid junction potential; measurements of acid dissociation constants; theory and metrology of aqueous and non-aqueous electrolytic conductivity; high-precision coulometric research; and the development of electrochemical detection systems. NIST scientists give special attention to the development of novel electrochemical instrumentation and the application of electroanalytical techniques to matters of national importance. Instrumentation is available for precise $\mathrm{pH}$, electromotive force, conductimetric, coulometric, potentiometric, and voltammetric measurements.

\section{Contact:}

Kenneth W. Pratt

(301) 975-4131

email: kenneth.pratt@nist.gov

B324 Chemistry Building

\section{TRACE-GAS ANALYSIS}

Researchers are using Fourier transform infrared spectroscopy (FTIR), tunable diode laser adsorption spectroscopy, gas chromatography, electrochemical analysis, and other specialized analysis techniques to develop primary standard gas mixtures and to measure trace gases in air, the environment, stack emissions, and process streams. One goal is to analyze complex mixtures of gases emitted from process streams in real time using spectroscopic techniques.

Another is to develop a quantitative database of FTIR spectra of volatile organic compounds for use in remote monitoring. Researchers also are seeking to measure extremely low-level contaminant gases in ultrapure materials, to develop standards, and to analyze trace gases that are important in ambient atmospheric measurements. Additionally, researchers are pursuing analysis of environmentally important trace gases in air and from point sources and the development of very low concentration volatile organic standards.

\section{Contact:}

Franklin R. Guenther

(301) 975-3939

email: franklin.guenther@nist.gov

B156 Chemistry Building

\section{OPTICAL TECHNIQUES FOR TRACE-GAS ANALYSIS}

This project involves development of optical techniques for trace-gas analysis with applications in areas such as environmental and industrial process monitoring. Recent improvements in laser devices and data acquisition systems offer opportunities to extend highly sensitive spectroscopic techniques to detect and quantify the components of various gas mixtures. In particular, sensitive analytical detection techniques for molecules consisting of five or more atoms are desirable. Current approaches include Fourier transform infrared spectroscopy, tunable diode laser absorption spectroscopy, and polarization spectroscopy using a solidstate laser system.

Contacts:

Pamela M. Chu

(301) 975-2988

email:pamela.chu@nist.gov

B324 Chemistry Building

Franklin R. Guenther

(301) $975-3939$

email: franklin.guenther@nist.gov

B 156 Chemistry Building

\section{SPECTROSCOPY STANDARDS AND PROCESS ANALYSIS}

Spectrophotometers are important tools for quality assurance, process control, and regulatory compliance measurements. To ensure that these devices are performing properly, NIST' manufactures and certifies Standard Reference Material optical filters. Currently, NIST provides materials and filters to measure wavelength accuracy, assess photometric accuracy, and determine the amount of stray light in ultraviolet and visible spectrophotometers. NIST is conducting research to extend its offerings to the near-infrared 
region where Fourier transform nearinfrared (FT-NIR) spectroscopy and Fourier transform Raman (FT-Raman) spectroscopy have become viable, routine techniques, especially for process monitoring. NIST is investigating the use of FT-NIR in combination with FT-Raman to identify and quantify mixtures in sealed containers. An example is the quantitation of mixed oxygenates in sealed ampoules of reformulated gasoline. A future goal is the design and evaluation of a combined NIR/Raman instrument for realtime identification and quantitation of mixtures in a process stream.

Contacts:

John C. Travis

(301) 975-4117

email: john.travis@nist.gov

Steven J. Choquette

(301) 975-3096

email: steven.choquette@nist.gor

A213 Chemistry Building

\section{LABORATORY AUTOMATION TECHNOLOGY AND STANDARDS}

The thrust of this program is to develop, evaluate, and demonstrate new concepts that eventually can lead to the successful, routine application of laboratory automation. The full potential of automated chemical analysis systems has not been achieved because the process of interconnecting analytical and clinical chemistry laboratory devices remains resource-intensive and difficult. A general lack of interfacing standards, a dearth of instruments designed from a systems-use perspective, and an over-reliance on the anthropomorphic model further exacerbate the situation. To facilitate the automation of the analytical laboratory, standard methods for instrument-to-controller communication, device control, data and material transfer, and error and exception handling are needed to provide instruments with realistic plug-andplay interfaces. New instrument designs need to allow remote control, provide automated access to sample and material ports, and exhibit system-centric behavior.

Contact:

Gary W. Kramer

(301) 975-4132

email: gary.kramer@nist.gov

A213 Chemistry Building

\section{AUTOMATED SAMPLE PREPARATION AND SENSING}

Scientists often must prepare samples before analysis using extraction, digestion, or other isolation and purification techniques. NIST researchers are developing new chemistries, miniaturization approaches such as microfluidics, and automation for techniques such as supercritical fluid extraction, solidphase extraction, and flow injection. These automated sample preparation methods are being coupled with new and existing microseparation/detection schemes such as capillary electrophoresis, immunoassaybased techniques, and biosensors for real-time monitoring of chemical and biochemical reactions in flow- and batchprocesses. NIST's sensor research focuses on the development of inexpensive yet sensitive devices. Research involves the use of immobilized antibodies for attenuation, fluorescent, chemiluminescent, optoelectrochemical, and interferometric approaches to provide selectivity and detectability in microfluid assays. In addition, NIST is investigating the combination of microflow injection analysis and capillary electrophoresis with optical waveguide detection for laboratory-on-a-chip applications.

Contacts:

William A. MacCrehan

(301) 975-3122

email:william.maccrehan@nist.gov

Gary W. Kramer

(301) 975-4132

email: gary.kramer@nist.gov

A213 Chemistry Building

\section{ANALYTICAL INFOMETRICS}

To ensure that chemical information necessary for decision making can be provided in an efficient and timely manner, NIST is investigating all aspects of the measurement process, including experimental design; data validation, storage, and retrieval; chemometrics, multivariate statistics, and applied mathematics; data rectification and meta-analysis; quality control, assurance, and improvement; and instrument control and communications. Examples include multivariate infrared and Raman spectroscopy for characterization of organic mixtures using multivariate statistical models, graphical methods for analysis and presentation of interlaboratory comparison studies, development of standards for laboratory automation, and improved methods for evaluating and utilizing analytical measurement uncertainties.

Contact:

David L. Duewer

(301) 975-3935

email: david.duewer@nist.gov

A213 Chemistry Building 


\section{CHEMICAL ANALYSIS WITH NEUTRON BEAMS}

The use of prompt radiations from nuclear reactions is well established as a tool for elemental analysis and compositional mapping. Two techniques are used at NIST: neutron-capture prompt-gamma-ray activation analysis (PGAA) and neutron depth profiling (NDP). Each employs both thermal- and cold-neutron beams from the NIST Center for Neutron Research. PGAA is used to determine a suite of elements that are inaccessible by conventional neutron activation analysis, such as hydrogen, boron, carbon, and nitrogen, as well as those with large capture cross sections, such as cadmium, gadolinium, and mercury. NDP measures the depth distribution of nuclides that emit charged particles on slowneutron capture. Researchers are developing methods with improved specificity, accuracy, sensitivity, and spatial resolution through detailed studies of the interaction of neutrons and their products with samples and detectors.

\section{Contacts:}

Richard M. Lindstrom

(301) 975-6281

email: richard.lindstrom@nist.gov

Robert R. Greenberg

(301) 975-6285

email: robert.greenberg@nist.gov

B125 NIST Center for Neutron Research

\section{NEUTRON ACTIVATION ANALYSIS}

Neutron activation analysis (NAA) provides the sensitivity, selectivity, and capability for multielemental determinations that are often required in studies involving the role of trace elements in biological, environmental, and materials analysis studies. Due to their unique capabilities, the various NAA techniques frequently play an important role in the certification of elemental concentrations in NIST Standard Reference Materials. The accuracy and precision of the various forms of NAA ultimately are limited by the precision of counting statistics that in favorable cases may be a few tenths of a percent. However, to achieve this level of accuracy, all other sources of error must be reduced to comparable levels. Experimental and computational studies address such matters as new and improved chemical separation procedures, neutron and gamma-ray interactions with analytical samples and detectors, high-accuracy neutron flux monitoring, high and varying count-rate gammaray spectrometry, peak integration routines, and gamma-ray and fast-neutron interferences. A variety of nuclear spectrometry equipment, laboratory facilities, personal and minicomputer facilities, and the irradiation facilities of the NIST Center for Neutron Research are available for this work.

\section{Contact:}

Robert R. Greenberg

(301) 975-6285

email: robert.greenberg@nist.gov

B125 NIST Center for Neutron Research
FOCUSING OF COLD NEUTRONS FOR ANALYTICAL MEASUREMENTS

The availability of long wavelength neutrons and recent advances in neutron optics provide an opportunity to design analytical probes for use in materials research. The purpose is to measure the concentration of the elements in a fine (sub-millimeter), two-dimensional array across the surface of a material. The detection limit of neutron absorption experiments will be improved by using optical elements to focus long wavelength neutrons onto small sample areas.

Different methods can be used to focus cold neutrons; the emphasis is on those based on the principle of total external reflection of neutrons at small grazing angles. These include polycapillary glass fibers, metal capillaries, nickel-coated conic sections of revolution, nickel-coated curved micro-guides, and curved channel plates. However, in all cases, focusing is achieved at the expense of increased angular divergence. Therefore, it is more useful for measurement techniques that are dependent only on the neutron capture reaction rate and not on collimation. Such a system would have an impact on the detection limits for absorption techniques such as prompt gamma activation analysis and neutron depth profiling.

Contacts:

David F.R. Mildner

(301) 975-6366

email: david.mildner@nist.gov

Heather Chen-Mayer

(301) 975-3782

email: h.chen-mayer@nist.gov

B125 NIST Center for Neutron Research 


\section{RESEARCH FACILITIES}

\section{FLUID FLOW} MEASUREMENT AND RESEARCH FACILITIES

The VIST flow measurement facilities are used to establish, maintain, and disseminate flowrate measurements, standards, and data for the wide range of conditions needed by U.S. industry and government agencies. Industry requests include flowmeter calibrations, special tests, round-robin testing programs to establish realistic traceability chains in the form of flow measurement assurance programs, data-generation programs for industrial groups and trade associations, and use of testbeds for carrying out industrial research programs focused on flow measurement topics.

The metering research facilities combine primary calibration techniques with the capability to conduct detailed survers of fluid flows that affect flowmeter performance. These capabilities include computational fluid dynamics (CFD) as well as laser Doppler velocimetry techniques used mainly in water flow facilities. CFD techniques include commercially available codes as well as specialized codes tailored to specific conditions.

\section{CAPABILITIES}

Fluid flow facilities enable a range of fluid and flow conditions in a wide range of pipe sizes:

- Water: maximum flowrate of 40000

L/min up to $0.5 \mathrm{~m}$ diameter with temperature near ambient and pressure up to 1.01 $\operatorname{MPa}(10 \mathrm{~atm})$.

- Hydrocarbon liquids having densities of $0.6-0.8 \mathrm{gms} / \mathrm{cc}$ and kinematic viscosities of 1-30 centistokes: maximum flowrate of 1600 $\mathrm{L} / \mathrm{min}$ in tubes and pipes up to $50 \mathrm{~mm}$ in diameter with temperature near ambient and pressure up to $1.01 \mathrm{MPa}$ (10 atm).

- Air: maximum flowrate of $85 \mathrm{~m}^{3}$ per minute in pipes up to $100 \mathrm{~mm}$ in diameter with temperature near ambient and pressure up to $3.55 \mathrm{MPa}$ (35 atm).

- Gas flows having variable composition and temperature: the component gases of auto exhaust with flows totaling $2.8 \mathrm{~m}^{3}$ per minute in 50-millimeter pipes and temperatures to $400^{\circ} \mathrm{C}$.

\section{APPLICATION}

These facilities are used to establish and maintain the national standards for fluid flowrate measurement systems to achieve orderliness in the marketplace, to produce satisfactory measurements for optimizing productivity in continuous industrial processes, and to monitor environmental quality. These facilities also are used to generate critical databases needed to initiate or update the national standards on generic fluid-metering topics. These standards are used for accurate custody transfer of fluid resources or products in the domestic and international marketplace or for studying critical industrial processes. Potential users are industries involved in the custody transfer of fluid resources and products, the chemical and petrochemical industries, the power and energy-generation industries, the auto industries, and government agencies such as NASA, the U.S. Department of Defense, and the U.S. Environmental Protection Agency.

\section{AVAILABILITY}

The facilities are available upon request to U.S. industry, other government agencies, and academia for collaborative research projects, including calibrations of flowmeters or other pipeline elements.

\section{Contact:}

George E. Mattingly

(301) 975-5939

email: george.mattingly@nist.gov

105 Fluid Mechanics Building

\section{LIQUID-NITROGEN FLOW MEASUREMENTS}

The liquid-nitrogen flow measurement facility serves as the national calibration facility for cryogenic flow measurement devices. The facility incorporates a dynamic gravimetric method to measure liquid nitrogen. Well instrumented for monitoring temperature, pressure, and time, the facility also is capable of determining volumetric flow rates. The facility is located completely indoors and is not subject to environmental changes.

\section{CAPABILITIES}

The facility has a flowrate range of approximately $1 \mathrm{~kg} / \mathrm{s}$ to $10 \mathrm{~kg} / \mathrm{s}$. The pressure can vary from $0.4 \mathrm{MPa}$ to $0.76 \mathrm{MPa}$ at temperatures between $80 \mathrm{~K}$ and $90 \mathrm{~K}$. In this closedloop flow facility, NIST researchers can establish and maintain stable flow conditions for extended test periods. For volumetric flow measurements, the density is determined by making pressure and temperature measurements and calculating density from an equation of state.

\section{APPLICATIONS}

The nitrogen flow facility is used primarily as a calibration facility for cryogenic flowmeters; however, it also can be used for developmental testing and evaluation. NIST researchers are able to vary the system parameters and evaluate flowmeter sensitivity to variables other than flowrate. Because they can accurately measure fluid properties as well as flowrate, the facility also can be used to evaluate pressure and temperature sensors associated with the flowmeters.

\section{AVAILABILITY}

Collaborative or proprietary programs for this test facility can be arranged. The facility must be operated by NIST staff.

\section{Contact:}

Jennifer L. Scott

(303) $497-3684$

email: jscott@boulder.nist.gov

Mailcode 838.07

Boulder, Colo. 80303-3328 


\section{ELECTRONICS AND ELECTRICAL ENCINEERING LABORATORY}

The Electronics and Electrical Engineering Laboratory (EEEL) provides the fundamental basis for all electrical measurements in the United States. In close consultation with industry, research and calibration programs are tailored to meet the most critical measurement needs for the manufacture and operation of electrical and electronic systems, including semiconductor, magnetic, radiofrequency, microwave, optical, optoelectronic, and superconducting equipment; flat-panel displays; electronic instrumentation; and electrical power apparatus and systems.

Other programs are concerned with basic research to develop quantum standards that enable more accurate maintenance of the fundamental electrical units. Laboratory researchers also conduct studies on the new measurements needed for the successful development of promising future technologies such as high-temperature superconductors, quantum mechanical devices, and hybrid computer chips that utilize both electronic and lightwave signals. These measurement techniques, as well as Standard Reference Materials developed for optical fiber diameter, silicon resistivity, and superconducting critical current, play a significant role in helping to improve the efficiency and quality of manufacturing.

In addition, the laboratory manages metrology development work across NIST in response to the needs of mainstream silicon semiconductor device manufacturing. It also applies science and technology to solve key problems of the criminal justice communities.

\section{Contact:}

Judson C. French, Director

(301) $975-2220$

email: judson.french@nist.gov

fax: (301) 975-4091

B358 Metrology Building

www.eeel. nist gov

\section{COOPERATIVE RESEARCH OPPORTUNITIES}

77 Office of Microelectronics Programs

77 Office of Law Enforcement Standards

\section{Electricity}

77 Resistance Standards and Materials

78 Quantum Hall Effect

78 Applying High-T, Superconductors to Precision Electrical Measurements

78 Josephson-Effect Voltage Standards

79 Advanced AC-DC Voltage and Current Measurements

79 Synthesis of Precise Signals

79 Testing Electronic Systems

79 Fast Pulse and Waveform Acquisition Standards

80 Metrology for Electrical Power Systems

80 Dielectrics Research

80 Plasma Processing/Plasma Chemistry

81 Video Processing

81 Metrology for Flat-Panel Displays

81 Integrated Intrastructure for Electronics Design

82 Integrated Infrastructure for Electronics Manufacturing

\section{Semiconductor Electronics}

82 Metrology for Nanoelectronics

82 Optical Characterization Metrology

83 Scanning Probe Microscope Metrology

83 Thin-Film Process Metrology

83 Silicon-on-Insulator Metrology

84 Metrology for Modeling and Simulation

84 Metrology for Process and Tool Control

84 Interconnect Reliability Metrology

84 Dielectric Reliability Metrology

85 Microelectromechanical Systems

\section{Electromagnetic Fields}

85 Guided-Wave Microwave Standards and Measurements

86 High-Speed Microelectronics

86 Electromagnetic Characterization of Materials

87 Electromagnetic Interference and Compatibility

87 Antenna Measurements

\section{Electromagnetic Technology}

87 Josephson Array Development

88 Nanoscale Cryoelectronics

88 High-Performance Sensors, Infrared Detectors, and Mixers

88 Superconductor Standards and Technology

89 Superconductor Interfaces and Electrical Transport

89 High-Temperature Superconducting Electronics

89 Magnetic Recording Metrology

90 Magnetic Instruments and Materials Characterization

90 Nanoprobe Imaging for Magnetic Technology

\section{Optoelectronics}

90 Laser Radiometry

91 High-Speed Optoelectronic Measurements

91 Fiber-Optic Metrology

92 Integrated Optic Metrology

92 Optical Fiber Sensors

92 Fiber and Discrete Components

93 Dielectric Materials and Devices

93 Semiconductor Materials and Devices

\section{RESEARCH FACILITIES}

93 Semiconductor Processing Laboratory

94 Molecular-Beam Epitaxy Facility

94 Wafer Probing Laboratory

95 Mode-Stirred Chambers

95 Ground Screen Antenna Range

95 Transverse Electromagnetic Cell

96 Electromagnetic Anechoic Chamber

96 Concentric Loop Antenna Systems

97 Standard Transient/Impulsive Field Facility

97 Mobile Transient Reception/Transmission System

97 Integrated-Circuit Fabrication Laboratory

97 Ultralow-Temperature Electronics Facility

98 Magnetic Thin-Film Fabrication and Imaging Facility

98 Near-Field Scanning Facility for Antenna Measurements 


\section{COOPERATIVE RESEARCH OPPORTUNITIES}

OFFICE OF MICROELECTRONICS PROGRAMS

The Office of Microelectronics Programs (OMP) serves as an information focal point for semiconductor-related research at NIST. OMP is responsible for matrix management and contemporary relevance of the National Semiconductor Metrology Program (NSMP). OMP also manages NIST's strong working relationships with the Semiconductor Industry Association (SIA), the Semiconductor Research Corp. (SRC), and SEMATECH.

The NSMP was established by Congress (within the Department of Commerce) in 1994 in direct response to industry needs. The FY 1998 program portfolio consists of 23 multiyear projects with activities spanning nearly all of the NIST laboratory organizations. Strong emphasis is on metrological issues for mainstream silicon CMOS technology identified in the National Technology Roadmap for Semiconductors (SIA, 1997). OMP actively seeks industry collaborations in support of the portfolio and sets priorities based on direct industry contact and through participation in the planning activities of the SIA, SRC, and SEMATECH. Results from NSMP activities are largely public information and are freely available to domestic manufacturers.

\section{Contact:}

Robert I. Scace

(301) $975-4400$

email: scace@nist.gov

fax: (301) 975-6513

A323 Technology Building

www.eeel.nist.gov/810.01

\section{OFFICE OF LAW ENFORCEMENT STANDARDS}

The mission of the Office of Law Enforcement Standards (OLES) is to apply science and technology to the needs of the criminal justice community, including law enforcement, corrections, forensic science, and fire service. To accomplish this mission, OLES develops methods for testing equipment performance and for examining evidentiary materials; develops standards for equipment and operating procedures; develops Standard Reference Materials; and performs other scientific and engineering research as requested by sponsoring agencies.

The areas of research investigated by this office include clothing, communication systems, emergency equipment, investigative aids, protective equipment, security systems, vehicles, speed measuring equipment, weapons, analytical techniques, and Standard Reference Materials used by the public safety community. Specific projects are based upon the most recent recommendations of the Law Enforcement and Corrections Technology Advisory Council and vary depending upon the priorities of the criminal justice community.

\section{Contact:}

Kathleen M. Higgins

(301) 975-2757

email: kathleen.higgins@nist.gov

fax: (301) 948-0978

A323 Technology Building

www.eeel.nist.gov/810.02

\section{ELECTRICITY}

Division Contact:

William E. Anderson

(301) $975-2400$

email:william.anderson@nist.gov

fax: (301) 926-3972

B164 Metrology Building

www.eeel.nist.gov/811

\section{RESISTANCE STANDARDS AND MATERIALS}

Component precision resistors of both film and wire construction have found widespread use as references and dividers in precision instrumentation such as digital multimeters and calibrators. The quality of these resistors and their level of immunity to the effects of environmental parameters, such as temperature and mechanical shock, have enabled the 3-month performance of these instruments to begin to approach that of the standards most commonly used to calibrate them. This fact and the desirability of calibrating such instruments where they will be used have heightened the need for a next generation of resistance standardsstandards whose performance in adverse conditions would eclipse that of existing standards in a laboratory environment.

NIST scientists are beginning a program to develop new standards with significantly improved performance, both short- and long-term, under field conditions. To do so, the electrical/physical properties of a number of alloys are being investigated, and new resistor designs are being formulated and tested. Future efforts will investigate metallurgical techniques such as rapid quenching, ion implantation in semiconductors 
and glasses for resistors $>10^{7}$, and Evanohm or Nichrome film deposition on Si substrates. The desired output will be fixedvalue standards in the range from $1 \mathrm{ohm}$ to $10^{12}$ ohms with fractional drift rates of less than $10^{-6}$ per year', fractional temperature coefficients of less than $10^{-7}$ per ${ }^{\circ} \mathrm{C}$, and low power and voltage coefficients. A metallurgical facility with the capability of monitoring the electrical properties of materials during annealing and a silicon processing facility are available, along with access to precision resistance measurement systems and the national resistance standards.

Contacts:

Ronald F. Dziuba

(30I) 975-4239

email: ronald.dziuba@nist.gov

Alan F. Clark

(30I) 975-2139

email:alan.clark@nist.gov

B258 Metrology Building

\section{QUANTUM HALL EFFECT}

The quantum Hall effect now provides the basis for the national unit of resistance. The representation of the resistance standard presents many interesting problems. Researchers at NIST are investigating the physical principles underlying the effect, understanding sample-specific artifacts, exploring the ac quantum Hall effect, and improving the measurement systems. Research is being conducted on the range of parameters over which the quantum Hall effect provides the most accurate and reproducible standard of resistance.

Using GaAs heterostructures grown at NIST, researchers are using a dedicated class-10 clean room facility to investigate different methods of making contacts to the devices that will have very low resistances (in the milliohm range) even at temperatures below $4.2 \mathrm{~K}$ and in high magnetic fields.
NIST researchers also are working to improve and simplify the measurement systems used to calibrate resistors; a new ${ }^{3} \mathrm{He}$ refrigerator and 16-tesla magnet facility have been developed for use with a new cryogenic current comparator. This improved the accuracy of NIST calibrations severalfold.

\section{Contacts:}

Marvin E. Cage

(301) $975-4224$

email: marvin.cage@nist.gov

Alan F. Clark

(301) 975-2139

email: alan.clark@nist.gov

B258 Metrology Building

\section{APPLYING HIGH-TC SUPERCONDUCTORS TO PRECISION ELECTRICAL MEASUREMENTS}

NIST and other national standards laboratories for years have used cryogenic current comparators (CCCs) to make ratio measurements of voltage, current, and resistance with relative uncertainties of $10^{-8}$ or less. This approach has not found widespread commercial use because the cryogenic current comparator must be operated at liquidhelium temperatures, which presents a variety of operational difficulties. Moreover, existing comparators are working prototypes rather than completed instrumentation systems and are difficult to use.

Recent advances in superconductivity technology have made the application of hightemperature superconductors practical. In at least one case, an integrated-circuit superconducting quantum interference device magnetometer, similar to devices used in CCCs to detect low levels of magnetic flux, has been built that operates at liquidnitrogen temperatures. Thus, the possibility for developing a commercial instrument based on a CCC now has been opened. Such an instrument might be run with a refrigerator at liquid-nitrogen temperatures.
This development and the possibility of commercialization make it feasible to automate the basic CCC design, which then will be more attractive for general calibration use. NIST scientists are engaged in designing, building, and testing CCCs to support measurements of the new national resistance standards based on the quantized Hall effect. This involves establishing a few select ratios that range from 1:1 to 100:1. Future efforts will include the development of CCCs with selectable ratios over a somewhat larger range.

Contacts:

Ronald F. Dziuba

(301) 975-4239

email: ronald.dziuba@nist.gov

Randolph E. Elmquist

(301) 975-6591

email: randolph.elmquist@nist.gov

B258 Metrology Building

\section{JOSEPHSON-EFFECT VOLTAGE STANDARDS}

High-accuracy voltage-standard systems have proliferated among many industrial, government, and international standards laboratories with the advent of the Josephson-array device. Within this laboratory, there are three array voltage-standard systems in operation, including a fully automated 10-volt array system. Guest researchers can gain hands-on experience with array system operation and verification and cooperate on studies into both precision voltage metrology and Josephson-array physics.

The metrology goals are to improve measurement precision to better than one part in $10^{8}$ in applications of direct system-tosystem intercomparisons and lab-to-lab volt transfers, achieve greater reliability in automation algorithms, and further the development of solid-state reference standards and precision digital voltmeters. 
The physics research addresses the effects of electromagnetic noise on the stability and accuracy of the Josephson quantized-voltage steps, studies the boundaries of chaotic behavior in junction-junction interactions, and explores other possible array device applications, such as the generation of ac signals through frequency modulation of the millimeter-wave drive frequency.

Contacts:

Richard L. Steiner

(301) 975-4226

email: richard.steiner@nist.gov

Alan F. Clark

(301) $975-2139$

email:alan.clark@nist.gov

B258 Metrology Building

\section{ADVANCED AC-DC VOLTAGE AND CURRENT MEASUREMENTS}

Thermal voltage and current converters offer the most accurate and broadband method for measuring ac voltage and current for applications in communications, power generation, aerospace, and defense. Thermal transfer standards are calibrated by NIST in terms of reference converters, which themselves have been characterized by reference to the NIST primary standardsspecial multijunction thermal converters whose performance is known. These primary and working standards in common use throughout the metrology community employ thermal converters fabricated from wire elements. Researchers at NIST are studying new methods for the manufacture of film thermal converter structures made by the use of photolithography on silicon substrates. The application of this new technology may result in improved performance and reduction in the cost of thermal converters.

Contacts:

Joseph R. Kinard

(301) $975-4250$

email: joseph.kinard@nist.gov

Barry A. Bell

(301) 975-2419

email: barry.bell@nist.gov

B162 Metrology Building

\section{SYNTHESIS OF PRECISE SIGNALS}

NIST is conducting both theoretical and experimental research on the synthesis of precision ac waveforms for use in ac voltage standards operating nominally below $100 \mathrm{MHz}$ and producing both sinusoidal and arbitrary waveforms. The theoretical work includes Walsh functions and Fourier analysis, time-domain analysis, and precision RMS-to-dc conversion techniques. Experimental work involves high-speed, highaccuracy digital-to-analog conversion; precision, high-speed switching; assembly and interpretive-level programming for hardware control; and wideband, fastsettling amplifiers.

Contacts:

Nile M. Oldham

(301) 975-2408

email: nile.oldham@nist.gov

Barry A. Bell

(301) 975-2419

email: barry.bell@nist.gov

B162 Metrology Building

\section{TESTING ELECTRONIC SYSTEMS}

NIST scientists are developing new testing approaches for electronic systems to minimize the attendant testing costs while ensuring product quality. Program emphasis is on development and application of generic error modeling methods for describing the systems to be tested. Once an accurate model is available, it can predict the performance of a device based on the fewest possible tests. Theoretical work centers on dimensionality selection for empirical models to minimize prediction errors and on the assignment of uncertainties and confidence limits when making predictions based on empirical models. Results of this work are being used by the semiconductor industry to reduce the costs of testing mixed-signal integrated circuits and by electronic instrument manufacturers to cut the high costs of calibration test points.

Contacts:

T. Michael Souders

(301) 975-2406

email: t.souders@nist.gov

Barry A. Bell

(301) 975-2419

email: barry.bell@nist.gov

B162 Metrology Building

\section{FAST PULSE AND WAVEFORM ACQUISITION STANDARDS}

NIST has an active program to provide a basis for characterizing both the time domain and frequency domain performance of sampling and digitizing systems, including analog/digital converters, sampling oscilloscopes, and waveform recorders. Theoretical and experimental research establishes test methods, reference waveforms, and state-of-the-art sampling technology to support these systems. Research 
areas include opto-electronic and electrooptical techniques for sampling and pulse generation in the 1-picosecond to 5-picosecond regime; advanced signal processing methods, including deconvolution, phase-plane compensation and spectral estimation; and ultrahigh accuracy techniques to support modern sigma-delta sampling technology.

\section{Contacts:}

T. Michael Souders

(301) $975-2406$

email: t.souders@nist.gov

Barry A. Bell

(301) $975-2419$

email:barry.bell@nist.gov

B162 Metrology Building

\section{METROLOGY FOR ELECTRICAL POWER SYSTEMS}

Electrical measurements are critical to the operation of electrical power systems in many ways; they are fundamentally important to the control of power flow, the maintenance of reliability and quality, and the revenue metering of electrical power. NIST research is conducted to support the high reliability of electric power delivery, public safety, and faimess in the sale of electric power to customers.

Nearly all equipment installed in the electric power system is subjected to acceptance tests at high voltage to ensure it can withstand accidental high voltage surges as well as those occurring during normal system operation. NIST researchers are working both to improve the precision of conventional methods traditionally used in high voltage testing as well as to develop optical and electrooptical techniques that complement and offer significant advantages over conventional measurement approaches. Power quality is also of great concern for utilities, which provide the electric power, and for consumers, who have equipment such as computers that is sensitive to electric power surges, sags, and other transient phenomena. NIST is working with the electric power industry to identify the sources and presence of electric power degradation and to mitigate its effects on sensitive equipment. Magneto-optical measurement devices of electrical current are being developed for metering of electrical power. Research at NIST includes the verification of the accuracy of these devices that are being introduced into the power system. Other research areas include measurement of electric and magnetic fields and precision measurements of electric power and energy.

\section{Contacts:}

Gerald J. FitzPatrick

(301) 975-2737

email: gerald.fitzpatrick@nist.gov

James K. Olthoff

(301) $975-2431$

email: james.olthoff@nist.gov

B344 Metrology Building

\section{DIELECTRICS RESEARCH}

NIST scientists are developing measurement methods to characterize dielectrics used as electrical insulators in electric power systems. Emphasis is on the investigation of phenomena that affect reliability and safety associated with operation of electrical systems. Specific projects include investigation of the production of toxic byproducts in electrical discharges, research on the environmental impact of the use of gaseous dielectrics, and the development of diagnostics for predicting failure (or breakdown) of insulating materials. Theoretical work addresses Boltzmann equilibrium statistics, chemical kinetic computer codes, and computer-aided data acquisition and analysis. Experimental work focuses on highvoltage ac and dc tests, gas chromatography and mass spectrometric techniques for chemical characterization, and partial discharge measurements in cables and in gasand liquid-insulated systems.

Contacts:

Loucas G. Christophorou

(301) 975-2432

email: loucas.christophorou@nist.gov

James K. Olthoff

(301) 975-2431

email: james.olthoff@nist.gov

B344 Metrology Building

\section{PLASMA PROCESSING/ PLASMA CHEMISTRY}

NIST scientists are investigating the chemical and physical processes occurring in lowtemperature discharges by applying a wide range of diagnostics to well-characterized discharges that are similar to those used in the manufacturing of microelectronic devices. The goal of this research is to improve the measurement techniques required to ensure the reproducibility and control of semiconductor etching discharges. The discharges under study include radio-frequency ( $\mathrm{rf}$ ) discharges (generated in Gaseous Electronics Conference rf reference cells, a standard cell used by research labs worldwide) and low current dc Townsend discharges. Diagnostics applied to these discharges include mass spectrometric detection of neutral and ionic species generated in the discharges, analysis of discharge electrical parameters, detection of plasma optical emission, and laser-induced fluorescence. Additional areas of research include the accumulation and critical analysis of standard reference data (such as cross sections and rate coefficients) for use by the semiconductor industry, the measurement of electron attachment cross sections for 
etching gases, and the investigation of the role of surface charging in low-temperature discharges.

Contact:

James K. Olthoff

(301) 975-2431

email: james.olthoff@nist.gov

B3ft Metrolog: Building

\section{VIDEO PROCESSING}

Video quality presently is evaluated using subjective means; however, the exploding digital video revolution requires significantly more sophisticated and accurate measurements. The static test patterns and linear measurement tools for analog video sistems do not characterize adaptive, nonlinear digital compression systems. NIST is developing a collection of measurement tools for the testing and evaluation of digital rideo signals subjected to compression processing. Similarly, measurement techniques are being developed for the evaluation of the risual performance of video displars.

One of the tools used for real-time video processing is the Princeton Engine, a video supercomputer. Consisting of 1,024 parallel processors with wideband video input and output channels, each processor operates on one picture element per video scan line, and all processors execute the same instruction. Programming is accomplished using a subset of the $C$ language having special constructions for parallel operation. Video recorders, multiscan monitors, highdefinition monitors, and additional video support equipment are available. NIST researchers are interested in using the Video Technology Laboratory for a wide variety of collaborative research projects. Such collaborations would focus on precompetitive research with broad applications in advancing the state of the art in digital video systems.

\section{Contact:}

Charles Fenimore

(301) 975-2428

email: charles.fenimore@nist.gov

A53 Technology Building

\section{METROLOGY FOR FLAT-PANEL DISPLAYS}

Researchers at NIST are developing the measurement technology for the characterization of advanced image display systems. A set of meaningful performance specifications is needed that can be used to assess display quality and that can be applied across the wide spectrum of display technologies that either are available or will become available shortly. Display quality issues are not simply a matter of light measurement, power efficiency, display environment, or signal quality. Rather, many of these factors act in concert to affect display quality, with an important addition-the complexities of human visual perception. Research topics include the development of radiometric and colorimetric measurements of emissive and non-emissive displays, the automation of such measurements, investigation of the visual perception of the eye, and modeling of display characteristics using the Princeton Engine video supercomputer (see item on video processing).

\section{Contacts:}

Edward F. Kelley

(301) $975-3842$

email: edward.kelley@nist.gov

James St. Pierre

(301) 975-4124

email: james.st.pierre@nist.gov

A53 Technology Building
INTEGRATED INFRASTRUCTURE FOR ELECTRONICS DESIGN

The electronics industry continues to move toward a completely electronic, or computer sensible, exchange of component information throughout the product life cycle, from design to manufacturing to field support. The ability to represent accurately electronic circuit geometry, behavior, and other parameters in standard computer file formats is crucial to the success of electronic commerce of component information (ECCI) for electronics. Through the Integrated Infrastructure for Electronics Design project, NIST scientists are working with the electronics industry to develop the standards, infrastructure, methodologies, and tools necessary to facilitate the exchange of electronic product data - with a focus on the design phase and the interface to manufacturing - in the global marketplace.

NIST researchers are working with industry consortia, such as the Silicon Integration Initiative and SEMATECH, and standards organizations, such as the International Electrotechnical Commission and the Institute of Electrical and Electronics Engineers, to develop the standards, infrastructure, and methodologies necessary to allow the U.S. electronics component industry to compete aggressively in this global marketplace. In response to industry needs, NIST has ongoing research in several areas:

- online data dictionaries,

- conformance and certification methodologies for the electronic design automation (EDA) industry,

- EDA information model development,

- ECCI design life-cycle integration experiments,

- harmonization of existing and proposed standards, 
- object-oriented electronic component representations, and

- specifications for ECCI utilities.

Contact:

James St.Pierre

(301) 975-4124

email: jimstp@nist.gov

A53 Technology Building

INTEGRATED

INFRASTRUCTURE FOR

ELECTRONICS MANUFACTURING

Electronics manufacturers face increasing pressures in today's global manufacturing environment, where being first to market is often the chief determinant of market share. Increased competition pressures manufacturers to cut costs throughout the manufacturing process, and increased product complexity forces manufacturers to maintain flexible factories of high-capital equipment and best-of-breed software applications. In addition, globalization of the customer and supplier base drives the need for globally distributed manufacturing facilities and suppliers. As a result, the manufacturing industry is in need of standards and technology to quickly and efficiently knit heterogeneous equipment and software together and to rapidly transfer information across corporate barriers and multivendor computer environments. Through this project, NIST scientists are working with industry to develop and validate the use of open computer systems and standards to meet this need.
NIST researchers have partnered with the National Electronics Manufacturing Initiative to develop and validate methodology and standards to enable a "plug-and-play factory." This industry-led project will recommend a software framework for shopfloor integration, based on work being done at Georgia Tech to evaluate the applicability of candidate approaches for electronics manufacturing. NIST researchers also have teamed with industry in the Internet Commerce for Manufacturing project to develop and validate standards needed for electronic commerce of printed circuit assembly services. This effort is demonstrating the use of emerging, more comprehensive standards to move design information into the manufacturing process and to add efficiency to online contractual transactions.

Contact:

Barbara Goldstein

(301) 975-2304

email: bgoldstein@nist.gov

A53 Technology Building

\section{SEMICONDUCTOR ELECTRONICS}

Division Contact:

David G. Seiler

(301) 975-2054

email: david.seiler@nist.gov

fax: (301) 948-4081

B344 Technology Building

www.eeel.nist.gov/812

\section{METROLOGY FOR NANOELECTRONICS}

The goal of this project is to provide technological leadership to semiconductor and equipment manufacturers by developing and evaluating the methods, tools, and artifacts needed to improve the state of the art in compound semiconductor growth and nanometrology (measurements on a scale of 10 nanometers to 100 nanometers). A stateof-the-art molecular-beam epitaxy facility is devoted to in-situ metrology using a variety of X-ray, optical, and electrical in-situ methods. Among these are an in-situ X-ray fluorescence probe, multiple wavelength ellipsometry, $\mathrm{X}$-ray reflectivity, and various radiometric methods to measure wafer temperature during deposition. A focused ion beam facility is used to fabricate nanostructures for both research and metrology of nanoscale devices. In-situ measurements of growth and structural parameters are being examined in addition to fabrication properties required for the reliable manufacture of nanostructure devices. Research materials and methods to improve measurement standards also are being developed.

\section{Contacts:}

Joseph G. Pellegrino

(301) 975-2123

email: joseph.pellegrino@nist.gov

Wen F. Tseng

(301) 975-5291

email:wen.tseng@nist.gov

\section{A305 Technology Building}

\section{OPTICAL CHARACTERIZATION METROLOGY}

Optical spectroscopic studies in the visible and near-visible regions of the electromagnetic spectrum are invaluable for determining both materials- and device-related properties. The ability to couple to electronic states of interest in device applications and their non-destructive nature make optical spectroscopic analyses attractive research and analytical tools. Studies currently under way at NIST focus on understanding the electronic and structural behavior of semiconductor materials, such as Si, GaAs, and $\mathrm{SiGe}$; microstructures, including quantum wells and superlattices; and photonic and electronic devices. Excellent spectroscopic facilities are available to perform highresolution photoluminescence, photoluminescence-excitation, Raman and resonance Raman scattering, reflection, 
absorption, and modulation spectroscopic measurements, such as electroreflectance and photoreflectance. The equipment used includes high-resolution spectrometers, excitation lasers, cryostats, and associated optical and electronic instruments.

Contact:

Paul M. Amirtharaj

(301) $975-5974$

email:paul.amirtharaj@nist.gov

A305 Technology Building

\section{SCANNING PROBE MICROSCOPE METROLOGY}

Scanning probe microscopes (SPMs), such as the atomic force microscope, are one of few techniques with the spatial resolution necessary to probe within individual transistors of state-of-the-art integrated circuits. This project applies SPMs to measure the optically, vibrationally, and electrically pumped impedance between an SPMI tip and a semiconductor or device structure to determine the spatial variation in their electrical properties. For example, scanning capacitance microscopy (SCM) has been developed as a technique to measure two-dimensional (2D) dopant profiles within silicon transistors with 10-nanometer spatial resolution. Quantitative 2D dopant profiles are required by the semiconductor industry to develop next-generation integrated circuits. A unique aspect of this work has been the development of a model of the SCM based on a finite element solution of Poisson's Equation for the capacitance between the SCM tip and a semiconductor. Results from the model have been incorporated into easy-to-use, personal-computer-based software that extracts dopant profiles from SCM images. Other SPM-based techniques are being developed to measure lithographic overlay, dielectric constant, and carrier lifetime.

\section{Contact:}

Joseph J. Kopanski

(301) 975-2089

email: joseph.kopanski@nist.gov

A305 Technology Building

\section{THIN-FILM PROCESS METROLOGY}

Fabrication of thin films of various types is a fundamental building block in the semiconductor device industry. Increasingly stringent requirements on the structure and composition of these films are reflected in increasingly stringent requirements on the metrology tools and procedures used for process development and process monitoring. NIST researchers are developing improved procedures, reference data, and calibration artifacts to support in-situ process monitoring needs as well as in-line and at-line measurements. Current activities focus on thin-film dielectrics. Research on dielectrics, principally $\mathrm{SiO}_{2}$ but also nitrides and layered structures, includes:

- improving ellipsometric characterization of materials needed for gate dielectrics for the year 2000 and beyond;

- developing an understanding of the effect of interface roughness on accurately determining the film properties needed by industry;

- developing new and more flexible mechanisms for supporting traceability to NIST in the area of measurement of thin-gate dielectrics; and
- developing a database of high-accuracy optical constants for silicon and important dielectric layers at temperatures typical of silicon processing steps.

Contact:

James R. Ehrstein

(301) 975-2060

email: james.ehrstein@nist.gov

B310 Technology Building

\section{SILICON-ON-INSULATOR METROLOGY}

Silicon-on-insulator (SOI) wafers have advantages over bulk silicon in process simplicity and for applications involving low power, high temperature, integrated power, high speed, and radiation hardness. The National Technology Roadmap for Semiconductors notes that development of low-cost SOI substrate wafers could advance integrated circuit performance a full generation. SOI has been identified as the material of choice for the Defense Advanced Research Projects Agency's Low Power Electronics Program, which is developing the infrastructure for the fabrication of integrated circuits for the portable, battery-operated, communications and computer electronics of the future. This project supports development of improved SOI material by creating and applying advanced metrology techniques to the evaluation of the material. NIST has developed the capability of annealing SOI wafers at the high $\left(1350{ }^{\circ} \mathrm{C}\right)$ temperatures required for fabricating the material and has the capability to fabricate simple test structures on SOI. Analytical capabilities include advanced chemical-etching techniques combined with optical and electron microscopy and precision electronic measurements.

Contact:

Peter Roitman

(301) 975-2077

email: peter.roitman@nist.gov

B310 Technology Building 


\section{METROLOGY FOR MODELING AND SIMULATION}

Modeling and simulation activities cut across the entire semiconductor industry. Computer-aided design (CAD) continues to assume more importance as design cycle times become shorter and shorter and hardware prototypes become more and more expensive to build. As more reliance is being placed on computer-aided designs to be accurate, the software models used in these designs also must be accurate and relevant to the situations being simulated. The objectives of this project are to help ensure the accuracy and relevance of these models and thus improve the efficiency and timeliness of $\mathrm{CAD}$ and to increase the confidence that CAD users have in their designs. This is accomplished by developing and evaluating methods for measuring model parameters, developing methods to "validate" model performance and applicability, and supporting the industry infrast:-'1cture for promulgating these activities. The project's recent focus has been on model validation for highpower semiconductor devices and packages and for the system-level thermal performance of microelectronic packages. Work also is being initiated on metrology requirements for semiconductor thermal process modeling.

\section{Contact:}

Allen R. Hefner, Jr.

(301) 975-2071

email: allen.hefner@nist.gov

B310 Technology Building

\section{METROLOGY FOR PROCESS AND TOOL CONTROL}

Integrated-circuit (IC) test structures, teststructure-based reference materials, and test methods developed by NIST are used widely by the semiconductor industry and other government agencies. These devices can be used to characterize IC manufacturing processes, to evaluate the effectiveness of semiconductor processing equipment, to obtain crucial parameters for process or circuit simulators, to perform product acceptance tests, and to determine the reliability of the products manufactured. NIST work involves test-structure design, modeling, data acquisition, and data analysis. Institute engineers are investigating pattern recognition techniques for the rapid diagnosis of IC manufacturing processes. They also are developing new structures for nanometerlevel metrology and for establishing methods to determine the reliability of thin films used in state-of-the-art microcircuits.

\section{Contact:}

Michael W. Cresswell

(301) 975-2072

email: michael.cresswell@nist.gov

B360 Technology Building

\section{INTERCONNECT RELIABILITY METROLOGY}

Electrical interconnect reliability of integrated circuits continues to be a topic of intense interest as evidenced by an increasing number of publications on the subject each year. This interest is the result of the planned aggressive scaling of integrated circuits and the need for ever greater reliability as expressed in the National Technology Roadmap for Semiconductors. A key underpinning of efforts in this area is the development of the measurement tools and standards to facilitate the goals of the industry. NIST researchers work with domestic semiconductor manufacturers and others to develop new and improved test structures, test methods, and diagnostic procedures for enhanced characterization and reliability of thin-film metal interconnects used in integrated circuits.

Advances in microelectronic circuit density, complexity, and reliability as well as greater demands for ever-shorter times to develop and market new products are forcing the U.S. semiconductor industry to use a new approach to reliability. The traditional approach of using screen and accelerated stress tests is becoming increasingly impractical to ensure the reliability of microelectronic products because too many parts and too much time are required. NIST is working with the semiconductor industry to implement the new "building-in reliability approach," which emphasizes understanding and controlling the causes for reduced reliability.

\section{Contact:}

Harry Schafft

(301) 975-2234

email: harry.schafft@nist.gov

B360 Technology Building

\section{DIELECTRIC RELIABILITY METROLOGY}

The U.S. semiconductor industry is aggressively scaling gate-oxide film thickness in microelectronic devices to achieve higher chip performance and packing density. Reduced time to market and new oxide processes require fast and effective reliability characterization techniques. NIST', in collaboration with the semiconductor industry, is developing physically correct models and tests to predict reliability of thin oxides under $\mathrm{dc}$ and ac operating conditions. Research is being performed to advance the understanding of time-dependent dielectric breakdown in thin $\mathrm{SiO}_{2}$ films by verifying the electric field dependence of the mechanism. High temperature is used to accelerate dielectric failure so data can be obtained at lower electric fields in reasonable test times. 
Current projects focus on the evaluation of accelerated stress tests for predicting the long-term reliability of ultrathin dielectrics. The project also facilitates the development of national standards for characterizing dielectric integrity to help ensure consistent measurements among a company's multiple manufacturing plants and between vendors and customers.

Contact:

John S. Suehle

(301) 975-2247

email: john.suehle@nist.gov

B360 Technology Building

\section{MICROELECTRO- MECHANICAL SYSTEMS}

Microelectromechanical systems (MEMS) represent a rapidly growing segment of the U.S. semiconductor industry with a multibillion-dollar market expected to expand 10 -fold over the next decade. This emerging technology uses mechanical structures, made with integrated-circuit (IC) microfabrication techniques, to perform sensing and actuation functions. Commercial applications for this technology include pressure sensors, inertial sensors, fluid regulation and control, optical switching, mass data storage, and chemical and biological sensing and control. Areas of interest include standardization, environmental monitoring, and control in biomedical, military, and space applications. Systems aspects address the development of new circuits and processing techniques for monolithic integration of MEMS-based systems with new circuits for control, communication, self-test, and selfcalibration functions. Standards aspects address the need for test structures and test methods for measuring and understanding the electromechanical properties and reliability aspects of these micromechanicalbased systems. Custom processing techniques and incorporation of these techniques to post-processing of commercial foundry-fabricated ICs are being developed and utilized for device fabrication.
Computer-aided design methods and standard libraries of device designs are being developed for rapid commercialization and technology transfer. Areas of specialization include microheating elements to produce temperature-programmable surfaces for applications in thermal flat-panel displays and integrated gas analyzers and development of CMOS-based broad-band power detectors for precision power measurement.

Contact:

Michael Gaitan

(301) 975-2070

email:michael.gaitan@nist.gov

B360 Technology Building

\section{ELECTROMAGNETIC FIELDS}

Division Contact:

Dennis Friday

(303) 497-3131

email: friday@boulder.nist.gov

fax: (303) 497-3122

Mailcode 813.00

Boulder, Colo. 80303-3328

www.boulder.nist.gov/div813

\section{GUIDED-WAVE} MICROWAVE STANDARDS AND MEASUREMIENTS

The commercial and defense electronics industries rely on microwaves for a variety of applications, such as communications, radar, navigation, and environmental monitoring. Microwaves are desirable because of their high frequency and short wavelength. The high frequencies allow for very wide bandwidths, and the short wavelengths are important for reducing the size of components and devices. The accurate characterization of microwave devices and components is critical to the design, development, testing, and performance of modern microwave systems. The primary task of device characterization at microwave frequencies consists of measuring the transmission or reflection response of a device to a known or controlled stimulus.

The principal quantities that characterize electromagnetic waves propagating in transmission lines or similar guided-wave structures are impedance, attenuation, scattering parameters, power, and noise. Rapidly developing microwave technology requires the support of advanced measurement techniques and standards for these quantities. The microwave industry and the U.S. Department of Defense rely on NIST for calibrations of transfer standards to provide accurate, traceable measurements required for product development, performance evaluation, quality assurance, and commercial interchangeability. To support international traceability requirements, NIST compares its measurements of these quantities with those made by other national metrology institutes by participating in international comparisons coordinated by the International Bureau of Weights and Measures.

During the past decade, NIST researchers have developed six-port vector network analyzers (VNAs) for measuring scattering parameters, impedance, and attenuation. The six ports provide an independent measurement technique for verifying the accuracy of commercial VNAs. Calibration services for scattering parameters, impedance, and attenuation are offered in popular coaxial and waveguide sizes from $10 \mathrm{MHz}$ to $100 \mathrm{GHz}$. NIST also supports the microwave community by developing new measurement techniques and evaluating the accuracy of current techniques. Commercial VNAs have become an indispensable tool for modern microwave measurements. NIST currently is working on methods for assessing and for verifying the accuracy of vector network analyzers. As part of this effort, NIST administers a measurement comparison program with the Institute of Electrical 
and Electronics Engineers Automatic RF Techniques Group that allows VNA users to compare their measurements with the measurements of others.

Microcalorimeters have been developed at NIST for the most accurate microwave power measurements. NIST researchers have developed both coaxial and waveguide microwave calorimeters to characterize thermistor mounts. Thermistor mounts serve as reference standards for calibrating power meters and other power measuring equipment. Present efforts are directed toward developing coaxial power standards that will operate up to 50 gigahertz. Calibration services for coaxial and waveguide thermistor mounts are available from 10 megahertz to 100 gigahertz.

NIST does research on primary noise standards and radiometer systems to support noise temperature and noise figure measurements. One port noise temperature is determined by reference to a standard noise generator via a radiometer. Calibration services for measuring the thermal noise of coaxial and waveguide noise sources are available at limited frequencies from $30 \mathrm{MHz}$ to $100 \mathrm{GHz}$. Researchers are developing an automated noise figure radiometer that will operate over the frequency range from $1 \mathrm{GHz}$ to $18 \mathrm{GHz}$. This system will measure the noise figure of active devices.

\section{Contact:}

Robert M. Judish

(303) 497-3380

email: judish@boulder.nist.gov

Mailcode 813.06

Boulder, Colo. 80303-332

\section{HIGH-SPEED MICROELECTRONICS}

While the explosion of wireless applications is fueling the demand for microwave and radio-frequency microelectronics, advances in the silicon industry continue to drive the size of digital circuits down and their clock rates up. These trends in the wireless and digital industries have led to increasingly stringent requirements for the electromagnetic characterization of monolithic microwave integrated circuits (MMICs), dense multilayer interconnects, and other highspeed microelectronic structures. In response to these requirements, NIST researchers are developing measurement methods to characterize key, high-frequency components and high-performance electronic packages and interconnections.

NIST supports the industry through research and development of on-wafer metrology, particularly for the measurement of scattering, impedance, and noise parameters. Fabrication of co-planar and microstrip calibration standards is an important element in the task. The project is supported by the NIST Industrial MMIC Consortium, which provides close collaboration with industry in developing accurate and traceable on-wafer measurements.

The project aims for practical calibration and measurement methods that are suitable for commercial laboratories. Methods are implemented in instrument control and data processing software that interface with a range of laboratory instruments, including microwave network analyzers, radiofrequency network analyzers, and digital sampling oscilloscopes. This range of options brings the advanced NIST technology into the hands of microwave, wireless, and digital engineers.

Contacts:

Roger Marks

(303) 497-3037

email:marks@boulder.nist.gov

Dylan Williams

(303) 497-3138

email: dylan@boulder.nist.gov

Mailcode 813.06

Boulder, Colo. 80303-3328

\section{ELECTROMAGNETIC CHARACTERIZATION OF MATERIALS}

It is widely recognized that critical needs exist for accurate data on the electromagnetic properties of certain materials used extensively throughout the aerospace, microwave, electronics, and communications industries. The electromagnetic properties of materials program at NIST seeks to support industry by evaluating and improving measurement techniques, by providing wellcharacterized reference materials and measurement services, and by organizing measurement intercomparisons. Current capabilities include room-temperature measurements of complex permittivity and permeability for bulk materials in the spectral range, $100 \mathrm{kHz}$ to $60 \mathrm{GHz}$, as well as highprecision cavity measurements of low-loss dielectrics near $10 \mathrm{GHz}$. NIST is extending its measurement capabilities, for both bulk and thin-film materials, into the millimeter range and at elevated and cryogenic temperatures. Adequate and more accurate materials characterization data will help industry obtain optimal component and 
system performance with greatly reduced costs for corrective redesign.

Contacts:

Andrew G. Repjar

(303) 497-5703

email: repjar@boulder.nist.gov

Claude M. Weil

(303) $497-5305$

email: weil@boulder.nist.gov

Mailcode 813.08

Boulder, Colo. 80303-3328

\section{ELECTROMAGNETIC INTERFERENCE AND COMPATIBILITY}

NIST researchers are engaged in a wide range of projects aimed at quantifying electromagnetic interferences (EMI) and electromagnetic compatibility (EMC). One thrust of the NIST work is to develop measurement techniques and methodologies for measuring emission of unintentional radiation from electronic devices. Another aspect under active investigation is the susceptibility of electronic equipment to such radiation. The researchers are identifying and defining quantities that characterize the susceptibility of a device and then developing methods to measure those quantities. Successful completion of this research should result in the development of standards and measurement techniques for EMI and EMC that are meaningful, technically practical, and reliable. These techniques then could be incorporated into voluntary standards by both U.S. and international standards organizations.

Contact:

Motohisa Kanda

(303) 497-5320

email:mkanda@boulder.nist.gov

Mailcode 813.07

Boulder, Colo. 80303-3328

\section{ANTENNA MEASUREMENTS}

Researchers at NIST are developing reliable techniques and standards for measuring key performance parameters of antennas and components used with satellites, Earth terminals, radars, and communications systems. Near-field scanning now is used routinely to characterize microwave and millimeterwave antennas. NIST researchers are focusing on developing and implementing techniques to correct for errors in the scan surfaces and applying all near-field techniques to higher frequencies. Software for the analysis of spherical near-field data recently has been rewritten and improved. Other research areas include spacecraft and phased-array antenna measurements, antenna diagnostics using near-field techniques, and antenna systems measurements using celestial radio sources.

\section{Contacts:}

Andrew G. Repjar

(303) $497-5703$

email: repjar@boulder.nist.gov

Carl F. Stubenrauch

(303) 497-3927

email: stubenrauch@boulder.nist.gov

Mailcode 813.08

Boulder, Colo. 80303-3328

\section{ELECTROMAGNETIC TECHNOLOGY}

Division Contact:

Richard E. Harris

(303) 497-3776

email: harrisr@boulder.nist.gov

fax: (303) 497-3066

Mailcode 814.00

Boulder, Colo. 80303-3328

http://emtech.boulder.nist.gov

\section{JOSEPHSON ARRAY DEVELOPMENT}

Manufacturers of precision electronic components and instrumentation need intrinsic electrical standards at a level of accuracy above that achievable by traditional electrical metrology and artifact standards. The characterization and calibration of modern digital voltmeters, reference standards, and analog-to-digital and digital-to-analog converters require the development of new and improved intrinsic standards for the measurement of ac and dc voltage. Target customers are electronic instrument makers, Department of Defense contractors, and national and military standards laboratories.

The project pioneered the development of practical Josephson voltage standards and, by encouraging the commercialization of these standards, has allowed U.S. industry to dominate the world market for Josephson voltage systems and components. Continuing work is designed to make these systems faster, easier to use, and more reliable. The project is developing a new generation of programmable voltage standards that can move rapidly to any specified output voltage. Ultimately, the new standards should be fast enough to synthesize ac waveforms.

Contact:

Clark A. Hamilton

(303) 497-3740

email: hamilton@boulder.nist.gov

Mailcode 814.03

Boulder, Colo. 80303-3328 


\section{NANOSCALE CRYOELECTRONICS}

Ultrasmall electronic devices operated at cryogenic temperatures offer unique capabilities that impact both fundamental metrology and industrial instrumentation. This project is developing a device for accurately counting electrons that will provide a fundamental standard for capacitance and allow an essentially new determination of the fine-structure constant. Using ultrasmall (100-nanometer) tunnel junctions operated at ultralow temperature $(0.05 \mathrm{~K})$, the device pumps electrons onto a capacitor one by one at a rate determined by an external clock. This device will become metrologically important when it is improved to the point where electrons are counted with an error rate less than about 1 part in $10^{9}$.

Another cryogenic device under development meets the need for an X-ray detector with the improved energy resolution required for precise X-ray microanalysis. Such an X-ray detector, with an energy resolution of a few electron volts, can be made using the rapid change in resistance of a superconductor near its transition temperature to sense the $\mathrm{X}$-ray-induced temperature rise of electrons in a normal metal film held at about $0.1 \mathrm{~K}$. Such ultrasensitive thermometers offer enormous potential to materials analysis in the semiconductor and other industries and promise remarkable advances for optical detectors, high-energy physics, and analysis of biological molecules.

Contact:

Richard L. Kautz

(303) 497-3391

email: kautz@boulder.nist.gov

Mailcode 814.03

Boulder, Colo. 80303-3328

\section{HIGH-PERFORMANCE SENSORS, INFRARED DETECTORS, AND MIXERS}

This project addresses the needs of users and manufacturers of long-wavelength infrared (IR) detectors. Precise radiometric calibration of such systems requires an improved absolute cryogenic radiometer for blackbody and band-limited IR radiation with higher accuracy and sensitivity than is presently available. The physical foundation of the project is the low noise and high sensitivity of superconducting transition-edge thermometers. Use of a transition-edge detector also is expected to improve the sensitivity of the ac/dc thermal conversion measurements by a factor of between 10 and 100 over room temperature detectors. In addition, manufacturers and users of room-temperature infrared imagers are seeking increased functionality from their systems. With support from the Department of Energy and a large commercial defense contractor, the project explores novel means of obtaining increased functionality, such as antenna-coupling of IR detectors for polarization discrimination.

This project also explores the capabilities of very high-frequency diodes of various types, particularly superconducting and roomtemperature metallic tunnel junctions. The frequency agility provided by such highspeed diodes will be important to applications such as the wavelength-division multiplexed telecommunications system in which very precise measurement and control of IR frequency is required. A further application for these devices is infrared rectification for solar energy generation, which, because it offers the possibility of raising the efficiency beyond conventional solar cells, is of great interest to the Department of Defense for size-constrained, powerstarved environments such as satellites.

Contact:

Erich N. Grossman

(303) 497-5102

email: grossman@boulder.nist.gov

Mailcode 814.03

Boulder, Colo. 80303-3328

\section{SUPERCONDUCTOR STANDARDS AND TECHNOLOGY}

Manufacturers of superconducting wire need practical and accurate methods for characterizing critical current, ac loss, and other performance parameters. The unbiased feedback of conductor performance and measurement considerations to U.S. manufacturers is important to maintain their competitive position in support of magnetic resonance imaging, electric power, laboratory magnets, and other applications.

For $\mathrm{Nb}_{3} \mathrm{Sn}$ wires, the properties and handling of the sample mandrel can affect the measured critical current significantly. Sample damage, sample variability, and mounting variability can have a major effect on the measured critical current of high-temperature superconductors. This project provides standards, measurement techniques, quality assurance, reference data, and clarification of issues for both high- and low-temperature superconducting wire technology. In conjunction with international standards organizations, NIST researchers develop standards for critical current and other parameter measurements, conduct research, and lead interlaboratory comparisons. They represent, update, and 
seek input from U.S. industry throughout the process of standards creation in order to protect U.S. interests in international trade.

Contact:

Loren F. Goodrich

(303) 497-3143

email: goodrich@boulder.nist.gov

Mailcode 814.05

Boulder, Colo. 80303-3328

\section{SUPERCONDUCTOR} INTERFACES AND ELECTRICAL TRANSPORT

The high-temperature-superconductor (HTS) industry needs high-quality contacts and interfaces for both thin-film and bulk conductors. Industry has looked to NIST for engineering help and an understanding of how to control the surfaces of these new materials. The new HTS materials also have significant magnetic field anisotropy, which has opened a new set of measurement and modeling problems for conductor performance. Many of the companies that have expressed a need for the expertise and the equipment available at NIST are small start-up companies without extensive infrastructure.

The thin-film fabrication equipment offers both sputter and laser-ablation deposition of HTS materials, reflection high-energy electron diffraction analysis, in situ characterization of process gas and background contaminants, ion-milling, and etching, all in the same vacuum chamber. Equipment to perform in situ scanning tunneling microscopy surface analysis of HTS films allows surface conductivity maps to be made immediately after film fabrication.
Recent developments in growth of highenergy physics accelerators and the deregulation of the electric power utilities have resulted in demand for superconducting magnets with both higher fields and larger size. Both trends lead to higher magnetic loading of the superconductor, which necessitates measurements of the effect of stress on electrical performance. The project instrumentation in the electromechanical area is the only apparatus in the United States for electrical transport measurements of superconductors at high magnetic fields.

Contact:

Jack W. Ekin

(303) $497-5448$

email: ekin@boulder.nist.gov

Mailcode 814.05

Boulder, Colo. 80303-3328

\section{HIGH-TEMPERATURE SUPERCONDUCTING ELECTRONICS}

High-temperature superconductivity (HTS)

has opened the possibility for operating superconducting electronic instrumentation at temperatures accessible with present-day cryocoolers. Low-temperature superconductors are used to produce unique standards, such as the Josephson volt, and measurement apparatus, such as superconducting quantum interference devices. Equivalent HTS devices would expand the applicability of these devices far beyond standards and research laboratories.

NIST scientists have developed fabrication, testing capabilities, and theoretical competence for HTS devices in the areas of microwave and terahertz metrology and technology. They work with the HTS communication industry to measure and improve the power-handling capabilities of HTS devices as well as to improve microwave measurement and characterization techniques for HTS films and devices. They also work with industry and other NIST divisions to develop and test HTS bolometers for calibrated radiometers, and they evaluate and improve HTS Josephson junctions for use in voltage standards, terahertz detectors, and other devices to meet the measurement and application needs of industry.

\section{Contact:}

David A. Rudman

(303) 497-5081

email: rudman@boulder.nist.gov

Mailcode 814.03

Boulder, Colo. 80303-3328

\section{MAGNETIC RECORDING METROLOGY}

The magnetic recording industry is advancing rapidly the state of the art in highdensity information storage and read devices. To maintain their competitive advantage in rigid-disk manufacture, U.S. firms must constantly look to new properties of magnetic materials. The accurate characterization of new materials often is beyond the capability of the small companies most eager to exploit them. Thus, NIST develops metrology to assist the magnetic recording industry and develops techniques to characterize the performance of ultrahigh-density magnetic recording systems and of submicrometer magnetoresistive sensors.

NIST researchers have developed a scanning micromagnetic recording system to characterize ultrahigh-density recording. The system combines the ability to read and write conventional bit tracks under a variety of controlled conditions with the ability to image the magnetic structure. It also allows the characterization of advanced sensors without the need for full head fabrication. Development is coordinated with the needs of commercial disk drive, head, and media manufacturers as well as with the National Storage Industry Consortium's heads program. The researchers develop micromagnetic models of magnetoresistive sensors 
and media as well as characterization techniques for the new generation of submicrometer magnetoresistive sensors to be used in ultrahigh-density magnetic recording.

Contact:

David P. Pappas

(303) $497-3374$

email: pappas@boulder.nist.gov

Mailcode 814.00

Boulder, Colo. 80303-3328

MAGNETIC INSTRUMENTS AND MATERIALS

\section{CHARACTERIZATION}

Researchers, developers, producers, and users of magnetic materials need tools for the accurate determination of magnetic properties and the analytical interpretation of data. Industries supported include: manufacturers of inductive recording heads, magnetoresistive read-back heads, thin-film and particulate recording media, and magnetoresistive magnetic memories; producers of microwave materials; companies researching magnetoresistive sensors; superconductor wire manufacturers; and magnetic-particle researchers in medicine. The project provides measurement services, often in the form of collaborations, to laboratories that do not have magnetic measurement and analysis capability.

NIST develops instruments, measurement protocols, and theoretical models to characterize the magnetic properties of films, particles, and bulk solids as functions of magnetic field strength, field history, temperature, and time. Researchers develop, promote, and transfer to industry magnetic metrology for applications in magnetooptics, magnetic data storage, magneto- chemistry, power conversion, and highfrequency electromagnetics.

Contact:

Ron Goldfarb

(303) 497-3650

email: goldfarb@boulder.nist.gov

Mailcode 814.05

Boulder, Colo. 80303-3328

\section{NANOPROBE IMAGING FOR MAGNETIC TECHNOLOGY}

Magnetic recording technology in 1997 was a $\$ 33$ billion worldwide industry for harddisk drives alone. The technology has advanced to where nanometer-scale morphological, magnetic, and electrical properties play important roles in drive performance. Images showing microroughness, device dimensions, magnetic field patterns, and local electronic processes provide important information about the fundamental operation and ultimate limitations of drive components. In addition, images of components shipped for assembly can be used to determine quality before manufacture of the complete drive. Scanning-probe microscopies (SPM), such as scanning-tunneling, atomicforce, and magnetic-force microscopies, and scanning potentiometry are uniquely qualified for many of these applications because of the nanometer-scale dimensions of the various types of probes.

By working closely with industry, this project helps to determine which kinds of SPM technology developed by the scientific community may have commercial impact. By optimizing techniques for measurement, the researchers establish standard levels of instrument performance. They maintain an active research program to develop new imaging and image measurement techniques tailored to specific problems designated by the magnetic recording industry.

Contact:

John M. Moreland

(303) 497-3641

email: moreland@boulder.nist.gov

Mailcode 814.05

Boulder, Colo. 80303-3328

\section{OPTOELECTRONICS}

\section{Division Contact:}

Gordon W. Day

(303) 497-5204

email: gwday@boulder.nist.gov

fax: (303) 497-7671

Mailcode 815.00

Boulder, Colo. 80303-3328

www.boulder.nist.gov/div815

\section{LASER RADIOMETRY}

NIST researchers develop measurement methods and standards for characterizing laser sources and detectors used primarily with continuous-wave radiation. They also develop and maintain measurement services for laser power and energy, optical fiber power, and related parameters.

Accurate characterization of optoelectronic sources and detectors is crucial to the effective development and use of industrial technologies such as lightwave telecommunications, laser-based medical instrumentation, materials processing, photolithography, data storage, and laser safety equipment. The laser radiometry project focuses on selected critical parameters 
intrinsic to optoelectronic sources and detectors, especially the calibration of optical fiber power meters and laser power/energy meters at commonly used wavelengths and power levels. Absolute optical measurements are traceable through high-accuracy cryogenic electrical substitution radiometers to national electrical standards for power and energy. In addition, special test measurements are available for linearity, spectral responsivity, and spatial uniformity of optical power meters and detectors. In support of source characterization, measurement methods are developed to characterize beam intensity profiles and propagation of laser beams. Project members participate in national and international standards committees developing standards for laser safety. laser radiation measurements (such as beam profile and pointing stability), and optical-power-related measurements. They extend and improve source and detector characterizations through the development of improved technology such as low-noise, spectrally flat, highly uniform pyroelectric detectors, solid-state light trapping detectors, deep ultra-violet optical calorimeters, and new tunable-wavelength laser systems.

\section{Contact:}

Christopher L. Cromer

(303) 497-5620

email: cromer@boulder.nist.gov

Mailcode 815.01

Boulder, Colo. 80303-3328

\section{HIGH-SPEED OPTOELECTRONIC MEASUREMENTS}

NIST provides advanced metrology and standards relating to temporal properties of optical sources and detectors used with optoelectronic systems. Researchers also develop and maintain measurement services for optoelectronic frequency response, impulse response, relative intensity noise, noise figure, and low-level pulsed energy.
High-bandwidth measurements are needed to support high-performance systems that take advantage of the potential bandwidth of optical fiber. Systems presently being installed operate at 5 gigabits per second to 10 gigabits per second using pure optical time division multiplexing (OTDM); research is being conducted on the next generation of OTDM systems at 20 gigabits per second to 40 gigabits per second. Increasingly tight tolerances in both digital and analog systems require frequency response measurements with low uncertainty.

Project members use both frequency-

domain and time-domain techniques to characterize the modulation response of optoelectronic components with the low uncertainty, large frequency range (over 5 decades), and fine frequency resolution required by international standards for present and future optoelectronic systems. Source and detector noise measurements are required to predict low-bit error ratios in computer interconnects, high carrier-tonoise ratios in analog systems, and to support erbium-doped fiber amplifier noisefigure measurements using electrical noise measurement methods. Intensive use of laser target designators by the armed forces requires traceable, low-level pulse power and energy calibration standards at 1.06 micrometers and 1.55 micrometers.

Contact:

Paul D. Hale

(303) 497-5367

email: hale@boulder.nist.gov

Mailcode 815.01

Boulder, Colo. 80303-3328

\section{FIBER-OPTIC METROLOGY}

Optical fibers largely have replaced coaxial cable in long-distance telecommunications systems and rapidly are being installed in local-area applications. NIST staff interact with industry groups to develop measurement methods and reference standards for the characterization of these components.
The joining of optical fibers requires the fiber to have accurately controlled dimensions. NIST-developed Standard Reference Materials for cladding diameter allow manufacturers to calibrate instrumentation used in manufacturing and quality control; geometrical standards for fiber coatings and connector ferrules have been developed as well. Dispersion, the variation of propagation velocity with wavelength or polarization, sets the limit for the rate at which information can be transmitted. Measurement methods and standards for chromatic dispersion are available, and polarizationmode dispersion standards currently are under development.

The development of optical amplifiers has brought revolutionary changes to the design of communications. Since these new components require special methods of characterization, measurement services for spectral gain and noise figure are now in development. Non-linear properties of fiber, such as four-wave mixing and soliton effects, have been studied and applied to instrumentation. Novel implementations of reflectometry in fiber also are being studied.

Project staff develop advanced measurement methods and Standard Reference Materials for optical fibers and interact with standards groups to provide a metrology base for the lightwave communication industry.

\section{Contact:}

Paul Williams

(303) 497-3805

email:pwilliam@boulder.nist.gov

Mailcode 815.02

Boulder, Colo. 80303-3328 


\section{INTEGRATED OPTIC METROLOGY}

Optical waveguides in planar geometries, often called integrated optics, are increasingly used in communications and other optoelectronic systems. This project develops advanced measurement methods for integrated optical waveguides and interacts with standards groups to provide a metrology base for the lightwave communications industry. As the optical communications industry moves toward local-area networks and toward fiber to the home, there is increasing need for inexpensive passive components, such as splitters. Additionally, such components are needed because longdistance telephony is retrofitting to wavelength-division multiplexing (WDM). Several companies are manufacturing $1 \times N$ splitters or are about to market them; in addition, arrayed waveguide gratings and other devices in integrated optics are giving rise to multiplexers for dense WDM. There are, however, no standard measurement procedures similar to those for fiber-index profile and mode-field diameter. Nor are there artifact standards similar to those for fiber geometry. It also is not obvious how to perform analogous measurements when the mode field pattern of an integrated optical waveguide is not circularly symmetric or when the fiber measurement is performed using a cutback technique or a mandrel wrap. Thus, several critical measurements are under examination.

Contact:

Matt Young

(303) 497-3223

email: myoung@boulder.nist.gov

Mailcode 815.02

Boulder, Colo. 80303-3328

\section{OPTICAL FIBER SENSORS}

The NIST optical fiber sensors project supports the sensor industry broadly by providing measurements and standards for the characterization of optical materials and components used in sensors. Researchers also develop and evaluate new fiber optic sensors for other government agencies and industry. Most of the work has been devoted to high-sensitivity, high-bandwidth electric current and magnetic field sensing, although recent work has involved other measurands. A broad range of research and development is performed, including transducer, component, systems, and materials work. When possible, newly developed sensor technology is transferred to interested U.S. companies. A successful example involves annealed fiber coil technology that creates stable current sensors out of common optical fiber and now is available commercially.

In collaboration with U.S. companies, NIST developed a Standard Reference Material for optical retardance. The device, based on Fresnel rhombs, has nominally 90 -degree retardance at 1.3 micrometers with 0.1 degree stability over wide ranges of wavelength, angle, and temperature. In addition to the Standard Reference Material, special measurement services for retardance using the accurate methods developed at NIST are offered. NIST researchers also are collaborating with industry to develop measurements that support optical data storage. Efforts now focus on substrate characterization, with the goal of providing materials that improve the calibration of disc birefringence testers.

\section{Contact:}

Kent B. Rochford

(303) $497-5170$

email: rochford@boulder.nist.gov

Mailcode 815.03

Boulder, Colo. 80303-3328

\section{FIBER AND DISCRETE COMPONENTS}

Advanced optical communications systems use many different types of components to control and modify propagating signals. NIST develops measurement technology to characterize these components and understand their limits.

This project currently is conducting research on polarization-dependent loss and gain metrology, characterization of photo-induced Bragg fiber gratings, and wavelength standards for optical fiber communications. Polarization-dependent loss and gain in components affect a system's performance, especially when many components are in the system. NIST is developing a polarization-dependent loss calibration standard for commercial test instruments and is characterizing polarizationdependent gain of fiber amplifiers. Photoinduced Bragg gratings in optical fiber are likely to be incorporated in fiber lasers, dispersion compensators, and filters. The researchers evaluate the growth characteristics and long-term stability of these fiber gratings. They also are developing Standard Reference Material absorption cells for wavelength calibration in the 1.5 micrometer region. These cells can be used to calibrate the instruments that characterize the spectrum of sources and wavelength dependence of components. This calibration capability will become increasingly important as wavelength-division multiplexing optical communication systems are implemented.

\section{Contact:}

Sarah L. Gilbert

(303) 497-3120

email: sgilbert@boulder.nist.gov

Mailcode 815.03

Boulder, Colo. 80303-3328 


\section{DIELECTRIC MATERIALS AND DEVICES}

NIST is developing measurement methods and acquiring critical data to improve the manufacturing of dielectric optical devices and materials. This work supports eventual and current commercial applications requiring passive optical components, electrooptic and non-linear devices, and compact solid-state lasers. Research activities include developing rapid non-destructive evaluation methods for bulk and thin-film ferroelectric materials such as lithium niobate, lithium tantalate, potassium titanyl phosphate, and non-linear polymers. Domain-engineered geometries of these materials also are under investigation. Commercial application of this work supports device and product development for optical data storage, biomedical lasers, vehicle navigation, and optical communications. NIST also is improving methods for the manufacture of compact rare-earth-doped solid-state waveguide lasers and amplifiers. This effort currently is emphasizing neodymium-. erbium-, and ytterbium-doped silicate and phosphate glasses. Critical measurements include evaluation of the dopant concentration profiles that define waveguides and spectroscopic properties such as lifetimes and cross sections. Rigorous numerical modeling is leading to optimized designs of modelocked lasers, Q-switched lasers, and optical amplifiers. Various pulsed, continuous-wave, branched, and narrowline lasers have been developed, including distributed Bragg-reflector lasers. Commercial applications include sensors and optical telecommunications.

Contact:

Norman A. Sanford

(303) $497-5239$

email: sanford@boulder.nist.gov

Mailcode 815.04

Boulder, Colo. 80303-3328

\section{SEMICONDUCTOR} MATERIALS AND DEVICES

The commercial success of semiconductor optoelectronic devices in an ever-widening array of applications (telecommunications, computer interconnects, data storage, display, printing, and sensor systems) requires low-cost manufacturing. NIST scientists develop measurement tools suitable for crucial stages in the manufacture of compound semiconductor devices such as lightemitting diodes, diode lasers, detectors, and modulators. The operation of key devices depends critically on the thickness and compositional uniformity of epitaxial layers. To increase device yield, NIST is improving optical methods for the in-process monitoring and control of semiconductor layer deposition. NIST researchers use computer simulations and the correlation of data from several in-situ and ex-situ techniques to improve the measurements' accuracy. Test structures and novel measurement techniques have been developed to measure precisely optical constants, defect diffusion, and quantum microcavity effects. Researchers fabricate semiconductor quantum-well devices used in laser and detector metrology and sensing applications. Ultra-short pulse measurements are applied to semiconductor materials characterization and the fabrication and characterization of high-speed devices. In support of next-generation data communications, display, and data storage products, NIST scientists are measuring and modeling the properties of vertical-cavity surface-emitting lasers.

\section{Contact:}

Robert K. Hickernell

(303) $497-3455$

email:bobhick@boulder.nist.gov

Mailcode 815.04

Boulder, Colo. 80303-3328
RESEARCH FACILITIES

\section{SEMICONDUCTOR PROCESSING LABORATORY}

As integrated circuit (IC) sizes increase to more than $1 \mathrm{~cm}^{2}$ and feature sizes within the circuits decrease to less than $1 \mu \mathrm{m}$, critical demands are placed on the measurement capability required to control and monitor IC fabrication successfully. To meet the demand, NIST researchers are developing state-of-the-art measurement procedures for microelectronics manufacturing.

The Semiconductor Processing Laboratory provides a quality physical environment for a variety of research projects in semiconductor microelectronics as well as in other areas of physics, chemistry, and materials research. The laboratory facilities are used for projects addressing many areas of semiconductor materials and processes, including process control and metrology, materials characterization, and the use of integrated circuit materials and processes for novel applications.

The laboratory complex occupies about $372 \mathrm{~m}^{2}$, approximately half of which is composed of clean rooms. Within the clean rooms, work areas are maintained at class 30. The facility is designed so the work areas can be modified easily to accommodate the frequent equipment and other changes required by research.

\section{CAPABILITIES}

The laboratory has a complete capability for IC fabrication. Principal processing and analytical equipment is listed below.

- Diffusion, Oxidation, and Annealing. Six furnace tubes for up to 75-millimeterdiameter wafers and five tubes for up to 100-millimeter-diameter wafers. 
- Photolithography. Research mask aligner (proximity and contact) for wafers up to $100 \mathrm{~mm}$ in diameter and irregularly shaped samples and $10 \times$ direct-step-on wafer system for 75-millimeter-diameter wafers. Photoresist spin coating and developing and related chemical processing, including oxygen plasma stripping. E-beam writing and scanning electron microscope exam-ination of small features on 75 -millimeter wafers.

- Film Deposition. Low-pressure chemical vapor deposition systems for depositing silicon nitride, polysilicon, and lowtemperature silicon dioxide. Radio frequency and dc vacuum sputtering of metals and dielectrics. Electron beam and hot filament vacuum evaporation of metals.

- Etching. Wet and dry etching processes. Plasma barrel etching of nitride films and wet chemical etching of silicon for micromachining.

- Ion Implantation. Multipurpose $200 \mathrm{keV}$ ion implanter.

- Analytical Measurements. Thin-film reflectometry and other thickness measurements, optical microscopy, and grooving and staining.

- In-Situ Metrology. In-situ, real-time, multiple wavelength ellipsometry to measure optical constants of silicon and other chemical vapor deposition materials such as silicon dioxide, polysilicon, and silicon nitride.

\section{APPLICATIONS}

Small quantities of specialized semiconductor test specimens, experimental samples, prototype devices, and processed materials can be produced. The processes and processing equipment can be monitored during operation to study the process chemistry and physics. The effects of variations in operating conditions and process gases and chemical purities can be investigated. Research is performed under well-controlled conditions.
A research-oriented facility, the laboratory is not designed to produce large-scale ICs or similar complex structures. Rather, the laboratory emphasizes breadth and flexibility to support a wide variety of projects.

Currently, research projects address many aspects of microelectronic processing steps and materials as well as silicon micromachining. Examples include: metaloxide-semiconductor measurements; metalsemiconductor-specific contact resistivity; uniformity of resistivity, ion-implanted dopant density, surface potential, and interface state density; characterization of deposited insulating films on silicon carbide; ionization and activation of ion-implanted species in semiconductors as a function of annealing temperature; electrical techniques for dopant profiling and leakage current measurements; and processing effects on silicon-on-insulator materials. A simple CMOS process has been established.

\section{AVALLABILITY}

Laboratory staff welcome collaborative research projects consistent with the research goals of the NIST semiconductor program. Work is performed in cooperation with the technical staff of the laboratory.

The most productive arrangements begin with development of a research plan with specific goals. The commitment of knowledgeable researchers to work closely with NIST staff and the provision of equipment and other needed resources are required. Because hazardous materials are present, laboratory staff must supervise all research activities.

\section{Contact:}

Donald B. Novotny

(301) 975-2699

email: donald.novotny@nist.gov

B310 Technology Building

\section{MOLECULAR-BEAM EPITAXY FACILITY}

Molecular-beam epitaxy (MBE) of III-V semiconductors is used to fabricate heterostructures with highly controlled electrical, optical, and structural properties. The facility's primary role is to study and measure material parameters of advanced compound semiconductors, especially in ways that promote new and improved measurement techniques. The MBE facility is equipped with a dual-chamber MBE system. One chamber is devoted to the fabrication of heterostructures for research and metrology. This effort includes high-mobility modulation-doped field-effect transistors, quantum Hall devices, self electro-optical effect devices, superlattices, lasers, and optical modulators. The adjoining chamber is a state-of-the-art MBE for developing and performing in-situ metrology of advanced semiconductors. What distinguishes this effort from others is the availability of numerous in-situ probes that can simultaneously measure the same materials parameters over a wide range of temperatures. This will lead to a better understanding of the limitations of an individual probe and will provide industrial manufacturers with important correlations they can use for improved growth control.

\section{Contact:}

Joseph G. Pellegrino

(301) 975-2123

email: joseph.pellegrino@nist.gov

A305 Technology Building

\section{WAFER PROBING LABORATORY}

The NIST Wafer Probing Laboratory provides the capability for automated dc probing of test devices on up to 200-millimeter wafers. The system consists of a state-of-the-art commercial parameter analysis test system upgraded with a nanovolt digital multimeter controlled by a workstation. A computercontrolled 200-millimeter wafer prober 
allows for fast wafer mapping of devices. A switching matrix allows for the use of up to 36 independent connections; these may go either directly to a probe card for wafer probing or, through use of adapter boards, directly to packaged parts. Currently, the Wafer Probing Laboratory is primarily used in the development and evaluation of test structures for very large-scale integration for metrology applications; the system also is capable of measuring the dc characteristics of devices such as transistors. Additional equipment in the Wafer Probing Laboratory includes a 125-millimeter manual wafer probe station and inspection microscopes. This facility is available in support of collaborative research with NIST.

Contact:

Richard A. Allen

(301) 975-5026

email: richard.allen@nist.gov

B360 Technology Building

\section{MODE-STIRRED CHAMBERS}

NIST researchers have designed and constructed mode-stirred (reverberating) chambers to measure radiated electromagnetic emission, immunity of electronic equipment, and shielding effectiveness of materials and cable/connector assemblies. A mode-stirred chamber is an electrically large (in terms of wavelength), high-quality cavity whose boundary conditions are varied by means of a rotating conductive tuner.

\section{CAPABILITIES}

The mode-stirred chamber simulates nearfield conditions for tests at frequencies from $200 \mathrm{MHz}$ to $40 \mathrm{GHz}$. Equipment as large as $1.5 \mathrm{~m} \times 2.0 \mathrm{~m} \times 3.0 \mathrm{~m}$ can be tested in highlevel test fields up to $1000 \mathrm{~V} / \mathrm{m}$.

\section{APPLICATIONS}

In addition to performing radiated-emission or immunity measurements of electronic equipment, the mode-stirred chambers can measure the shielding effectiveness of gasketing, composites, and other materials used for radio-frequency shielding applications. The chambers also can be used to measure the shielding effectiveness of wiring harnesses, printed circuit boards, and connector assemblies. To perform faster immunity measurements, NIST researchers are studying frequency stirring as an alternative to mechanical stirring. Preliminary data indicate that good field uniformity can be obtained by using bandwidths on the order of $10 \mathrm{MHz}$.

\section{AVAILABILITY}

Two chambers are available. NIST staff are available for collaborative programs or to advise and interpret measurement results.

Contact:

Motohisa Kanda

(303) 497-5320

email: mkanda@boulder.nist.gov

Mailcode 813.07

Boulder, Colo. 80303-3328

\section{GROUND SCREEN ANTENNA RANGE}

The ground screen antenna is an open area test site.

\section{CAPABILITIES}

The ground screen consists of 6.35-

millimeter mesh galvanized hardware cloth stretched over a level concrete slab. The screen is $30.5 \mathrm{~m}$ wide by $61 \mathrm{~m}$ long and permits far-field measurements in the highfrequency portion of the spectrum. The mesh dimension provides for an efficient ground plane well into the ultrahigh frequency part of the electromagnetic spectrum.

\section{APPLICATIONS}

The range can be used for the following applications:

- antenna calibrations,

- antenna patterns at any polarization,

- electromagnetic immunity measurements,

- electromagnetic radiated emission measurements,

- calibration of field intensity meters, and

- wave propagation studies.

AVAILABILITY

This facility is used heavily in performing calibrations for industry and other governmental agencies. It is available for independent or collaborative work.

Contact:

Motohisa Kanda

(303) $497-5320$

email: mkanda@boulder.nist.gov

Mailcode 813.07

Boulder, Colo. 80303-3328

\section{TRANSVERSE ELECTROMAGNETIC CELL}

NIST researchers have designed and constructed several transverse electromagnetic (TEM) cells that are available for use. A TEM cell is an enclosure for performing radiated electromagnetic emission and susceptibility measurements of electronic equipment. Its design is based on the concept of an expanded transmission line operated in a TEM mode.

\section{CAPABILITIES}

The cell provides a shielded environment for testing without introducing multiple reflections experienced with the conventional shielded enclosure. It simulates very closely a planar far field in free space and has constant amplitude and linear phase characteristics. 


\section{APPLICATIONS}

In addition to radiated electromagnetic interference testing, other applications of the TEM cells include the calibration of antennas and the study of biological effects of radio-frequency radiation.

\section{AVAILABILITY \\ Several TEM cells with five different sizes and five upper frequency limits in the 100 $\mathrm{MHz}$ to $1 \mathrm{GHz}$ frequency range are available. In collaborative programs, NIST staff are available to advise and interpret measure- ment results. Independent testing also can be arranged.}

Contact:

Motohisa Kanda

(303) 497-5320

email:mkanda@boulder.nist.gov

Mailcode 813.07

Boulder, Colo. 80303-3328

\section{ELECTROMAGNETIC ANECHOIC CHAMBER}

The electromagnetic (EM) anechoic chamber at NIST is a facility for generating standard, well-characterized electromagnetic fields. Such fields are fundamental to the research, development, and evaluation of antennas, field probes, and EM material properties.

\section{CAPABILITIES}

EM fields up to $100 \mathrm{~V} / \mathrm{m}$ can be established in the chamber over the broad frequency range from $200 \mathrm{MHz}$ to $40 \mathrm{GHz}$ and up to $200 \mathrm{~V} / \mathrm{m}$ for certain bands above $1 \mathrm{GHz}$. A majority of the individual components composing the measurement system are under computer control, thus enhancing statistical control of the measurements. The chamber measures $8.5 \mathrm{~m} \times 6.7 \mathrm{~m} \times 4.9 \mathrm{~m}$.

\section{APPLICATIONS}

The EM chamber is used in areas such as:

- research, development, and evaluation of new EM-field-generation and measurement methods;

- calibration of field measurement instruments;

- immunity testing of electronic equipment;

- shielding effectiveness and material parameter studies; and

- special tests for industry, government agencies, and universities.

\section{AVAILABILITY}

This facility is used heavily in performing calibrations for industry and other governmental agencies. It is available for independent or collaborative work with NIST.

Contact:

Motohisa Kanda

(303) 497-5320

email:mkanda@boulder.nist.gov

Mailcode 813.07

Boulder, Colo. 80303-3328

\section{CONCENTRIC LOOP} ANTENNA SYSTEMS

NIST researchers have developed an antenna system consisting of three concentric, orthogonal metal loops, each having two diametrically opposed gaps. Analog signals from the gaps are relayed to processing electronics by fiber-optic links in order to prevent distortion of the measured fields by electrical conductors. The signals are combined to give both the electric and magnetic components of an incident field.

\section{CAPABILITIES}

The present system consists of 1-meterdiameter loops, which are usable from $3 \mathrm{kHz}$ to $100 \mathrm{MHz}$. The frequency range can be shifted upward by using smaller diameter loops. The minimum detectable power radiated from a device near the center of the loops ranges from $0.1 \mathrm{fW}$ at $10 \mathrm{MHz}$ to $1 \mathrm{pW}$ at $100 \mathrm{MHz}$, with a $1 \mathrm{~Hz}$ noise bandwidth. The system has a dynamic range of $100 \mathrm{~dB}$.

\section{APPLICATIONS}

Loop antenna systems can be used for:

- measurements of total $\mathrm{E}$ and $\mathrm{H}$ emissions from electronic devices such as video display terminals (VDT) that are placed near the center of the three loops;

- determination of the Poynting vector from incident plane waves;

- near-field measurements of power radiated from strong sources used in electromagnetic interference and electromagnetic pulse testing; and

- measurement of field levels near large conducting structures where plane wave approximations are not valid.

\section{AVAILABILITY}

The present 1-meter-diameter system is being used as a research tool to develop standard measurement techniques for emissions from VDTs. It is available for collaborative work in this or other areas of potential usefulness. Loops with other diameters or special requirements could be fabricated by special arrangement.

Contact:

Motohisa Kanda

(303) 497-5320

email:mkanda@boulder.nist.gov

Mailcode 813.07

Boulder, Colo. 80303-3328 


\section{STANDARD TRANSIENT/ IMPULSIVE FIELD FACILITY}

This facility is designed to generate and transmit standard transient fields. The system consists of a 30-square-meter ground plane and a 3-meter conical transmitter. The input signal is transmitted as a welldefined spherically expanding wave that can be used to evaluate the impulse response of electromagnetic probes and sensors

\section{CAPABILITIES}

The transmit capabilities are primarily limited by the output spectrum and amplitude of the input signal source. In-house sources allow measurements of frequency components between $50 \mathrm{MHz}$ and $10 \mathrm{GHz}$, and field levels of up to $100 \mathrm{~V} / \mathrm{m}$. The transmitted wave is known to an accuracy of $\pm 1 \mathrm{~dB}$.

\section{APPLICATIONS}

The primary use for this facility is the calibration of broadband probes and sensors. Other applications are measuring the shielding effectiveness of structures and walls and measuring the immunity of electronic devices and equipment to transient electromagnetic fields.

\section{AVAILABILITY}

This facility is available for calibration of broadband devices. Other applications are possible on a limited basis. Tests requiring higher frequencies or field levels are possible with special arrangements.

Contact:

Hotohisa Kanda

(303) 497-5320

email:mkanda@boulder.nist.gov

Wailcode 813.07

Boulder, Colo. 80303-3328

\section{MOBILE TRANSIENT} RECEPTION/TRANSMISSION SYSTEM

Several broadband antennas are available for transmission and reception of transient signals. By combining these antennas, broadband transient generators, high-speed transient digitizers, and sophisticated signal processing, a variety of measurements are possible.

\section{CAPABILITIES}

The capabilities are related closely to the desired application. With existing antennas, it is possible to transmit transient signals with spectral components from $25 \mathrm{MHz}$ up to $14 \mathrm{GHz}$ and field amplitudes of greater than $200 \mathrm{~V} / \mathrm{m}$. Receiving antennas have similar frequency restrictions and sensitivities determined by the receiving equipment. Sensitivities of better than $500 \mathrm{~V} / \mathrm{m}$ are typical.

\section{APPLICATIONS}

This system has been applied in a wide variety of diverse applications, and many more are possible. Some of the specific applications are measurement of the shielding effectiveness of materials, automobiles, and aircraft; non-invasive evaluation of electrical properties of materials; reflectivity of dissipative macrostructures, such as radiofrequency absorber and ferrite tiles; evaluation of reverberation and anechoic chamber performance; and measurement of fields radiated from electrostatic discharges.

\section{AVAILABILITY}

This system is readily available for interesting applications. Higher frequencies, amplitudes, and greater sensitivities are possible but require fabrication of special antennas.

\section{Contact:}

Motohisa Kanda

(303) 497-5320

email:mkanda@boulder.nist.gov

Mailcode 813.07

Boulder, Colo. 80303-3328
INTEGRATED-CIRCUIT FABRICATION LABORATORY

NIST maintains a complete fabrication laboratory for superconducting integrated circuits. Devices employing both low- and high-temperature superconductors are supported. Demonstrated capabilities include the fabrication of 20,000-junction Josephson 10-volt array standards using niobium trilayer technology. The laboratory is housed in an M2.5/3.5 (Class 100/1000) clean room. Individual facilities include a digital pattern generator, submicrometer resolution waferstepper, precision contact aligner, laboratory-scale electron-beam lithography system, pulsed laser deposition system, metal and insulator thin-film deposition and etching systems, and requisite accompanying processing tools. Silicon wafer processing facilities for microelectromechanical system fabrication include oxidation, diffusion, silicon nitride growth, polysilicon growth, and low-temperature doped oxide growth. These facilities are available on a limited basis in support of collaborative research with NIST.

\section{Contact:}

James A. Beall

(303) 497-5989

email: beall@boulder.nist.gov

Mailcode 814.03

Boulder, Colo. 80303-3328

\section{ULTRALOW-TEMPERATURE ELECTRONICS FACILITY}

$\mathrm{A} \mathrm{H}^{3} / \mathrm{H}^{4}$ dilution refrigerator provides an approximately $20 \mathrm{mK}$ low-temperature environment for ultrasensitive measurement systems. Two projects using this system are integrated circuits incorporating ultrasmall metal tunnel junctions for counting single electrons and a record-setting $\mathrm{X}$-ray detector having superior energy resolution and speed 
compared with any other detector. The facility is remarkable for its shielding from external radiation, including that from thermal sources at temperatures higher than its own.

\section{Contact:}

John Martinis

(303) 497-3597

email:martinis@boulder.nist.gov

Mailcode 814.03

Boulder, Colo. 80303-3328

\section{MAGNETIC THIN-FILM FABRICATION AND IMAGING FACILITY}

NIST maintains a magnetics fabrication and characterization facility. The fabrication facility provides vacuum deposition of layered magnetic thin films, including materials that exhibit giant magnetoresistive behavior. Instrumentation includes several varieties of scanned probe microscopies such as the magnetic force microscope, magnetic resonance force microscope, and scanning near-field magneto-optic microscope. Other instrumentation includes an ac susceptometer, a Kerr optical analysis platform, a superconducting quantum interference device magnetometer, and a vibrating sample magnetometer.

Contacts:

Stephen Russek

(303) 497-5097

email: russek@boulder.nist.gov

John Moreland

(303) 497-3641

email: moreland@boulder.nist.gov

Mailcode 814.05

Boulder, Colo. 80303-3328

\section{NEAR-FIELD SCANNING FACILITY FOR ANTENNA MEASUREMENTS}

This automated facility is designed to measure the near-zone phase and amplitude distributions of the fields radiated from an antenna under test. Mathematical transformations are used to calculate the desired antenna characteristics.

\section{CAPABILITIES}

Near-field data can be obtained over planar, cylindrical, and spherical surfaces; the planar technique is the most popular. Efficient computer programs are available for processing the large quantities of data required.

When operated in the planar mode, the facility is capable of measuring over a $4.5 \mathrm{~m} \times$ $4.5 \mathrm{~m}$ area with probe position errors of less than $\pm 0.01 \mathrm{~cm}$. Improved position accuracy is possible with further alignment, especially over smaller areas. Antennas with apertures up to about $3 \mathrm{~m}$ in diameter can be measured with a single scan. The facility has been used successfully over the frequency range $750 \mathrm{MHz}$ to $75 \mathrm{GHz}$. It incorporates provisions for scanning larger antennas in segments.

\section{APPLICATIONS}

- Antenna Characteristics. The facility is used primarily for determining the gain, pattern, and polarization of antennas. Accuracies are typically $\pm 0.15 \mathrm{~dB}$ for absolute gain and $\pm 0.10 \mathrm{~dB} / \mathrm{dB}$ for polarization axial ratio. Patterns can be obtained down to the $-50 \mathrm{~dB}$ to $-60 \mathrm{~dB}$ levels with side lobe accuracy typically about $\pm 1.0 \mathrm{~dB}$ at the $40 \mathrm{~dB}$ level. (The exact uncertainties depend on the frequency, type, size of antenna, and other factors.) Near-field data also can be used to compute near-field interactions (such as mutual coupling) of antennas and radiated field distributions in the near zone.
- Antenna Diagnostics. Near-field scanning is also a valuable tool for identifying problems and for achieving optimal performance of various types of antenna systems. It has been used to advantage in locating faulty elements in phased-array antennas and for adjusting feed systems to obtain the proper illumination function at the main reflector. Phase contour plots of the near-field data also can be used to determine surface imperfections in reflectors used for antennas or compact ranges.

- Probe Calibrations. A spherical probe calibration facility serves as a far-field range for measuring the receiving characteristics of probes used to obtain near-field data. These measurements are required to determine the probe coefficients, which, in turn, are used to calculate accurate, probe-corrected, farfield gain and pattern characteristics of an antenna.

\section{AVAILABILITY}

Two kinds of arrangements can be made to use this facility. NIST staff can perform specified tests or measurements on a reimbursable basis. In this case, the customer has no direct use of the facility; all measurements are performed by NIST staff, and the customer is issued a test report. As an alternative, work may be performed on a cooperative basis with NIST staff. This arrangement permits the user the advantage of developing firsthand knowledge of the measurement processes, and the user is responsible in large part for the accuracy of test results. In either case, arrangements need to be made well in advance, and reimbursement is required for the facility use and time of NIST staff involved.

Contact:

Andrew G. Repjar

(303) $497-5703$

email: repjar@boulder.nist.gov

Mailcode 813.08

Boulder, Colo. 80303-3328 


\section{INFORMATION TECHNOLOGY LABORATORY}

About 60 percent of all U.S. workers have jobs that depend on the information they generate and receive on advanced information networks. Innovations in computer hardware, software, and digital communications will challenge managers to apply new technology for productivity increases throughout the American economy in the coming years and will have pervasive effects on industry structure as well as on the quality of government services. Also, since computers will be distributed throughout society, both at home and in the workplace, computer integration, interoperability, usability, reliability, and security will become even more important.

NIST's Information Technology Laboratory (ITL) concentrates on developing tests and test methods for information technologies that are still in the early stages of development-long before they are available in new products. But even once information technology products are available, tests developed by ITL provide impartial ways of measuring them so developers and users can evaluate how products perform and assess their quality based on objective criteria.

Technical research, industry collaborations, and standards-related work of the ITL address issues emerging from today's information revolution.

Contact:

Shukri Wakid, Director

(301) 975-2900

email: swakid@nist.gov

fax: (301) 840-1357

B263 Technology Building www.nist.gov/itl

\section{COOPERATIVE RESEARCH OPPORTUNITIES}

\section{Software Diagnostics and Conformance Testing}

99 Software Quality

100 Conformance Testing

100 Future Standards for Software

100 Geographic Information Systems

Computer Security

100 Security Technology

101 Systems and Network Security

\section{Advanced Network Technologies}

101 High-Speed Networks

101 Multimedia and Digital Video

102 Next-Generation Internet

Human-Computer Interface Technologies

102 Spoken Language Technology

102 Text Search and Retrieval

103 Visual Image Processing

103 Information Visualization

\section{Mathematical and Computational} Sciences

103 Mathematical Modeling

104 Mathematical Software

104 Optimization and Computational Geometry

104 Image Compression

\section{Statistical Engineering}

105 Collaborative Research and Development

105 Measurement Process Evaluation

High-Performance Systems and Services

106 Scientific Visualization

106 Continual Upgrades

107 Parallel Computing

107 Performance of Modern-Architecture Computers

107 Information Storage and Interconnect Systems

\section{RESEARCH FACILITIES}

108 Computer and Network Security Facility

108 Advanced Network Facility
COOPERATIVE RESEARCH OPPORTUNITIES

\section{SOFTWARE DIAGNOSTICS AND CONFORMANCE TESTING}

\author{
Division Contact: \\ Mark W. Skall \\ (301) 975-3262 \\ email:mark.skall@nist.gov \\ fax: (301) 948-6213 \\ 562 NIST North \\ www.itl.nist.gov/div897
}

\section{SOFTWARE QUALITY}

Growing dependence on computers requires assurance that critical systems will operate reliably and exactly as intended without adverse effects, even when outside circumstances cause other systems to fail. NIST researchers are developing tools and methods for analysis and testing of high-integrity software. Static analysis tools to reduce errors in software development and maintenance include Unravel, a program-slicing tool for analyzing changes to $C$ language source code. A reference implementation of role-based access control for World Wide Web servers is being developed as well. To allow software developers to measure the effectiveness of development techniques, and compare their results with others, a unique database of software errors, faults, and failures is being developed. Formal methods are being used to improve the precision of software specifications, standards, and tests. In addition to developing the first formal model for role-based access control, researchers are using formal methods for automated generation of tests for specifications. An online 
collection of papers and software can be found at http://hissa.nist.gov.

\section{Contact:}

D. Richard Kuhn

(301) 975-3290

email: kuhn@nist.gov

517 NIST North

\section{CONFORMANCE TESTING}

NIST researchers are designing and developing test methods for conformance tests and using these methods to produce test metrics and test suites for evaluating the quality and correctness of information technology products. Several conformance test metrics and test suites have been produced for evaluating implementations of Virtual Reality Modeling Language, language compilers, computer graphics metafile, Java, database language SQL, Programmers Imaging Kernel System (PIKS), and POSIX. In collaboration with industry, the user community, and various testing laboratories, NIST researchers work to identify new technologies and to develop measurement schemes, test collections, reference implementations, test suites, and tools necessary to advance the technology and produce usable, reliable implementations.

Past research has resulted in a method for minimizing subjectivity in the evaluation of visual results in graphics testing. This method is implemented by a customizable interface, randomized self-explanatory displays, and automatic capture of results. Recent activities focus on new methods for software testing based on statistical measures as well as automated test generation methods to develop conformance tests. More information is available on www.itl.nist.gov/ div897/ctg/ctg.htm.

\section{Contact:}

Lynne S. Rosenthal

(301) 975-3353

email: 1sr@nist.gov

562 NIST North

\section{FUTURE STANDARDS FOR SOFTWARE}

NIST recognizes the need to increase and adjust its involvement in technology specifications used in the development of hightechnology software. In today's information processing environment, it is becoming increasingly common for many new technology specifications to be developed in organizations outside the formal standards environment and for those technology specifications to quickly become de facto standards. Accordingly, NIST researchers are seeking to be involved with organizations, both inside and outside the formal standards environment, that are developing pivotal, forward-looking technology specifications in multiple areas related to the production of high-technology software. This involvement will emphasize the development of appropriate metrics, measurement technology, and techniques for testing conformance to new high-technology software specifications. More information is available on www.itl.nist.gov/div897/ssg/ssg.htm.

\section{Contact:}

Bruce K. Rosen

(301) 975-3345

email: bruce.rosen@nist.gov

562 NIST North

\section{GEOGRAPHIC INFORMATION SYSTEMS}

Geographic information systems (GIS) technology allows users to collect, manage, and analyze large volumes of spatially referenced and associated data. New research directions are emerging from the interdisciplinary uses of GIS technology through studies integrating computer graphics standards, database management standards, expert systems technology, and Global Positioning System technology to support GIS applications. This group's research is focused on providing GIS compatibility through standards and conformance testing for GIS standards, such as the
Spatial Data Transfer Standard (Federal Information Processing Standard 173). Because the activities of many governmental and private organizations are land- or location-based or both, GIS technology will be important in integrating existing spatial data to administer, manage, and monitor people, money, and activities in accomplishing the objectives of these organizations.

\section{Contact:}

Bruce K. Rosen

(301) 975-3345

email: bruce.rosen@nist.gov

562 NIST North

\section{COMPUTER SECURITY}

\author{
Division Contact: \\ Stuart W. Katzke \\ (301) 975-2934 \\ email: stuart.katzke@nist.gov \\ fax: (301) 926-2733 \\ 426 NIST North \\ www.itl.nist.gov/div893
}

\section{SECURITY TECHNOLOGY}

Research and development efforts focus on several areas:

- common, interoperable cryptographic security technology, such as algorithms, functionality, and interfaces, and protocols;

- public key infrastructure for managing public key certificates needed to facilitate data integrity, authentication, access control, non-repudiation, and data confidentiality services in global applications; and

- application interfaces for cryptographic modules.

Development efforts include standards, guidance on the use of cryptographic technology, and conformance tests so that strong cryptographic mechanisms will be available for the protection of sensitive information. 
Cryptographic standards promote interoperability and an acceptable level of security. Testing of products that were built to conform to the standards verifies that the provisions of the standards were implemented correctly. NIST has begun testing of more complex cryptographic modules through accredited, private-sector laboratories and plans to promote testing of entire systems in the future. The cryptographic module validation program encompasses testing for cryptographic modules (Federal Information Processing Standard, or FIPS, 140-1), the Data Encryption Standard and its modes of operation (FIPS 46-2 and 81), the Secure Hash Standard (FIPS 180-1), and the Digital Signature Standard (FIPS 186). For details, visit http://csrc.nist.gov/cryptval.

Contact:

Hiles Smid

(301) $975-2938$

email:miles.smid@nist.gov

426 NIST North

\section{SYSTEMS AND NETWORK SECURITY}

Research, development, and application efforts focus on secure, interoperable systems to protect the integrity, confidentiality, reliability, and availability of information and systems. R\&D efforts address technical areas such as advanced countermeasures (for example, intrusion detection, firewalls, and scanning tools); vulnerability analysis and mitigation, access control, and incident response; security criteria and metrics; assurance methods; role-based access control to network resources; and Internet security. Nore information is available on http://csrc.nist.gov.

The National Information Assurance Partnership, recently established by NIST and the National Security Agency, will form a partnership with the government, industry, and academic communities to accomplish several goals:
- assist those communities in meeting their security assurance and testing requirements,

- conduct R\&D in security assurance and testing methods and approaches, and

- establish a commercially viable Common Criteria-based testing program. More information is available on http://niap.nist.gov.

\section{Contact:}

Tim Grance

(301) $975-4242$

email: tim.grance@nist.gov

426 NIST North

\section{ADVANCED NETWORK TECHNOLOGIES}

Division Contact:

Craig Hunt

(301) $975-3600$

email: craig.hunt@nist.gov

fax: (301) 590-0932

445 NIST North

http://snad.ncsl.nist.gov

\section{HIGH-SPEED NETWORKS}

NIST researchers are working with industry in the development of protocols for the broadband integrated services digital network (B-ISDN) or asynchronous transfer mode (ATM) networks, and hybrid fiber-coaxial (HFC) systems. The goal is to expedite the development and deployment of high-speed, interoperable communications systems and services. NIST provides leadership at the ATM Forum in developing test suites for ATM product interoperability and standards conformance testing.
Research projects include ATM network simulation and modeling, evaluating the completeness and correctness of ATM routing protocols, evaluating proposals for the Media Access Protocol for HFC systems, and developing test and measurement methods for interoperability and conformance. More information is available on http:// isdn.ncsl.nist.gov.

Contact:

David Su

(301) 975-6194

email: david.su@nist.gov

445 NIST North

\section{MULTIMEDIA AND DIGITAL} VIDEO

NIST researchers are working with industry to promote the development of cost-effective, interoperable, distributed multimedia applications and to enable the development of digital video technologies for broadcast, interactive television, video-on-demand, and video conferencing. Research emphasizes measurement techniques for characterization of distributed multimedia technologies and digital video devices and services; techniques for integrating multimedia services with network technologies; and industry-driven standards for multimedia technologies and digital video devices and services.

NIST researchers undertake forward-looking research projects for evaluating generationafter-next technologies needed for collaboration, including the development of tools for fine-grained distributed event logging and monitoring over the Internet. The technologies developed will provide an infrastructure so that collaborative tools being tested may log information and expose the log selectively to distributed test drivers. This work 
is conducted in collaboration with the Defense Advanced Research Projects Agency. More information is available on http://snad.ncsl.nist.gov/madvtg/ madvtg.html.

\section{Contact:}

Jean-Philippe Favreau

(301) 975-3634

email: jean-philippe.favreau@nist.gov 445 NIST North

\section{NEXT-GENERATION INTERNET}

NIST researchers are working to remove barriers to the next generation of reliable and secure internetworking technologies and integrated network services. The focus of research is on testing methods and reference implementations for next-generation internetworking technologies; interoperability among next-generation internetworking products; and measurement techniques and performance characterizations for network services that integrate voice, video, and data.

Research projects include investigating changes to the Internet architecture that will support guaranteed bandwidth and quality of services for real-time applications, such as audio, video, and synchronized data. This project focuses on the scalability of the proposed enhancements, interoperability issues, and methods and metrics to characterize the digital data streams. More information is available on http://snad.ncsl.nist.gov/itg/ itg.html.

\section{Contact:}

Doug Montgomery

(301) $975-3630$

email:dougm@nist.gov

445 NIST North

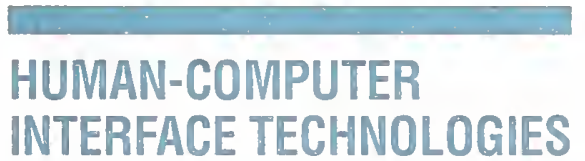

Division Contact:

Martin Herman

(301) 975-2944

email: martin.herman@nist.gov

fax: (301) 975-5287

A216 Technology Building

www.itl.nist.gov/div894

\section{SPOKEN LANGUAGE TECHNOLOGY}

Recent advances in automatic speech recognition (ASR) technology have enabled the development of automatic dictation and spoken language understanding systems and prototype spoken language interfaces to information technology. Interdisciplinary efforts involve the natural language processing, information retrieval, and cognitive engineering (for example, usability testing and human factors) communities.

Much of the relevant research is "corpusbased" and relies on shared use of spoken language databases and standard test methods.

NIST works closely with researchers, other government agencies (such as the Defense Advanced Research Projects Agency), and the Linguistics Data Consortium in the collection, processing, characterization, and distribution of spoken language corpora.

Approximately 150 CD-R0Ms have been produced by NIST for use within the ASR and spoken language research community. NIST also develops and implements periodic benchmark tests to define the state of the art for research ASR systems. The scope of these tests includes several forms of large vocabulary continuous speech, including speech read from prepared texts, conversational speech, goal-directed spontaneous speech, and, most recently, radio broadcasts.
Research facilities include workstations, speech-signal-processing software tools and peripherals, and CD-ROM production tools. Areas of interest include characterization of spoken language data, ASR, natural language understanding and information access, and usability testing. More information is available on www.itl.nist.gov/div894/ 894.01/slp.htm.

Contact:

David S. Pallett

(301) 975-2935

email: david.pallett@nist.gov

A2I6 Technology Building

\section{TEXT SEARCH AND RETRIEVAL}

NIST is working to accelerate the transfer of better text search and retrieval technology into commercial systems. One approach is to conduct a conference attracting international participation from more than 50 research groups in text retrieval, both from industry and academia. The Text Retrieval Conference (TREC) is now starting its seventh year. Participating groups work with large, diverse test coilections built at NIST, submit their results for a common evaluation, and meet for a 3-day workshop to compare techniques and results. The conference is starting to serve as a major technologytransfer mechanism in the area of text retrieval. (See http://trec.nist.gov.)

NIST also has developed a public domain prototype retrieval system (the PRISE system) capable of handling over 3 gigabytes of data. This system uses natural language input and state-of-the-art statistical ranking mechanisms. The prototype serves as a research vehicle within NIST and as a starter kit for groups outside NIST interested in working with these new types of search 
engines or with the Z39.50 (ANSI/NISO) protocol for search and retrieval, which is used for communication between the PRISE client and server. The PRISE server is especially designed to isolate the search engine from the details of the Z39.50 protocol and to minimize the effort needed to interface the server to natural language search engines other than PRISE. More information is available on www-nlpir.nist.gov.

Contact:

Donna K. Harman

(301) 975-3569

email: donna.harman@nist.gov

A216 Technology Building

\section{VISUAL IMAGE PROCESSING}

The visual image processing group develops test methodology and testbed systems and publishes test data for evaluating imagebased systems used in optical-character recognition (OCR), document conversion to electronic form, fingerprint classification, and face recognition. These evaluation methods are designed to include a wide variety of statistical and neural network algorithms and system architectures including optical computing systems. The methods being developed are used for automated fingerprint classification, automation of data entry from images of handprinted forms, automation of conversion of machine-printed documents to electronic form, and measurement of recognition systems on realistic applications. Data sets, evaluation software, prototype OCR, and fingerprint classification and verification systems are distributed on CD-ROM. More information is available on www.nist.gov/itl/ $\operatorname{div} 894 / 894.03$

Contact:

Charles L. Wilson

(301) 975-2080

email: charles.wilson@ nist.gov

A216 Technology Building

\section{INFORMATION VISUALIZATION}

The visualization group conducts research to demonstrate the utility and feasibility of information visualization and computer graphic techniques to access, manipulate, and exchange complex information. Information visualization is a process of transforming data and information that are not inherently spatial into a visual form allowing the user to observe and understand the information.

NIST is developing an interactive visual interface to a statistical text retrieval system. The objective is to demonstrate the utility of visual interfaces for supporting access to large collections of complex documents. Evaluation methodologies and test corpora for measuring scalability and usability of visual interfaces, which are being constructed to support this endeavor, will be made available to the research community. In the manufacturing domain, NIST is collaborating with industrial partners to investigate how the application of three-dimensional visualization, specifically Virtual Reality Modeling Language, can speed up the manufacturing process. This effort includes the use of commercial off-the-shelf software to create visualizations of factory floor assembly lines and support for parts design and assembly. NIST researchers are analyzing usability and performance capabilities of a number of virtual environment and World Wide Web visualization tools for these and other related applications. More information is available on www.nist.gov/itl/div894/vvrg.

\section{Contact:}

Sharon J. Laskowski

(301) $975-4535$

email: sharon.laskowski@nist.gov

A216 Technology Building
MATHEMATICAL AND COMPUTATIONAL SCIENCES

Division Contact:

Ronald F. Boisvert

(301) 975-3812

email: ronald.boisvert@nist.gov

fax: (301) 990-4127

365 NIST North

http://math.nist.gov/mesd

MATHEMATICAL MODELING

Mathematical and computational problems are becoming more elaborate as measurement techniques, physical understanding, and computational capability improve. Solving these problems requires innovative combinations of the methods of modern applied and computational mathematics. With the collaboration of other scientists and engineers, NIST mathematicians develop and analyze mathematical models of phenomena; design and analyze computational methods and experiments; transform these methods into efficient numerical algorithms for modern, high-performance computers; and validate and extend the models by comparing them with experiments. Major research interest areas include crystal growth, fluid flow, electromagnetic waves, magnetic materials, molecular dynamics, foams, and polymers. Frequently occurring mathematical areas include partial differential equations, random processes, and inverse problems. More information is available on http://math.nist.gov/mcsd.

Contact:

James L. Blue

(301) 975-3809

email: james.blue@nist.gov

365 NIST North 


\section{MATHEMATICAL SOFTWARE}

The increasing prevalence of computation in science and engineering has generated an acute need for accurate and robust computer software to solve frequently occurring mathematical and statistical problems. NIST mathematicians and computer scientists are actively involved in the development of algorithms for the solution of such problems, as well as in their reliable and maintainable implementation on modern highperformance computers. Division researchers undertake specific projects in response to both internal NIST needs and the needs of the computational science community in industry and academia. Recent efforts address such problems as the evaluation of mathematical functions, the adaptive solution of partial differential equations on distributed memory multiprocessors, the solution of large sparse linear systems, and object-oriented numerical software design.

Access to such software is provided by the Guide to Available Mathematical Software, a virtual repository of mathematical and statistical software for use in computational science research. This work is part of NIST's efforts to improve the environment for mathematical software research, development, and use. of particular concern in recent years has been the development of testing and evaluation methodology, including reference data, algorithms, and related services, which serve to assess the performance of algorithms and software products. Recent examples include the Matrix Market, a repository of test data for large sparse linear algebra problems, and the Digital Library of Mathematical Functions, an online successor to the popular National Bureau of Standards Handbook of Mathematical Functions. More information is available on http://math.nist.gov/mesd.

\section{Contact:}

Ronald F. Boisvert

(301) $975-3812$

email: ronald.boisvert@nist.gov

365 NIST North

\section{OPTIMIZATION AND COMPUTATIONAL GEOMETRY}

The use of optimization techniques is increasing in design, process modeling, and broad areas of science and engineering, economics, and management. Examples include the use of optimization models in curve and surface fitting, parameter estimation, maximum entropy, minimum energy, and maximum likelihood as well as in newer areas such as performance improvement in production systems and advanced design and control. Improved algorithms and computational power have led to the consideration of multidisciplinary optimization models that pose significant new challenges in all areas of optimization. Division researchers design, analyze, and implement large-scale optimization algorithms and use these methods to develop and solve optimization models in many areas. Current concentration is on large-scale algorithms for nonconvex, nonlinear programming problems using interiorpoint methods and sequential quadratic programming.
Computational geometry is a rapidly emerging field with applications in robotics, statistical mechanics, manufacturing engineering, cartography, computer graphics, materials science, and molecular dynamics. NIST researchers are developing robust and efficient computational schemes for large-scale terrain modeling, manufactured parts recognition, and related problems. Algorithms and software are in wide use at NIST and many other scientific and commercial centers. More information is available on http://math.nist.gov/mesd.

Contact:

Ronald F. Boisvert

(301) 975-3812

email: ronald.boisvert@nist.gov 365 NIST North

\section{IMAGE COMPRESSION}

A recurring theme in information science is the need for efficient encoding of stored and transmitted information. Common information encoding schemes are typically ill-suited to computers and to data networks and, as a result, can be improved substantially. Image compression is an important emerging concern because the infrastructure does not meet the user demands for still images, sequences of still images (for example, in exploratory surgery), and video. More importantly, the trends indicate that the demand for image compression will increase while the systems of the future, by being highly mobile, will rely on inherently limited communications and storage technologies (for example, wireless communications and storage media of minimal weight). 
NIST scientists perform applied and reference implementation research in areas including the development of efficient image compression techniques with emphasis on wavelets, on adapting generic compression techniques for image compression, and on error correction codes that are tuned to the needs of image compression. The scientists also develop reference software and data that facilitate algorithm development and the testing of such algorithms for performance and correctness of output (for example, compliance testing). Finally, metrics for quantifying the quality of the images produced by lossy compression schemes are being developed. More information is available on http://math.nist.gov/mcsd.

Contact:

Tassos Nakassis

(301) 975-3632

email: anastase.nakassis@nist.gov

365 NIST North

\section{STATISTICAL ENGINEERING}

Division Contact:

Keith Eberhardt

(301) $975-2853$

email: keith.eberhardt@nist.gov

fax: (301) 990-4127

353 NIST North

www.itl.nist.gov/div898

\section{COLLABORATIVE}

RESEARCH AND

DEVELOPMENT

VIST statisticians collaborate with other researchers within ITL, other NIST labs, and industry. Most projects address measurement and standards aspects of physical science, engineering, and information technologies. Statisticians help in understanding the problem, the relevant data, and their relationship to the purpose of investigation. The collaboration continues with generation of data, use of available data, model specification, data analysis, uncertainty evaluations, and graphical analyses. Information technologies provide new challenges and opportunities for creative application of statistical methods. Collaborations with industry are done through cooperative research and development agreements (CRADAs).

Recent and ongoing projects include the following:

- improved standardization of hardness measurements to allow industry to write tighter specifications for product hardness;

- developed a statistical measure of sharpness of scanning electron microscope images — industry is using the technique;

- developed a web service (www.itl.nist.gov/ div898/strd/index.html) that provides reference data sets with certified computational results that enable objective evaluation of statistical software;

- developing statistical methods for software conformance testing to indicate confidence that a program is correct and executes correctly;

- developing a statistical process control paradigm for security of computer networks that flags intruders as process anomalies through a visualization interface;

- developing statistical methods for testing performance of information retrieval search engines;

- developing methods to characterize measurement uncertainty and establish traceability to NIST of highly accurate measurements made by coordinate measuring machines; and
- developing a generic test method through a CRADA for electromigration reliability testing of magneto-resistive heads used in computer disk drives, which is a multibillion dollar industry.

More information is available on www.itl. nist.gov/div898.

Contact:

Raghu Kacker

(301) 975-2109

email: raghu.kacker@nist.gov

353 NIST North

\section{MEASUREMENT PROCESS EVALUATION}

Measurement is the backbone for advancing scientific research and creating new technologies. NIST statisticians collaborate with subject experts in developing techniques for evaluating measurement processes, tying measurement processes to accepted standards, and ensuring the quality of measurements. Expertise in the design of experiments, modeling, estimation of components of variance, interlaboratory studies, quality control, and uncertainty analysis, coupled with a strong focus in applied research, brings statisticians into contact with leading researchers in measurement science, both at NIST and elsewhere. This expertise provides opportunities for contributing to the measurement science base for emerging technologies such as the following:

- high-speed communications using optical fibers,

- ultra-large-scale integrated circuits, and

- trapping of polarized ultracold neutrons. 
There also are opportunities to work with NIST scientists and instrument manufacturers on improving the performance of precision instruments such as the following:

- vector network analyzers for the microwave industry,

- spectrophotometry measurement systems,

- probes for measuring sheet resistance of silicon wafers, and

- ballistic imaging systems for evaluating forensic evidence.

Statisticians also are active in the development and application of computational methods and algorithms for feature extraction and pattern recognition in images created using several methods:

- atomic force microscopy,

- high flux X-ray tomography,

- neutron tomography,

- optical reflectance, and

- electron and optical microscopy.

More information is available on www.itl.nist.gov/div898.

Contacts:

Keith Eberhardt

(301) 975-2853

email: keith.eberhardt@nist.gov

Carroll Croarkin

(301) 975-2849

email: carroll.croarkin@nist.gov

353 NIST North
HIGH-PERFORMANCE SYSTEMS AND SERVICES

Division Contact:

Dean Collins

(301) 975-2869

email: dean.collins@nist.gov

fax: (301) 963-9137

A257 Technology Building

www.itl.nist.gov/div895

\section{SCIENTIFIC VISUALIZATION}

Researchers at NIST are developing and applying advanced methods for using stateof-the art, computer-based scientific graphics for rendering complex experimental, computational, and analytical results in physics and chemistry. Researchers use a collection of vector and raster workstations, photographic and video hardware, highspeed networking for transmitting large graphics data sets between computers and graphics devices, and computational geometry algorithms and software for the analysis of two- and three-dimensional data sets. Techniques also have been developed to manipulate dynamic objects in automated design and manufacturing systems; to display quasicrystal structures with icosahedral symmetries and scanning electron tunneling microscopy data with polarization analysis; and to study models of turbulent combustion showing the dependence of solutions on time and fuel-oxidizer mixture parameters.

\section{Contact:}

Gordon E. Lyon

(301) 975-5679

email: lyon@nist.gov

A248 Technology Building

\section{CONTINUAL UPGRADES}

The laboratory maintains a central scientific computing environment for NIST staff in Gaithersburg and Boulder. It procures and operates computer and communications facilities and maintains them at state-of-theart levels suited to the needs of a highly diverse scientific and engineering research and development community. The continuing program of upgrading responds to advances in hardware, software, and communications technologies as well as to changes in the kinds of tools used in modern scientific research.

NIST specialists $\log$ and analyze the use of the components of the facilities-hardware, software, operating systems, and networksto determine what changes or new equipment will be most useful. They take steps to acquire them where possible or to develop them internally. They design interfaces as needed for users to gain access to the resources best suited to their needs. This work proceeds with a broad view of the overall operation of the computing environment and its interactions with external environments as well as a detailed understanding of the progress of hardware and software capabilities and of the roles of visualization and networking in the design and execution of scientific computing projects.

Contact:

Jack Newmeyer

(301) 975-2966

email: jack.newmeyer@nist.gov

B08 Technology Building 


\section{PARALLEL COMPUTING}

NIST researchers are active in a variety of areas designed to provide easy access and use of parallel or clustered computing. NIST scientists are facilitating the development of a standard for interoperability among different vendor implementations of the message passing interface (MPI). They are producing a test suite for testing an implementation's conformance to this interoperable MPI standard.

NIST scientists develop software libraries and algorithms for advanced development and for collaborations with the other NIST labs over a diverse range of topics such as optical absorption, fluid flow in porous media, dissipative particle dynamics, and dendritic growth in metallic alloys. These libraries simplify use of parallel computing through such things as the automatic creation and use of MPI data structures with utilities such as AutoMap, AutoLink, and AutoLoad.

Researchers also create parallel tools such as Pade for transferring files, executing commands remotely, and receiving the output of those commands on clusters of heterogeneous computers. They create user interfaces such as WebSubmit, which is a Web-based graphical user interface used to submit parallel computing jobs to supercomputers. More information is available on www.itl.nist.gov/div895/sasg.

Contact:

Judith E. Devaney

(301) 975-2882

email: judith.devaney@nist.gov

A248 Technology Building
PERFORIMANCE OF MODERN-ARCHITECTURE COMPUTERS

NIST researchers in the area of computer systems performance are promoting the effective evaluation and efficient use of advanced computers. Areas of interest include characterization of new computer architectures to identify improved technology for applications, exploration of economical program ming methods that standardize across classes of architecture, and design of coherent evaluations that economically and reliably characterize the machines.

NIST researchers also are involved in the development of instrumentation and related management techniques for gigabit networks and for clusters of workstations and computers used for scientific calculations. A number of instrumentation products are available; these include VLSI MultiKron ${ }^{\circledR}$ clock chips and plug-in boards, a comprehensive tuning tool S-Check ${ }^{(8)}$ for improving the performance of concurrent codes, and hardware for local synchronized clocks on cluster systems. More information is available on http:// cmr.ncsl.nist.gov.

Contact:

Alan Mink

(301) 975-5681

email: amink@nist.gov

A248 Technology Building
INFORMATION STORAGE AND INTERCONNECT SYSTEMS

The scope of the project is to develop test methods, technology, and standards for flat panel displays, digital data storage, multimedia, and photonic information processing systems that enable high performance computing and communications. Emphasis is on systems integration and the metrological techniques for integrated information systems and subsystems. Research and development is categorized in three areas:

- advanced display technology systems working with the U.S. display industry to test and develop digital display interfaces and resolution-mapping algorithms;

- holographic storage and advanced optical solutions-conducting research in the areas of optical character recognition systems (fingerprints and images) and developing metrology techniques to characterize holographic storage systems; and

- high-performance storage concepts and standards-characterizing emerging highstorage optical media like optical tape and digital video disks and working with the U.S. storage industry to develop universal test methods for media-error monitoring tools for optical tape.

More information is available on http:// cmr.ncsl.nist.gov.

Contact:

Victor McCrary

(301) 975-4321

email: victor.mccrary@nist.gov

A248 Technology Building 
RESEARCH FACILITIES

\section{COMPUTER AND NETWORK SECURITY FACILITY}

The NIST Computer and Network Security Facility is used to improve the current security posture of federal computer and telecommunication systems and to provide security for these systems as they migrate toward open system environments. Research performed in the facility is aimed at applying methods to protect the secrecy and integrity of information in computer systems and data networks, evaluating personal identification and authentication techniques to control access to information resources, and developing computer and network security architectures to determine proper implementation of controls for integrity and confidentiality of information and authentication of users.

\section{CAPABILITIES}

The facility is equipped with desktop computers and workstations, security devices, terminals, personal identification systems, and access to supercomputers through localarea, national, and global networks. Several communications technologies and applications environments are available for research efforts for developing and testing security protocol standards.

Operational capabilities include a computer emergency response team to facilitate identification and response to acute computer and telecommunications security incidents involving self-replicating computer viruses.
Test and evaluation capabilities range from specific functionality tests of cryptographic modules to test methodologies for network security protocols to the specific criteria used to evaluate the trustworthiness of systems that handle unclassified, but sensitive, data.

A laboratory is available for research in risk management techniques and methodologies and evaluation of risk management software to determine applicability to environments at different agencies. Several computers support the development of advanced computer access control systems based on smart-token technology and the virus laboratory for research in multiuser environments. A small systems security laboratory completes the Computer and Network Security Facility.

\section{APPLICATIONS}

The facility is used primarily to develop and test federal standards for computer and network security. Support is provided to other federal agencies and industry where the protection of unclassified data is required.

\section{AVAILABILITY}

Collaborative research programs can be arranged.

\section{Contact:}

Stuart W. Katzke

(301) 975-2934

email: stuart.katzke@nist.gov

426 NIST North

\section{ADVANCED NETWORK FACILITY}

The facility is equipped with desktop computers, workstations, protocol analyzers, and simulators as well as ATM, ISDN, Internet, and satellite communications facilities and switches.

\section{APPLICATIONS}

Facilities are used to develop and assess design alternatives, evaluate performance, and test standards for advanced communications and distributed multimedia systems, which include the following:

- ATM Network-The testbed consists of an ATM switch and several workstations. The testbed is connected to the NIST ATM network and a wide-area ATM testbed.

- Digital Video Interoperability TestbedThe testbed consists of facilities for testing the video-on-demand application conforming to the Digital Audio/Visual Council specification, including MPEG2 video source and server, digital storage management command and control system, and set-top units. Various network access mechanisms, in addition to ATM networks, are being planned.

\section{AVAILABILITY}

Collaborative research programs with govern ment, industry, and academia can be arranged.

Contact:

Craig Hunt

(301) 975-3600

email:craig.hunt@nist.gov 445 NIST North 


\section{MANUFACTURING ENGINEERING LABORATORY}

NIST engineers and scientists are developing many of the underpinning components of automated intelligent-processing srstems that soon will be the core of all world-class manufacturing operations. These components include intelligent machines; advanced sensors for real-time in-process measurements; software for precision control of machine tools: and information technology for integrating all elements of a product's life cycle.

NIST's .Hanufacturing Engineering Laboratory (MEL) provides technical support for industry groups that develop standards for measurements, measurement techniques, hardware, software, and data interfaces.

WEL realizes the fundamental units of length and mass and disseminates measurements in those areas as well as in force, vibration, acoustics, and ultrasonics. MEL researchers are working to develop a sound basis for measurements and standards that support advanced applications of information in manufacturing.

It operates the National Advanced Manufacturing Testbed, a unique national resource for studying the advanced infrastructure technologies required to support future manufacturing operations at both the systems and equipment levels. Laboratory researchers also work at the forefront of the emerging field of nanofabrication, developing measurement tools for atomicscale production technologies of the future.

Laboratory staff members work closely with their industry counterparts, from the planning of research projects to the dissemination of results.

\section{Contact:}

Richard H.F. Jackson, Director

(301) 975-3400

email: richard.jackson@nist.gov

fax: (301) 948-5668

B322 Metrology Building www.mel.nist.gov

\section{COOPERATIVE RESEARCH OPPORTUNITIES}

\section{Precision Engineering}

110 Complex Form Metrology Laboratory

110 Surface Finish and Microform Measurement

110 Atomic-Scale Measuring Machine

111 Measuring Patterned Layers on Integrated Circuits

111 Computational Metrology of Manufactured Parts

111 Coordinate Measuring Machine Calibration Methodologies

112 Hexapod Metrology

112 Large-Scale Artifact Calibration

112 Laser Tracker Metrology

\section{Automated Production Technology}

113 Closed-Loop Manufacturing Program

113 Precision Machining Research

113 Advanced Optical Systems

114 Sensor Interfaces and Networking

114 Machine-Tool Performance Models and Machine Data Repository

114 Controlling Subsurface Damage in Single-Crystal Components

115 Force Research

115 Acoustic and Vibration Research

115 Mass Research

116 Ultrasonics for Industry

\section{Intelligent Systems}

116 Enhanced Machine Controller

116 Next Generation Inspection System

117 Intelligent Systems Architecture for Manufacturing

117 Outdoor Mobility

118 RoboCrane ${ }^{\circledR}$

118 Advanced Welding Manufacturing System

118 Hexapod Project at the National Advanced Manufacturing Testbed

119 Operator Interface

119 Software Engineering for Real-Time Controllers

\section{Manufacturing Systems Integration}

120 Systems Integration for Manufacturing Applications Program

120 Tolerancing and Metrology Research

121 Engineering Design Research

121 Computer-Aided Manufacturing Engineering

122 National Industrial Information Infrastructure Protocols

122 Product Data Exchange Standards for Manufacturing

123 STEP Conformance and Interoperability Testing

123 Manufacturing Resource Data Representation

124 Process Specification Language

\section{RESEARCH FACILITIES}

124 National Advanced Manufacturing Testbed

125 Acoustic Anechoic Chamber Facility

125 Mass Standards Facility 


\section{COOPERATIVE RESEARCH OPPORTUNITIES}

\section{PRECISION ENGINEERING}

Division Contact:

Dennis A. Swyt

(301) 975-3463

email:dennis.swyt@nist.gov

fax: (301) 869-0822

A109 Metrology Building

www.mel.nist.gov/div821/home.htm

\section{COMPLEX FORM METROLOGY LABORATORY}

The mission of the Complex Form Metrology Laboratory is to develop and extend NIST's world-class dimensional measurement capabilities to include forms with complex shapes (e.g., gears, threads, and turbine blades), necessary to satisfy industry's advanced measurement needs. Building on NIST's expertise in the measurement of American Petroleum Institute thread gauges, MEL currently is re-establishing NIST as the pinnacle of dimensional traceability for complex form three-dimensional artifacts for gear manufacturers. Traceability is essential if U.S. industry is to maintain quality and interchangeability of its parts and assemblies, especially as dimensional tolerances continue to decrease. In turn, reliable methods for ensuring dimensional precision and accuracy underlie the ability of U.S. manufacturers to compete in world markets. To this end, NIST has installed, error mapped, and "super tweaked" a new high-accuracy coordinate measuring machine in a state-of-the-art temperature( \pm 0.1 degree Celsius) and humidity( \pm 2 percent) controlled environment. Working with an industrial advisory group-the American Society of Mechanical Engineers' Committee on Gear Metrology_-NIST already has begun to satisfy the traceability needs of the gear industry. A special measurement capability for gear involute, lead, and index artifacts now is available. The laboratory, in its research and measurements, places particular emphasis on the establishment of uncertainty for the measurement of complex forms.

Contact:

Howard Harary

(301) 975-3485

email: howard.harary@nist.gov

B113 Metrology Building

\section{SURFACE FINISH AND MICROFORM MEASUREMENT}

Surface microstructure affects the operation of components in the automobile, aerospace, semiconductor, metals, and optics industries. NIST is developing measurement techniques and standards to benefit all of these manufacturing industries.

NIST played a key role in coordinating the development of a new national standard for surface texture measurement as part of the American Society of Mechanical Engineers Committee B46. For the metals industry, NIST has developed a new approach to measuring the geometry of Rockwell $\mathrm{C}$ hardness indenters that has quickly become the most accurate in the world. NIST plans to use the instrument to control indenter geometry, thereby controlling the accuracy of the hardness measurement itself. This will unify Rockwell C hardness scales worldwide.

For the optics and semiconductor industries, NIST has developed a calibrated atomic force microscope, which is calibrated against the wavelength of light in all three coordinate axes. A principal goal of this project is to calibrate three-dimensional artifacts that will be used to calibrate scanning probe microscopes. NIST also has used this instrument to measure prototype atombased step height standards that collaborators at the University of Maryland fabricated from silicon single crystals. The Precision Engineering Division also is responsible for certifying Standard Reference Materials for roughness and for calibration of the magnification of scanning electron microscopes.

Contact:

Theodore Vorburger

(301) 975-3493

email: theodore.vorburger@nist.gov A117 Metrology Building

\section{ATOMIC-SCALE MEASURING MACHINE}

To help meet the measurement needs of industries preparing to manufacture future generations of nanoelectronic devices and circuits, NIST has designed and built a system-called the Molecular Measuring Machine (M-cubed) — to measure to nanometer accuracies the positions of features located anywhere within a 50-millimeter by 50-millimeter area. Achieving this capability for M-cubed required the development and integration of many forefront technologies: atomic-resolution scanning probes, ultrahigh-accuracy interferometry for displacement measurements, precision nanomotion generation, and combined active and passive vibration-isolation systems.

In one demonstration of its capabilities, M-Cubed imaged with nanometer-scale resolution an array of chromium lines over a 5-micrometer by 1-millimeter area. Analysis of the image data yielded an average line spacing of 212.69 nanometers. The estimated standard uncertainty for the measurement was of 0.03 nanometer, which is about one-tenth the distance of typical interatomic spacings. In another measurement, the atomic-resolution scanning probe was able to track continuously a grating surface for 10 millimeters, counting out 49,996 lines 
and measuring an average line spacing of 200.011 nanometers. This grating now is being used as a reference standard for an $\mathrm{X}$-ray spectrometer being built by NASA for use in space. M-cubed also will serve as an exploratory tool for building mechanical and electrical structures in the nanometer size range. Among the organizations that have collaborated on the construction of M-cubed are several major universities and national laboratories as well as IBM Watson Research Center, AT\&T Bell Laboratories (now Lucent Technologies), and Zygo Corp.

Contact:

John Kramar

(301) 975-3447

email: john.kramar@nist.gov

A117 Metrology Building

\section{MEASURING PATTERNED LAYERS ON INTEGRATED CIRCUITS}

NIST researchers are developing techniques for measuring the critical dimensions of patterned layers on integrated circuits. Work involves theoretical projects on the formation of images in optical, scanning electron, and scanning probe microscopes as well as experimental and design projects on the construction of new metrology instruments for the calibration of standards. The project was initiated about 25 years ago at the request of the semiconductor industry.

Critical dimensions for current semiconductor production are at about 0.25 micrometer. These ever-decreasing dimensions have created a continual demand for new and improved measurement techniques and related standards. As feature sizes become smaller than the wavelength of light used in conventional optical metrology instruments, measurements and standards become especially important. The dimensions of current NIST optical photomask standards range from about 0.5 -micrometer to 30 -micrometer linewidths and potentially will extend to smaller dimensions in the future. A series of three linewidth/pitch Standard Reference Materials (SRMs) for photomasks is now available. For the scanning electron microscope, a semiconductorbased research material (RM 8090) currently is available for SEM magnification calibration with a minimum pitch of 0.2 micrometer stepping to a maximum pitch of about 3 millimeters. The artifacts for the future Standard Reference Material currently are being fabricated. RM 8090 (and the future SRM) is useful at both high and low accelerating voltage modes of the instrument. Research is in process for the development of new and improved standards for use in instruments utilizing optical, scanning electron, and scanning probe microscopy for integrated circuit metrology.

\section{Contact:}

Michael T. Postek

(301) 975-2299

email:michael.postek@nist.gov

A117 Metrology Building

\section{COMPUTATIONAL METROLOGY OF MANUFACTURED PARTS}

Coordinate metrology, such as embodied in coordinate measuring machines (CMMs), involve complex mechanical structures and mathematical compensation and manipulation of data. Although CMMs are widely used in industry, their sources of measurement error are poorly understood and factors affecting the inspection strategy are far from optimized. Consequently, significant economic benefit can be realized by understanding the fundamental metrology of CMM inspection.

This project focuses on first-principle calculations of CMM error sources and their propagation through the inspection system into the final result, such as the measured geometry. NIST is conducting research on:

- point-sampling strategies for real, threedimensional manufactured parts produced by various manufacturing processes;
- modeling and assessment of residual errors in CMMs, probes, and manufactured parts;

- modeling of the propagation of errors through the overall process to allow calculation of confidence-level estimates of the size of manufacturing deviations relative to tolerances in the presence of measurement uncertainty; and

- the impact and assessment of measurement uncertainty in the formulation of part tolerance specifications.

Results from these research activities will allow computer simulation of the measurement process, such as a virtual CMM, permitting CMM metrologists to quantitatively assess the impact of different inspection scenarios and provide traceability to CMM measurements.

Contact:

Steve Phillips

(301) 975-3565

email: steven.phillips@nist.gov

B113 Metrology Building

COORDINATE MEASURING MACHINE CALIBRATION METHODOLOGIES

Coordinate measuring machines (CMMs)

are becoming the tool of choice for the dimensional inspection of manufactured parts in industrial and defense applications. Current procedures for CMM calibration are typically based upon national standards that were designed to promote commerce, such as the buying and selling of CMMs, and were not designed to determine task-specific measurement accuracy.

This project concentrates on the development of artifacts and methodologies for calibrating CMMs in a manner that can be used in the calculation of measurement uncertainty. Additionally, the project involves the use of CMM interim testing to regularly ensure the dimensional capability of the inspection system. This work also will serve 
as a prototype inter-service CMM calibration program for use throughout the U.S. Department of Defense and will provide a unified approach to CMM evaluation and traceability, which will reduce duplication of effort in complying with a multitude of standards. Results of the project will be proposed to national and international standards committees, and calibrated artifacts will be available through NIST's Standard Reference Material Program and other domestic sources.

\section{Contact:}

Steve Phillips

(301) 975-3565

email: steven.phillips@nist.gov

B113 Metrology Building

\section{HEXAPOD METROLOGY}

Machining centers based upon the Stewart platform concept offer the combination of structural rigidity, high-speed tool positioning, and full five-axis motion control. These features have drawn the attention of the automotive and aerospace industries and tool, die, and mold manufacturers. Since the machine configuration is based on computationally intensive servo-control algorithms, rather than upon fixed-axis mechanics, the need to perform tool position metrology for this class of machine tools is critical for both the characterization of positioning accuracy and the evaluation of the performance guarantees of these systems.

The project has three distinct objectives: (1) develop metrology tools for characterizing the performance of these machines, (2) implement on-machine metrology to enhance the positioning accuracy of the NIST hexapod, and (3) provide access to the hexapod metrology database via the National Advanced Manufacturing Testbed (NAMT) environment.

The approach to achieve the first objective is the design, development, and calibration of a full six-degree-of-freedom metrology instrument to characterize the positioning accuracy of the tool tip. The second objective, which is long term, is to implement a laser-based strut length metrology and control system to enhance the positioning accuracy of the NIST hexapod. This objective also requires the development and use of large-scale metrology techniques based on an absolute-distance-measuring laser tracker that is distinctly different from conventional machine tool metrology. The final objective focuses upon the implementation of sensors and data acquisition systems, which are accessible through the NAMT.

\section{Contact:}

Fred Rudder

(301) 975-6500

email: fred.rudder@nist.gov

B113 Metrology Building

\section{LARGE-SCALE ARTIFACT CALIBRATION}

Large-part manufacturing is requiring everdecreasing tolerances. Many large-scale parts, even in high-technology applications, lack interchangeability due to dimensional variation. For example, more than one ton of shims can be needed to assemble a large commercial aircraft. This additional weight can cost approximately $\$ 1$ million per year per plane in additional operating costs. Still, large-scale coordinate metrology is a relatively neglected field. It lacks specific American National Standards Institute or International Organization for Standardization standards and associated artifacts to assess the metrology instrumentation. Similarly, the domestic infrastructure for high-accuracy calibrations of large dimensional standards is nearly non-existent. Manufacturers often must rely on foreign metrology equipment vendors for calibration services. To fill these gaps, the largescale coordinate metrology group has embarked on a program of standardization, artifact development, and calibration for large-scale coordinate metrology systems, such as coordinate measuring machines, theodolites, and laser trackers. One element of this program is the Large-Scale Metrology Calibration and Research Laboratory, currently under development. It will provide a facility to perform high-accuracy onedimensional measurements and calibrations, up to 2 meters, with a target expanded uncertainty $(\mathrm{k}=2)$ of 0.3 micrometer +0.5 $\times \mathrm{L}$ micrometer/meter where $\mathrm{L}$ is in meters.

Contact:

Gregory Caskey

(301) 975-3789

email: gregory.caskey@nist.gov

B113 Metrology Building

\section{LASER TRACKER METROLOGY}

Developed at NIST, the laser tracker, a portable three-dimensional, interferometricbased coordinate measuring instrument, is being eyed for a growing assortment of largescale measurement tasks. To maintain competitiveness in the emerging worldwide economy, many manufacturers and suppliers have begun implementing International Organization for Standardization (ISO) 9000 quality systems and seeking ISO Guide 25-based measurement accreditation-both of which require traceability and hence measurement uncertainty estimates. Unfortunately, the laser tracker suffers the same difficulty as all threedimensional coordinate measuring instruments when it comes to uncertainty estimation. The error mechanisms are very complex and often task specific.

The large-scale coordinate metrology group intends to work with users and manufacturers, through the American Society of Mechnical Engineers/American National Standards Institute Standards working group, to develop a series of test procedures and artifacts that will characterize adequately the measurement performance capability of these instruments. The output will be a national standard whose contents will detail these tests as well as provide guidance for combining the test results into a realistic 
uncertainty estimate. Because of the newness of this technology, this will be the first known effort to standardize the performance assessment of the laser tracker. It is anticipated that the American national standard would be submitted to the ISO for consideration as the international standard governing this technology

Contact:

Charles J. Fronczek Jr.

(301) $975-4079$

email: charles.fronczek@nist.gov

B113. Metrology Building

\section{AUTOMATED PRODUCTION TECHNOLOGY}

Dirision Contact:

E. Clayton Teague

(301) $975-6600$

email: clayton.teague@nist.gov

fax: (301) 869-3536

B102 Sound Building

www.mel.nist.gov/div822/home.htm

\section{CLOSED-LOOP}

\section{MANUFACTURING PROGRAM}

This program aims to achieve higher quality in existing manufacturing processes. A threelaver, closed-loop control architecture is being implemented. The three layers are real-time, process-intermittent, and postprocess control loops. The real-time and process-intermittent control loops implement algorithms to predict and/or measure machine- and process-related systematic errors and then compensate for them in real time or near real time. The post-process control loop is used to verify the models used for the other two control loops and to tune them by detecting residual systematic errors measured on the finished parts, correlating these errors to machine- and process-related errors, and modifying control parameters of the other loops accordingly.
Feature-based error analysis techniques are being developed to identify the residual systematic errors of the machining system. NIST researchers are working with industry and academia to use the dimensional measurement interface specification, an American National Standards Institute standard, in analyses of part features. They are developing tools for feature segmentation of part geometries to improve analyses of machining processes. They also are developing a quality database using feature types and errors measured on these features as key fields.

Contact:

M. Alkan Donmez

(301) $975-6618$

email: alkan.donmez@nist.gov

B106 Sound Building

\section{PRECISION MACHINING RESEARCH}

There is an ever-increasing demand for tighter tolerance components made from "advanced" materials. The higher strength and wear resistance of these materials also make them more difficult to machine. Simultaneously, there is the demand for finer features in integrated circuits, driving the need for improved optics in the lithographic systems that make them on substrates, which also need to improve continuously. Within its Precision Machining Research Facility (PMRF), NIST undertakes an integrated program of research and development in manufacturing and metrology methods to serve these needs.

It is well known that the cost of machining is limiting the rate of application of advanced ceramics. Research into highspeed grinding of ceramics offers the prospect of reducing costs. Rapid wheel wear, however, degrades part accuracy, and both surface finish and the scale of surface defects introduced during grinding must be controlled. Hard steels are commonly ground to achieve high-accuracy components. Turning with cubic boron nitride tools may have economic advantages, especially for small lot sizes, but tool wear can cause problems with surface integrity. PMRF researchers are developing a basic understanding of the mechanisms of material removal and applying advanced sensor methods to process control. (New techniques also are being developed for measuring optical and electronic surfaces. For information, see Advanced Optical Systems, below.)

Contact:

Chris Evans

(301) 975-3484

email: christopher.evans@nist.gov

B102 Sound Building

\section{ADVANCED OPTICAL SYSTEMS}

Advanced optical systems increasingly are designed around high-accuracy, aspheric optical elements. Measuring the figure error of generalized aspheres to the required accuracy is a complex and unsolved problem. NIST has worked with commercially available phase-measuring interferometers and demonstrated that software compensation for some systematic errors is possible. Other issues arising in the use of these instruments to measure aspheres, when no null lens is used, limit achievable accuracy. As a result, NIST has initiated a project to develop a next generation instrument. This instrument is being built under NIST contract and is due to be installed in late 1998 . The resulting measurement service will support the manufacture of lightweight, high-performance optical systems for spacebased applications and multilayer mirror systems for extreme ultraviolet and X-ray lithography.

\section{Contact:}

Chris Evans

(301) 975-3484

email: christopher.evans@nist.gov

B102 Sound Building 


\section{SENSOR INTERFACES AND NETWORKING}

Sensors and actuators are used in a wide variety of applications - industrial automation, manufacturing process control, automated controls of building systems, semiconductor manufacturing, vehicle control, and intelligent highways. Increasingly sophisticated and capable, sensors are devices and miniature systems that measure pressure, acceleration, flow, force, temperature, vibration, torque, position, chemical composition, and other process or environmental variables. The multibillion dollar market for sensors is poised for rapid growth. Smart sensors, which incorporate digital communication and control networking technologies, offer opportunities for a host of new, innovative uses.

However, the lack of a common interface for connecting sensors to microprocessors and, thus, to control and field networks impedes new applications and the benefits they are expected to deliver. It is prohibitively costly for sensor producers to develop custom interfaces to support the multitude of networks and protocols in the market. Thus, sensor manufacturers are seeking a standard interface for sensors. NIST is working with industry and the Institute of Electrical and Electronics Engineers (IEEE), a voluntary standards organization, to develop a set of common interfaces for smart sensors. The objective is to solve the device interchangeability problem and to further progress toward universal plug-and-play compatibility between sensors and networks. The standard interfaces and associated technologies, known as the IEEE 1451, also will provide the enabling technology for the integration and networking of sensors and actuators in distributed measurement and control systems. In addition, it will minimize the risk of technology investment and accelerate the implementation of smart technology on sensors.

Contact:

Kang Lee

(301) 975-6604

email: kang.lee@nist.gov

B106 Sound Building

\section{MACHINE-TOOL PERFORMANCE MODELS AND MACHINE DATA REPOSITORY}

To reduce design and production cycles, manufacturers need tools to predict their manufacturing capabilities before they start manufacturing prototypes for new products. Prototyping is usually an iterative process, taking considerable time and effort before actual production can begin. It is a very costly effort, since, in general, the outcome cannot be predicted with existing design and analysis tools. Developing tools to simulate and carry out this iterative process in the virtual domain presents a unique opportunity for industry to reduce time for new product introduction.

This project aims to replace actual machining and inspection of parts during prototyping with virtual machining and virtual inspection modules incorporated into a $\mathrm{CAD} / \mathrm{CAM}$ system. The virtual machining module will simulate the movement of the cutting tool when making a part. In this simulation, the effects of error motions, predicted from machine-tool characterization data, will be reflected in the tool path. Virtual machining will result in an electronic approximation of the part that can be inspected by the virtual inspection module. The virtual inspection module will determine the uncertainties associated with the selected inspection plans and equipment. These uncertainties will be checked against the specified design tolerances of the part. This virtual environment will make it possi- ble to optimize the manufacturing process by trying different machines and making changes to the process plans or part designs.

A major challenge in creating a virtual manufacturing environment is the representation of the performance and capabilities of various machine tools. Currently, there are no provisions in machine tool or coordinate measuring machine standards to store the performance information in any electronic media. The lack of standard representation prevents the creation of machine data repositories that are needed to test different simulation algorithms and to compare the performance of a given machine against many other machines within a similar category. To overcome this problem, NIST is collaborating with industry and academia to develop a data dictionary along with a standard format for representing meaningful machine tool performance data. A Web-based repository also is being developed to accommodate this data format. In the next step, this repository will be populated with machine tool data from the project collaborators. In addition, remote data analysis and graphical representation tools are being developed within the repository.

\section{Contact:}

M. Alkan Donmez

(301) 975-6618

email: alkan.donmez@nist.gov

B106 Sound Building

\section{CONTROLLING SUBSURFACE DAMAGE IN SINGLE-CRYSTAL COMPONENTS}

Minimizing subsurface damage (SSD) is a key to reducing fabrication costs and improving in-service performance for many optical and electronic components made from single-crystal materials. The lack of reliable means to measure SSD results in increased fabrication time and costs, and it necessitates additional steps to ensure adequate performance. The hazard of SSD is real. 
Damage incurred early in manufacturing is covered in later stages. Although components appear fully functional, they often are badly impaired. This is equally true for glass, metal, and ceramic parts.

This project is a partnership between the Ceramics Division of the NIST Materials Sciences and Engineering Laboratory and MEL's Advanced Production Technology Division. It supports the Sapphire Statistical Characterization and Risk Reduction (SCARR) Program, an effort sponsored by the U.S. military. SCARR aims to develop reference fabrication and diagnostic practices for sapphire and to build a supporting properties database for the material.

NIST's approach is, first, to define the physical nature and extent of the damage, using the best available method. Next, using NIST laboratory facilities, researchers apply one of several non-destructive evaluation methods to parts representative of ongoing fabrication steps. Optical microscopy - in one of its many forms - and X-ray topography are the methods of choice. Performing evaluations at the fabrication site, during processing, is the primary goal of this project.

\section{Contacts:}

Robert S. Polvani

(301) 975-3487

email: robert.polvani@nist.gov

A117 Metrology Building

David Black

(301) $975-5976$

email: david.black@nist.gov

A163 Materials Building

\section{FORCE RESEARCH}

NIST research on force supports a variety of industrial sectors, including the aerospace, automotive, weighing, and construction industries as well as manufacturers of materials and testing equipment. Results further progress in private-sector research and development efforts, and they contribute to development of standards and improved calibration services.

Force measurement capabilities include a unique, fully automated facility featuring the application of deadweight standards from 0.5 kilonewton to 4448 meganewtons. Over the entire range, the standard uncertainty in the applied force is 0.0005 percent. Known worldwide, the facility is normally maintained at 23 degrees Celsius. However, most of the deadweight machines are equipped with environmental chambers that cover a temperature range from - 10 degrees Celsius to 40 degrees Celsius.

\section{Contact:}

Simone L. Yaniv

(301) 975-4917

email: simone.yaniv@nist.gov

B102 Sound Building

\section{ACOUSTIC AND VIBRATION RESEARCH}

Research on acoustic- and vibration-related issues supports a variety of industries, of ten leading to standards and to testing and measurement methods that improve industrial and scientific capabilities. Acoustic and vibration measurements underpin a broad spectrum of activities, including noise control and abatement, health and safety programs, product development, acceptance testing, condition monitoring, and object detection.

Some of the economic impacts are very large. Acoustic measurements of new jet engine noise levels can have multibillion dollar impacts. Vibration and acoustic measurements in product development in the auto industry are extensive. National goals in health and safety also are very strongly affected.

NIST researchers use advanced signalprocessing techniques to measure and characterize frequency-dependent sensitivities of transducers and instrumentation used in the generation or measurement of sound, vibration, and mechanical shock. Measurement capabilities include a 450 cubic meter anechoic chamber, which has been used for special measurements on, for example, towed arrays, micromachined microphones, and loud speakers.

Contact:

Donald Eitzen

(301) 975-6625

email: donald.eitzen@nist.gov

A147 Sound Building

\section{MASS RESEARCH}

Research in the area of mass supports the realization and dissemination of the fundamental unit of mass, its traceability to the international standard, and the measurement of solid density. This research impacts a broad spectrum of industries including the pharmaceutical, instrumentation, and nuclear industries. Further, mass, a fundamental unit, is key to the definition of derived units in both mechanical and electrical metrology; thus, the research potentially affects all manufacturing and all technical communities. Measurement capabilities cover the range from 1 milligram to 27000 kilograms. The most accurate measurements are performed in a dedicated clean room facility with tight environmental controls.

Contact:

Zeina Jabbour

(301) $975-4468$

email: zeina.jabbour@nist.gov

A147 Sound Building 


\section{ULTRASONICS FOR INDUSTRY}

The ultrasonics group performs research, develops standards, and offers calibration services in support of a number of industrial sectors. Research includes the prediction, generation, measurement, and analysis of high-frequency mechanical or "ultrasonic" waves. Ultrasonic transducers are developed and evaluated as prospective standards and for applications to the testing of materials and manufactured parts. Calibration systems are maintained for the manufacturing and medical communities.

Both pulse-echo and acoustic-emission techniques are studied and used. The range of ultrasonic frequencies extends from tens of kilohertz to tens of megahertz, with applications in gases, liquids, and solids. Manufacturing applications of the technology include acoustic emission and referenceartifact calibrations, non-destructive material-property ar:d defect evaluation, dimensional and su:face topography measurements, and sensor-based process control. A principal medical application is for the calibration of a transducer's radiated power in diagnostic usage.

Contact:

Gerald Blessing

(301) 975-6627

email: gerald.blessing@nist.gov

A147 Sound Building

\section{INTELLIGENT SYSTEMS}

\section{Division Contact:}

James S. Albus

(301) 975-3418

email: james.albus@nist.gov

fax: (301) 990-9688

B124 Metrology Building

http://isd.cme.nist.gov

\section{ENHANCED MACHINE CONTROLLER}

Controllers for manufacturing equipment, such as machine tools and robots, traditionally have been proprietary systems. The closed nature of these controllers limits the ability to fully integrate them into the manufacturing enterprise. Modifying closed controllers with new technology often is prohibitively expensive, and life-cycle costs are kept high as options for securing replacement parts or upgrades often are limited to single sources. Recently, the open systems model of desktop computing has been adopted by commercial controller vendors. Emerging open architecture controllers leverage the computing and communications markets, resulting in a dramatic improvement in performance and integration. Many of these controllers also provide interfaces for accessing and modifying internal parameters, enabling third parties to incorporate technology enhancements quickly and cheaply. The goal now is to ensure some compatibility among them.

The enhanced machine controller (EMC) program is a NIST effort to develop and validate a specification for interfaces to open architecture controllers. This specification is being developed jointly with the Open Modular Architecture Controller (OMAC) Users Group, an organization of end users, vendors, and technology providers. Originating with a concept encouraged by General Motors Corp., Ford Motor Co., and Chrysler Corp., the OMAC Users Group now includes 58 members. Through the OMAC Application
Programming Interface Working Group, NIST is working to develop and validate this specification in production applications.

NIST software for machine tool and robot control resulting from the validation process is freely available. Tests at small- and medium-sized manufacturers are being conducted through the NIST Manufacturing Extension Partnership. The intent is to transfer NIST open architecture controls technology to the small business community, so that technology advancements can be made available easily.

\section{Contact:}

Frederick M. Proctor

(301) 975-3425

email: frederick.proctor@nist.gov B124 Metrology Building

\section{NEXT GENERATION INSPECTION SYSTEM}

In-process and post-process inspection of parts often slows the manufacturing process. The inspection of parts with complex geometry, where closely spaced measurements are needed, is especially time consuming. Although the speed and density of data collection can be increased greatly with advanced sensors, these sensors of ten cannot be integrated into existing controllers due to closed or proprietary controller architectures.

The next generation inspection system (NGIS) project maintains a coordinate measuring machine-based testbed for developing and experimenting with open architecture controllers, interface standards, and multiple advanced sensors. NIST's focus is to achieve fast, accurate, and flexible coordinate measurement of both simple- and complex-geometry manufactured parts. NIST's current approach uses vision and $\mathrm{CAD}$ model part data to guide inspection using analog sensors. NIST is collaborating with the National Center for Manufacturing Sciences NGIS consortium, whose members are technology users and vendors. 
The next generation of inspection systems will inspect parts faster and allow better integration of computer-based inspection systems into the factory. User benefits will be higher quality, lower cost products; greater productivity; and reduced time-to-market. Open architecture standards will lead to better systems that are easier to upgrade, stimulation of component markets, and lower component prices through increased competition.

Contact:

William Rippey

(301) $975-3417$

email:william.rippey@nist.gov

B124 Metrology Building

\section{INTELLIGENT SYSTEMS ARCHITECTURE FOR MANUFACTURING}

Intelligent systems architecture for manufacturing (ISAM) is a reference model architecture for intelligent manufacturing systems. It is intended to provide a theoretical framework for the development of standards and performance measures for intelligent manufacturing systems. It also is intended to provide engineering guidelines for a wide variety of manufacturing applications. The ISAVI model addresses the manufacturing enterprise at a number of levels of abstraction:

- At the highest level of abstraction, ISAM provides a conceptual framework for viewing the entire manufacturing enterprise as an intelligent system consisting of machines, processes, tools, facilities, computers, software, and people operating over time on materials to produce products.

- At a lower level of abstraction, ISAM provides a reference model architecture for supporting the development of standards and performance measures, as well as for designing manufacturing systems and software.
- At a still lower level of abstraction, ISAM is intended to provide engineering guidelines for implementing specific instances of manufacturing systems such as machining and inspection systems.

ISAM consists of a hierarchically layered set of intelligent processing nodes organized as a nested series of control loops. In each node, tasks are decomposed, plans are generated, world models are maintained, feedback from sensors is processed, and control loops are closed. In each layer, nodes have a characteristic span of control, with a characteristic planning horizon and corresponding level of detail in space and time.

Contact:

Harry A. Scott

(301) $975-3437$

email: harry.scott@nist.gov

B127 Metrology Building

\section{OUTDOOR MOBILITY}

Intelligent vehicle systems require open system architecture standards. Intelligent vehicles contain a multiplicity of subsystems that recognize objects such as obstacles and landmarks, map the environment for navigation, detect and react to unexpected objects, locate objects for manipulation and handling tasks, compare object scenes for security and surveillance, plan paths, and operate safely and robustly in unstructured environments. Open-systems architecture standards are needed to promote efficient integration of these subsystems and simplify development.

The goal of this project is to provide a testbed for evaluating and validating opensystems architecture standards for intelligent vehicle systems. Development will be a jointly sponsored effort that leverages technology from the NIST intelligent machines initiative program and support from complementary programs sponsored by other agencies. These include the Army Research Lab (ARL) Demo III Unmanned Ground Vehicles program and the AUTONAV research project involving the German Ministry of Defense, the U.S. Department of Defense, and the AUTONAV/U.S. Department of Transportation Crash Avoidance program. The system will use advanced technology available from the AUTONAV research team comprising NIST, ARL, David Sarnoff Research Center, Universitat der Bundeswehr in Munich (UBM), and Dornier (Daimler-Benz).

The testbed consists of a high-mobility multipurpose wheeled vehicle - a fourwheel-drive Army vehicle equipped with control actuators (on the steering, brake, and throttle, for example); advanced sensors; and an open-architecture, real-time control system. This vehicle is capable of both highway driving and off-road driving over rough terrain. Advanced sensors on the vehicle include cameras, a laser range-imaging camera, an inertial navigation system, and a Global Positioning System satellite-based navigation system. The vehicle can be operated remotely by a human operator via teleoperation or autonomously via machine vision systems. The control system is the NIST real-time control system, an opensystem reference architecture. Emerging markets for intelligent vehicle systems include autonomous material handling, operations in hazardous environments, security surveillance, advanced motor vehicle control, and aids for people with disabilities.

Contact:

Maris Juberts

(301) 975-3424

email: maris.juberts@nist.gov

B124 Metrology Building 


\section{ROBOCRANE ${ }^{\circledR}$}

The NIST RoboCrane is a versatile robot crane that can precisely position and orient its work platform in all six degrees of freedom, so that large loads and equipment can be held rigidly in place-even at an angle. RoboCrane is the core of the intelligent systems integration testbed for large-scale manufacturing and construction.

The prime motivation for the testbed is to foster a coordinated and efficient technical response to industry's recognized need for open-architecture standards. These standards will facilitate development and use of sensor-interactive, intelligent-machine systems in large-scale tasks, such as construction, road building, bridge repair, and aircraft assembly. Because interface standards now are lacking, subsystems are difficult to integrate and new capabilities are not added easily. As a result, system functionality is limited, development is prolonged, and maintenance costs are high. By enabling plug-and-play compatibility, standard interfaces would foster development of more efficient systems, and they would create new market opportunities for software and hardware manufacturers. Greater compatibility also would simplify and reduce the cost of customization and system upgrading.

With the aim of testing and validating open systems architectures and their underlying components, researchers at the testbed are exploring precision applications, such as machining and finishing operations, and they are evaluating combinations of sensors and control strategies that result in safe and reliable operation in unstructured, perturbation-prone environments.

Through collaborations with manufacturers, universities, and other organizations, prototype standards and technologies will be integrated and transferred into practical applications such as manufacture of aircraft, ships, construction equipment, and railroad rolling stock; construction and maintenance of buildings, highways, and bridges; environmental clean-up of radioactive or toxic waste sites; and undersea mining, construction, repair, and salvage operations. These partnerships provide NIST with an opportunity to refine advanced intelligent control concepts. They also further NIST's efforts to develop standards and measurement techniques for intelligent machine systems.

\section{Contact:}

Roger Bostelman

(301) 975-3426

email: roger.bostelman@nist.gov

B124 Metrology Building

\section{ADVANCED WELDING MANUFACTURING SYSTEM}

Manufacturers and researchers have shown that there are tremendous productivity, quality, and economic gains from using computerized systems to perform planning, programming, and control for automated welding. The challenges to manufacturers come in integrating the many specialized software and hardware components.

Research at the Advanced Welding Manufacturing System (AWMS) testbed is focusing on autonomous gas metal arc welding technology. It has three goals:

- develop and validate standards that will contribute to increased use of automated welding technology-potential customers identified so far include shipbuilding, heavy equipment manufacturing, and automotive manufacturing;

- demonstrate the ability of interface standards and intelligent control technology to increase productivity, improve quality, and reduce the cost of system integration; and

- develop improved technology for automated welding.
AWMS activities will be performed with industry partners and based on industrystated needs. Faster progress in welding automation systems technology can expand the range of applications where machines can perform reliable welds in a cost-effective manner. Standards for interoperability of specialized advanced control, sensor, hardware, and software components will contribute to better, less expensive welding systems; increased market share for compliant component vendors; and stimulation of new product development. Further, AWMS research with industry will develop new intelligent control systems and anticipate standards needs for the future.

\section{Contact:}

William Rippey

(301) 975-3417

email: william.rippey@nist.gov

B124 Metrology Building

\section{HEXAPOD PROJECT AT THE NATIONAL ADVANCED MANUFACTURING TESTBED}

Rapid production of quality contoured parts requires machine tools that combine speed, accuracy, stiffness and multi-axis versatility. In addition, manufacturers look for qualities such as ease of installation and movability to enable plants to be reconfigured to meet changing market demands. A new class of parallel-actuated machine tools based on the Stewart platform mechanism presents new possibilities for meeting these needs.

However, much remains to be learned about the characteristics of these hexapod machine tools before they will see widespread production application. Industry workshops have highlighted several needs:

- standard test methods and measurement procedures to evaluate their performance, 
- a reservoir of application experience to draw from,

- modeling and simulation tools to help speed the development of machining applications and test methods,

- remote access capabilities to make it easier for collaborators to interact and participate in hexapod research, and

- investigation of controller and integration issues.

This project is addressing these needs by working with industry, university, and government partners to develop capabilities in the areas of characterization, remote access, and simulation of hexapod machines. The work is being carried out within the National Advanced Manufacturing Testbed (NAMT) on an experimental prototype octahedral hexapod machine. A NIST Enhanced Machine Controller (EMC) is being developed for the octahedral hexapod to allow integration with factory-level control software and to enable investigation of experimental control algorithms. To the extent possible, models, measurement techniques, and other project results are being developed in a generic form to allow them to be easily applied to other Stewart platform machines. NIST researchers are participating in a national Hexapod Users Group to coordinate research activities and share results.

Contact:

Albert J. Wavering

(301) 975-3461

email: albert.wavering@nist.gov

B124 Metrology Building

\section{OPERATOR INTERFACE}

The operator interface program is researching needs for interface standards for remote and distributed manufacturing, particularly in the area of remote collaborative work involving operation of machines and programs. One of the approaches NIST is exploring for remote interaction is to construct remote "virtual environments," which are based on real-time text and near-realtime graphics. Remote users will interact richly with other remote participants and local NIST researchers in real time, over the Internet, at low cost.

Within the virtual environment, each remote participant is represented by a virtual entity called an "avatar." The avatar can interact both with other persons' avatars and with the environment in which all the avatars exist. The user sees on his or her screen what the environment represents to his or her avatar, and the environment reacts to the actions of the user's avatar. Hence, other participants also see the acts of the user's avatar reflected on their screens.

The environment itself manages consistency so that when one person's avatar makes some change to the environment-such as moving something around or going to another part of the environment - all other avatars experience the result in an appropriate manner, transparent to the users. A unique feature of the NIST environment is that real-world device controllers may be represented by avatars in the environment. This allows bidirectional interaction between remote users and remote devices through their avatars.

\section{Contact:}

Ernest Kent

(301) $975-3460$

email: ernest.kent@nist.gov

B124 Metrology Building

\section{SOFTWARE ENGINEERING FOR REAL-TIME CONTROLLERS}

Methodologies for designing and building intelligent real-time control systems will improve productivity and capabilities in factories, power plants, transportation systems, and other complex applications. The current state of the practice lacks the necessary techniques and tools for methodically designing, analyzing, and validating control for these extremely complicated systems. Hence, highly specialized engineers are required for the design and implementation of such systems. The goal of this project is to provide methodologies and tools to aid in the software engineering aspects of building realtime controllers.

In order to ensure compatibility with existing practice and enhance usability by U.S. industry, NIST will generate a mapping between its own open system architecture and commonly accepted sof tware engineering terminology. NIST researchers have begun comparisons between the real-time systems reference architecture and other paradigms, such as object-oriented architectures. They also are investigating formal methods and architectural description languages to determine whether they provide benefits in communicating architectural principles and in facilitating system design, construction, and validation.

Another project thrust is the experimental development of a component-based approach to building intelligent control systems, with the eventual goal of supporting automated or semi-automated composition tools. Working with commercially available computer-aided control system design tools, NIST researchers are creating controller "building blocks" and using them to construct a test system. The building blocks are elements of the controller open architecture, which can be assembled with the aid of a tool. Researchers also have generated in-depth specifications for a particular class of components. These specifications can be used for selecting, simulating, and validating components when designing and building a controller.

\section{Contact:}

Elena Messina

(301) 975-3510

email: elena.messina@nist.gov

B124 Metrology Building 


\section{MANUFACTURING SYSTEMS INTEGRATION}

\section{Division Contact:}

Steven R. Ray

(301) $975-3524$

email: steven.ray@nist.gov

fax: (301) 258-9749

A127 Metrology Building

www.mel.nist.gov/msid

\section{SYSTEMS INTEGRATION FOR MANUFACTURING APPLICATIONS PROGRAM}

Under the federal government's High Performance Computing and Communications (HPCC) effort, NIST engaged in a major initiative to enhance integration of advanced manufacturing applications through utilization of information infrastructure technologies. This multiyear initiative, called Systems Integration for Manufacturing Applications (SIMA), involves all seven NIST Measurement and Standards Laboratories with strong participation by U.S. industry, universities, and federal agencies. Launched in 1994, SIMA has three major elements: manufacturing systems, standards development, and testbeds/ technology transfer.

The manufacturing systems element focuses on development of interface specifications for advanced manufacturing systems. Manufacturing applications being targeted by SIMA projects include design, planning, scheduling, process modeling, shop control, simulation, inspection, assembly, and machining. The integration and interface technologies being applied include networking, database technologies, frameworks, and protocols for data exchange. SIMA projects span the industrial manufacturing domains of mechanical products, electronics, and construction.
The standards development element focuses on applying NIST expertise to assist industry in implementing voluntary consensus standards relevant to computer-integrated manufacturing. Successful implementation of manufacturing standards requires validation, pilots, and formal testing to ensure the standards meet the intended requirements. To this end, SIMA projects work on deployment of standards testing methods utilizing HPCC technologies and participate in pilot implementations of HPCC technologies by industry.

The testbeds and technology-transfer element focuses on establishment of testbeds that both serve the infrastructure needs of SIMA projects and can be used as demonstration sites for collaborative tests between SIMA projects and industrial partners. One such facility, the Advanced Manufacturing Systems and Networking Testbed, has been established, and another is under construction. Technology-transfer efforts also include development of infrastructure technologies specialized to disseminate manufacturing information using HPCC techniques.

Numerous successful collaborative relationships with industry are under way. Among these is the effort to design and develop a comprehensive electronic handbook for characterization of engineering problems and relevant software applications with SEMATECH (Austin, Texas). Making these NIST statistical solutions available remotely facilitates accurate analysis and solution of engineering problems in the most expeditious manner, such as at the user's workstation. Another SIMA project has facilitated the establishment of the PlantSTEP consortium (Kansas City, Kan.), which is working to speed the development of data exchange protocols needed for the design of process plants. Working with NIST, the consortium ensures that the developing standard satisfies the intended data exchange requirements for process-plant design. In another SIMA project, the development of testing methodologies for pilot implementations of a data-exchange protocol for new product design in the automotive industry is helping to verify the usability of that standard for exchanges between U.S. car companies and their suppliers.

Contact:

Jim Fowler

(301) 975-3180

email: james.fowler@nist.gov

A127 Metrology Building

\section{TOLERANCING AND METROLOGY RESEARCH}

Concentrating on coordinate measuring systems (CMSs), NIST researchers are developing the technical underpinnings of a unified framework for tolerance standards essential to a range of design and manufacturing activities. Ongoing projects are applying fundamental metrology principles, numerical analysis theory, and statistical methods to develop concepts and approaches for evaluating the performance of CMS data-analysis software. Other work is applying coordinate metrology to complex surface fitting, uncertainty estimation, and statistical tolerancing. Dimensional measurement methods for CMSs are another focus, which ultimately should lead to more effective sampling strategies and data-analysis algorithms. Research is coordinated with ongoing standardization efforts in the United States and internationally. Participation in standards committees guides selection of specific research topics and ensures that the results are disseminated to industry.

\section{Contact:}

Neil Christopher

(301) 975-3888

email: neil.christopher@nist.gov A127 Metrology Building 


\section{ENGINEERING DESIGN RESEARCH}

Design plays a significant role in the iterative and collaborative engineering process. Decisions made during the engineering design stage have a considerable impact on the product's life-cycle costs. Hence, the global competitiveness of U.S. companies and industries depends significantly on the capabilities and intellectual resources embodied and leveraged in design technologies. Through research and technology development, the engineering design group supports and advances the evolution of future design-related standards that respond to industry's identified needs. Technical staff participate in various standards efforts. Technology transfer is facilitated through an engineering design testbed.

The primary goal is to help U.S. industry realize the full potential of current and future engineering-design tools and techniques. NIST researchers are investigating the issues involved in integrating a variety of commercial and university "design" tools. Topics addressed by current projects include virtual reality interfaces, product and process modeling, constraint representation, optimization, and engineering ontologies.

A key issue in achieving an integrated product development environment involves the development of appropriate communication and representation mechanisms. Standards are critical to these communication and representation mechanisms. Active participants in the International Organization for Standardization's STEP (Standard for the Exchange of Product Model Data) initiative, NIST staff are addressing how to incorporate features, constraints, rationale, and other design information within the STEP framework.
To promote technology transfer, a testbed for engineering design has been established. This testbed provides a platform for testing and validating design methodologies, developing standards for product and process models, storing and accessing design case studies, aiding in supplier-chain integration, and helping in various aspects of technology transfer. NIST researchers are working with several universities and industries, particularly through the Defense Advanced Research Projects Agency.

Contact:

Ram D. Sriram

(301) 975-3507

email: ram.sriram@nist.gov

A127 Metrology Building

\section{COMPUTER-AIDED MANUFACTURING ENGINEERING}

Just as computer-aided design and engineering tools have revolutionized product design during the past decade, computer-based tools for production system engineering can revolutionize manufacturing. A new type of computer-aided engineering environment is envisioned, one that will improve the productivity of manufacturing and other industrial engineers. This environment would be used by engineers to plan the manufacture of new products and to design and implement future manufacturing systems and subsystems.

The overall goal of computer-aided manufacturing engineering (CAME) is to lower manufacturing costs, reduce delivery times, and improve product quality through the coordinated development and use of advanced tools. This project is aimed at advancing the development of software environments and tools for the design and engineering of manufacturing systems. NIST has formed the CAME Consortium with industrial partners to address these issues. With industrial consortium partners, universities, and Defense Department manufacturing facilities, NIST researchers are creating an integrated framework, operating environment, common databases, and interface standards for diverse manufacturing engineering software applications. This environment will support and integrate a variety of emerging tools and techniques for designing, modeling, simulating, and evaluating the performance of manufacturing processes, equipment, and enterprises.

The goal of one project is to build an integrated Manufacturing Engineering Tool Kit for developing and validating manufacturing data for machined parts production. The tool kit contains computer-aided design, process planning, simulation and product data management systems. A methodology has been specified for validating manufacturing data in a machine-shop environment. Other researchers are creating a Production System Engineering Tool Kit for designing and modeling production lines for the mechanical assemblies. Interface specifications are being developed to allow commercial off-the-shelf software to interoperate. Examples of the types of software products contained within the tool kits include computer-aided design, process planning, numerical control program verification, product data management, manufacturing simulation, and plant layout.

Prototype tool kits and their interfaces have been demonstrated to the public on several occasions.

\section{Contact:}

Charles McLean

(301) 975-3511

email: charles.mclean@nist.gov

A127 Metrology Building 


\section{NATIONAL INDUSTRIAL INFORMATION INFRASTRUCTURE PROTOCOLS}

This activity is developing technology to enable industrial virtual enterprises and to accelerate adoption of STEP (Standard for the Exchange of Product Model Data) in the operation of these enterprises. Work is being accomplished under a cooperative research and development agreement with the National Industrial Information Infrastructure Protocols (NIIIP) Consortium, comprising various manufacturers, technology providers, universities, and federal agencies. The overall NIIIP program is funded through a Technology Reinvestment Project award. As a virtual enterprise, the NIIIP Consortium is a temporary confederation of firms that come together to share costs and skills to exploit fast-changing opportunities. The NIIIP Consortium will deliver iterations of a reference architecture, software toolkits that are the building blocks of an instantiated reference architecture, research prototypes, and pilot demonstrations. In accomplishing these deliverables, NIIIP will adopt and converge existing standards and technology from STEP, the Object Management Group $(O M G)$, the Internet Society, and the Workflow Management Coalition.

NIST efforts enable improved engineering practices. Advanced communication capabilities for distributed computing resources are being applied to allow for transparent access to distributed resources, including shared data representations. Additionally, workflow management technology will be exploited to expedite the engineering process. NIST research has focused on the integration of STEP technology and standards, while object-oriented technology and standards emerge from OMG. The project is premised on the adoption of STEP Data Access Interface (SDAI) as an international standard. This project will validate the proposal for an SDAI/IDL (Interface Definition
Language) binding. NIIIP plans to develop, demonstrate, and transfer this technology into widespread industrial use.

\section{Contact:}

Katherine Morris

(301) 975-3081

email: katherine.morris@nist.gov

A127 Metrology Building

\section{PRODUCT DATA EXCHANGE STANDARDS FOR MANUFACTURING}

The goal of this activity is to accelerate the development and deployment of product data standards to enable the sharing and reuse of design, engineering, and manufacturing information. The strategy is to work with industry to translate its requirements into standards, principally International Organization for Standardization (ISO) 10303 (Product Data Representation and Exchange), to validate these standards and then to pilot test these standards in an industrial setting. World-wide interest in ISO 10303, also known as STEP, is motivated by industry's desire to achieve critical operational and strategic capabilities. STEP:

- enables a number of improved product development strategies such as concurrent engineering, enterprise integration, and electronic commerce;

- facilitates companies working together as a virtual enterprise on product development; and

- makes possible the use of better approaches to increase efficiency and reduce time to market in developing new or improved products.

Initial implementations of this international standard are by vendors of computeraided design (CAD) systems. Each CAD system's unique proprietary format inhibits the direct exchange of information among various manufacturing processes.
NIST is assisting industry by facilitating standards development and addressing feedback from validation and implementation activities. The initial STEP standard is capable of conveying existing CAD model representations. Additional capabilities are being developed to address other manufacturing applications. NIST is accelerating this work by providing an environment that supports and advances efforts to improve the efficiency and quality of these specifications. An integrated suite of software tools is being established that will interact with the STEP registry at NIST, which contains STEP specifications, related documents, and representative data. This suite will provide "intelligent" access to any part of these references and to generated aspects of the documents that do not require application domain knowledge.

To achieve widespread adoption of these standards, industry must understand the benefits and understand how to manage the risks associated with adopting this new technology. NIST currently is working with the automotive industry on the AutoSTEP pilot project, in which STEP is being used to exchange design and part data between suppliers and original equipment manufacturers. NIST is providing its expertise on requirements analysis, testing methods, and STEP technology. In addition, NIST supplies a neutral site for Internet communications between pilot members. The goal is to document the benefits of using STEP within the context of supply chain business scenarios.

\section{Contact:}

Jim Fowler

(301) $975-3180$

email: james.fowler@nist.gov

A127 Metrology Building 


\section{STEP CONFORMANCE AND INTEROPERABILITY TESTING}

The STEP (Standard for the Exchange of Product Model Data) conformance testing project is sponsored jointly by the NIST Systems Integration for Manufacturing Applications Program and Navy ManTech. The technical goal is to provide an objective means of evaluating a software system for its ability to meet the requirements of STEP, an international standard (officially International Organization for Standardization 10303) developed to let companies effectively exchange design and engineering information with their customers and suppliers as well as internally. The initial customers of the project results are developers of computer-aided engineering systems and product data management systems.

Experience with complex standards has shown that claims of compliance with a standard often are unreliable. When implementations of a standard do not meet requirements, adoption of the standard can be delayed or prevented. The primary focus of this effort is the development of software tools and methods for assessing whether new software applications comply with the standard. The tools need to be extensible to accommodate the expanding set of applications supported by STEP. This project leverages earlier work done by NIST on EXPRESS, the formal description language used to specify STEP and STEP Class Library tool kits.
NIST has formed alliances with the Industrial Technology Institute, PDES Inc., and the Automotive Industry Action Groupindustrial organizations driving the development and application of STEP. NIST and its industrial partners have initiated a beta testing program to give vendors early access to STEP testing tools during product development. This allows them to become familiar with the tools, gain confidence that their product can successfully pass testing, and use the tools to improve the quality of their products. Vendors also gain from the expanded market brought on by increased user confidence in tested products. The same tools also can be employed by end users to assess the ability of these products to interoperate in a specific industrial context, further expanding the market for standards-based products.

This approach provides an infrastructure for an efficient conformance testing program, which will help open world markets to U.S.developed STEP products. In concert with these activities, NIST is aggressively participating in international standards efforts related to conformance testing and product certification.

\section{Contact:}

Simon Frechette

(301) $975-3335$

email: simon.frechette@nist.gov

A127 Metrology Building

\section{MANUFACTURING RESOURCE DATA REPRESENTATION}

The NIST manufacturing resource data representation project is a continuation of prior efforts carried out under the rapid response manufacturing intramural project. This project is designed to establish information models that specify a common and standardized electronic representation for manufacturing resource data. This representation proposes a structure for the classification and characteristics of machine tools, cutting tools, tool holders, cutting inserts, and other resources. Project results provide a catalyst for a standardized manufacturing resource data structure.

Standards activities have been initiated through both International Organization for Standardization (ISO) and American National Standards Institute. Current efforts are to facilitate standardization and implementation of the proposed data structure, lead U.S. efforts for standardization of cutting tool data through the IS0 TC29/WG34 standards group, and facilitate liaison between ISO technical committees to ensure compatibility of standards and no duplication of effort. Impacts of this project include the ability to share manufacturing resource data among manufacturing applications, easier effort for maintenance of resource data and industry databases, direct import of manufacturing resource vendor data into customer applications, and a standardized structure for electronic tooling catalogs.

Contact:

Kevin K. Jurrens

(301) $975-5486$

email: kevin.jurrens@nist.gov

A127 Metrology Building 


\section{PROCESS SPECIFICATION LANGUAGE}

NIST research in the definition of a neutral representation of product data, most recently realized through STEP (Standard for the Exchange of Product Model Data), has resulted in real benefits for U.S. manufacturing industry. Like product data, process data also is used throughout the life cycle of a product, from early assessment of process options, through process planning, production scheduling, and control. In addition, the notion of process underlies the entire manufacturing cycle, coordinating the workflow within engineering and manufacturing. The goal of the Process Specification Language (PSL) project is to create a neutral process representation that would facilitate process data sharing among various applications because they would all "speak the same language," either as a second language or as their native language.

What makes this work unique is its focus on the semantics, or meanings, of the elements of the language. With the growing complexity of information and the increasing need to completely and correctly exchange process information among different disciplines, the need for unambiguous capture of the meaning of concepts within the given representations is becoming more apparent. The PSL will consist of a formal semantic underpinning upon which multiple presentations can be mapped, ultimately enabling the automated exchange of process information within a manufacturing enterprise, or even within a supply chain enterprise.

\section{Contact:}

Amy Knutilla

(301) 975-3514

email: amy.knutilla@nist.gov

A127 Metrology Building
RESEARCH FACILITIES

NATIONAL ADVANCED MANUFACTURING TESTBED

Through the National Advanced Manufacturing Testbed (NAMT) research program, a distributed testbed built on a state-of-the-art, high-speed computing and communications infrastructure has been developed. The testbed is enabling scientists and engineers from industry, NIST, academia, and other government agencies to work collaboratively to solve measurement and standards issues that impede companies and industries from making the most of their information technology.

The NAMT testbed has geographically distributed partners and emphasizes virtual technology to support collaborative research on standards for information-based manufacturing. The equipment, expertise, and capabilities of NAMT partners are electronically connected through the testbed's common infrastructure. Moreover, collections of resources and personnel can be easily configured_-and reconfigured_-in response to changing research needs and objectives. The virtual technology elements of the testbed support research on applications of simulation and modeling methods that are essential to rapid prototyping and fast fabrication, among a host of other key capabilities. Work at the NAMT is devoted not only to developing and validating models and simulations of individual processes, but also to ensuring the integrity and accuracy of computerized representations of the performance of entire manufacturing systems.
The NAMT infrastructure supports real-time interactions among collaborators and realtime access to hardware and software. It integrates voice, video, and data on the same network to create a cohesive collaborative environment. Today, in contrast, organizations use separate networks dedicated to particular uses, such as telephone networks for voice communication, packet-switching networks for data transmission, and closed circuit television for videoconferencing.

Information technology resources available to NAMT partners include the following:

- physical communications components such as networking gateways, routers, and networking software that provide collaborators with access to equipment, documents, databases, project information, test data, and testing suites;

- commercial and experimental software applications, such as design, engineering, and simulation packages;

- multimedia communications such as videoconferencing, groupware, and email exploders to facilitate effective collaboration among remotely located partners, as well as security and safety mechanisms;

- advanced machine tools and research equipment that might otherwise be unavailable to collaborators; and

- vast and varied technical expertise that is immediately accessible through the national network. 
An innovation in research collaboration, the NAVT aims to speed development of a critically needed information infrastructure for U.S. manufacturing. Cooperation, collaboration, and consensus are essential to building this key requirement for future manufacturing competitiveness. The NAVT has a strong foundation of research partners from industry, other government agencies, and the academic community, and new opportunities for collaboration are continuously being explored. The NAMT accommodates different levels of partnership through both formal and informal arrangements. Included among the many ways in which partnership can exist are cooperative research and development agreements, guest researcher agreements, memoranda of understanding, the NIST Industry Fellows Program, contracts, and participation in NAMT-hosted technical workshops. Interested organizations and prospective partners are encouraged to learn more by visiting the NAVT web page at www.mel.nist.gov/namt/nam2.htm.

\section{Contact:}

\section{David Stieren}

(301) $975-3197$

email:david.stieren@nist.gov

A327 Metrology Building

\section{ACOUSTIC ANECHOIC CHAMBER FACILITY}

This facility is a vibration-isolated, shellwithin-shell structure that is one of the quietest and best acoustically characterized rooms in the world. The inner room is supported by 52 coil springs and has walls $0.3 \mathrm{~m}$ thick. All interior surfaces are covered with custom-designed wedges that protrude into the room about $1.8 \mathrm{~m}$. The inner room is $6.7 \mathrm{~m}$ wide, $10 \mathrm{~m}$ long (wedge tip to wedge tip), and $6.7 \mathrm{~m}$ high. The walls are designed to be 99.9 percent sound-absorptive over frequencies above $45 \mathrm{~Hz}$. The ambient noise in the chamber is so low it cannot be measured above a few hundred hertz with the best quality laboratory microphones.

\section{APPLICATIONS}

Acoustical measurements under free-field conditions are performed in the chamber. Research done in the chamber supports standards development, improved measurement methods, and sensor development. Measurement services are provided to a broad range of industries and government agencies. In addition, the chamber has been used to support the development of a wide range of transducers, including advanced loudspeakers and hearing aids, micromachined silicon microphones, and sonar arrays prior to sea trials.

\section{Contact:}

Victor Nedzelnitsky

(301) 975-6638

email: victor.nedzelnitsky@nist.gov

A147 Sound Building

\section{MASS STANDARDS FACILITY}

Dedicated to mass research and development this facility consists of a class 1000 clean room with temperature control to within $0.1^{\circ} \mathrm{C}$ in the range of $20^{\circ} \mathrm{C}$ to $22^{\circ} \mathrm{C}$, temperature gradients of less than $0.1{ }^{\circ} \mathrm{C} / \mathrm{m}$, and relative humidity control to within \pm 2 percent in the range of 45 percent to 50 percent. Additional environmentally controlled laboratories are dedicated to mass measurements in the range $1 \mathrm{mg}$ to $27200 \mathrm{~kg}$.

\section{APPLICATIONS}

Research and development activities include the characterization of physical and chemical properties of artifact mass standards and support of research efforts aimed at monitoring the mass unit by means of fundamental constants. Mass measurement services also are provided.

\section{Contact:}

Zeina Jabbour

(301) $975-4468$ email: zeina.jabbour@nist.gov A147 Sound Building 


\section{MATERIALS SCIENCE AND ENGINEERING LABORATORY}

The Materials Science and Engineering Laboratory provides technical leadership and participates in developing the measurement and standards infrastructure related to materials critical to U.S. industry, academia, government, and the public. Materials science and engineering programs at NIST cover a full range of materials issues from design to processing to performance. A unifying aim is to acquire the knowledge and tools needed for intelligent manufacturing methods with real-time automated process controls.

Separate research initiatives address ceramics, metals, polymers, composites, and superconductors. This research supports efforts of U.S. industry to develop reliable, low-cost manufacturing methods for producing tailor-made materials and products with superior properties.

Through laboratory-organized consortia and one-to-one collaborations, NIST's materials scientists and engineers work closely with industrial researchers. Examples include work on improved processing of rapidly solidified metal powders, polymer composites, ceramic machining, aerospace alloys, and non-destructive evaluation sensors for aluminum and steel manufacturing. The laboratory also is strengthening its relationships with manufacturers of high-technology products, the major users of advanced materials.

\section{Contact:}

Leslie E. Smith, Director

(301) $975-5658$

email: leslie.smith@nist.gov

fax: (301) 975-5012

B309 Materials Building

www.msel.nist.gov

\section{COOPERATIVE RESEARCH OPPORTUNITIES}

\section{Advanced Materials Programs}

127 Ceramic Coatings

127 Dental and Medical Materials

128 Electronic Packaging, Interconnection and Assembly

128 Evaluated Materials Data

128 High-Temperature Superconductivity

129 Magnetic Materials

129 Mechanical Properties of Brittle Materials

130 Polymer Characterization

131 Thin-Film Measurements and Standards

\section{Advanced Processing Programs}

131 Ceramic Machining

132 Ceramic Processing

132 Intelligent Processing of Materials

133 Metals Data and Characterization

133 Metals Processing

134 Polymer Blends and Processing

134 Polymer Composites

135 Ultrasonic Characterization of Materials

\section{RESEARCH FACILITIES}

136 NIST Center for Neutron Research

140 Materials Science X-ray Beamlines

140 Center for Theoretical and Computational Materials Science

141 Magnetic Engineering Research Facility

142 Small-Angle X-ray Scattering Facility

142 Powder Characterization and Processing Laboratory
ORGANIZATIONAL STRUCTURE

MSEL is separated into five divisions. Contacts for each division are listed below.

\section{Ceramics Division}

Contact:

Stephen W. Freiman

(301) 975-6119

email: sfreiman@nist.gov

fax: (301) 975-5334

A256 Materials Building

www.ceramics.nist.gov

\section{Materials Reliability Division}

Contact:

Harry I. McHenry

(303) 497-3268

email:mchenry@boulder.nist.gov

fax: (303) 497-5030

Mailcode 853.00

Boulder, Colo. 80303-3328

www.boulder.nist.gov/div853

\section{Metallurgy Division}

Contact:

Carol A. Handwerker

(301) 975-6158

email: carol.handwerker@nist.gov

fax: (301) 975-4553

B261 Materials Building

www.metallurgy.nist.gov

\section{Polymers Division}

Contact:

Bruno M. Fanconi

(301) 975-6769

email: bruno.fanconi@nist.gov

fax: (301) 975-3928

A309 Polymer Building

www.msel.nist. gov/structure/polymers.html

\section{NIST Center for Neutron Research}

Contact:

J. Michael Rowe

(301) 975-6210

email:mike.rowe@nist.gov

fax: (301) 869-4770

A106 NIST Center for Neutron Research

http://rrdjazz.nist.gov 


\section{COOPERATIVE RESEARCH OPPORTUNITIES}

\section{ADVANCED MATERIALS PROGRAMS}

\section{CERAMIC COATINGS}

The ceramic coatings program is a measurement and characterization effort that addresses the processing reproducibility and performance prediction issues that are primarily associated with thermal-spraydeposited ceramic coatings. The program focuses on plasma-spray-deposited ceramic thermal barrier coatings used in aircraft gas turbines and expected to be used in landbased turbines and diesel engines. Sales in the thermal-spray industry currently are valued at more than $\$ 1$ billion annually, a significant portion of which is ceramic thermal-barrier coatings.

Collaborations have been established with industrial organizations including Pratt \& Whitney, General Electric Co., Caterpillar, Inc., Metco, MetTech, Inc., and Zircoa, Inc., as well as the Thermal Spray Laboratory at the State University of New York at Stoney Brook and the Thermal Spray Laboratory at Sandia National Laboratory. The program includes collaboration with the National Aerospace Laboratory and the National Mechanical Engineering Laboratory, both in Japan, to examine functionally gradient materials. Collaboration also is under way with Bundesanstalt für Materialforschung und-prüfung (Germany) for the development of characterization techniques for thin, hard films. Research is conducted on the processing and properties of physicalvapor-deposited ceramic coatings in collaboration with Praxair.
The approach taken in the plasma-spray (PS) research has been to build on the analytical capabilities at NIST and the material processing capabilities of collaborators. This program tackles the following technical challenges:

- measurement of the physical and chemical properties of stabilized zirconia and tungsten carbide feedstocks;

- determination of the quantity, size, and orientation of porosity and microcracks in PS ceramic coatings suitable for use in modeling the thermomechanical behavior of these materials;

- development of methods to measure chemical, elastic modulus, and thermal properties on a scale suitable for use in microstructural models of behavior;

- development of techniques to model thermomechanical behavior of thermal-barrier coatings to enable more reliable performance prediction;

- development of techniques for accurate measurement of the thermal conductivity of PS coatings by use of the guarded hot-plate technique; and

- development and refinement of more sensitive methods for accurate analysis of oxide phases and residual stresses, which affect performance and durability of coatings.

\section{Contact:}

Stanley J. Dapkunas

(301) 975-6119

email: stanley.dapkunas@nist.gov

A256 Materials Building

\section{DENTAL AND MEDICAL MATERIALS}

The dental and medical materials program provides basic materials science, engineering, test methods, and standards to sectors of the health-care industry for the development of new or improved materials and delivery systems. The focus of this program is the development of improved dental restorative materials with greater durability, wear resistance, and clinical acceptability.

Dental restorative composites are heterogeneous materials having three essential phases:

- a polymeric matrix that comprises the continuous phase;

- fillers of various types, sizes, shapes, and morphologies that constitute the disperse phase; and

- an interfacial phase that, in varying degrees, bonds the continuous and disperse phases into a unitary material rather than a simple admixture.

While all three phases are important in determining the properties of the composites, this program is focused primarily on the interfacial and polymer matrix phases. Since the polymerization shrinkage that occurs in the matrix phase is one of the most commonly cited deficiencies of dental restorative composites, resources are allocated to develop high conversion, durable, low shrinkage polymeric materials for use in dental resin and composite applications.

Although only a minor component of these composites, the interfacial phase that develops from the interaction of the silane coupling agent with the polymer matrix and the siliceous filler exerts a profound effect on the properties of the composites. Because these composites are used in an aggressive, aqueous environment that constantly challenges the vulnerable silane mediated polymer-filler bond, understanding of this critical interfacial phase is being acquired 
so that strategies can be developed for its improvement.

The occupational and environmental hazards associated with the use of mercurycontaining dental alloys also are being addressed through the development of substitute materials with similar physical properties. This project is focused on acid-assisted consolidation of chemically precipitated silver powders and property measurements of hand-consolidated test compacts prepared with the tools and procedures normally employed by dentists. Wear and biocompatibility studies on the hand-consolidated compacts are in progress.

\section{Contact:}

Francis Wang

(30I) $975-6726$

email: francis.wang@nist.gov

A143 Polymer Building

\section{ELECTRONIC PACKAGING, INTERCONNECTION, AND ASSEMIBLY}

MSEL has developed a program committed to addressing the U.S. microelectronics industry's most pressing materials measurement and standards issues, which are central to the development and utilization of advanced materials and material processes within new product technologies. This program embraces the following objectives:

- development and delivery of standard measurements and data;

- development and application of in situ measurements on materials and material assemblies having micrometer- and submicrometer-scale dimensions;

- quantification of the divergence of material properties from their bulk values as dimensions are reduced and interfaces are approached; and
- development of a fundamental understanding of materials needed for future packaging, interconnection, and assembly schemes.

With these objectives in mind, the program presently consists of nearly 20 separate projects that examine key materials-related issues: electrical, thermal, and mechanical characteristics of polymer and metal thin films; solders, solderability and solder joint design; interfaces and adhesion; electromigration and stress voidage; and built-up stress and moisture in plastic packages. These projects always are conducted in concert with partners from industrial consortia, individual companies, academia, and other government agencies. The program is coupled strongly with other microelectronics programs within government and industry, including NIST's National Semiconductor Metrology Program, a national resource responsible for the development and dissemination of new semiconductor measurement technology.

\section{Contact:}

Wen-Li Wu

(30I) 975-6839

email: wen-li.wu@nist.gov

B320 Polymer Building

\section{EVALUATED MATERIALS DATA}

The objective of the evaluated materials data program is to develop and facilitate the use of evaluated databases for the materials science and engineering communities. Both research- and application-directed organizations require readily available evaluated data to take advantage of the large volume of materials information developed on publicly and privately sponsored programs. This information, particularly numeric data, is available in an ever-increasing number of publications published worldwide. The necessity to consolidate and allow rapid comparison of properties for product design and process development underlies the database projects.
Evaluated databases are developed in cooperation with the NIST Standard Reference Data Program and often coordinated with the activities of other laboratories and scientific or technical societies. Research consists of the compilation and evaluation of numeric data as well as recently initiated efforts directed at more effective distribution and use of data. Database activities reflect laboratory programs with scientific capabilities required for appropriate data evaluation.

Database projects in MSEL include the following: Phase Diagrams for Ceramists, in cooperation with the American Ceramic Society; the Structural Ceramics Database for nitrides, carbides, and oxides; a ceramic machinability database; a high- $\mathrm{T}_{\mathrm{C}}$ superconductivity database; and the NACE/NIST Corrosion Performance Database. The associated Crystal Data Center provides fundamental crystallographic data on inorganic materials.

\section{Contact:}

Stanley J. Dapkunas

(301) 975-6I19

email: stanley.dapkunas@nist.gov

A256 Materials Building

\section{HIGH-TEMPERATURE SUPERCONDUCTIVITY}

A significant program in high- $\mathrm{T}_{\mathcal{C}}$ (critical transition temperature) superconductivity is being conducted in MSEL and other Measurement and Standards Laboratories at NIST. The primary focus of the MSEL program is on bulk superconducting materials for wire and magnet applications. In carrying out this program, researchers in MSEL work closely with their counterparts in other NIST laboratories and collaborators in U.S. industry, universities, and other national laboratories. 
The program has four primary thrusts:

- the development of phase diagrams for unique ceramic materials;

- characterization of the effects of strain on loss of current in superconducting wires;

- examination of flux pinning in materials; and

- the use of thermal neutron scattering techniques and profile refinement analyses to investigate crystal and magnetic structures, composition, dynamics, and crystal chemical properties.

Contact:

Stephen W. Freiman

(301) 975-6119

email: stephen.freiman@nist.gov

A256 Materials Building

\section{MAGNETIC MATERIALS}

The focus of the magnetic materials program is the development of the measurement science needed to characterize the properties and performance of new magnetic materials. Proper measurements of key magnetic properties, determination of the fundamental science behind the magnetic behavior of these new materials, analysis of the durability and performance of magnetic devices, and development of Standard Reference Materials are key elements of this program. Of particular interest is understanding the magnetic behavior of lowdimensional systems, in which one or more characteristic dimensions have been reduced to nanometer sizes. Areas of present study include the following:

- processing of magnetic multilayers for optimal giant magnetoresistance effect;

- observation and micromagnetic modeling of magnetic domains for understanding magnetization statics and dynamics in advanced and conventional materials;
- measurement and characterization of nanoscale magnetic interactions in multilayers, nanocomposites, and lowdimensional systems, needed for understanding and applying the new physics of these materials;

- measurement and modeling of the enhanced magnetocaloric effect in nanocomposites;

- structure and magnetic characterization of new superconducting materials;

- nanotribology (measurement of stiction, friction, and wear at the nanometer scale) of magnetic hard disks;

- measurement and understanding the origin of magnetic exchange bias in conventional and advanced magnetic structures and devices;

- development of magnetic sensors of mechanical properties for incorporation as in situ controls in a steel mill; and

- development of a measurement system for the preparation of an absolute magnetic moment standard.

By experimentally addressing important issues in magnetism, by bringing together the industrial and scientific communities through the organization of workshops and conferences in the area, and by the development and preparation of appropriate standards, NIST acts to accelerate the utilization of advanced magnetic materials by the industrial sector and to enable industry to take advantage of new discoveries and innovations.

\section{Contact:}

Robert D. Shull

(301) 975-6035

email: robert.shull@nist.gov

B152 Materials Building

\section{MECHANICAL PROPERTIES OF BRITTLE MATERIALS}

Mechanical properties are the source of the greatest benefits as well as the most severe limitations of ceramic materials. Owing to their high strength-to-weight ratio, their relatively inert behavior in aggressive environments, their high hardness and wear resistance, and their ability to withstand significantly higher temperatures than metals or polymers, ceramics offer the potential for major improvements in component design for a wide range of applications. On the debit side, however, ceramic materials typically exhibit statistically variable brittle fracture, environmentally enhanced subcritical crack growth, sensitivity to machining damage, and creep/deformation behavior at elevated temperatures. Additionally, a lack of techniques that can detect and quantify critical flaws before failure ensues severely curtails current uses of ceramics. Unpredictable failure behavior of ceramics stems from three sources:

- limited data and a deficiency of basic understanding of failure processes in ceramics;

- limited standard test techniques to permit interlaboratory comparisons of materials behavior and collection of engineering data; and

- inadequate models and statistical techniques for life prediction and reliability analyses. The mechanical properties of brittle materials program has components specifically addressing each of these issues.

Basic understanding of the mechanical behavior of ceramics is investigated at both room temperature and elevated temperatures. At room temperature, mechanical properties and failure processes are investigated in fiber-reinforced ceramic matrix composites as a function of microstructural scale and in aluminum nitride substrates as a function of processing conditions, phase 
content, and microstructure. Microstructural stresses related to enlanced fracture toughness are measured via micro-Raman techniques in heterogeneous microstructures and correlated with micromechanical modeling. Micromechanical computer simulations are used to elucidate distributions of residual stress distributions in highly anisotropic ceramics as a function of crystallographic texture. At elevated temperatures, the basic mechanisms responsible for crack growth, creep, and creep rupture are investigated for various silicon nitride compositions and for membrane and fuel cell materials.

To improve interlaboratory comparisons and to increase confidence in generated data, new standard test techniques for hardness and toughness are being developed and tested in round-robin experiments. Research and interlaboratory studies in instrumented indentation address the use of this technique for measuring elasticity and hardness of thin films and coatings. Micro-Raman techniques are being developed and calibrated so that quantitative assessments of microstructural residual stresses can be mapped for heterogeneous microstructures. At elevated temperatures, new creep specimens that permit higher stresses with reduced non-gage section failures were designed. Intra- and interlaboratory studies demonstrated the robustness of these geometries. International interlaboratory studies are under way to elucidate their relationship to alternate testing geometries.

Finally, techniques to predict lifetimes of ceramics under constant and variable loading conditions are being developed. A nonparametric bootstrap approach for assessing the confidence of lifetime predictions is investigated and compared with analytical techniques. Work includes applying these techniques to aluminum nitride materials for thermal management systems and to fused silica and other glasses for spacecraft window applications. A new experimental procedure was developed for characterizing time-dependent failure under static loads.

\section{Contact:}

Edwin Fuller

(301) 975-5795

email: edwin.fuller@nist.gov

A329 Materials Building

\section{POLYMER CHARACTERIZATION}

The polymer characterization program provides measurement methods, data, and Standard Reference Materials needed by U.S. industry, research laboratories, and other federal agencies to characterize polymers for processibility, rheological and mechanical properties, and performance. Molecular mass and its distribution have significant effects on the processibility of polymers through dramatic effects on their rheological properties. Mechanical properties and performance are affected significantly by the solid-state structure formed during processing. Importantly, unlike many other common engineering materials, polymers have mechanical properties that exhibit timedependent viscoelastic and aging behaviors, even at low temperatures. As a result, the focus of the program is on techniques that measure molecular mass distributions, solidstate structures, mechanical properties, and rheological behavior of polymeric materials.

Primary methods employed for molecular mass characterization are dilute solution light scattering and osmometry. Chromatographic techniques, which require calibration by standards of known molecular mass, provide information on molecular mass distribution. Recent activities exploit advances in mass spectrometry using matrix-assisted laser desorption ionization to develop the method as a primary tool for the determination of the molecular masses of synthetic polymers. Solid-state structure of polymers is elucidated using small- and wide-angle $\mathrm{X}$-ray scattering, atomic force microscopy, and electron microscopy, as well as spectroscopic methods such as solid-state nuclear magnetic resonance and infrared spectroscopy.

Adequate characterization of the timedependent viscoelastic and aging behaviors of polymers requires large amounts of testing. For this reason, methods are developed that reduce the number of tests required to describe the non-linear thermo-viscoelastic properties of polymers. The approach applies the frameworks of solid and fluid continuum mechanics to interrelate mechanical responses under different geometries of deformation and in varied deformation histories. Phenomenological models and underlying physical theories are tested using the NIST torsional dilatometer, conventional rotational rheometry, and servohydraulic mechanical testing machines.

The polymer industry and standards organizations assist in the identification of current needs for Standard Reference Materials. Based on these needs, research on characterization methods and measurements is conducted leading to the certification of Standard Reference Materials. Molecular standards are used primarily for calibration of gel permeation chromatographs, the principal method employed by industry for assessing molecular mass and molecular mass distributions. Melt flow standards are used in the calibration of instruments used to determine processing conditions for thermoplastics. Rheological standards are developed for secondary calibrations of rheological instruments in industry and academia.

Contact:

Bruno M. Fanconi

(301) 975-6769

email: bruno.fanconi@nist.gov

A309 Polymer Building 


\section{THIN-FILM MEASUREMENTS AND STANDARDS}

Functional ceramics (that is, ceramics primarily intended for optical, electronic, or thermal management applications) are increasingly being used in film geometries. In response to this growing segment of the ceramics community, the thin-film measurements and standards program endeavors to provide improved measurement tools and data that are needed to evaluate advanced ceramic films and film systems. Increasingly critical film performance requirements (such as reduced dimensions, increased purity, improved interface properties, increased production rates, and tighter control of properties) place stringent demands on film processing control, models, and characterization techniques. However, lack of measurement methods to monitor film processing and accurately characterize film properties as well as limited theoretical understanding of interrelationships between processing conditions and final film properties reduce most film processing to empirical procedures. The activities in this program are designed to address these measurement and modeling issues, both with regard to specific, near-term industrial needs as well as to the development of a materials science knowledge base required for use of ceramic films in future applications. Near-term and long-range goals have been developed based upon both general discussions between MSEL staff and representatives of industry and universities at professional meetings and consortia workshops as well as focused, collaborative research projects with specific organizations.
The film characterization techniques in use or under development include electrical, mechanical, optical, thermal, and X-ray measurements. Specific research activities include the following:

- investigations of the processing and microstructural features that control poling behavior and domain stability in ferroelectric films;

- development and utilization of spectroscopic procedures to evaluate film composition in $\mathrm{BaTiO}_{3}$ and to detect defects in ferroelectric and semiconductor films;

- development of methods to measure and statistically analyze texture and texture distributions in films and to relate these data to processing conditions;

- development of measurement procedures, models, and standards to permit quantitative evaluation of thermal diffusivity in thin films and to relate thermal diffusivity to film microstructure and morphology; and

- application of advanced X-ray measurement capabilities (such as EXAFS and DAFS) to the analysis of film structure and composition and the construction of an in-house state-of-the-art X-ray facility.

A critical requirement of the projects cited above has been the ability to generate model film systems. To this end, this program includes two film deposition capabilities: metallorganic vapor deposition and pulsed laser deposition.

Contact:

Grady White

(301) $975-5752$

email: gwhite@nist.gov

A215 Materials Building

\section{ADVANCED PROCESSING PROGRAMS}

\section{CERAMIC MACHINING}

The ceramic machining program was established in response to a comprehensive survey of the U.S. advanced ceramics industry indicating that the high cost of machining and, at times, uncertain reliability associated with machining damage are primary impediments to the widespread use of these materials. This program is designed to address generic industry needs related to measurement methods and standards in order to assist industry in the development of machining technology for the manufacture of reliable and cost-effective components made from advanced ceramics. Several specific projects are under way to study:

- effects of abrasive machining on mechanical properties of ceramics,

- intelligent machining of ceramics,

- chemical and chemomechanical effects of grinding fluids, and

- abrasive finishing and wear of dental ceramics.

Ceramic materials studied in these projects include those ceramics intended for structural applications, such as silicon nitride, and the ceramics used for dental restorations, such as machinable glass-ceramics. The first two projects are conducted jointly with the 22-member Ceramic Machining Consortium with input from NIST"s Precision Engineering Division, Statistical Engineering Division, and Standard Reference Data Program. The consortium members, representing a broad spectrum of industry including materials producers, machine tool builders, suppliers of expendables (such as grinding wheels and fluids), and end users, participate by providing materials, testing, advice, and other in-kind contributions. The consortium members also provide 
input to the other two projects and assist NIST in formulating the scope of the research projects. The close working relationship developed between industry, academic institutions, and NIST not only ensures the relevance of the research projects but also promotes an efficient and timely transfer of research information to industry for implementation.

Contact:

Said Jahanmir

(301) $975-3671$

email: sjahanmir@nist.gov

A329 Materials Building

\section{CERAMIC PROCESSING}

Ceramic products are primarily produced by powder processing, where raw material powders are mixed with forming additives and shaped by various means into green bodies, which then are fired to the final, hardened state. The processing costs can vary greatly depending on the reproducibility and reliability of the process operation. One key to reliable and rapid development of new products is having good test methods to analyze the material at its different stages of processing. Unfortunately, no satisfactory measurement infrastructure yet exists within the ceramics industry, and, as a result, much processing relies largely on art and experience.

The program on ceramic processing focuses on the development and improvement of measurement methods of generic value to all ceramic companies. Clearer definitions are needed as to what needs to be measured, how is it to be measured, and how reliable is the measurement. Also, the value of the measurement to optimizing the processing operations is needed.
Since all subsequent operations depend on the raw materials' characteristics, the measurement of the physical and chemical properties of powders is an important component of the program. The reliability of various measurement techniques is being assessed in a cooperative international program under the direction of the International Energy Agency and its subtask on ceramic powder characterization. The subtask is being coordinated at NIST in the ceramic processing program. In addition, Standard Reference Materials needed to calibrate the measurement instruments in use are being developed. A project that studies the mechanism of drying, using nuclear magnetic resonance imaging, is in progress and is providing direct insight on the moisture gradients formed during drying.

A consortium called the Ceramic Processing Characterization Consortium (CPCC) was formed in June 1997. Its mission is to assist the U.S. ceramic industry in establishing a generic, powder-processing measurements infrastructure. The goal is to assess the measurement needs in ceramic processing and to take all necessary and feasible actions to find viable solutions. The members of the CPCC are volunteers from companies, instrument makers, universities, and national laboratories. Their contributions to the projects of the CPCC should result in rapid advances in the near future. The current projects follow:

- powder characterization,

- green body characterization,

- moisture measurements,

- dispersion and rheology, and

- microstructure development.

Teams for each of these projects have been formed. The reliability and reproducibility of commonly used instruments will be assessed, new methods will be developed, and a better understanding of how the measured properties affect the behavior of the material at different stages of processing will be developed through basic research studies.
All studies will be generic and nonproprietary. All members of the CPCC share in carrying out the work in the CPCC project teams. The consortium members represent more than 60 companies, government labs, and universities.

Contact:

George Onoda

(301) 975-4489

email: george.onoda@nist.gov

A256 Materials Building

\section{INTELLIGENT PROCESSING OF MATERIALS}

Research activities in the intelligent processing of materials (IPM) program investigate the conversion of materials into value-added products using model-based control of processing variables. Information for real-time process control is provided by on-line sensors that measure material characteristics or processing conditions or both. Intelligent processing will enable industry to economically produce materials with improved quality, consistent properties, and enhanced functionality. The IPM program makes important contributions to two of MSEL's three strategic thrusts: advanced materials and advanced processing.

The IPM concept is the principal approach used to achieve the MSEL goal to "foster the development and implementation of technologies for advanced processing of materials." IPM has three central elements:

- process understanding expressed in terms of a process model,

- real-time information on processing parameters and material condition obtained with on-line process sensors, and

- a model-based sensing and control strategy to achieve the desired characteristics in the finished product. 
IPM projects advance each of these elements, and joint projects with industry are integrating these elements into improved processing capabilities.

The IPM program is an important contributor to the MSEL goal to "foster the use of advanced materials in commercial products." Advanced materials are materials with microstructures designed and controlled to provide superior properties and performance for specific functions. Microstructural control is perhaps the most important application of IPM. The idea is to model microstructural evolution during processing, sense microstructural changes in real time, and use a model-based control strategy to achieve the desired microstructure in the finished product. Microstructural consistency is essential to the commercialization of advanced materials because it ensures reliable properties and performance of the material.

The IPM program also contributes to MSEL's measurement technology goal. A major focus of the IPM projects is process sensors, which industrial collaborators repeatedly identify as a crucial need. Sensor technology is a core competence of MSEL, which has its roots in sensor development for non-destructive evaluation of materials. Unique MSEL capabilities are being used to measure thermophysical properties at elevated temperatures; these data are combined with model enhancements and then incorporated in industrial software for metal casting. In addition, specialized measurement capabilities such as nuclear magnetic resonance and small angle neutron scattering are used to understand microstructure/morphology evolution in ceramics and polymers.

Contact:

Tom Siewert

(303) 497-3523

email: siewert@boulder.nist.gov

Mailcode 853.07

Boulder, Colo. 80303-3328

\section{METALS DATA AND CHARACTERIZATION}

The performance of metals during use and their behavior during processing can be understood and predicted only with the availability of a detailed body of information on their physical properties and microstructure. The value of this information is greatly enhanced if it is developed within the context of models or theories that describe how the measured properties of a metal will vary with changes in composition, microstructure, temperature, geometry, or other parameters. The metals data and characterization program includes activities that refine the technology for measuring the properties and behavior of metallic materials and that correlate these properties and behavior to alloy microstructures.

The large majority of metals are used in applications based on their mechanical properties, with other applications based on electronic, magnetic, optical, or other functional properties forming smaller but nonetheless critical markets. Whatever the application, satisfactory long-term performance of metallic components demands chemical and microstructural stability, sometimes in the presence of harsh environments. This program identifies those processing, microstructure, and properties characterizations that are critical to U.S. industry for both the processing and the performance of metals and carries them out within the context of the NIST mission of providing data and standards. A significant part of the program is the use of advanced microscopy techniques to characterize the microstructures that form the basis of the measured properties.

Contact:

Robert J. Schaefer

(301) 975-5961

email: robert.schaefer@nist.gov

B261 Materials Building

\section{METALS PROCESSING}

The properties of metals and their alloys depend strongly on their processing history. For example, the distributions of phases, grain structure, alloy compositional segregation, and defects in final commercial products depend on the conditions under which materials are processed and fabricated. These distributions in turn are crucial in determining the alloy strength, ductility, homogeneity, and other properties important for industrial applications. The metals processing program focuses on measurements and predictive models needed by industry to design improved processing conditions, provide better process control, develop improved alloy and coating properties, tailor material properties for particular applications, and reduce costs.

Major successes in applying measurements and modeling to processing applications have been achieved in interactions with the aerospace, powder metallurgy, electroplating, and electronics industries. Predictive models for solidification and microstructural evolution during processing have been incorporated by industry into design systems for casting aerospace alloys and producing defect-free electronic materials, helping to reduce rejection rates arising from defective parts. Cooperative research and development projects with industry have resulted in significant improvements in process control for atomization of steel and superalloy powders. Standard Reference Materials certified for coating thickness, microhardness, or chemical composition are being fabricated by electrodeposition techniques and powder metallurgy. Critical mechanistic, chemical, and process variables controlling the structure/property relationships of coatings and thin films produced by electrodeposition are being developed to take further advantage of this electrochemical process, which does not require high-purity starting materials and is readily adaptable to large-scale production. 
There are three kinds of measurements and predictive models for processing being pursued in this program.

- Measurements and models are developed to help design materials production processes, such as measurements and evaluations to provide alloy phase diagrams, which are the roadmaps that alloy designers use to predict the alloy phases that can be produced under specific processing conditions. These evaluations are playing key roles in NIST collaborations with industrial consortia on electronic solders and casting of superalloys for aerospace applications.

- Measurements are made under dynamic conditions to monitor, in real time, properties of materials while they are actually being produced and to determine difficultto-measure process parameters while the process is occurring. Special fast-response sensors, simulations, and imaging techniques have been developed for application to powder atomization and thermal spray processes, and workshops have been held to transfer these techniques to industry. Dynamic models of the process are important both for design of manufacturing procedures and for applications of real time feedback and control.

- To evaluate the adequacy of process models, it is important to measure the properties of the final materials and relate them to the process conditions. Current work in this respect includes evaluation of methods used to optimize properties of electrodeposited coatings and corrosion resistance of rapidly solidified nitrogenated steels.

\section{Contact:}

John R. Manning

(301) 975-6157

email:manning@nist.gov

A153 Materials Building

\section{POLYMER BLENDS AND PROCESSING}

The polymer blends and processing program is designed to establish expertise in static and kinetic aspects of phase behavior in polymer blends, effects of shear flow on mixing and separating, and reactive processing to promote compatibility. The focus on these areas furthers program objectives by accelerating development of new measurement tools, including specialized light- and neutron-scattering methods, and by applying those tools to expand the knowledge base for thermodynamics and kinetics of polymer blends. Work extends to the effects of additives in a blend system, the relative behavior of blends in bulk compared to in thin films at interfaces, and the effects of complex thermal and mechanical histories on the phase separation. Fundamental advances in theory and modeling continue to guide and interpret the measurements.

Current research in the program has four areas of emphasis:

- measurement technology for on-line characterization of temperature, phase behavior, and shear deformation;

- shear effects on phase diagrams and phase morphology;

- activity of additives, compatibilizers, and fillers; and

- control of interfacial effects in blends and during processing.

In each of these areas the program works with industry to develop measurement methods using tools of fluorescence, light scattering, neutron scattering and reflectivity, $\mathrm{X}$-ray scattering, birefringence, microscopy (AFM, TEM, phase contrast), and rheology. Industrial collaborators include Aristech Chemical Corp., Dendritech, Inc., DSM Research, Dow Chemical Co., Dow Corning Corp., DuPont, Dynisco, Inc., Eastman Kodak Co., Exxon Research and Engineering Co., General Electric Co., Goodyear Tire
\& Rubber Co., Mobil Corp., Raychem Corp., Rohm and Haas Co., and $3 \mathrm{M} \mathrm{Co}$.

In order to promote communication and technology transfer with an even broader range of industrial partners, the Polymer Blends and Processing Center has been established. The focus of the center is efficient adoption of measurement technologies developed at NIST and assessment of new research directions for the polymer blends and processing program. The center also promotes initiatives that cut across research projects to improve opportunities for industrial collaborators to use NIST measurement capabilities.

Contact:

Eric Amis

(301) 975-6681

email: eric.amis@nist.gov

B210 Polymer Building

\section{POLYMER COMPOSITES}

The polymer composites program seeks to facilitate the introduction of lightweight, corrosion-resistant composite materials into commercial applications by expanding the essential science base and generating test methods, reference data, and standard materials. The outstanding properties of composites lead to products that are superior and competitive in international markets. The diverse transportation, construction, marine, offshore oil, medical devices, and sporting goods industries have recognized those benefits and are beginning to make significant use of these materials. For this to continue, however, two significant barriers must be addressed: the lack of rapid, reliable, cost-effective fabrication methods and the poor understanding of and predictive capability for long-term performance. In response to these challenges, the composites program initiated two tasks: one on processing science and the other on interfacial microstructure. The degradation of the interface over time is primarily responsible for the loss of mechanical properties. The automotive industry strongly influences the 
composites program since many of the processing and durability issues span many automotive applications, and solutions developed at NIST are expected to rapidly propagate throughout the industry. Additionally, the group interacts with companies interested in offshore oil platforms, infrastructure, aerospace, and a variety of other applications.

The goal of the processing science task is to develop the technology required to monitor, model, and control the events that occur during composite fabrication. The program focuses on liquid composite molding since this fabrication method is of great interest to all industry sectors and is the consensus choice of the automotive industry as the method with the most promise for making structural automotive parts. The approach in this task involves three steps:

- Measurement tools are developed and used to characterize the material properties that control processing, for example, permeability.

- Sophisticated process simulation models are formulated to analyze the effects of processing parameters rapidly and inexpensively so they can be optimized.

- Process monitoring sensors are developed and used to provide feedback for verification and improvement of the simulation models and to help develop the technology for online process control.

The current activities in this task involve five projects, including a major industryuniversity-government program sponsored by the Defense Advanced Research Projects Agency.

The work in the microstructure task focuses on developing test methods for assessing the resin/fiber interfacial adhesion and the subsequent degradation of adhesion resulting from fluid attack, particularly moisture. The long-term goals are to develop effective test methods, to use those tests to identify the chemical and physical mechanisms of degradation, and to formulate reliable predictive models. The program focuses on glass fiber materials since they are the primary candidates for automotive applications. In addition, the researchers are beginning to look at graphite reinforced composites since these systems are important for marine and infrastructure applications.

Microscale tests such as the single fiber fragmentation test are being analyzed to determine if they can provide realistic estimates of the performance of the resin/fiber interface in composite systems. A variety of interfacial physical and chemical structures are generated during preparation of microscale test specimens by varying the coating chemistry on the fiber, the resin processing speed, and the moisture content of the material. Full-scale composite specimens also are produced and tested with identical fiber coatings and processing conditions for comparison with the microscale tests and to provide, in conjunction with the microscale tests, realistic structure/performance relationships. There are currently four specific projects in this task, including a collaboration with the Automotive Composites Consortium to determine the effects of processing conditions on the interface of polyurethane matrix composites.

\section{Contact:}

Richard Parnas

(301) 975-5805

email: richard.parnas@nist.gov

B108 Polymer Building

\section{ULTRASONIC CHARACTERIZATION OF MATERIALS}

The program on ultrasonic characterization of materials is directed to the development of model-based methods of physical measurement that characterize the internal geometries of materials, such as defects, microstructures, and lattice distortions. The goal of the program is to convert these measurement methods into sensors suited for production line and in-service measurements of materials quality and serviceability.

A primary focus of the ultrasonic characterization program is microstructural characterization of metals and alloys, composite materials, and engineered surfaces. The idea is that models relate microstructure and physical properties. Thus, by measuring quantities related to physical properties, the salient microstructural features can be ascertained. For example, sound velocity is related to elastic properties, and thus, ultrasonic measurements can be used to characterize fiber-orientation distributions in composites or texture in metals. These model-based measurements enable industry to replace microscopy with non-destructive methods for the microstructural characterization needed to ensure the quality of advanced materials.

The ultrasonic characterization program is making significant contributions to measurement technology and materials modeling. NIST researchers have worked with industry to commercialize advances in non-contact ultrasonics, wave-form-based acoustic emission, composites nondestructive evaluation, and non-linear ultrasonics. Modeling advances include exploring Green's function methods for wave propagation in anisotropic materials, obtaining elastic constants from resonance spectra, and determining texture based on ultrasonic measurements.

\section{Contact:}

George A. Alers

(303) 497-7899

email: alers@boulder.nist.gov

Mailcode 853.06

Boulder, Colo. 80303-3328 
RESEARCH FACILITIES

\section{NIST CENTER FOR NEUTRON RESEARCH}

The NIST research reactor is the centerpiece of the NIST Center for Neutron Research (NCNR), a national center for the application of neutron methods to a variety of problems of national concern. A major component of the center is the cold neutron source and guide hall, the first major facility in the United States devoted to cold neutron research. The cold source, which employs a liquid hydrogen moderator near the reactor core to produce intense neutron beams, offers modern cold neutron instrumentation unique in this country. A wide variety of internal and external research and measurement programs have benefited from the broad range of capabilities at the NCNR available to researchers from industry, universities, and government laboratories.

\section{CAPABILITIES}

The NIST reactor is a $\mathrm{D}_{2} 0$ cooled and moderated reactor, with a peak thermal core flux of $4 \times 10^{14}$ neutrons $/ \mathrm{cm}^{2}$-s. The core comprises 30 fuel elements of a unique, splitcore design in which nine radial beam tubes look at a 17-centimeter gap between fuelelement halves. A large-volume cold source, guide hall, and eight guide tubes; two tangential and one vertical beam tube; a thermal column; several vertical thimbles; and four "rabbit" tubes complete the configuration.

The reactor operates continuously, 24 hours a day on five-week cycles, followed by shutdowns of approximately a week for refueling and maintenance. The reactor utilizes the available flux in a very efficient manner through relatively short core-to-instrument distances and large-diameter beam tubes. As a result, the flux on the sample for most instruments is comparable to that at other major research reactors of higher power and peak core flux. It is the only research reactor in the United States in which a large volume cavity for a cold source was included in the structure from the beginning. Instrumental capabilities are listed below according to the properties investigated.

\section{CRYSTALLOGRAPHY AND MICROSTRUCTURE}

- BT-1 high-resolution neutron powder diffractometer. This instrument is used to obtain neutron powder diffraction data for crystallographic analysis by the Rietveld method or for other characterization purposes. It is a 32-detector instrument that can be used with three different monochromators and two different incident Soller collimators to tailor the instrument response to the needs of the experiment. Diffraction peak widths are as low as 10 minutes $(\mathrm{d} / \mathrm{d}=$ $8 \times 10^{-4}$ ) with near Gaussian line shapes. The instrument can be used with furnaces, refrigerators, and cryostats so that data may be collected at temperatures from $0.3 \mathrm{~K}$ to $1200 \mathrm{~K}$, and magnetic fields to $7 \mathrm{~T}$. For room-temperature data collection, a sixposition sample changer is available. Time on the BT-1 diffractometer is available via proposals

- BT-8 diffractometer. Newly commissioned at the BT- 8 beam port at the NIST reactor is a state-of-the-art diffractometer for residual stress, texture, and single-crystal studies, or DARTS. A basic monochromator drum has been modified to safely allow take-off-angles up to 120 degrees for high resolution diffraction measurement of residual stresses.

Unique primary and secondary beamaperture systems, which allow a choice of potential sampling volumes from $5 \times 5 \times 5$ $\mathrm{mm}^{3}$ down to $1 \times 1 \times 1 \mathrm{~mm}^{3}$, are incorporated. Each system translates toward or away from the sample to facilitate the study of large material structures or components without requiring realignment of apertures or repositioning of samples. The sample table has 170-millimeter translational motion in the $\mathrm{x}, \mathrm{y}$, and $\mathrm{z}$ directions and can accommodate samples up to $50 \mathrm{~kg}$. Among the other features are a new 1-millimeter resolution position-sensitive detector system and a four-crystal monochromator system with remote selectability. This instrument is intended to be user friendly and available for the solution of industrial or other outside problems.

- NG-3 30-meter small angle neutron scattering instrument. Sponsored by the National Science Foundation as part of the Center for High Resolution Neutron Scattering, this instrument is installed on a dedicated neutron guide, NG-3. Designed to cover a wide Q-range, from $0.015 \mathrm{~nm}^{-1}$ to nearly $6 \mathrm{~nm}^{-1}$, it is suitable for examining structural features in materials ranging from roughly $1 \mathrm{~nm}$ to $500 \mathrm{~nm}$. At least 75 percent of the instrument time will be allocated to guest researchers by the Program Advisory Committee through the NCNR proposal system.

- NG-7 30-meter small-angle neutron scattering instrument. The 30-meter smallangle neutron scattering (SANS) instrument on neutron guide NG-7 is virtually identical to the NG-3 SANS. It is sponsored by NIST, the Exxon Research and Engineering Co., the University of Minnesota, and Texaco Research and Development. As an instrument developed by a participating research team (PRT), 75 percent of the beam time is used by the members of the PRT and the remaining 25 percent is available through the NCNR proposal system.

Together, the 30-meter SANS instruments combine long flight paths and variable collimation to provide flexibility, angular resolution, and beam intensities that compare favorably with any SANS instruments in the world. Large-area position-sensitive detectors provide exceptional sensitivity to materials structures ranging from roughly $1 \mathrm{~nm}$ to $500 \mathrm{~nm}$. Computer automated equipment is available for maintaining samples at temperatures from $4 \mathrm{~K}$ to $700 \mathrm{~K}$ and in magnetic fields up to $2 \mathrm{~T}(20 \mathrm{kG})$. To extract structural information from the data, the researchers analyze SANS patterns with an interactive color graphics system and related programs. Polarized neutron 
capabilities are available on the NG-3 30-meter instrument.

- NG-1 8-meter small-angle neutron scattering instrument. The 8-meter SANS instrument is located at the end of neutron guide $\mathrm{NG}-1$ where the guide cross section is $50 \mathrm{~mm} \times 50 \mathrm{~mm}$. This is a moderate resolution instrument suitable for examining structural features in materials from roughly $1 \mathrm{~nm}$ to $100 \mathrm{~nm}$. This SANS instrument is used primarily for the study of polymers.

- NG-7 NIST/IBM/University of Minnesota neutron reflectometer. Neutron reflectometry probes the neutron scattering density at depths up to several thousand angstroms, with an effective depth resolution of a few angstroms. What is measured is the profile of reflectivity as a function of angle beyond the critical angle for total external reflection for samples that present a smooth, flat surface, preferably several square centimeters in area. The method is extensively used for studies of polymer and biological surfaces, Langmuir-Blodgett films, and thin films and multilayers of metals and semiconductors, both magnetic and non-magnetic. This cold neutron reflectometer permits routine measurement of reflectivities as low as $10^{-7}$ in typical run times of a few hours. Independent movement of both sample and detector allows measurement of off-specular scattering. A position-sensitive detector permits simultaneous measurement of specular and off-specular scattering.

- NG-1 cold neutron reflectometer with polarized beam option. This reflectometer is used in investigations of magnetic multilayers, artificial biological membranes, semiconductor surfaces, and other materials and phenomena in surface and interfacial science. In contrast to the reflectometer on guide NG-7, the sample surface geometry is vertical rather than horizontal. Reflectivities below $10^{-8}$ can be measured. It has full polarized beam capability, provided by transmission supermirror polarizers. Not only can the incident beam be polarized, but also polarization analysis of the reflected beam can be performed in a routine fashion. Polarization efficiencies as high as 98 percent are possible. A special feature of this instrument is the molecular beam epitaxy chamber, which is available for in-situ neutron scattering studies.

\section{MATERIALS DYNAMICS—Medium Resolution,} Incident Neutrons: E>10 meV

- BT-2 triple-axis/polarized-beam spectrometer. This instrument is used extensively for magnetic scattering studies. It can be operated either as a standard triple-axis spectrometer or as a polarized-beam spectrometer, depending on the monochromator crystal choice, and has an incident neutron energy range from $5 \mathrm{meV}$ to $40 \mathrm{meV}$. The latter can be a pyrolytic graphite (002) monochromator for standard 3-axis operation or a Heusler alloy monochromator for polarized beam experiments. Remotely positionable filters, either $15.2 \mathrm{~cm}$ (6 inches) of cooled ( $77 \mathrm{~K}$ ) polycrystalline $\mathrm{Be}$, or $5.1 \mathrm{~cm}$ ( 2 inches) of pyrolytic graphite, may be inserted in the beam from the reactor before the monochromator crystal. The collimator housings before and after the sample position have been designed to provide guide fields for polarized beam operation, and the Soller collimators and blades are made from non-magnetic materials for the same reason. Spin-rotator devices can be mounted before and after the sample position to flip the neutron spins. There is also a guide field that can be selected by computer control to be either vertical to the scattering plane or in it. An extensive variety of ancillary equipment to control the sample environment is available.

- BT-4 triple-axis/filter-analyzer spectrometer. This inelastic scattering instrument offers choices for analyzer and monochromator that make it the most versatile of the thermal-neutron scattering instruments at NIST. One may use either the standard triple-axis analyzer or cooled ( $77 \mathrm{~K}$ ) filter analyzers of two types. The first, a block of polycrystalline Be metal, yields an effective analyzer energy resolution of $3.5 \mathrm{meV}$. The second filter analyzer option employs a combination of polycrystalline Be, followed by a block of polycrystalline graphite. The latter determines the effective analyzer energy resolution, which in this case is 1.2 $\mathrm{meV}$. The monochromator choices are $\mathrm{Cu}$ (220) for higher resolution studies or for measurements with higher incident neutron energies, and pyrolytic graphite (002) for lower incident energies, with moderate resolution and higher beam intensities. The incident neutron energy range is from $3.5 \mathrm{meV}$ to $250 \mathrm{meV}$. Monochromator changes can be made within a few minutes from the instrument console. Both monochromators are vertically focusing with a radius of curvature, which changes to optimize intensity during the course of data acquisition.

- BT-9 triple-axis spectrometer. This instrument is a conventional triple-axis spectrometer, usually employing a vertically focusing pyrolytic graphite monochromator. Recently (mid-1994 to mid-1995), improvements have been made to the monochromator drum and the analyzer assembly. A new monochromator assembly is in construction, which will permit remote selection of a focusing $\mathrm{Cu}(220)$ monochromator, Si (311) or PG (002), providing an incident energy range from $10 \mathrm{meV}$ to $100 \mathrm{meV}$.

\section{MATERIALS DYNAMICS—High Resolution, Incident Neutrons $E=1-15 \mathrm{meV}$}

- Spin-polarized triple-axis spectrometer. This instrument is part of the Center for High Resolution Neutron Scattering supported by the National Science Foundation, from which the Center derives half of its funding. Two-thirds of its beam time will be reserved for guest researcher experiments through the NCNR proposal system. Located on guide NG-5, it is currently operated in three different modes: a conventional tripleaxis mode, a horizontally focusing mode, and a polarized beam mode. A vertically focusing pyrolytic graphite (PG) monochromator produces beams with wavelengths from $2.2 \AA$ to $6.1 \AA$ (17 meV down to $2 \mathrm{meV}$ ). Energy resolution is in the range of 0.03 $\mathrm{meV}$ to $1 \mathrm{meV}$, depending on incident wavelength and collimation. In the horizontally 
focusing mode, a multicrystal analyzer with 11 independently rotating $2 \mathrm{~cm} \times 15 \mathrm{~cm}$ (width $\times$ height) $P G$ blades can be used to focus scattered neutrons of a particular energy onto a single detector (diameter of $2.54 \mathrm{~cm}$ and length of $15 \mathrm{~cm}$ ) and yield a signal increase of a factor of approximately four by relaxing $Q$ (wave vector) resolution. In the polarized beam mode of operation, supermirror transmission polarizers, consisting of a stack of single-crystal Si plates with $\mathrm{Fe} / \mathrm{Si}$ supermirror coatings, are inserted in the incident and scattered beams.

- NG-6 Fermi-chopper time-of-flight spectrometer. This spectrometer has a $150 \mathrm{~mm}$ by $60 \mathrm{~mm}$ (height $\times$ width) beam cross section. The pulsed monoenergetic neutron beam is produced by a combination of monochromator crystals and a Fermi chopper. The double monochromator consists of two PG crystals, one of which can be curved vertically to focus neutrons onto the sample position. The curvature can be varied automatically to adjust for changes in monochomator-sample distances as the incident energy is varied. Two Fermi choppers with different blade curvatures are available. An oscillating radial collimator between the sample and detectors eliminates scattering from cryostat and furnace shields around the sample position. The energy resolution of this instrument, the first of two time-offlight spectrometers to be operating in the $\mathrm{NCNR}$, lies in the range from $60 \mu \mathrm{eV}$ to $1000 \mu \mathrm{eV}$. With incident neutron energies from $2.2 \mathrm{meV}$ to $15 \mathrm{meV}$, the spectrometer allows a broad range of quasielastic scattering experiments on diffusional motions in solids and liquids, and inelastic scattering experiments on magnetic and vibrational excitations.

- Disk chopper time-of-flight spectrometer (DCS). The DCS at neutron guide NG-4 can be used for a variety of experiments, such as investigating quasielastic scattering and low energy inelastic scattering spectra in materials that exhibit diffusional and vibrational phenomena. It uses a set of chopper disks and a partitioned guide to produce pulses of neutrons of a single wavelength at the sample position. There are three slots in each of the disks belonging to the first and last pair of counter-rotating chopper pairs. By appropriately phasing these disks, the resolution of the instrument can be changed without having to change the incident wavelength or the speed of the choppers. Some of the noteworthy features include the flexible choice of neutron wavelength and resolution; 840 detectors covering 5 percent of 4 pi steradians; a $0.2 \mathrm{~nm}$ to $1.2 \mathrm{~nm}(2 \AA$ to $12 \AA)$ incident wavelength range $(0.5 \mathrm{meV}$ to $20 \mathrm{meV})$; elastic energy resolution of $3 \mu \mathrm{eV}$ to $1.2 \mathrm{meV}$. Two thirds of total beam time is available to guest researchers via proposals.

- High-flux backscattering spectrometer (HFBS). The HFBS occupies the end position on guide NG-2. This instrument enables scientists to perform ultra-high-energy resolution studies of the low-frequency dynamics of a large variety of systems. Applications of backscattering spectroscopy are numerous and include studies of rotational tunneling, molecular reorientation, diffusion, dynamics of liquids, and critical scattering near phase transitions. The goal of the HFBS is to provide an energy resolution of less than $1 \mu \mathrm{eV}$ FWHM, while maximizing the neutron flux as much as possible using state-ofthe-art neutron optics. To this end, the instrument incorporates several fluxenhancing elements including a 4-meterlong converging guide, a large spherically focusing monochromator and analyzer, and a novel device known as a phase-space transform chopper. Representative performance characteristics include energy resolution of $0.75 \mu \mathrm{eV}$ FWHM; a dynamic range of $-60 \mu \mathrm{eV}$ to $+60 \mu \mathrm{eV} ; \mathrm{Q}$-resolution of $0.1 \AA^{-1}$ to $0.2 \AA^{-1}$ FWHM; and an elastic Q-range of $0.1 \AA^{-1}<Q<1.8 \AA^{-1}$.

- Spin echo spectrometer (SES). Sensitive to the time-dependent density-density correlation function, the SES directly measures the intermediate scattering function $G(Q, t)$. It bridges the gap in time scale between conventional inelastic neutron scattering and dynamic light scattering. The NIST SES is optimized for measurements of soft condensed matter systems and will provide a Q-range of $0.01 \AA^{-1}$ to $1 \AA^{-1}$ and Fourier times of up to $10^{-7} \mathrm{~s}$. It will be used for studies of systems such as polymers, including glassy polymers; biological model systems; and proteins.

\section{CHEMICAL ANALYSIS}

- Elemental analysis. Neutron activation analysis is performed utilizing the clean room for sample preparation, the reactor irradiation facilities, semi-hot and warm radiochemistry labs, and state-of-the-art radiation-counting labs. Development of methodology has aimed at accuracies and sensitivities over concentrations of $10^{-10}$ percent to 100 percent. Radiochemical separations for specific elements and multielement analysis at the ultratrace level are available. A thermal neutron-capture prompt-gamma activation analysis facility is operational, with a neutron fluence of $5 \times 10^{8} \mathrm{n} / \mathrm{cm}^{2} / \mathrm{s}$ in a 2-centimeter-diameter beam.

- Cold neutron depth profiling instrument. With a measured chemical sensitivity 20 times that of the existing NIST thermalbeam instrument, this station at NG-0 features automated sample handling, near real-time spectral processing, goniometer positioning of sample and detectors, and sample temperature control. Concentrations down to a few parts in $10^{6}$ can be determined, depending on the element and the matrix. Profiling to depths of a few tens of micrometers is obtained, with resolution in depth varying between a few nanometers and a few tenths of a micrometer.

- Cold neutron prompt-gamma-ray activation analysis. Related factors provide much greater sensitivity for this method than any existing thermal-beam instrument in the world. First, the high quality of the neutron beam and the low background at NG-7 allow closer sample-detector spacing, resulting in higher counting efficiency and better sensitivity, especially in the energy region below $1 \mathrm{MeV}$. Second, the high count rates possible with this high efficiency (greater than 50 thousand counts per second) can be 
measured without loss of quality with recent advances in instrumentation. This equipment provides unique measurements of chemical elements, such as hydrogen (detection limit $<2 \mu \mathrm{g}$ ), which are difficult to detect by other means.

\section{DOSIMETRY AND FUNDAMENTAL NEUTRON PHYSICS}

- Neutron standards and dosimetry. A number of neutron fields for standards and dosimetry are available. These include a Cf fission source, a ${ }^{235} \mathrm{U}$ cavity fission source, the thermal column beam, an intermediate energy standard neutron field, and 2-, 24.5-, and 144-kev filtered beams.

- Fundamental physics station. This facility is available for use in collaboration with the NIST fundamental physics research group. Occupying an end guide position in the guide hall, the physics station was recently instrumented for a new measurement of the lifetime of the neutron.

- Neutron Interferometry and Optics Facility. This facility, located in the guide hall of the NCNR, is the world's premier user facility for neutron interferometry and related neutron optical measurements. A neutron interferometer (NI) splits, then recombines, neutron waves. This gives the NI its unique ability to experimentally access the phase of neutron waves. Phase measurements are used to study the magnetic, nuclear, and structural properties of materials, as well as fundamental questions in quantum physics. Related, innovative neutron optical techniques for use in condensed matter and materials science research are being developed.

\section{OTHER CAPABILITIES}

- Instrument development station. A cold neutron beam position deliberately has been left uninstrumented, except for the provision of an optical bench and positioning devices, in order to allow for development of new neutron beam methods and devices, especially in the areas of neutron optics and neutron-based chemical analysis methods. The station is located at a beam port, NG-0, which looks at the cold source, but terminates in the reactor confinement building rather than in the guide hall. A particularly interesting and successful project that has been carried out at this station in recent years has to do with neutron focusing using capillary optics to produce a neutron lens.

- Irradiation facilities. Four pneumatic tubes with fluence ranges of $3 \times 10^{11}$ $\mathrm{n} / \mathrm{cm}^{2} / \mathrm{s}$ to $2 \times 10^{14} \mathrm{n} / \mathrm{cm}^{2} / \mathrm{s}$ for irradiations of seconds up to hours are available. These use polyethylene irradiation containers with volumes up to $40 \mathrm{~mL}$. The cadmium ratio range for these facilities is 4 to $3000(\mathrm{Au})$. For long irradiations 6-centimeter- and 9-centimeter-diameter in-core thimbles are used. These are $\mathrm{D}_{2} 0$ filled with fluences of $2-4 \times 10^{14} \mathrm{n} / \mathrm{cm}^{2} / \mathrm{s}$.

- Neutron radiography. Radiography facilities are available at a highly thermalized beam of the thermal column. Fluences range from $10^{5} \mathrm{n} / \mathrm{cm}^{2} / \mathrm{s}$ to $10^{7} \mathrm{n} / \mathrm{cm}^{2} / \mathrm{s}$, depending on resolution, with a $\mathrm{Cd}$ ratio of 500:1 and an L/D ratio adjustable from 20:1 to $500: 1$. The beam is $25 \mathrm{~cm}$ in diameter at the image plane $2 \mathrm{~m}$ from the reactor face. Facilities for autoradiography of paintings, including labs and a darkroom, are available. This facility currently is being modified to allow new studies using tomographic methods.

\section{APPLICATIONS}

The unusual sensitivity and range of measurements possible at the NCNR provide applications in materials structures, materials dynamics, chemical analysis, and neutron physics. Currently operational instruments are used to study crystal structures, microstructures, and molecular dynamics in the bulk and surfaces of metals, ceramics, polymers, composites, and biological materials. Systems under study include colloidal mixtures, catalysts, thin films, layered structures, and interfaces; magnetic systems including amorphous magnets and spin glasses, superconductors, and magnetic multilayers; hydrogen in metals; shearinduced phenomena; molecular geometry of polymer and biological macromolecules; chemical composition of semiconductors; and other advanced materials. Other major programs include studies in environmental chemistry, nutrition, biomedicine, energy, and electronic devices, with emphasis on Standard Reference Materials for these applications as well as neutron fluence standards for power reactor pressure vessel irradiation surveillance, ultralight mass assay for commercial track recorder detectors, absolute fission-rate measurements, and development of thermal neutron beam monitors.

\section{AVAILABILITY}

The NCNR operates as a national facility open to all qualified researchers. Twentyfive thermal- and 15 cold-neutron experimental stations have been developed for use by the general U.S. research community, operating more than 250 days per year. On most of the cold neutron instruments twothirds of the available time is allocated by a program advisory committee on the basis of scientific merit of written proposals. Participating research teams - which constitute another mode of utilization - are responsible for design, construction, and maintenance of the facilities in return for three-fourths of the available time.

Annually about 1,200 researchers from government organizations, U.S. industrial and university laboratories, and foreign laboratories participated in research at the facilities, either collaboratively with NIST staff or on a proprietary basis.

\section{Contact:}

J. Michael Rowe

(301) 975-6210

email:mike.rowe@nist.gov

A106 NIST Center for Neutron Research 


\section{MATERIALS SCIENCE $X$-RAY BEAMLINES}

N1ST operates two beam stations on the X23A port at the National Synchrotron Light Source (NSLS) at Brookhaven National Laboratory in New York. The light source provides an intense continuous-spectrum beam of collimated and polarized X-rays many orders of magnitude brighter than the beams provided by conventional laboratory sources. These two beam stations offer access to dedicated instrumentation for small-angle X-ray scattering, X-ray diffraction imaging (topography), and extended $\mathrm{X}$-ray absorption fine structure.

\section{CAPABILITIES}

Small-angle X-ray scattering can be carried out in the photon energy range from $5 \mathrm{keV}$ to $11 \mathrm{keV}$. The minimum wave vector is $4 \times 10^{-3} \mathrm{~nm}^{-1}$ and the wavelength resolution is $\Delta \lambda / \lambda=10^{-4}$, enabling anomalous small-angle scattering with excellent resolution. Diffraction imaging of single crystals and powders is carried out with monochromatic photons between $5 \mathrm{keV}$ and $30 \mathrm{keV}$. An energy-tunable $\mathrm{X}$-ray image magnifier enables imaging of microstructure down to less than $1 \mathrm{~mm}$. The energy-scanning experiments, primarily X-ray absorption fine structure (XAFS), also are performed over an energy range from $5 \mathrm{keV}$ to $30 \mathrm{keV}$.

\section{APPLICATIONS}

Small-angle scattering measurements on ceramic and metallurgical materials are used to characterize the microstructure in the 2-nanometer to 1-micrometer size range as a function of starting chemistry and processing parameters. Scattering from a particular entity can be separated from other scatterers in a complex material using anomalous small-angle $\mathrm{X}$-ray scattering. Diffraction imaging is used to study imperfections and strains in single crystals and powder compacts. The structure of strained semiconductor interfaces and metal multilayers can be studied using XAFS. A combination of XAFS and diffraction will provide a capability for site-specific local structure determination in crystals.

\section{AVAILABILITY}

Beam time is available to qualified scientists provided safety requirements are met and scheduling arrangements can be made. Proposals for collaborative use of the facility are reviewed at N1ST; proposals for independent use of the facility should be submitted to the NSLS.

\section{Contact:}

Gabrielle G. Long

(301) $975-5975$

e-mail: gabrielle.long@nist.gov

A163 Materials Building

\section{CENTER FOR \\ THEORETICAL AND COMPUTATIONAL MATERIALS SCIENCE}

The N1ST Center for Theoretical and Computational Materials Science (CTCMS) is a research program addressing industry's needs for theory and modeling tools for materials design and processing. Founded in 1995, the CTCMS is a center of expertise in computational materials research that develops tools and techniques and fosters collaborations. CTCMS goals are to investigate important industrial problems in materials theory and modeling with novel computational approaches, create innovative and productive opportunities for collaboration in materials theory and modeling, develop powerful new tools for materials theory and modeling, and accelerate their integration into industrial research.

\section{CAPABILITIES}

To use more effectively the nation's resources, the CTCMS integrates ongoing research at various institutions by forming temporary multidisciplinary and multiinstitutional research teams as required to attack key materials issues. The CTCMS has three principal activities, all operating interactively: planning, research, and technology transfer. Workshops are held as the first step in defining technical research areas with significant technological impact, identifying team members, and building the infrastructure for collaborative research. The CTCMS provides an infrastructure and support for its members, including an interactive World Wide Web information server (www.ctcms.nist.gov) and modern computing and workshop facilities.

\section{APPLICATIONS}

Current research areas include theory and simulation of phase transformation kinetics and morphology, micromagnetics, composite materials, foams, microstructure and dynamics of disordered and partially ordered materials, complex fluids, materials reliability, reactive wetting, pattern formation in polymers and alloys, granular materials, crystal growth, sintering, and solidification. Simulation techniques include finite element, finite difference, Lattice Boltzmann, molecular dynamics, Monte Carlo, and cellular automata methods. Current CTCMS working groups include the following:

- Micromagnetic materials. This working group is addressing the need for accurate, standardized micromagnetics modeling tools. Software tools developed by the group and selected sample geometries may be found at www.ctcms.nist.gov.

- Solder interconnect design. The solder interconnect design team is developing public-domain software tools to improve electronic packaging processes. Tools developed by the solder group that model standard solder interconnect geometries are available at www.ctcms.nist.gov.

- Microstructure and dynamics of frustrated materials. This working group is applying new computational capabilities to characterize the relationship between microstructure and dynamics in glasses, plastics, and other amorphous rnaterials and developing a new set of measurement standards. 
- Pattern formation in filled polymers. This new working group is developing computational tools to characterize and improve the properties and functionality of filled polymer materials.

- Deformation of metals. This new working group is developing a theory that bridges the length scales between single atomistic dislocations and macroscopic deformation of a piece of metal, such as an aluminum bar or an automobile part.

- Green's function library. This team of researchers is developing an interactive, electronic library tool of Green's function and boundary element solutions to reduce the time and cost of industrial component design.

- Object-oriented finite element modeling of composite materials. This team of researchers is developing a set of objectoriented finite element modeling tools to improve the characterization and property prediction of composite materials. Public domain software tools are available at www.ctcms.nist.gov.

Also available on the CTCiS webserver are public domain software tools for modeling 3-D crystal shapes. The program, known as Wulffman, was developed at the CTCMS and is designed to run with Geomview software developed at the Minnesota Geometry Center. It currently is being used in industry to design materials used in reflective paints.

\section{AVAILABILITY}

The CTCMS facilitates numerous interactions between industry, academia, NIST, and other government and national labs to apply materials theory and modeling to solve U.S. industrial problems in materials design and processing. Researchers interested in joining existing efforts or starting new ones are encouraged to contact the CTCMS. The center welcomes proposals for focused workshops in materials theory and modeling at any time. Proposals will be funded on the basis of scientific merit and availability of funds. Computing and workshop facilities are available to U.S. industry, other government agencies, and academia for collaborative research projects. The CTCMS participates in the National Research Council postdoctoral fellowship program and hosts short-term and long-term visitors.

\section{Contact:}

Sharon Glotzer

(301) $975-5729$

email: sharon.glotzer@nist.gov

A309 Materials Building

\section{MAGNETIC ENGINEERING RESEARCH FACILITY}

\section{CAPABILITIES}

This is an elaborate new facility specifically designed for advancing key enabling technologies in the field of ultrahigh-density data storage. Films can be deposited both by the methods preferred in basic research (molecular beam epitaxy) and by the methods of industrial manufacturing (magnetron sputtering). Numerous in situ characterization techniques are available including scanning tunneling microscopy, $\mathrm{X}$-ray photoelectron spectroscopy, Auger electron spectroscopy, ion scattering spectroscopy, low-energy electron diffraction, reflection high-energy electron diffraction, and mass spectrometry. For in situ magnetic measurements, both a superconducting magnet and an electromagnet are available and are equipped for magnetoresistance and magneto-optical Kerr effect measurements. As such, this facility constitutes the most elaborately instrumented magnetic thinfilm deposition facility in the world.

The capabilities of this in situ instrumentation allow samples to be investigated at every step of fabrication with the most modern surface, interface, and magnetic diagnostics. Properties that can be investigated include elemental composition, thickness, atomic structure, roughness, and magnetic and magnetoresistive properties. These capabilities allow researchers to establish the correlations between the film structure and properties and to use the resulting insights to control and improve the properties of device-related materials.

\section{APPLICATIONS}

This facility presently is being used to prepare magnetic spin valves possessing giant magnetoresistance (GMR) effects and to study the physics related to their fabrication. These devices, which are partially comprised of 1- to 2-nanometer-thick alternating layers of $\mathrm{Co}$ and $\mathrm{Cu}$, will be used in the next generation computer hard disk read-heads and possibly in a new generation of non-volatile memory chips to compete with dynamic random access memory. For the past three years in this highly competitive area, Magnetic Engineering Research Facility (MERF) activities have led the world in devices possessing the largest GMR values with the switching fields small enough for devices. Through close association with the National Storage Industry Consortium, which comprises the leading magnetic recording companies, NIST has provided the MERF results to the recording industry on a continuous basis. In 1997 two Japanese companies began commercial production of GMR read-heads for hard disks, and U.S. manufacturers are just about to do the same. Fierce competition is under way to dominate this key technology of the information storage industry. This introduction of GMR heads means that only eight years elapsed between the discovery of the GMR effect and its introduction into commercial products. The MERF facility is being used to support U.S. industry in the competition by making measurements that industry is not equipped to make. This approach is expected to lead to the development of GMR readheads in the future that are even better than the ones of today and help keep U.S. industry competitive in world markets. 


\section{AVAILABILITY}

The MERF is open to all qualified U.S. researchers who are interested in collaborative research. Scientists from industry particularly are encouraged to take advantage of the opportunities for collaborative research of interest to their companies. Several such collaborations presently are under way. However, facility time can be made available for new collaborations if the proposed research is designed to promote the agenda of our customers.

\section{Contacts:}

William F. Egelhoff , Jr.

(301) $975-2542$

email: william.egelhoff@nist.gov

B248 Chemistry Building

Robert D. Shull

(301) 975-6035

email: robert.shull@nist.gov

B152 Materials Building

\section{SMALL-ANGLE X-RAY SCATTERING FACILITY}

Small-angle X-ray scattering (SAXS) is a technique in which a highly collimated beam of X-rays (wavelength range $0.07 \mathrm{~nm}$ to $0.3 \mathrm{~nm}$ ) is used to probe the structure of materials on the size scale of $0.1 \mathrm{~nm}$ to $100 \mathrm{~nm}$

Materials exhibiting structure in this size range include polymers, biological macromolecules, ceramics, metals, and alloys. The small-angle scattering patterns can be analyzed to characterize the size and shape of the scattering centers as well as their spatial distribution and surface area. Data obtained from these experiments are complementary to data obtained from other diffraction studies and from morphological studies using electron microscopy.

\section{CAPABILITIES}

The NIST 10-meter SAXS camera uses a

12-kilowatt rotating anode $\mathrm{X}$-ray generator as a source of $\mathrm{X}$-rays. The target is usually copper lambda $(\mathrm{K}$ alpha $)=1.54$, but additional wavelengths are available. The collimation path is defined so as to permit $10^{-2}$ $\mathrm{nm}^{-1}$ resolution in reciprocal space at the surface of a two-dimensional positionsensitive proportional detector. The collimation path and the scattered beam path are evacuated, and all elements of vacuum operation, X-ray optical configuration, sample selection, and calibration are computer controlled. Image data are collected by a minicomputer, and a complete collection of software is available for displaying, analyzing, and modeling the results.

Sample chambers are available for measurements at high temperatures and to deform specimens during measurement.

\section{APPLICATIONS}

The SAXS technique is used to study molecular conformation, microphase domain structures, crystallization phenomena, network formation, craze initiation, void distribution, and similar phenomena resulting from fluctuations in electron density within a material. Such studies are currently of broad interest in all areas of materials science.

\section{AVAILABILITY}

This facility is operated by members of the NIST staff in support of their active research program in polymeric materials. It is available for use by researchers from industry, academia, and other government agencies on either a collaborative or proprietary basis.

\section{Contact:}

John D. Barnes

(301) 975-6786

email: john.barnes@nist.gov

A209 Polymer Building

\section{POWDER}

CHARACTERIZATION AND PROCESSING

\section{LABORATORY}

Advanced ceramics are manufactured by the consolidation of fine powders. Researchers at NIST are working to develop the scientific foundation needed for improving reproducibility and reducing the cost of producing ceramic components. The powder characterization facility offers specialized instrumentation for measuring physical properties, phase composition, and surface chemical properties. In addition, facilities exist for processing and synthesizing ultrapure powders

\section{CAPABILITIES}

- Physical properties measurement. Particle-size distribution, specific surface area, specific gravity, and porosity are some of the major physical properties for which instrumentation is available. Powder-size distribution can be determined by gravity sedimentation followed by X-ray absorption, centrifugal sedimentation, light diffraction, and photon correlation spectroscopy. The size range of these instruments covers $0.03 \mu \mathrm{m}$ to $200 \mu \mathrm{m}$. Each instrument works in a specific range and provides the data in the form of a discrete size range. The particles are examined directly by the application of scanning and transmission electron microscopy of particles as small as $0.001 \mu \mathrm{m}$. 
- Surface and interface chemistry measurements. The surface and interface characterization of powders contributes to the knowledge base of the surface interactions of particles in contact with dispersants and binders. As the particles become smaller, their surface characteristics become more significant. MicroRaman and Fourier transform infrared spectroscopy are used to study surface composition, and electrophoretic mobility and acoustophoretic mobility are used to study modification to the powder surface as a result of an interaction with dispersants and binders.

- Phase composition. Since most of the ceramic powders undergo phase transformation during densification, understanding the phase changes in specific densification environments is an active part of NIST research. The Siemens high-temperature X-ray diffractometer has a temperature range from room temperature to $3000 \mathrm{~K}$ and a positionsensitive detector. In addition, sintering can be carried out in oxygen-free argon or nitrogen environments.
- Solid-state imaging. The solid-state nuclear magnetic resonance (NMR) spectrometer/imager carries out measurements in chemical shift, nuclear spin density, relaxation times, and imaging of NMR active nuclear distribution. Ceramic powder slurries, green bodies, and dense ceramics can be analyzed for identification of impurities, chemical state, and composition distribution by non-destructive evaluation. In addition, the NMR can determine amorphous phase content of the powders.

- Powder synthesis. The ability to synthesize powders of controlled characteristics is necessary for development of a powderprocessing knowledge base. The fine-powder synthesis facility consists of a chemical flow reactor for controlled synthesis and inert atmosphere chambers. A solution atomizer is available to generate polydisperse aerosols in the range of $0.001 \mu \mathrm{m}$ to $1.0 \mu \mathrm{m}$, as is a spray dryer to form monodisperse agglomerates in the range $0.5 \mu \mathrm{m}$ to $100 \mu \mathrm{m}$.
- Colloidal suspensions preparation. Colloidal processing of ceramic powders has emerged as an attractive technology for producing defect-free ceramics. However, some major issues still remain to be addressed, including the lack of characterization techniques for slurries that contain high concentrations of solids and scientific understanding of limitations in the preparation of such slurries. The powder processing laboratory consists of an acoustophoresis instrument, a rheometer, a highenergy agitation ball mill, and slurry consolidation equipment. These techniques are used to study interface chemistry, flow behavior, size reduction, morphology modification, and densification of polydisperse particles and similar processes resulting from interactions between the particles and their environment.

\section{AVAILABILITY}

These facilities are used primarily to support NIST research programs using ceramic powders. They are available for collaborative or independent work by qualified government, industry, or university personnel with preference given to projects related to ceramics research.

Contact:

George Onoda

(301) $975-4489$

email: george.onoda@nist.gov

A256 Materials Building 
The NIST Physics Laboratory supports U.S. industry by providing measurement services and research for electronic, opti$\mathrm{cal}$, and radiation technology. It pursues directed research in the physical sciences; develops new physical standards, measurement methods, and data; conducts an aggressive dissemination program; and collaborates with industry to commercialize inventions and discoveries. The laboratory's programs range from tests of fundamental postulates of physics to the more immediate needs of industry and commerce.

Much of the laboratory's research is devoted to overcoming the barriers to the next technological revolution, in which individual atoms and molecules will serve as the fundamental building blocks of electronic and optical devices. To develop the necessary measurement capabilities for these new products, laboratory scientists use highly specialized equipment to study and manipulate individual atoms and molecules.

The laboratory's work in support of industry covers a broad scope of activities. For example, the laboratory is working to improve optical measurement techniques used in remote sensing, advanced color graphics systems, and optically pumped atomic clocks. Research also is focused toward advancements in the measurement and dosimetry of ionizing radiation used in medicine and industry and supports the development of emerging technologies such as X-ray lithography, digital X-ray imaging, and electron beam processing.

Contact:

Katharine B. Gebbie, Director

(301) $975-4201$

email:katharine.gebbie@nist.gov

fax: (301) 975-3038

B160 Physics Building

http://physics.nist.gov

\section{COOPERATIVE RESEARCH OPPORTUNITIES}

Office of Electronic Commerce in Scientific and Engineering Data

145 Electronic Commerce in Scientific and Engineering Data

145 Dissemination of Databases over Computer Networks

\section{Fundamental Constants Data Center}

145 Evaluation of Fundamental Constants, Measurement Uncertainties, and SI

\section{Electron and Optical Physics}

146 Photodiode Detectors for Radiometry

146 EUV Optics Characterization

146 Tunneling Microscopy

147 Magnetic Microstructure

147 Nanofabrication with Atom Optics

147 Condensed Matter Theory

147 Data for Electronic Structure Calculations

$148 \mathrm{X}$-ray Nanotomography

$148 X$-ray and EUV Microscopy

\section{Atomic Physics}

148 Vacuum Ultraviolet Radiometry

148 Low-Temperature Plasmas

149 Research on Highly lonized Atoms

149 Laser Cooling and Trapping

149 High-Precision Laser Spectroscopy

149 Fourier Transform Spectrometry

150 Interactions of Cold, Trapped Atoms

150 Theory for Nanoscale Systems and Metrologies

150 Precision X-ray and Gamma-ray Spectroscopy

150 Synthetic Multilayers

151 Applications of X-ray Technology

\section{Optical Technology}

151 Luminescence Spectral Radiometry

151 Photometry

152 High-Accuracy Cryogenic Radiometry

152 Thermal Radiometry

152 Near Ultraviolet Radiometry

152 Spectral Radiometry

153 Infrared Spectral Radiometry
153 Spectroscopic Applications

153 Non-Linear Optical Measurements

153 Optical Scattering Measurements

154 Near-Field Scanning Optical Microscopy

154 Time-Resolved Infrared Spectroscopy

154 Elementary Chemical Reaction Dynamics

\section{lonizing Radiation}

155 Radiation Processing

155 Measurement Quality Assurance

155 Neutron Physics

156 Neutron Dosimetry

\section{Time and Frequency}

156 Ion Storage Research

156 Atomic Beam Frequency Standards

157 Noise in Electronic and Optical Systems

157 Statistical Analysis of Time-Series Data

157 Time Transfer and Network Synchronization

157 Far-Infrared Spectroscopy

157 High-Performance Diode Lasers

\section{Quantum Physics}

158 Bose-Einstein Condensation

158 Thin Films

158 Laser Deposition of Thin Films

158 Mobility of Cluster Ions

159 Stabilized Lasers

\section{RESEARCH FACILITIES}

159 Synchrotron Ultraviolet Radiation Facility III

159 Magnetic Microstructure Measurement Facility

159 High-Resolution UV and Optical Spectroscopy Facility

160 Low-Background Infrared Radiation Facility

160 Controlled Background Radiometric Facility

160 Medical-Industrial Radiation Facility

161 Electron Paramagnetic Resonance Facility

162 Radiopharmaceutical Standardization Laboratory

162 Neutron Interferometer and Optics Facility

\section{SERVICES}

163 Time and Frequency Services 


\section{COOPERATIVE RESEARCH OPPORTUNITIES}

OFFICE OF ELECTRONIC COMMERCE IN SCIENTIFIC AND ENGINEERING DATA

Office Contact:

Edward B. Saloman

(301) $975-5554$

email: edward.saloman@nist.gov

fax: (301) 975-4578

B161 Technology Building

\section{ELECTRONIC COMMERCE IN SCIENTIFIC AND ENGINEERING DATA}

The Office of Electronic Commerce in Scientific and Engineering Data works to promote compatibility and integration in the dissemination of non-product-specific information required by U.S. industry. It seeks to make scientific, engineering, technical, codes/standards, and related regulatory information available to U.S. industry in a usable, accessible, unified manner. The office's goal is to help make it possible for industry to create an electronic marketplace that will allow participants to efficiently locate, access, protect, contribute, and pay for scientific, engineering, and regulatory information. This information will be provided in open formats and computersensible form along with specification of the quality and security of the provided information. Work on this effort began with an industry/government team organized in conjunction with the National Initiative for Product Data Exchange. The team identified and defined 19 specific functions needed to make such an information capability a reality. A World Wide Web page is being created to identify the required functions and to provide information about progress in each of them. In addition, plans are to make web databases available to developers as testbeds to demonstrate their methods of achieving these functions. This web page will serve both to inform the data producing and using communities about progress toward an effective dissemination system as well as to encourage the computer technology community to build the capabilities necessary for technical data into its systems. In addition, the databases disseminated by the Physics Laboratory on its web page will serve as models of effective dissemination of scientific and engineering data.

Contact:

Edward B. Saloman

(301) 975-5554

email: edward.saloman@nist.gov

B161 Technology Building

\section{DISSEMINATION OF DATABASES OVER COMPUTER NETWORKS}

The Office of Electronic Commerce in Scientific and Engineering Data is responsible for the Physics Laboratory's World Wide Web page. It produces Physics Laboratory material for publication on the web, encourages and supports the production of material by others, and assures the high quality of information disseminated by the Physics Laboratory over the electronic networks. In addition, the office develops methods to display information generated within the laboratory in an effective manner on the web. This office also works with the Physics Laboratory divisions and Standard Reference Data staff in developing physical reference databases for dissemination on the web. It designs effective interfaces between the information and the user to facilitate use of the data. Several databases are available already and may be accessed from the Physics Lab web page under Physical Reference Data
(http://physics.nist.gov/PhysRefData/ contents.html), and a number of other databases are being developed for use on the web.

\section{Contact:}

Edward B. Saloman

(301) $975-5554$

email: edward.saloman@nist.gov

B161 Technology Building

\section{FUNDAMENTAL CONSTANTS DATA CENTER}

Center Contact:

Barry N. Taylor

(301) 975-4220

email: barry.taylor@nist.gov

fax: (301) 975-4578

B161 Technology Building

\section{EVALUATION OF FUNDAMENTAL CONSTANTS, MEASUREMENT UNCERTAINTIES, AND SI}

The fundamental physical constants, such as the Rydberg, Planck, fine-structure, and Avogadro constants, are the links in the chain that bind all of science and technology together. Further, they can serve as the basis for improved practical representations of the International System of Units (SI) and thus for more accurate measurements of importance to both science and technology.

The primary goal of the Fundamental Constants Data Center (FCDC) is to issue periodically a set of recommended values of the fundamental physical constants and basic conversion factors of physics and chemistry. This is accomplished by critically reviewing all data relevant to the constants that is available at a given epoch and analyzing it by a variety of methods, including leastsquares. The resulting set of recommended 
values is distributed widely via archival journals, handbooks and reference books, textbooks, professional society magazines, and a web site.

Because of the FCDC's expertise in analyzing fundamental constants data, it is deeply involved in the worldwide effort to standardize the method of expressing uncertainty in measurement. To this end, it revises and publishes from time to time NIST Technical Note 1297, Guidelines for Evaluating and Expressing the Uncertainty of NIST Measurement Results.

Another principal task of the FCDC is to serve as the NIST-authorized organization for the interpretation of SI in the United States. As part of this task, the FCDC revises and publishes periodically NIST Special Publication 811, Guicle for the Use of the International System of Units (SI).

Center Contact:

Barry N. Taylor

(301) $975-4220$

email:barry.taylor@nist.gov

B161 Technology Building

\section{ELECTRON AND OPTICAL PHYSICS}

Division Contact:

Charles W. Clark

(301) 975-3709

email: charles.clark@nist.gov

fax: (301) 208-6937

B102 Radiation Physics Building

http://physics.nist.gov/Divisions/Div841/

div841.html

\section{PHOTODIODE DETECTORS FOR RADIOMETRY}

Highly stable photodiode detectors with uniform spatial sensitivity are developed, calibrated, and distributed as transfer standard detectors for radiometry in the wavelength region of 5 nanometers to 254 nanometers. Detectors presently available at NIST include
$\mathrm{Al}_{2} \mathrm{O}_{3}$ photocathode windowless photodiodes for the region 5 nanometers to 122 nanometers; CsTe photocathode windowed (evacuated) photodiodes for the region 116 nanometers to 254 nanometers; and silicon photodiodes, developed in collaboration with industry, for the region 5 nanometers to 254 nanometers. Some other types of detectors can be calibrated by special arrangement. Broadband photometers also have been developed in collaboration with outside users and calibrated in this spectral region, e.g., combinations of silicon photodiodes with thin-film filters for plasma diagnostics and vacuum ultraviolet solar radiometry.

Contact:

L. Randall Canfield

(301) 975-3728

email:1.canfield@nist.gov

B119 Radiation Physics Building

\section{EUV OPTICS CHARACTERIZATION}

The emerging field of high-reflectance, normal-incidence soft $\mathrm{X}$-ray or extreme ultraviolet (EUV) optics has a wide range of applications. The ability to produce highquality images at wavelengths below 40 nanometers has allowed construction of EUV solar telescopes with unprecedented resolution, EUV microscopes able to study living biological samples with submicrometer resolution, and EUV photolithographic systems that are proposed as tools for the next generation of integrated circuits.

NIST has an EUV multilayer characterization facility at the Synchrotron Ultraviolet Radiation Facility storage ring. The current facility, which has been disassembled for upgrading, was designed to measure the reflectance or transmittance of EUV optics such as mirrors, filters, and gratings as a function of wavelength, angle of incidence, and position on the optic. NIST is constructing a new facility that will extend measurement capabilities to larger and more curved optics and shorter wavelength.
A thin-film deposition chamber has been added to the reflectometry facility that allows measurements of films as they are being deposited. From these measurements the optical constants of important multilayer materials can be determined free from influence of surface contaminants.

Contact:

Charles Tarrio

(301) 975-3737

email: charles.tarrio@nist.gov

B102 Radiation Physics Building

\section{TUNNELING MICROSCOPY}

Scanning tunneling microscopy (STM) is a highly sensitive probe of surfaces, which utilizes the quantum mechanical principle of tunneling to probe surface topography on a nanometer scale. The STM also is inherently sensitive to surface electronic properties that can be exploited to detect the surface electron density of states and, in certain cases, for selective imaging of different elemental species. An ultrahigh vacuum STM with extensive facilities for tip and sample preparation and characterization has been used by NIST scientists to investigate four main areas relating to nanometer-scale science: epitaxial growth, correlation of microstructure and magnetism, electron spindependent contrast measurements in STM, and electronic properties of nanostructures. Experimental efforts employ customdesigned instrumentation with which NIST scientists strive to push the frontiers of visualization of the nanometer-scale world. Currently, a tunneling microscope is being designed to operate in ultrahigh vacuum at liquid helium temperatures with the possibility of applying a magnetic field up to 10 tesla to the sample.

\section{Contact:}

Joseph Stroscio

(301) $975-3716$

email: joseph.stroscio@nist.gov

B206 Metrology Building 


\section{MAGNETIC MICROSTRUCTURE}

Low dimensional magnetic systems (such as thin films, multilayers, and surfaces) as well as reduced dimensional systems (such as granular materials and microscopic lithographic devices) exhibit many scientifically interesting and technologically useful properties. NIST scientists use three complementary magnetic imaging techniquesscanning electron microscopy with polarization analysis (SEMPA), magneto-optic Kerr microscopy, and magnetic force microscopy - to determine the role physical and magnetic microstructure plays in determining macroscopic magnetic properties. SEMPA, which images the magnetization by measuring the spin polarization of secondary electrons emitted in a scanning electron microscope, features high (20-nanometer) resolution, long working distance, large depth of field, and a direct measurement of the vector components of magnetization independent of topography. SEMPA is a relatively surface sensitive technique, making it especially well suited for in situ studies of thin-film and surface magnetism as recently demonstrated by investigations of the oscillatory exchange coupling of magnetic layers.

Contact:

John Unguris

(301) 975-3712

email: john.unguris@nist.gov

B206 Metrology Building

\section{NANOFABRICATION WITH ATOM OPTICS}

NIST scientists are studying the physics of laser focusing of atom beams to find ways to develop a fabrication tool that could lead to more compact microcircuits, higher density magnetic recording media, better sensors, and novel materials. Laser beams form lenses that focus neutral atoms into tiny regions as they deposit, building nanostructures on a surface. The chromium atoms used in this process emerge from an effusive, high-temperature oven, are collimated by laser cooling, and pass through a laser standing wave, which acts as an array of "lenses," focusing the atoms into an array of lines. The nanofabrication of a twodimensional array of chromium dots also can be achieved by using two orthogonal standing waves. The very regular arrays of chromium lines and dots with spacing tied to optical wavelength promise to provide useful standards. Atom optical methods potentially can be extended to a much broader range of materials. Metastable rare gas atoms can be manipulated with lasers and contain internal energy that has been used to expose a resist. A pattern of light can be used to de-excite the metastables; in this way light can be used as a mask for matter, instead of matter being used as a mask for light as in optical lithography.

Contact:

Jabez McClelland

(301) 975-3721

email: jabez.mcclelland@nist.gov

B206 Metrology Building

\section{CONDENSED MATTER THEORY}

Many theoretical techniques are used to study a wide range of problems related to the interactions of electrons in solids, including electronic structure calculations, transport in magnetic multilayers (giant magnetoresistance), exchange coupling in magnetic multilayers, surface growth, spindependent reflection from interfaces, magnetic hysteresis in ultrathin films, light emission produced by scanning tunneling microscopy of a magnetic surface, electron energy loss in magnetic and non-magnetic solids, high-temperature superconductivity, and various microscopic tunneling phenomena. The theory effort helps interpret and guide experiments and provides the theoretical understanding crucial to the development and application of new measurement techniques.

Contacts:

David Penn

(301) $975-3720$

email: david.penn@nist.gov

Mark Stiles

(301) $975-3745$

email: mark.stiles@nist.gov

B206 Metrology Building

\section{DATA FOR ELECTRONIC STRUCTURE CALCULATIONS}

Great advances in the calculation of materials properties from first principles have been made by the use of density functional theory. It now is possible to compute groundstate electronic structure, geometries, cohesive energies, and various response functions for solids containing approximately 100 atoms/unit cell, with an accuracy needed for practical materials design NIST researchers generate benchmark reference data for such calculations, which can be used by developers of new approximations or computational algorithms to test their results against data of known high numerical accuracy. The researchers have disseminated results for atomic total energies and orbital eigen-values for all elements, as computed in several common variants of the local density approximation, and are preparing a set of standard calculations for condensed matter systems. Cooperation is invited from developers of materials modeling software who wish to benchmark their codes against these data or who are willing to participate in round-robin comparisons to generate new benchmarks for complex systems.

Contact:

Charles W. Clark

(301) 975-3709

email: charles.clark@nist.gov

B102 Radiation Physics Building 


\section{X-RAY}

\section{NANOTOMOGRAPHY}

Computer-assisted tomography in medical imaging with a resolution of 1 millimeter is now routine. Synchrotron radiation has been used since the 1980 s to produce threedimensional images with resolution as small as 1 micrometer on geological and biological samples. NIST research is directed toward improving the resolution to 35 nanometers in the next few years. Researchers will study three-dimensional engineered structures several micrometers thick, initially focusing on $\mathrm{Al} / \mathrm{W} /$ silica integrated circuit interconnects. Recent achievements include tomographic imaging of a torn copper foil with 100-nanometer resolution. This research uses the 2-ID-B beamline at the Advanced Photon Source of Argonne National Laboratory.

\section{Contact:}

Zachary Levine

(301) 975-5453

email: zachary.1evine@nist.gov

B102 Radiation Physics Building

\section{X-RAY AND EUV MIICROSCOPY}

Advanced imaging techniques are required to study nanometer-scale structures of interest in the semiconductor industry, biology, and other fields. For example, as the number of levels in integrated circuits increases, techniques must be developed to inspect the different levels and the interconnects on the sub-micrometer scale. Imaging such small structures requires high-resolution techniques using high-energy photons. NIST has available or is developing three different complementary microscopy techniques covering the energy range from 40 electronvolts to 10 kiloelectronvolts. The first method, done in collaboration with the Advanced Photon Source, uses a step-andscan microprobe technique to obtain images of semiconductor structures in the
0.5 kiloelectronvolts to 5 kiloelectronvolts range with the ability to construct threedimensional images. The second technique, in collaboration with the University of Maryland, is an extreme ultraviolet (EUV) imaging microscope to study biological specimens with sub-nanosecond temporal resolution as well as high spatial resolution. The third microscope uses secondaryelectron conversion to cover the uniquely broad range from 40 electronvolts to 10 kiloelectronvolts. All three techniques have resolution on the order of 10 nanometers to 100 nanometers.

\section{Contact:}

Thomas B. Lucatorto

(301) 975-3734

email: thomas.lucatorto@nist.gov

B102 Radiation Physics Building

\section{ATOMIC PHYSICS}

Division Contact:

Wolfgang L. Wiese

(301) 975-3201

email:wolfgang.wiese@nist.gov

fax: (301) 990-1350

A267 Physics Building

http://physics.nist.gov/Divisions/Div842/

div842.html

\section{VACUUM ULTRAVIOLET RADIOMETRY}

NIST researchers conduct a comprehensive short-wavelength radiometry program, including development and characterization of new ultraviolet (UV) and vacuum ultraviolet (VUV) sources, detector characterization, and investigation of radiation damage to optical materials and detectors. NIST collaborates with industry to develop and test new VUV instrumentation, spectrometer designs, and detector systems, including devices for space flight use. Other collaborations include development and testing of specialized sources, narrow-band filters, and lasers, and measurements of
UV/VUV refractive indices. Researchers are interested in developing additional collaborations to study hollow cathode lamp sources, laser plasmas, and spark-discharge sources. State-of-the-art radiometric facilities and advanced optical instrumentation are maintained to support these investigations.

Contact:

John H. Burnett

(301) 975-2679

email: john.burnett@nist.gov

A167 Physics Building

\section{LOW-TEMPERATURE PLASMAS}

The properties of low-temperature plasmas play a key role in the processing of materials such as semiconductors. Proper characterization of these plasmas is essential to develop accurate plasma diagnostics and useful plasma models for specific applications. At NIST, plasma discharges are characterized utilizing optical emission spectroscopy, laser-induced fluorescence, laser scattering, and electric probe methods. Modeling of the plasma also is an integral part of this characterization. Discharge sources include low-pressure if plasmas, stabilized arcs, glow discharges, and inductively coupled plasmas.

An extensive array of laboratory equipment is available to accomplish this characterization, including several neodymiumyttrium aluminum garnet pumped, high-resolution $\left(<0.1 \mathrm{~cm}^{-1}\right)$ dye lasers; Ar ion-pumped dye and ring dye lasers; a Fizeau wavemeter; a high-throughput (f/4), high-resolution vacuum ultraviolet Fourier transform spectrometer; ultraviolet spectrometers; grazing incidence spectrometers; laboratory computers; and miscellaneous 
optics. The principal quantities measured are particle density distributions - both spatially and temporally — for electrons, atoms, ions, and molecules and atomic transition probabilities. Also included are electric-field distributions, electron and ion temperatures, and non-equilibrium phenomena.

Contact:

James R. Roberts

(301) $975-3225$

email: james.roberts@nist.gov

A167 Physics Building

\section{RESEARCH ON HIGHLY IONIZED ATOMS}

NIST's new electron beam ion trap (EBIT) source provides many opportunities for definitive measurements aimed at a basic understanding of plasma processes and atomic structure. In addition, possibilities for using the new source for nanofabrication and ion lithography currently are being investigated.

Ions can be generated over a wide range of species and charge states (ultimately up to fully stripped uranium). Ions are trapped radially and probed with a monoenergetic electron beam. Electrostatic end caps confine the ions axially. A large magnetic field is applied by a superconducting magnet to pinch the electron beam to high density and provide additional radial trapping. The carefully controlled conditions in EBIT allow scientists to unravel complex collision processes and measure spectra with very high accuracy. Highly charged ions can be produced and observed in fluorescence with adequate brightness. The ion temperature can be lowered by evaporative cooling techniques. Several instruments are available to characterize and probe the trapped ions, including X-ray and visible/ultraviolet spectrometers and a laser system. An extraction system for directing beams of highly charged ions onto surfaces is fully operational. An atomic force microscope is available for in-situ studies of surfaces modified by collisions with highly charged ions.

\section{Contact:}

John D. Gillaspy

(301) $975-3236$

email: john.gillaspy@nist.gov

A267 Physics Building

\section{LASER COOLING AND TRAPPING}

Thermal motion of atoms often adversely affects measurements. Using the radiation pressure from near-resonant laser beams, NIST scientists can cool a gas of atoms to within a few microdegrees of absolute zero. These cold atoms can be trapped by laser beams or other electromagnetic fields. Facilities for cooling and trapping atoms include continuous-wave dye, solid-state, and semiconductor lasers. Atoms are trapped in laser traps, magneto-optical traps, and magnetic traps. Sodium, rubidium, cesium, and xenon atoms are cooled, trapped, and used in such diverse applications as atomicfountain frequency standards and studies of laser-modified chemical reactions. Control of atomic motion by lasers also is being applied to problems such as atom interferometry and laser-directed deposition of atoms on surfaces.

\section{Contact:}

William D. Phillips

(301) 975-6554

email:william.phillips@nist.gov

A167 Physics Building

\section{HIGH-PRECISION LASER SPECTROSCOPY}

Highly stabilized tunable lasers permit the investigation of atoms and molecules with a level of detail and precision that cannot be obtained with conventional spectroscopic techniques. NIST work in this area ranges from observations of laser ionization of diatomic molecules in dense vapors to highly precise wavelength measurements that test the most advanced atomic theories for simple atoms. The high resolution provided by laser scanning permits studies of spectral line profiles, including pressure broadening, isotope shifts, and hyperfine structure. Sensitive detection techniques, including frequency modulation and optogalvanic spectroscopy and use of thermionic diode detectors, permit observation of low concentration species in discharges and vapor cells. Typical applications of these data include wavelength standards, detection of trace elements in samples, and laser isotope separation. Facilities include stabilized lasers that are tunable from the near ultraviolet to near infrared and a unique Fabry-Perot wavemeter that is capable of real-time laser wavelength measurements with an accuracy of a few parts in $10^{9}$.

Contact:

Craig J. Sansonetti

(301) 975-3223

email: craig.sansonetti@nist.gov

A167 Physics Building

\section{FOURIER TRANSFORM SPECTROMETRY}

High-resolution Fourier transform spectrometry allows the measurement of wide spectral regions with a precision unobtainable with grating spectrometry. This makes it ideally suited to the measurement of complex atomic spectra, where a spectrum of several thousand lines can be recorded with a wavelength precision of one part in $10^{8}$ in less than an hour. Measurements of wavelengths, hyperfine structure, isotope shifts, and line intensity ratios can be made to high accuracy. The high-resolution Fourier transform spectrometer at NIST has a resolution of $0.0025 \mathrm{~cm}^{-1}$ and a wavelength range of 250 nanometers to 5.5 micrometers. Suitable sources have narrow spectral lines and include microwave discharges, hollow cathode lamps, and Penning discharges. 
Applications include the study of spectra of transition group and rare earth elements for astrophysics and the lighting industry.

Contact:

Craig J. Sansonetti

(301) 975-3223

email: craig.sansonetti@nist.gov

A167 Physics Building

\section{INTERACTIONS OF COLD, TRAPPED ATOMS}

New algorithms and theoretical methods are being developed to describe collisional phenomena currently being observed in ultracold neutral atom traps, which ultimately will lead to the next generation of atomic clocks. These interactions also play a crucial role in the formation and stability of BoseEinstein condensates in nanokelvin atomic gases. The ability to manipulate such condensates is a key to developing atom optics and the proposed atom laser. Developing the theory to quantitatively explain precision NIST spectroscopic measurements in atom traps requires the development of new theoretical algorithms for solving large-scale matrix eigenvalue problems. Such algorithms have widespread applicability to many areas of chemistry and physics. Implementing these new methods now is feasible due to the development of state-of-the-art massively parallel processing computers.

\section{Contact:}

Paul Julienne

(301) 975-2596

email:paul.julienne@nist.gov

A267 Physics Building

\section{THEORY FOR NANOSCALE SYSTEMS AND METROLOGIES}

As the development of nanotechnology proceeds, the need for accurate models for nanoscale systems and for the metrologies to characterize these systems becomes more critical. The NIST quantum processes group is establishing the theoretical approaches and computational tools needed to model complex quantum nanostructures. T-shaped quantum wires, nanocrystallites, quantumdot quantum wells, and couple quantum nanostructures have been modeled in the program. Near-field optics has shown great promise for achieving subwavelength resolution in optical microscopy. The quantum processes group is developing a wide range of models and computational al gorithms to define the metrological and imaging capability of near-field optics.

\section{Contact:}

Garnett Bryant

(301) $975-2595$

email: garnett.bryant@nist.gov

A267 Physics Building

\section{PRECISION X-RAY AND GAMMA-RAY SPECTROSCOPY}

NIST has developed highly accurate spectroscopic instrumentation for wavelength/ energy measurements from the few kiloelectronvolt to the several megaelectronvolt regions. This measurement system is connected to the International System of Units' basic units of frequency and length by means of $\mathrm{X}$-ray interferometry and a precise lattice comparator. Principal applications include accurate secondary standards in the X-ray and gamma-ray regions and measurements contributing to fundamental constants such as the kilogram and the Avogadro number. The high resolution associated with this instrumentation also provides information on atomic and electronic structure in matter. Several X-ray instruments are available at NIST and a gamma-ray facility is available at the high flux reactor at Institut Laue-Langevin, Grenoble, France. Collaborative applications of these capabilities are welcomed.

Contact:

Ernest G. Kessler

(301) $975-4844$

email: ernest.kessler@nist.gov

A141 Physics Building

\section{SYNTHETIC MULTILAYERS}

For short-wavelength characterization of multilayer structures intended for larger wavelength X-ray optics, NIST researchers have established a high-performance multiaxis diffractometer. This system provides highly collimated and monochromatic $\mathrm{X}$-ray beams, which, after reflection from the structure under study, can be examined for both specular and non-specular reflection characterization. The normal operating wavelength is 0.154 nanometer, and the on-scale reflectivity covers a range of six decades. The researchers also have a thin-film production facility capable of handling a wide variety of materials in the range of thicknesses from near one monolayer to a micrometer. The production process uses ion beam sputtering with simultaneous quasi-neutral beam milling to produce thin layers and synthetic multilayers of exceptional uniformity. These capabilities currently are being applied to the development and standardization of thin-film standards for the semiconductor industry.

\section{Contact:}

Richard D. Deslattes

(301) 975-4841

email: richard.deslattes@nist.gov

A141 Physics Building 


\section{APPLICATIONS OF X-RAY TECHNOLOGY}

NIST researchers have applied their extensive experience with crystal diffraction techniques to the production and detection of $\mathrm{X}$-rays in support of space, semiconductor, and medical applications. Tunable monochromatic X-ray sources and crystal spectrometers have been provided to perform pre-flight or post-flight calibration services to numerous NASA X-ray telescope missions, including Solar Maximum Mission, P78-1, BBXRT, ASTRO-D, AXAF, and ASTRO-E. Curved crystal spectrometers also have been developed to measure the spectrum of $\mathrm{X}$-rays emitted by the generators used in mammography. These spectrometers are used as a non-invasive calibration system since the high-energy endpoint of the spectrum is numerically equivalent to the applied voltage. Previously developed analysis tools also have been applied to assessment of wafer materials and homoepitaxial overlayers used in semiconductor processing. Capabilities include the design and construction of custom instrumentation and attendant data acquisition and control systems for the production and detection of $\mathrm{X}$-rays, $\mathrm{X}$-ray crystal preparation and characterization, and various $\mathrm{X}$-ray spectroscopic applications. In addition, NIST maintains facilities to perform crystal lattice comparisons, X-ray topography, and digital imaging of X-rays.

Contact:

Larry Hudson

(301) 975-2537

email: larry.hudson@nist.gov

A141 Physics Building

\section{OPTICAL TECHNOLOGY}

Division Contact:

Albert C. Parr

(301) 975-2316

email: albert.parr@nist.gov

fax: (301) 869-5700

A207 Physics Building

http:/physics.nist.gov/Divisions/Div844/

div844.html

\section{LUMINESCENCE SPECTRAL RADIOMETRY}

Luminescence techniques have broad application in virtually every scientific field, including radiation measurement; remote sensing; analytical chemistry; and characterization of laser, semiconductor, and superconductor materials. The accurate spectral radiometric quantitation of light emission is an exacting task requiring painstaking radiometric measurements and knowledge of the fundamental chemical and physical processes represented by these radiative transitions. Standard lamps, both radiance and irradiance, and silicon detector radiometry provide the accuracy base for the spectral and quantum efficiency measurements. NIST is investigating luminescent phenomena such as photo-, chemi-, thermo-, electro-, and bioluminescences. Researchers are conducting luminescence radiometric research in the near-ultraviolet, visible, and near-infrared spectral regions and are developing accurate standards and measurement procedures for these regions. Facilities available for this research include various laser and lamp sources, a reference spectrofluorimeter, and a low-light-level spectroradiometer.

\section{Contact:}

Ambler Thompson

(301) 975-2333

email: ambler.thompson@nist.gov

A320 Metrology Building

\section{PHOTOMETRY}

Photometry is the science of radiometric measurement of the response function of human vision. The candela, one of the seven base units of the International System of Units, is the basic unit of photometry. The Optical Technology Division has established a new detector-based candela that has improved the accuracy of these measurements by a factor of two. This improvement has become the basis for improved accuracy of all other photometric measurements offered by the division.

Improved levels of accuracies are needed in industry to ensure the production of higher quality products so that U.S. companies can compete in the growing international market. Accurate light measurements are essential to the production of various lighting products such as light bulbs, discharge lamps, lighting fixtures, automobile headlights, and aircraft lamps. Accurate light measurements also are essential in the production of information displays such as cathode ray tubes, flat-panel displays,

light-emitting diodes, and various other optical components.

Another unit in photometry is the lumen, which is the measure of the total light output of lamps. The lumen is especially important to the lighting industry, where millions of lamps are produced every week. The Optical Technology Division recently has established a new lumen unit based on the detector-based candela that provides the highest accuracy levels of lumen measurements.

\section{Contact:}

Yoshi Ohno

(301) 975-2321

email: yoshihiro.ohno@nist.gov

A320 Metrology Building 


\section{HIGH-ACCURACY CRYOGENIC RADIOMETRY}

The Optical Technology Division bases many of its radiometric measurement scales, such as detector spectral responsivity, photometry, radiance, and irradiance, on a high-accuracy cryogenic radiometer (HACR). Cryogenic radiometers work on the principle of electrical substitution, where the temperature rise in a receiving cavity caused by optical heating is reproduced by electrical heating. Electrical substitution measurements tie the optical watt to electrical standards.

The HACR measures the optical power of single laser lines with an uncertainty of 0.02 percent or better and calibrates transfer detectors to disseminate a spectral responsivity scale. NIST researchers continue to improve the HACR base measurements and the optical transfer devices in different wavelength regions. Optical detector calibrations from the ultraviolet through the infrared are based on HACR measurements and are used in environmental, industrial, defense, and space applications. Cryogenic radiometry reduces the base uncertainty in the optical calibrations transferred to these customers.

\section{Contact:}

Jeanne Houston

(301) 975-2327

email: jeanne.houston@nist.gov

A320 Metrology Building

\section{THERMAL RADIOMETRY}

NIST researchers are investigating the use of thermal imaging cameras as a temperaturemeasuring tool. These devices may prove to be very useful in determining the quality of products and in investigating changes in different processes. Research projects involve the development of large-area blackbodies, use of Pt-Si as detector standards, and the characterization of thermal imaging cameras. Equipment available includes several heat-pipe blackbodies, a Pt-Si camera, and an infrared radiometer.

\section{Contact:}

Robert Saunders

(301) 975-2355

email: robert.saunders@nist.gov

B208 Physics Building

\section{NEAR ULTRAVIOLET RADIOMETRY}

The measurement of terrestrial solar irradiance at ultraviolet-B (UV-B) wavelengths (200 nanometers to 400 nanometers) is being investigated by NIST researchers to provide improved techniques and standards in this spectral region. This work is important to networks that monitor solar UV-B irradiance, to scientists studying the biological effects of ultraviolet radiation, and to researchers investigating the aging of materials. Specific projects include the development of experimental techniques for characterizing instruments that measure UV-B irradiance, spectral irradiance standards for use at field sites, and a transportable reference spectroradiometer. A permanent UV-B monitoring site, equipped with a broad suite of instruments, is maintained at NIST, and researchers coordinate intercomparisons among spectroradiometers from different monitoring networks.

Contact:

Ambler Thompson

(301) 975-2333

email: ambler.thompson@nist.gov

A320 Metrology Building

\section{SPECTRAL RADIOMETRY}

Research and development programs at NIST span many activities associated with the measurement of optical radiation, covering the spectrum from 200 nanometers in the ultraviolet to the far infrared. Included are spectral radiance and irradiance measurements for many varied applications, such as manufacturing process control, remote sensing of the Earth's environment, and defense needs. Researchers at NIST take demanding problems, such as the spectrophotometric measurement of dense optical media, and develop the detector metrology to perform the measurements and relate them to the stable, U.S. radiometric measurement base. Emphasis is placed on solidstate photodiode metrology and its application to all areas of radiometry, especially calibration services.

Several well-equipped laboratories for optical measurements in the ultraviolet, visible, and infared spectral regions are available for use, and new facilities are being developed to enable scientists and engineers to conduct research on detector improvements, detector applications, and optical properties of materials.

\section{Contact:}

Joseph Dehmer

(301) 975-3216

email: joseph.dehmer@nist.gov

A320 Metrology Building 


\section{INFRARED SPECTRAL RADIOMETRY}

Researchers at NIST are developing devices and techniques for high-precision measurements of radiant power in the 2 -micrometer to 30-micrometer spectral region to enable characterization of spectral sources, optical components, and detectors. Novel experiments are being planned to investigate physical and chemical processes in materials and molecular structures. State-of-theart radiometers, a cryogenic blackbody with multiple apertures, lead salt lasers, spectral instrumentation, and solid-state infrared detectors have been acquired. A unique facility called the Low-Background Infrared Radiation Facility is dedicated to this research and development effort. An Infrared Detector Comparator Facility, equipped with a prism-grating monochromator and a Fourier transform infrared spectrometer for characterizing detectors at ambient background, has been completed and soon will offer calibration services.

Related research projects are investigating methods for measuring the optical density of filters using laser heterodyne technology and determining the spatial uniformity and linearity in the response of infrared detectors. Collaborative research opportunities exist in measuring the optical properties of materials and fundamental molecular structures and in developing novel detectors.

Contact:

Raju Datla

(301) 975-2131

email: raju.datla@nist.gov

B208 Physics Building

\section{SPECTROSCOPIC APPLICATIONS}

The NIST spectroscopic applications group employs advanced spectroscopic methods using state-of-the-art lasers and microwave frequency sources in conjunction with molecular beam techniques to elucidate the details of chemical reactions that are important in a wide variety of industrial processes, including catalysis, combustion, chemical vapor deposition, and drug design. These benchmark studies provide the means for real-time optimization of chemical proc * esses and on-line monitoring for pollution control.

The group also carries out spectral studies of species important in atmospheric processes with particular emphasis on the reaction chemistry of ozone. The work provides spectral data for these species, which are used by scientists modeling the chemistry of the upper atmosphere. A recent thrust of the group centers around the determination of physical and electrical properties of numerous new chemical compounds that are being investigated by industry for use as alternative refrigerants.

Contact:

Richard Suenram

(301) 975-2165

email: richard.suenram@nist.gov

B208 Physics Building

\section{NON-LINEAR OPTICAL MEASUREMENTS}

Non-linear optical methods are used to measure properties of interfaces that may be found at the surfaces of materials, in thinfilm systems, or buried in layered materials. An example is the technique of sum frequency generation (SFG), in which two laser pulses at different frequencies combine to produce light at their sum frequency with an efficiency that depends on the broken symmetry at the interface. With femtosecond laser pulses, SFG provides a time-resolved optical diagnostic uniquely sensitive to interface structure. Measurements include spectroscopic characterization of electronic structure at buried epitaxial interfaces, ultrafast monitoring of carrier dynamics at semiconductor interfaces, assessment of the structure and quality of thin films, and vibrationally resonant SFG of organic films such as self-assembled monolayers. This research is a collaboration with the Chemical Science and Technology Laboratory. Resources include femtosecond laser sources for gerierating ultrafast pulses in the infrared through ultraviolet and instrumentation for spectral, directional, and polarization analyses of surface-generated optical signals.

\section{Contact:}

John Stephenson

(301) 975-2372

email: john.stephenson@nist.gov

B208 Physics Building

\section{OPTICAL SCATTERING MEASUREMENTS}

Studies are being made of how materials' properties and surface topography affect the distribution of light scattered from surfaces, with an aim to developing standard measurement methods and standard artifacts for use in industry. The description of light scattered from surfaces is a useful metrological tool for appraising performance of optical elements and for evaluating material processing. Applications include evaluation of highly polished optical surfaces, bulk optical materials, surface residues, and diffuse scattering materials. Experiments are under way to correlate the optical scatter from silicon wafers with properties such as haze, surface microroughness, and particulate contamination, with a goal to facilitate optical scattering measurements in assemblyline applications. The utility of polarization analysis of scattered light also is being investigated. Parallel research in near-field optics is elucidating the connection between microscopic features of the surfaces and the far-field optical scattering pattern. Facilities 
are available for laser-based measurements of the bidirectional reflectance distribution function of light-scattering materials and surfaces. Work is under way on theoretical modeling of the bidirectional reflectance distribution function. Clean rooms are available for handling optical samples.

The bidirectional characterization of optical scatter from surfaces is a useful diagnostic in evaluating elements contained within large optical systems that require the minimization of scattered light. This information is needed for the development of ring-laser gyroscopes and telescopes. It also is used for the characterization of materials for use in stray light reduction in thermal control and inspection processes in optical manufacturing settings. NIST research projects involve the development of a multiangle scattering reference instrument and the development of measurement methodologies and Standard Reference Materials for the spectral range from the ultraviolet to the infrared region.

Contact:

Thomas Germer (301) $975-2876$ email: thomas.germer@nist.gov A320 Metrology Building

\section{NEAR-FIELD SCANNING OPTICAL MICROSCOPY}

NIST researchers are using near-field scanning optical microscopy (NSOM) as a quantitative technique for non-invasive optical measurements on previously inaccessible length scales. So far, lateral resolution on the order of 20 nanometers has been achieved with this technique, and vertical resolution of less than 1 nanometer may be possible. The researchers are building wellcharacterized microscopes and small light sources and are working on methods to determine the resolution of commercially available near-field microscopes. At a fundamental level, this means understanding the mechanisms that generate contrast in different materials and modeling the fields around small light sources as they interact with various materials and surface features. The group collaborates with other NIST researchers interested in applying near-field microscopy to problems in chemical, opti$\mathrm{cal}$, and semiconductor technology. Applications include mapping of optical properties of nanostructured materials, investigations of structure in biological membranes, and near-field measurements of photonic structures. Resources include NSOM measurements in the visible, NSOM tip characterization, theoretical modeling of probe-surface interactions and optical contrast mechanisms, and access to complementary scanning microscopies such as scanning electron microscopy and atomic force microscopy.

\section{Contact:}

Lori Goldner

(301) $975-3792$

email: lori.goldner@nist.gov

A320 Metrology Building

\section{TIME-RESOLVED INFRARED SPECTROSCOPY}

Ultrashort laser pulses are used to observe fast processes that occur in the condensed phase. NIST researchers have developed unique femtosecond infrared spectroscopic techniques to study highly excited vibrational states, vibrational energy transfer, photochemical reactions, and the dynamics of hydrogen bond formation and rupture.

The measurements identify transient species and determine energy transfer rates, which serve to improve models of condensed phase chemistry. Current collaborations with industry include measurements on catalytic systems and polymerization reactions. They also are developing sources of femtosecond pulses in the terahertz frequency region to be used to probe directly quantum-well electron and solid-state phonon dynamics.

Resources include femtosecond laser sources generating ultrafast pulses in the infrared through ultraviolet, infrared and visible multielement detectors, and instrumentation for capturing transient spectra of samples with single laser pulses.

Contact:

Edwin Heilweil

(301) $975-2370$

email: edwin.heilweil@nist.gov

B208 Physics Building

\section{ELEMENTARY CHEMICAL REACTION DYNAMICS}

Researchers use laser pulses to observe and manipulate fundamental molecular transformations such as bond breaking and bond formation in order to develop an atomiclevel understanding of reactions important in combustion and propulsion chemistry, in the chemistry of the upper atmosphere, and in orbital environments. Current efforts emphasize elementary reactions of oxygen atoms with hydrogen, water, hydrocyanic acid, and methane. The experiments use state-resolved nanosecond and time-resolved femtosecond spectroscopic techniques and molecular beam methods to produce data to test quantum chemical models of these benchmark systems. Resources include intense, narrow bandwidth, tunable laser sources spanning the infrared to vacuum ultraviolet; tunable femtosecond lasers; laser-induced fluorescence and photoionization mass spectrometric detection of trace gas phase species; and pulsed supersonic jet sampling of gases.

\section{Contact:}

John Stephenson

(301) 975-2372

email: john.stephenson@nist.gov

B208 Physics Building 


\section{IONIZING RADIATION}

Division Contact:

Bert M. Coursey

(301) $975-5584$

email: bert.coursey@nist.gov

fax: (301) 869-7682

C229 Radiation Physics Building

http://physics.nist.gov/Divisions/Div846/

div846.html

\section{RADIATION PROCESSING}

To enhance quality-control methods used in industrial radiation processing of foods and in the production and use of medical devices, electronic components, and polymers, NIST researchers are developing standardization and measurement assurance methods related to industrial high-dose applications of ionizing radiation. As part of this program, they are investigating radiation, chemical mechanisms, and kinetic studies applied to chemical dosimetry systems in the condensed phase, including liquids, gels, thin films, and solid-state detectors.

They also plan to examine sensor materials such as doped plastics, solid-state matrices, fiber optics, organic dye solutions, semiconductors, scintillators, amino acids, metalloporphyrins, and organic or inorganic radiochromic and luminescent aqueous solutions and gels. A number of analytical methods will be used, including transmission and fluorescence spectrophotometry and electron spin resonance spectrometry as well as optical waveguide analysis and pulse radiolysis.
Various X-ray and gamma-ray sources and electron accelerators with energies in the 0.1-megaelectronvolt to 10-megaelectronvolt range are used in this work. Conventional ultraviolet, visible, and infrared spectrophotometers; high-intensity gammaray sources; pulsed and continuous beam electron accelerators; and organic-chemical analytical equipment also are available.

Contact:

Marc F. Desrosiers

(301) $975-5639$

email: marc.desrosiers@nist.gov

C229 Radiation Physics Building

\section{MEASUREMENT QUALITY ASSURANCE}

Credibility of ionizing radiation measurements has been a critical issue for the U.S. radiation, medical diagnostics and therapy, occupational safety, industrial, energy, defense, and environmental communities. To this end, NIST scientists disseminate the standards and technology required for reliable measurement of ionizing radiation to federal, state, and local radiation control programs as well as to the medical, industrial, and defense communities. In addition, NIST researchers monitor and evaluate radiation measurements needs; participate in radiation research, metrology development, and quality control activities; and develop methods for improving the accuracy of field measurements through a national system of secondary standards laboratories.

NIST has a strong influence on the design and implementation of measurement quality assurance programs that are accredited under the National Voluntary Laboratory Accreditation Program (secondary calibration laboratories for ionizing radiation and personnel dosimetry programs), the Conference of Radiation Control Program Directors (diagnostic X-radiation), Health Physics Society (private-sector calibration laboratories), and American Association of Physicists in Medicine (therapeutic radiation). Programs currently being developed will address measurement quality assurance needs in sectors that include industrial processing, radio-bioassay, and radioanalyses for environmental remediation and waste management.

In support of the accreditation programs, NIST provides technical expertise for laboratory technical document review and evaluation, traceability to the national physical standards through performance evaluation testing, and on-site assessments. The major research thrust is the development of a wide variety of appropriate transfer standard instruments and materials.

\section{Contact:}

Bert M. Coursey

(301) 975-5584

email: bert.coursey@nist.gov

C229 Radiation Physics Building

\section{NEUTRON PHYSICS}

NIST researchers are exploring three major areas of fundamental neutron physics: neutron interferometry, laser polarization of neutron beams, and various coupling coefficients of the weak interaction. The Neutron Interferometer and Optics Facility (NIOF) in the cold neutron guide hall has achieved unprecedented levels of phase contrast and stability. Work is under way at this new facility on the development of phase contrast imaging, on a measurement of the neutronelectron scattering length, and on neutron tomography. The NIOF also will operate part-time as a user facility for university and industrial scientists. At another location in the guide hall, development is in progress on neutron spin filters, based on laser polarization of ${ }^{3} \mathrm{He}$. These neutron polarizers offer advantages over conventional methods in experiments on parity-violating aspects of neutron beta decay and in studies of magnetic materials. This project also is providing assistance to medical researchers who employ polarized ${ }^{3}$ He for improved magnetic resonance imaging of the lung. 
Another major research and user facility is the Fundamental Physics Station. At this station three experiments have been carried out in collaboration with major universities: a beam measurement of the free neutron lifetime, a measurement of parity nonconserving neutron spin rotation in liquid ${ }^{4} \mathrm{He}$, and a search for time-reversal asymmetry in neutron beta decay. At present, a potentially much more accurate measurement of the neutron lifetime employing trapped ultracold neutrons is being carried out in collaboration with Harvard University, Los Alamos National Laboratory, and Berlin's Hahn Meitner Institute.

Contact:

David Gilliam

(301) 975-6206

email: david.gilliam@nist.gov

A106 NIST Center for Neutron Research

\section{NEUTRON DOSIMETRY}

NIST physicists develop and maintain standards for neutron dosimetry, both at the very high fluence levels appropriate to materials damage studies for nuclear reactors and at the much lower levels appropriate to standardization of radiation protection instruments. Standard neutron fields at NIST and at the University of Michigan have been characterized to provide test irradiation fields for the neutron dosimetry employed in assurance of materials integrity at nuclear power reactors in the United States. NIST scientists also collaborate with engineers and scientists from industry and the Nuclear Regulatory Commission in drafting regulatory guides for accurate measurements in neutron dosimetry at these reactors. Another set of standard neutron fields at much lower fluence rate levels is maintained at NIST for calibration of radiation protection instruments and personnel dosimeters. Efforts are under way to establish and maintain accreditation of other laboratories so that routine calibrations of neutron radiation protection instruments can be taken over by the private sector and by central military laboratories.

Contact:

David Gilliam

(301) 975-6206

email: david.gilliam@nist.gov

A106 NIST Center for Neutron Research

\section{TIME AND FREQUENCY}

\section{Division Contact: \\ Donald B. Sullivan \\ (303) $497-3772$ \\ email: dbs@boulder.nist.gov \\ fax: (303) 497-6461 \\ Mailcode 847.00 \\ Boulder, Colo. 80303-3328 \\ www.boulder.nist.gov/timefreq}

\section{ION STORAGE RESEARCH}

This program investigates the applications of ions, such as ${ }^{199} \mathrm{Hg}^{+}$, for high-accuracy frequency standards. The ions are stored in ion traps-devices that use electric, or a combination of electric and magnetic, fields to suspend the ions in free space. Laser radiation is used to cool the ions to temperatures on the order of a millikelvin, so the second-order Doppler shift (a serious problem in high-accuracy frequency standards) is extremely small. In some cases, ions are cooled even further, approaching the zeropoint motion limit set by Heisenberg's uncertainty principle. It is expected that frequency standards based on laser-cooled, stored ions will be much more accurate than the best current standards, which are based on cesium atomic beams. Research also is under way on related topics, such as the physics of non-neutral plasmas, quantum optics, quantum measurements, laser frequency stabilization, and non-linear optical sources.

\section{Contact:}

David J. Wineland

(303) $497-5286$

email:wineland@boulder.nist.gov

Mailcode 847.10

Boulder, Colo. 80303-3328

\section{ATOMIC BEAM} FREQUENCY STANDARDS

The first atomic frequency standard, based on ammonia, was built in 1950 at NIST (then the National Bureau of Standards) in Washington, D.C. Since then, NIST has constructed a series of seven standards (based on cesium beams) with performances improving at a rate of better than an order of magnitude every 10 years. NIST-7, introduced in 1993, is the most recent in this series. It is based on optical state selection and state detection rather than the more traditional magnetic methods and has an uncertainty of $5 \times 10^{-15}$. A cesium-fountain frequency standard has been constructed as a successor to NIST-7. The main advantages of this concept are the reduction in the Doppler shift and the increase in atom observation time. These severely limit the performance of NIST-7. The work in this program involves research on laser pumping of the states of atoms, improvements in atomic-beam ovens, and the development of digital servo-control systems for more reliably controlling critical parameters.

Contact:

Robert E. Drullinger

(303) 497-3183

email: rdrullinger@boulder.nist.gov Mailcode 847.20

Boulder, Colo. 80303-3328 


\section{NOISE IN ELECTRONIC AND OPTICAL SYSTEMS}

NIST has developed systems for making phase-noise and amplitude-noise measurements over a broad dynamic range of carrier frequency (into the millimeter range) and Fourier frequency (up to 10 percent of the carrier frequency). The accuracy of measurement is typically 1 decibel or better depending on the frequency range. These systems provide the basis for specifications now arising in communication, radar, and other aerospace equipment. Signals at higher millimeter and optical frequencies also can be characterized by beating them against a stable optical reference. A wide range of noise measurement equipment and systems for analyzing the output data is available. Most recently, this unique measurement capability has been applied to the study of phasemodulation and amplitude-modulation noise in bipolar-junction-transistor circuits. This work has led to a better understanding of noise processes in these circuits, and design rules for low noise performance have been developed. These rules can provide for a noise reduction (close to a carrier) of as much as 20 decibels.

\section{Contact:}

Fred L. Walls

(303) 497-3207

email:walls@boulder.nist.gov

Mailcode 847.00

Boulder, Colo. 80303-3328

\section{STATISTICAL ANALYSIS OF TIME-SERIES DATA}

Noise processes in high-performance clocks and oscillators are often not white (frequency independent), so the usual variance does not converge. The two-sample variances developed to handle such noise have become standards widely used in the specification of noise in systems demanding highspectral purity. These measures have been applied with some success to other measurement data. NIST researchers are continuing development of still better variances and have written software for the efficient calculation of a number of these measures. Outputs can be represented in both the frequency and time domains.

Contact:

David A. Howe

(303) 497-3277

email: dhowe@boulder.nist.gov

Mailcode 847.40

Boulder, Colo. 80303-3328

\section{TIME TRANSFER AND NETWORK SYNCHRONIZATION}

NIST has broad expertise in time transfer, particularly using satellite methods, that can be applied to synchronization of widely distributed network nodes. Telecommunications and electrical power networks are examples of systems requiring such synchronization. A NIST-developed, common-view method using global positioning system (GPS) satellites provides time transfer accuracy of better than 10 nanoseconds, and two-way exchange of signals through telecommunications satellites offers even higher performance. NIST owns and operates a number of specialized GPS receivers and satellite Earth stations needed for such work, and the NIST time scale provides unsurpassed stability as a reference for remote synchronization.

\section{Contact:}

Thomas E. Parker

(303) 497-7881

email: tparker@boulder.nist.gov

Mailcode 847.50

Boulder, Colo. 80303-3328

\section{FAR-INFRARED SPECTROSCOPY}

NIST has unique capabilities for highresolution studies of the spectra of atoms and molecules in the far-infrared region. The methods of tunable far-infrared spectroscopy and laser magnetic resonance (LMR) were developed by NIST, and several of each of these spectrometers currently are providing high-resolution measurements on spectra important in both space studies and studies of the chemistry of the upper atmosphere. Pressure-broadening studies at high resolution also have been performed, providing the basis for locating air pollutants at high altitude. Recent improvements in the NIST LMR systems have improved dramatically their sensitivity, making them especially useful in searches for difficult-todetect molecular species such as free radicals and molecular ions.

Contact:

Kenneth M. Evenson

(303) 497-5129

email: evenson@boulder.nist.gov

Mailcode 847.00

Boulder, Colo. 80303-3328

\section{HIGH-PERFORMANCE DIODE LASERS}

Diode lasers are used widely in many applications where spectral and spatial purity is not critical, but they could be used in a variety of other applications if these properties were improved substantially. Such applications include analytical chemistry and sensing of trace impurities or pollutants as well as narrow-line sources for length standards and optical manipulation of atoms and molecules. Recognizing the broad range of measurement applications for highperformance diode lasers, NIST has developed a program aimed at developing methods for controlling the output characteristics of these versatile and inexpensive lasers. The program selects specific practical 
applications and works on the system designs needed to provide solutions. Current projects include a calcium-stabilized laser for use as a length reference, methods for synthesizing signals in the optical region, and laser-spectroscopy methods for detecting trace impurities.

Contact:

Leo Hollberg

(303) $497-5770$

email: hollberg@boulder.nist.gov

Mailcode 847.80

Boulder, Colo. 80303-3328

\section{QUANTUM PHYSICS}

Division Contact:

James Faller

(303) 492-8509

email: fallerj@jila.colorado.edu

fax: (303) 492-5235

JILA, Boulder, Colo. 80309-0440

http://jilawww.colorado.edu

\section{BOSE-EINSTEIN CONDENSATION}

The discovery of Bose-Einstein condensation (BEC) by JILA scientists in June 1995 has opened up whole new areas of research. JILA (formerly the Joint Institute for Laboratory Astrophysics) is a joint venture of NIST and the University of Colorado. In BEC, atoms cooled to temperatures as low as 10 nanokelvin undergo a phase transition in which a large percentage of the atoms all take on exactly the same quantum wave function, becoming completely indistinguishable from one another. Preliminary studies on low-lying phonon-like excitations will develop into measurements on vortices and viscosity. Thermal behavior near the critical temperature and the kinetics of condensate formation are also promising topics for study. The implications of condensate formation for precision metrology must be explored as well, including theoretically predicted coherent atom beams, dubbed bosers.

\section{Contact:}

Eric A. Cornell

(303) 492-6281

email:cornell@jila.colorado.edu

JILA, Boulder, Colo. 80309-0440

\section{THIN FILMS}

Images of amorphous silicon films taken by a scanning tunneling microscope (STM) at various stages throughout the growth process show particles 3 nanometers to 5 nanometers in size forming in the vapor and bonding to the film surface during growth. If these particles can be prevented from forming or reaching the surface, it should be possible to improve the film's ability to convert light into electrical current. A laser scattering system is being developed to detect the silicon/hydrogen clumps as they are forming.

In another project, lines of aluminum as small as 3 nanometers in width have been deposited on silicon surfaces using the electron beam and electric field produced at the tip of an STM. Independent auger electron spectroscopy studies of the electron-induced deposition of aluminum show nearly pure aluminum deposits.

Contact:

Alan C. Gallagher

(303) 497-3936

alang@jila.colorado.edu

JILA, Boulder, Colo. 80309-0440

\section{LASER DEPOSITION OF THIN FILMS}

Evidence suggests that laser-deposited materials can attain better film properties at lower processing temperatures than materials deposited by normal thermal means. The microscopic basis for the effect of kineticenergy-enhanced epitaxy has been demonstrated at NIST for the first time. An apparatus has been developed to produce a neutral cobalt atom beam with a controlled energy. When cobalt atoms are deposited onto silicon at thermal energy, most of the atoms reside on the surface. However, deposition of cobalt atoms on a silicon(100) wafer at enhanced kinetic energies mimics substrate heating in the 500 kelvin range with thermally deposited cobalt, in which the silicide material forms.

Contact:

Stephen R. Leone

(303) 497-3505

srl@jila.colorado.edu

JILA, Boulder, Colo. 80309-0440

\section{MOBILITY OF CLUSTER IONS}

New methods have been established at NIST to measure the mobilities of ions clustered with water and other molecules important in the upper atmosphere. Ions are produced in a mass-selected ion source and injected into a flow tube where they are converted to clusters by three-body reactions with a solvent molecule. The mobility of the cluster ions is measured by the arrival times of ion "packets" at a mass spectrometer detector, following a pulsed depletion of a small fraction of the ions at two places in the flow tube. The method has been applied for benzene dimer ions, water cluster ions, ammonia cluster ions, and mixed clusters. 
In general, the size of the cluster ion determines the mobility in helium in a predictable fashion, but for collisions with molecules that have strong dipole moments, remarkably small mobilities are observed. The additional strong attractive forces and internal degrees of freedom of the molecules play a major role, causing the small mobilities.

Contact:

Stephen R. Leone

(303) 497-3505

srl@jila.colorado.edu

JILA, Boulder, Colo. 80309-0440

\section{STABILIZED LASERS}

The remarkable price reduction of diode lasers, taken with cost-effective frequency stabilization approaches, leads to consideration of possible future widespread exploration of frequency-stabilized diode lasers in a vast range of new applications. Traditional interferometric control systems profit from the laser system's increased performance along with its decreased cost and generated heat. A new concept in development will allow stabilization to produce a constant laser wavelength for interferometric applications. Advanced low noise tilt and displacement sensors now can be designed usefully and may become widespread when the stabilized laser system cost is decreased by one order of magnitude or more.

Contact:

John L. Hall

(303) 497-3126

email: jhall@jila.colorado.edu

JILA, Boulder, Colo. 80309-0440

\section{RESEARCH} FACILITIES

\section{SYNCHROTRON} ULTRAVIOLET RADIATION FACILITY III

The NIST Synchrotron Ultraviolet Radiation Facility (SURF) is used as a national standard of spectral irradiance for radiometric applications and a spectrometer calibration facility. The facility also is used for extreme ultraviolet and infrared microscopy and for fundamental research in the following areas: optical properties of materials; electron density of states in solids; surface characterization; photoelectron spectroscopy; atomic and molecular absorption spectroscopy; molecular kinetics and excitation and ionization dynamics; and radiation interactions with matter. Currently SURF II has been disassembled completely to make way for an improved and upgraded SURF III facility, which is expected to be completed in June 1998.

\section{Contact:}

Robert P. Madden

(301) 975-3726

email: robert.madden@nist.gov

B119 Radiation Physics Building

\section{MAGNETIC MICROSTRUCTURE MEASUREMENT FACILITY}

The magnetic microstructure of materials can be measured with very high spatial resolution by a technique called scanning electron microscopy with polarization analysis (SEMPA). An ultrahigh-vacuum electron microscope has been modified so secondary electrons from the sample can be analyzed for their electron spin polarization. This allows for a measurement of the surface magnetism with moments both in the plane and perpendicular to the plane of the sample.

\section{CAPABILITIES}

SEMPA allows the simultaneous observation of surface microstructure and surface magnetic domains with a resolution as high as $20 \mathrm{~nm}$.

\section{APPLICATIONS}

This unique measurement facility can be used for research in magnetic thin films, high-coercivity magnetic materials, highdensity magnetic storage media, and other advanced magnetic materials.

\section{AVAILABILITY}

These facilities are available for collaborative research by NIST and outside scientists in areas of mutual interest on a timeavailable basis.

Contact:

John Unguris

(301) 975-3712

email: john.unguris@nist.gov

B206 Metrology Building

\section{HIGH-RESOLUTION UV AND OPTICAL SPECTROSCOPY FACILITY}

Accurate atomic data for neutral atoms and ions are required in support of hightechnology products and manufacturing processes as well as advanced scientific applications. The primary source of such data is high-resolution optical spectroscopy. Spectrometers in NIST's High-Resolution Ultraviolet and 0ptical Spectroscopy Facility are the most powerful in the world for observations of emission and absorption spectra in the soft $\mathrm{X}$-ray to near infrared regions. The 10.7-meter grazing-incidence and normalincidence vacuum spectrographs permit observations from $3 \mathrm{~nm}$ to $600 \mathrm{~nm}$ with resolving powers of 70,000 to 400,000 and wavelength uncertainties as low as 0.0002 $\mathrm{nm}$. In the visible and near-infrared region, an echelle spectrograph provides resolving 
powers exceeding $1,000,000$. NIST's new high-resolution Fourier transform spectrometer will be capable of observations from $200 \mathrm{~nm}$ to $18 \mu \mathrm{m}$ with unmatched resolution and wavelength accuracy. A variety of discharge sources are used to excite spectra of neutral atoms and ions stripped of up to 20 electrons. Species up to 40 times ionized are observed in plasmas created by ablating samples with a high-power laser. Current NIST research includes development of wavelength standards used for calibration of the high-resolution spectrograph on the Hubble Space Telescope, observations of transitions in highly ionized atoms for plasma diagnostics in tokamaks, development of a promising new scheme for an extreme ultraviolet laser, and precise isotope shifts of mercury wavelengths needed to interpret ultraviolet spectra of stars.

Contact:

William C. Martin

(301) 975-3213

email:wmartin@nist.gov

A167 Physics Building

\section{LOW-BACKGROUND} INFRARED RADIATION

\section{FACILITY}

In the NIST Low-Background Infrared

Radiation Facility, radiant background noise levels less than a few nanowatts are attained in a large $(60 \mathrm{~cm}$ diameter $\times 152$ $\mathrm{cm}$ long) vacuum chamber by cooling internal cryoshields to temperatures less than $20 \mathrm{~K}$ using a closed-cycle helium refrigerator system. An absolute cryogenic radiometer (ACR) of the electrical substitution type that operates at $2 \mathrm{~K}$ to $4 \mathrm{~K}$ is housed in the chamber.

\section{CAPABILITIES}

The ACR is a broadband detector with a flat response from the visible to the long wavelength infrared spectral region. It can measure power levels of $20 \mathrm{nW}$ to $100 \mathrm{~W}$ at its 3-centimeter-diameter aperture within an uncertainty of less than 1 percent. The ACR has a resolution of $1 \mathrm{nW}$, and its time constant is about $20 \mathrm{~s}$.

\section{APPLICATIONS}

This unique facility can be used to measure total radiant power from sources such as cryogenic blackbodies. Ongoing improvements will allow measurement of the spectral distribution of radiation from sources and characterization of infrared detectors and optical components.

\section{AVAILABILITY}

The facility is operated by NIST staff in support of user infrared calibrations. It is available for collaborative research by NIST and outside scientists in areas of mutual interest.

Contact:

Raju Datla

(301) 975-2131

email: raju.datla@nist.gov

B208 Physics Building

\section{CONTROLLED}

\section{BACKGROUND}

\section{RADIOMETRIC FACILITY}

Infrared radiometry has an important role in space-based civilian, defense, and industrial applications. A facility to maintain an infrared scale for specialized applications was developed with funding from NIST, NASA, and the Department of Defense. In particular, the capability for measurements on large-area, vacuum-operational, blackbody sources operated from $200 \mathrm{~K}$ to about $400 \mathrm{~K}$ is being established. These measurements will be traceable to NIST via infrared radiometry through the radiance temperature of the source. An example of the type of scientific activity that the NIST facility supports is the use of satellites for the determination of temperature, based on radiance measurements, for the Earth's surface and atmosphere. These measurements are the basis for the study of global warming. A goal of the facility will be the development of infrared radiometers, which will be used to intercompare large-area blackbody sources used by contractors for NASA's Mission to Planet Earth Project.

This facility is not limited to infrared measurements. The capability to make comparisons of large area visible sources also will be possible. For both infrared and visible sources, users are able to bring their sources to NIST for calibration. This facility also is used for hosting intercomparisons of field radiometers, user sources, and training of key personnel. A multipurpose classroom is available where short courses and workshops on radiometry can be held.

Contact:

Carol Johnson

(301) 975-2322

email: cjohnson@nist.gov

B208 Physics Building

\section{MEDICAL-INDUSTRIAL RADIATION FACILITY}

NIST operates an electron accelerator as the heart of a new user facility for the medical and industrial radiation communities. The Medical-Industrial Radiation Facility (MIRF) is based on a rf-powered, travelingwave electron linac donated by the Radiation Therapy Center of the Yale University New Haven Hospital. This reconfigured accelerator provides electron energies from $7 \mathrm{MeV}$ to $32 \mathrm{MeV}$ at average beam currents of up to $0.1 \mathrm{~mA}$. In addition to the original beamsteering system and medical-therapy scanner/collimator head, three additional beam ports and a switching magnet have been added at NIST. The flexibility afforded by access to these four beam lines allows NIST to address issues in radiation metrology, radiation effects, and the uses of electron and high-energy photon beams. 


\section{CAPABILITIES}

The medical beam line can provide electron doses of up to $5 \mathrm{~Gy} / \mathrm{min}$ at the patient location and is equipped with a target to produce a $25 \mathrm{MeV}$ bremsstrahlung beam as used in high-energy photon therapy. On other beam lines, dose rates in excess of $1 \mathrm{kGy} / \mathrm{s}$ over a small area have been achieved with electrons, and exposure rates of about 2,500 $\mathrm{R} / \mathrm{min}$ can be attained with suitable bremsstrah-lung convertors to produce highenergy photon beams used in industrial radiography.

\section{APPLICATIONS}

MIRF offers unique opportunities for medical and industrial research. At the facility, a number of organizations are collaborating on a variety of projects:

- Medical dosimetry. Medical linacs are used for treating approximately 500,000 cancer patients annually at some 1,300 treatment facilities in the United States. Among the medical dosimetry applications of MIRF are the development and testing of instruments and dosimetry systems for use in clinical facilities as well as investigations into shielding requirements for the radiation scattered from the patient.

- Radionuclide production. Through photonuclear reactions, radioisotopes can be produced with high-energy electron accelerators as an alternative to the use of nuclear reactors. Applications on MIRF include production tests of radionuclides for use in nuclear medicine.

- Radiography. The facility provides for studies pertinent to industrial radiography and computed tomography. In addition, ongoing development on one of the beam lines is aimed at producing quasimonoenergetic photon beams of channeling radiation and coherent bremsstrahlung suitable for use in digital-subtraction angiography.

- Radiation effects and processing. Current applications include electron-beam treatment of waste water, curing of polymer composites, and radiation effects on electronics.

\section{AVAILABILITY}

MIRF is available for collaborative research by researchers from industry, academia, and other government agencies under the supervision of NIST staff.

Contact:

Charles E. Dick

(301) 975-5580

email: charles.dick@nist.gov

C229 Radiation Physics Building

\section{ELECTRON}

PARAMAGNETIC RESONANCE FACILITY

NIST is leading a national and international effort in electron paramagnetic resonance (EPR) dosimetry for measuring ionizing radiation. Paramagnetic centers (molecules or atoms with unpaired electrons) are produced by the action of radiation on materials. In the EPR measurement, irradiated materials are placed in a magnetic field and electron spin transitions are induced by an electromagnetic field of the appropriate frequency (typically in the gigahertz range). EPR is used as a non-destructive probe of the structure and concentration of paramagnetic centers. The centers created by ionizing radiation are proportional to the absorbed dose and provide a sensitive and versatile measurement method.

\section{CAPABILITIES}

The EPR dosimetry facility is supported by three state-of-the-art X-band EPR spectrometers capable of measuring radiation effects on a wide range of materials from inorganic semiconductors to biological tissues. The data acquisition system provides full computer control of all spectrometer functions, including real-time spectral display and rapid acquisition scan to analyze rapidly decaying signals. The data acquisition system is interfaced with an advanced data analysis station for data manipulation and is capable of simulating and deconvoluting multicomponent spectra.

\section{APPLICATIONS}

EPR dosimetry is operable over many orders of magnitude in absorbed dose $\left(10^{-2} \mathrm{~Gy}\right.$ to $10^{5} \mathrm{~Gy}$ ) and impacts many facets of society and industry:

- Radiation accident dosimetry. Using biological tissues (bone, tooth enamel) or inanimate materials (clothing), retrospective dose assessment and mapping can be accomplished.

- Clinical radiology. Ionizing radiation doses administered in cancer therapy can be measured for external beam therapy using dosimeters of crystalline alanine (an amino acid) or validated for internally delivered bone-seeking radiopharmaceuticals using bone biopsies.

- Industrial radiation processing. Routine and transfer dosimetry for industrial radiation facilities can be performed using alanine dosimeters as well as post-irradiation monitoring of radiation-processed meats, shellfish, and fruits using bone, shell, or seed.

The EPR facility also serves as a fully functional materials research facility for analyzing radiation effects on semiconductors, optical fibers, functional polymers, and composites.

\section{AVAILABILITY}

The EPR facility is available for collaborative research by researchers from industry, academia, and other government agencies under the supervision of NIST staff.

\section{Contact:}

Marc F. Desrosiers

(301) 975-5639

email:marc.desrosiers@nist.gov

C229 Radiation Physics Building 


\section{RADIOPHARMACEUTICAL STANDARDIZATION LABORATORY}

Radioactivity measurements for diagnostic and therapeutic nuclear medicine in the United States are based on measurements at NIST. Activity measurements for the gammaray-emitting radionuclides are made using $4 \pi \beta$ liquid scintillation spectrometry and $4 \pi \gamma$ ionization chamber. The calibration process also includes identification of radionuclidic impurities by germanium spectrometry. Recent development work has focused on therapeutic nuclides for nuclear medicine, radioimmunotherapy, and bone palliation. Future work will focus on intravascular brachytherapy and diagnostic imaging.

\section{CAPABILITIES}

The radiopharmaceutical standardization laboratory provides calibration services for radionuclides and is available for technical users who must make measurements consistent with national standards or who require higher accuracy calibrations than are available with commercial standards. NIST also undertakes basic research to develop new methods of standardizing radionuclides for diagnostic and therapeutic applications. These studies include measurements of decay-scheme parameters, such as half lives and gamma-ray emission probabilities, and identification of radionuclidic impurities.

\section{AVAILABILITY}

The customer has no direct use of the facility. NIST staff can provide calibration services for any previously standardized radionuclide. As part of the same program, research associates of the Nuclear Energy Institute produce standards that are certified by NIST as Standard Reference Materials for distribution to the radiopharmaceutical user communities.

Contact:

Brian E. Zimmerman

(301) $975-5191$

email: brian.zimmerman@nist.gov

Cl I4 Radiation Physics Building

\section{NEUTRON \\ INTERFEROMETER AND OPTICS FACILITY}

The Neutron Interferometer and optics Facility (NIOF) located at the NIST Center for Neutron Research is one of the world's premier user facilities for neutron interferometry and related neutron optical measurements. A neutron interferometer splits then recombines neutron waves. This gives the interferometer its unique ability to experimentally access the phase of neutron waves. Phase measurements are used to study the magnetic, nuclear, and structural properties of materials as well as fundamental questions in quantum physics. Related, innovative neutron optical techniques for use in condensed matter and materials science research are being developed.

\section{CAPABILITIES}

Neutrons are extracted from a dual-crystal parallel-tracking monochromator system, providing neutron energies in a range of $4 \mathrm{meV}$ to $20 \mathrm{meV}$. Neutrons are counted with integrating ${ }^{3}$ He detectors or by high-

resolution position-sensitive detectors (with a resolution better than $50 \mu \mathrm{m}$ ). The sensitivity of the apparatus is enhanced greatly by state-of-the-art thermal, acoustical, and vibration isolation systems. To reduce vibration, the NIOF is built on its own foundation, separate from the rest of the building The position of the interferometer is maintained to high precision by a computercontrolled servo system. The result is a neutron interferometer facility with exceptional phase stability $\left(5 \times 10^{-3} \mathrm{rad} /\right.$ day $)$ and fringe visibility ( 70 percent). The vibration isolation is $-7 \mathrm{~g}$; the positional stability, $2 \mu \mathrm{m}$ in translation and $1 \mu \mathrm{rad}$ in rotation; and the temperature stability, $0.1 \mathrm{~K} /$ day.

\section{APPLICATIONS}

Among the applications for the Neutron Interferometer and optics Facility are the following:

- neutron phase contrast imaging,

- neutron tomography,

- neutron Fourier spectroscopy for surface studies,

- determination of hydrogen content in materials,

- measurement of bound coherent scattering lengths,

- small-angle neutron scattering studies with perfect crystals,

- tests and demonstrations of quantum principles with matter waves,

- measurement of the neutron-electron scattering length, and

- phase transition studies.

\section{AVAILABILITY}

Beam time on the NIOF is available to qualified scientists from the United States and abroad, subject to approval and scheduling by the facility oversight committee.

\section{Contact:}

Muhammad Arif

(301) 975-6303

email:muhammad.arif@nist.gov A106 NIST Center for Neutron Research 


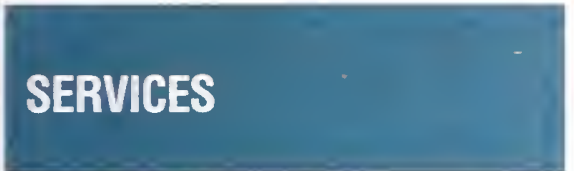

\section{TIME AND FREQUENCY} SERVICES

NIST disseminates time and frequency signals by radio, satellite, telephone, and the Internet. The time codes for each of these services include advanced alert for changes to and from daylight saving time and advanced notice of insertion of leap seconds.

\section{SHORT WAVE BROADCASTS}

Since 1923 NIST radio station WWV (Fort Collins, Colo.) has provided around-theclock shortwave broadcasts of time and frequency signals. A sister station, WWVH (Kauai, Hawaii), was established in 1948 in Hawaii. The stations do the following:

- broadcast at 2.5,5,10, and $15 \mathrm{MHz}$; WWV also broadcasts at $20 \mathrm{MHz}$;

- reliably cover continental United States and the Pacific at time accuracy of $1 \mathrm{~ms}$ to $10 \mathrm{~ms}$; and

- have a frequency accuracy of $1 \times 10^{-7}$.

Broadcasts include standard frequencies and time intervals, time of day (both voice and digital code), astronomical time corrections, and public service announcements (marine weather, geophysical alerts, Omega and GPS status information, and radio propagation information).

Telephone access: (303) 499-7111 for WWV and (808) 335-4363 for WWVH. Information is available at www.boulder.nist.gov/ timefreq.

\section{LOW-FREQUENCY BROADCAST}

In 1956 low-frequency station WWVB

(Ft. Collins, Colo.) began broadcasting at

$60 \mathrm{kHz}$. It offers several features:

- more predictable propagation (at $60 \mathrm{kHz}$ ) than that of WWV and WWVH,

- digital time code only,

- time and accuracy of $0.1 \mathrm{~ms}$ to $1 \mathrm{~ms}$,

- frequency accuracy of $1 \times 10^{-11}$ for measurements over 1 day, and

- good reception in most areas of the continental United States.

\section{GOES TIME CODE SERVICE}

NIST time and frequency services are relayed to most of the western hemisphere by satellites positioned high above the equator. This service offers several features:

- cooperates with the National Oceanic and Atmospheric Administration using two of their GOES weather satellites,

- has an accuracy of $100 \mu$ s limited by information on the location of the satellites,

- covers North and South America plus major portions of the Atlantic and Pacific, and

- includes digital time code and continuously updated satellite locations.

\section{AUTOMATED COMPUTER TIME SERVICE}

NIST also offers an Automated Computer Time Service that uses commercial telephone lines to deliver a digital time code for computers and automated systems. The service includes the following:

- time accuracy of $1 \mathrm{~ms}$ to $100 \mathrm{~ms}$ depending on modem and mode used,

- frequency accuracy of $1 \times 10^{-8}$ for measurements over 1 day, and

- telephone-circuit delay measurement and automated compensation for it.

For service call (303) 494-4774. Example user software is available (specify RM8101 Automated Computer Time Service) at (301) 975-6776 or www.bldrdoc.gov/ timefreq/service/acts.htm.

\section{Contact:}

D. Wayne Hanson

(303) 497-5233

email: hanson@boulder.nist.gov

Mailcode 847.40

Boulder, Colo. 80303-3328 
NIST provides a wide variety of services and programs to help U.S. industry improve its international competitiveness, commercialize new technology, and achieve total quality in all facets of business operations.

Companies spanning nearly all industrial sectors depend on the precision and reliability of NIST measurement services and products to keep their production processes running smoothly, efficiently, and safely. NIST reference materials, data, and calibrations help industry maintain quality control in the production of everything from aerospace alloys to voltmeters to breakfast cereals.

Responding to increased emphasis on quality standards in international markets, NIST provides information and assistance to about 20,000 organizations and individuals every year concerning national and international voluntary and regulatory product standards and certification systems.

In addition, NIST offers a user-friendly environment for businesses interested in cooperative research and development efforts, NIST-developed technologies available for license, guest researcher opportunities, technical information, or technical assessments.

The most current information is available from our web site at http:// ts.nist.gov/ts. There you can find the latest information on normative standards, laboratory accreditation, and technology transfer as well as catalogs of calibration services, Standard Reference Databases, and Standard Reference Materials.

Contact:

Peter L.M. Heydemann, Director

(301) $975-4500$

email: peter.heydemann@nist.gov

fax: (301) 975-2183

306 NIST North

http://ts.nist.gov/ts

\section{SERVICES AND PROGRAMS}

164 Metric Program

165 Small Business Innovation Research Program

\section{Standards Services}

165 Office of Standards Services

165 Laboratory Accreditation Program

165 Technical Standards Activities Program

166 Global Standards Program

166 Standards Information Program

167 Standards Conformity Program

\section{Technology Partnerships}

167 Office of Technology Partnerships

167 Research and Technology Applications Program

167 Industrial Partnerships Program

\section{Measurement Services}

168 Measurement Services

168 Standard Reference Data Program

168 Standard Reference Materials Program

168 Calibration Program

169 Weights and Measures Program

\section{Information Services}

169 Information Services
SERVICES AND PROGRAMS

\section{METRIC PROGRAM}

The Metric Program seeks to accelerate the national transition to the metric system of measurement, the preferred system of weights and measures for U.S. trade and commerce.

Implementing the 1988 amendments to the Metric Conversion Act of 1975, the Metric Program coordinates the metric transition activities of all federal agencies.

Because of the metric system's importance as an international standard, its use in product design, manufacturing, marketing, and labeling is essential for U.S. industry's success in the global marketplace. The use of the metric system in federal agency programs relating to trade, industry, and commerce is intended to support industry's voluntary adoption of the metric system.

The program provides leadership and assistance on metric use and conversion to businesses, state and local governments, standards organizations, trade associations, and the educational community.

Current Metric Program initiatives focus on education and public awareness to gain broad-based support for national metrication from industry and the general public.

Under the banner "Toward a Metric America," a series of information and public awareness campaigns seeks to build partnerships to accelerate adoption of the metric system in trade and commerce; encourage metric system use in all facets of education, including the honing of worker skills; and 
create a more favorable environment for public acceptance of national metrication.

Visit our web site at www.nist.gov/metric.

Contact:

Gerard C. Iannelli

(301) 975-3690

email:metric_prg@nist.gov

fax: (301) 948-1416

306 NIST North

\section{SMALL BUSINESS} INNOVATION RESEARCH PROGRAM

The Small Business Innovation Research Program provides funding on a competitive basis to small high-tech businesses that can carry out research on topics of interest identified by NIST's Measurement and Standards Laboratories. Annually in October, NIST issues a list of research and development topics for which proposals are solicited. There are two phases of awards. In Phase I, awardees can receive up to $\$ 75,000$ for a 6-month study to establish the technical feasibility of a proposed project. Successful Phase I participants may compete in Phase II for up to $\$ 300,000$ to support further development of the work for a period not to exceed 2 years.

Contact:

Norman H. Taylor

(301) 975-3085

email: norman.taylor@nist.gov

fax: (301) 548-0624

306 NIST North

http://ts.nist.gov/ts/htdocs/200/204/204.htm

\section{OFFICE OF STANDARDS} SERVICES

The Office of Standards Services (OSS) is the focal point for the Commerce Department's standards and conformity assessment activities. The office formulates and implements standards-related policies and procedures to enhance domestic commerce and international trade. The office provides representation to domestic and international organizations and federal agencies concerned with standardization, product testing, certification, laboratory accreditation, and other forms of conformity assessment. It chairs the Interagency Committee on Standards Policy to implement the Office of Management and Budget Circular No. 119, "Federal Participation in the Development and Use of Voluntary Standards," which is aimed at harmonizing standards and related programs of federal agencies. OSS also implements the National Technology Transfer and Advancement Act by coordinating standards and conformity assessment activities of federal, state, and local government agencies and with the private sector.

Contact:

Belinda L. Collins

(301) 975-4000

email: belinda.collins@nist.gov

fax: (301) 963-2871

282 NIST North

http://ts.nist.gov/ts/htdocs/210.htm

\section{LABORATORY ACCREDITATION PROGRAM}

The National Voluntary Laboratory Accreditation Program (NVLAP) provides thirdparty accreditation of testing and calibration laboratories. Accreditation programs are established in response to mandates or administrative action by the federal government or requests from private-sector organizations.
Accredited laboratories are listed in a published directory and at http://ts.nist.gov/ nvlap. NVLAP is in full conformance with the standards of the International Organization for Standardization (ISO) and the International Electrotechnical Commission, including ISO Guides 25 and 58. Accreditation provides confidence that a laboratory can provide the technical services claimed and has the quality system to maintain high levels of proficiency.

NVLAP accredits laboratories in the following fields of testing: acoustics, asbestos fiber, carpet, commercial products, computer applications, construction products, electromagnetic compatibility and telecommunications, energy efficient products, ionizing radiation dosimetry, and thermal insulation. NVLAP also accredits laboratories in these calibration areas: dimensional, electromagnetic-dc/low frequency, electromagnetic-rf/microwave, ionizing radiation, mechanical, optical radiation, thermodynamics, and time and frequency.

Contact:

James L. Cigler

(301) 975-4016

email: NVLAP@nist.gov

fax: (301) 926-2884

282 NIST North

\section{TECHNICAL STANDARDS ACTIVITIES PROGRAM}

The Technical Standards Activities Program (TSAP) provides technical support for publicand private-sector standardization and standards-related activities. TSAP manages U.S. representation and participation in the International Organization of Legal Metrology (OIML). OIML is a treaty organization of the international measurement community that promotes global trade through har monization of performance requirements (regulations) for measuring instruments used to ensure equity in commerce, ensure public and worker health and safety, and monitor environment protection. 
TSAP also manages technical support for domestic and international standardization activities and coordination for U.S. standards advisers posted abroad. The program serves as the Commerce Department's (DoC's) technical contact point to investigate non-tariff trade barriers for nonagricultural products under the Agreement on Technical Barriers to Trade of the World Trade Organization. It administers the DOC Voluntary Standards Program, providing a mechanism for private-sector sponsors to develop standards in the public interest with significant domestic and international trade impact. Current standards pertain to construction and industrial plywood, woodbased structural-use panels, and softwood lumber. The program provides the executive secretariat for the Interagency Committee on Standards Policy and coordinates NIST participation in the annual U.S. observance of World Standards Day.

\section{Contact:}

Samuel E. Chappell

(30I) $975-4029$

email: samuel.chappell@nist.gov

fax: (301) 926-I559

I64 NIST North

http://ts.nist.gov/ts/htdocs/210/2I5/215.htm

\section{GLOBAL STANDARDS PROGRAM}

The Global Standards Program (GSP) provides technical information and support to federal agencies and industry to assist them in resolving trade issues related to standards and conformity assessment. GSP monitors developments in standards and conformity assessment activities in the Western Hemisphere, the European Union, Russia and the Newly Independent States (NIS), Central Europe, the Middle East, and the AsiaPacific Region. It supports programs of the Commerce Department's (DoC's) International Trade Administration, such as the Special American Business Intern Training (SABIT) program for technical experts from
Russia and the NIS and conducts standards related economic and policy analyses.

GSP staff participate in the activities of interagency groups to establish U.S. government positions on standards-related aspects of major international agreements, such as the North American Free Trade Agreement. The program also supports work in the Asia Pacific Economic Cooperation and Free Trade Area of the Americas. Staff participate in international and regional organizations covering standards and conformity assessment, and also chair or participate in bilateral standards working groups.

GSP recruits and assigns standards experts to posts at key U.S. embassies and missions. Standards experts are currently in place in Mexico City, Mexico; Buenos Aires, Argentina; Brussels, Belgium (U.S. Mission to the European Union); Riyadh, Saudi Arabia; and New Delhi, India. These experts work with DOC commercial officers, other U.S. government agencies, U.S. business, and foreign organizations to identify and remove technical barriers to trade. GSP staff also organize and conduct workshops at NIST on U.S. standards and conformity assessment practices for foreign standards officials.

\section{Contact:}

Mary H. Saunders

(301) 975-2396

email: mary.saunders@nist.gov

fax: (30I) 963-287I

282 NIST North

http://ts.nist.gov/gsp

\section{STANDARDS INFORMATION PROGRAM}

The Standards Information Program (SIP) operates the National Center for Standards and Certification Information (NCSCI), a central repository for standards-related information in the United States. NCSCI provides access to standards, technical regulations, and related documents published by U.S. and foreign governments as well as by domestic, foreign, and international privatesector standards organizations. SIP responds to domestic and foreign requests for information on U.S. standards, technical regulations, and conformity assessment procedures and to requests for information about foreign standards and technical regulations through its access to the network of information centers (ISONET) of the International Organization for Standardization.

SIP serves as the U.S. inquiry point under the Agreement on Technical Barriers to Trade of the World Trade Organization (WTO) to inform the WTO secretariat in Geneva of proposed U.S. government regulations that might affect trade, receives corresponding proposed foreign regulations, and disseminates them to U.S. industry and $\operatorname{cog}_{\text {- }}$ nizant government agencies. SIP operates the U.S. North American Free Trade Agreement (NAFTA) inquiry point, which provides information about standards and-technical regulations of the NAFTA countries. SIP also operates two telephone hotlines. One, (301) 92I-4164, offers weekly updates on draft European standards and reports on draft standards of the European Committee for Standardization and the European Committee for Electrotechnical Standardization. 'The other, (301) 975-4041, offers weekly updates on proposed foreign regulations for those concerned about regulations and standards that might create technical barriers to trade.

\section{Contact:}

JoAnne R. Overman

(301) $975-4037$

email: ncsci@nist.gov

fax: (301) 926-1559

164 NIST North

http://ts.nist.gov/ts/htdocs/210/2I7/217.htm 


\section{STANDARDS CONFORMITY PROGRAM}

The Standards Conformity Program (SCP) has responsibilities under the Fastener Quality Act (FQA) (Public Law 101-592 as amended by Public Law 104-113), and the National Technology Transfer and Advancement Act (NTTAA). The SCP also provides operational support for the National Voluntary Conformity Assessment Systems Evaluation (NVCASE) program.

SCP issues final implementing regulations for the FQA; approves laboratory accreditation bodies to accredit fastener testing laboratories under the act and its implementing regulations; and provides technical advice and assistance to the Bureau of Export Administration, which is responsible for enforcement, and to the Patent and Trademark Office, which is responsible for recording insignia. For more information on the Fastener Quality Act, see www.nist.gov/fqa.

Under the NTTAA, SCP coordinates conformity assessment activities of federal, state, and local government agencies and with the private sector, aiming to eliminate unnecessary duplication and complexity in the development and promulgation of conformity requirements.

The NVCASE program recognizes competent accreditors of laboratories, certifiers, or registrars of quality assessors in order to provide assurances to other governments regarding the conformity of U.S. products that are exported to regulated markets in their countries.

\section{Contact:}

Subhas G. Malghan

(301) 975-5120

email: subhas.malghan@nist.gov

fax: (301) 975-2183

306 NIST North

http://ts.nist.gov/ts/htdocs/210/218/218.htm

\section{OFFICE OF TECHNOLOGY PARTNERSHIPS}

The primary objective of the Office of Technology Partnerships (OTP) is to build and sustain technology partnering activities between the NIST laboratories and its mission-related organizations. OTP does so by managing various technology transfer programs; managing NIST's intellectual property; carrying out assigned technology transfer functions under the StevensonWydler Technology Innovation Act of 1980 and the Federal Technology Transfer Act of 1986; performing industrial and intergovernmental liaison; and strengthening NIST-wide awareness of technology transfer options and their implications. The office assists NIST leadership in reviewing related policies and practices and in helping to propagate improvements in research and development relationships throughout NIST.

Contact:

Jack Williams

(301) 975-3850

email: jack.williams@nist.gov

fax: (301) 869-2751

213 NIST North

http://ts.nist.gov/ts/htdocs/220.htm

\section{RESEARCH AND}

\section{TECHNOLOGY APPLICATIONS PROGRAM}

The Research and Technology Applications Program is located at the NIST laboratories in Boulder, Colo., and provides information on NIST activities and services to industry, academia, and state and local governments in the western region.

\section{Contact:}

Bruce E. Mattson

(301) 975-3084

email:bruce.mattson@nist.gov

fax: (301) 869-2751

213 NIST North

http://ts.nist.gov/ts/htdocs/220/221/221.htm

\section{INDUSTRIAL PARTNERSHIPS PROGRAM}

The Industrial Partnerships Program pro-

vides assistance in several areas:

- working with NIST research and development (R\&D) programs;

- joint R\&D relationships;

- cooperative R\&D agreements (CRADAs);

- domestic (U.S.) guest researchers;

- industry fellow agreements;

- NIST R\&D relationship policies;

- use of NIST facilities;

- intellectual property issues;

- patents;

- licenses;

- non-disclosure arrangements; and

- commercializing NIST technologies.

Contact:

Bruce E. Mattson

(301) 975-3084

email: IPP@nist.gov

fax: (301) 869-2751

213 NIST North

http:/ts.nist.gov/ts/htdocs/220/222/222.htm 


\section{MEASUREMENT SERVICES}

The four components of measurement services-data, materials, calibrations, and weights and measures - provide U.S. technologists with access to the U.S. national standards of measurement. Uniform and accurate measurements order the marketplace and reduce risk and cost to buyers and sellers. Connection to a solid measurement foundation is essential to industry in attaining quality and performance goals, demonstrating standards conformity, and removing non-tariff trade barriers. The business of America is business, and the competitive forces within business drive the need for increased use and accuracy of measurement. NIST measurement services meet these needs at the point of measurement usage by delivering services directly to about 10,000 companies. A current emphasis of the program is to expand service delivery via accredited, NIST-traceable intermediate service providers.

\section{Contact:}

Peter L.M. Heydemann

(301) 975-4500

email: peter.heydemann@nist.gov

fax: (301) 975-2I83

306 NIST North

http://ts.nist.gov/ts/htdocs/230.htm

\section{STANDARD REFERENCE DATA PROGRAM}

For critical technical decisions, engineers and scientists in industrial and academic research rely on the NIST Standard Reference Data Program (SRDP). For 30 years, SRDP has provided well-documented numeric data to scientists and engineers for use in technical problem solving, research, and development. These recommended values are based on data that have been extracted from the world's literature, assessed for reliability, and then evaluated for the preferred values. These data activities are conducted by scientists at NIST and other institutions.

The NIST Standard Reference Database series has grown to over 50 electronic databases in chemistry, physics, materials, building and fire research, software recognition, and electronics. Versatile interactive databases provide easy access to NIST highquality data. Many databases are now available via the World Wide Web. The catalog of data products distributed by the NIST Standard Reference Data Program is available at www.nist.gov/srd. To receive a printed copy of the catalog, contact Joan Sauerwein at (30I) 975-2208.

\section{Contact:}

John Rumble, Jr.

(301) 975-2200

email: srdata@nist.gov

fax: (30I) 926-0416

113 NIST North

www.nist.gov/srd

\section{STANDARD REFERENCE MATERIALS PROGRAM}

The Standard Reference Materials Program has pioneered and continues to be the leader in the development of certified reference materials for quality assurance of measurements. Through the Standard Reference Materials Program, NIST provides more than 1,300 different Standard Reference Materials $\left(\right.$ SRM $\left.^{\circledR}\right)$ that are certified for their specific chemical or physical properties. SRMs are used for three main purposes: to help develop accurate methods of analysis (reference methods); to calibrate measurement systems; and to ensure the long-term adequacy and integrity of measurement quality assurance programs. NIST SRMs also legally constitute part of the National Measurement System infrastructure of the United States and, as such, are essential transfer mechanisms for national (and international) measurement traceability. The SRM Program provides a series of publications, known as the SP260 series, that is available to assist users in the application of SRMs. A complete listing of the SP260 series, the Standard Reference Materials Catalog, price list, brochures, newsletters, needs assessment forms, and feedback cards are available at http://ts.nist.gov/srm. Some of these publications give practical guidance for using the SRMs while others give additional information about the certification process of particular SRMs. Of special note is SP 260-100, Standard Reference Materials Handbook: Handbook for SRM Users, by J.K. Taylor, which was written to discuss general concepts of precision and accuracy as applied to SRMs and their impact on quality assurance and the measurement process.

\section{Contact:}

Thomas E. Gills

(30I) 975-2015

email: srminfo@nist.gov

fax: (301) 926-4342

II2 Engineering Mechanics Building

\section{CALIBRATION PROGRAM}

NIST calibration services link the makers and users of precision instruments to the basic and derived units of the International System (SI) of measurements. As one of the cornerstones for ensuring the consistency of measurements in the United States and internationally, this measurement transfer system is a critical factor in controlling manufacturing, assembly processes, and marketing as well as assuring the quality of manufactured goods. Users of these services send transfer standards to NIST where they are calibrated according to a measurement process that is stable, predictable, and statistically controlled. Currently, NIST provides more than 500 different calibrations, special tests, and measurement assurance programs in seven major measurement areas.

The Calibration Program distributes selected publications of general interest, including the Calibration Services Users Guide (SP 250), describing the calibration services 
NIST provides; the Calibration Fee Schedule (SP 250 appendix); Guidelines for Evaluating and Expressing the Uncertainty' of NIST Leasurement Results (TN 1297); Guide for the Use of the International System of Units (SP 811); and Experimentation and Measurement (SP 672). To request these publications, fax your name and address to the number below.

\section{Contact:}

Sharrill Dittmann

(301) 975-2002

email: calibrations@nist.gov

fax: (301) 869-3548

236 NIST North

http://ts.nist.gov/calibrations

\section{WEIGHTS AND MEASURES PROGRAM}

The Weights and Measures Program promotes uniformity among the states in weights and measures standards, laws, and practices to facilitate trade and protect U.S. businesses and citizens. It is estimated that these laws and regulations impact U.S. sales of products or services totaling over $\$ 4.13$ trillion annually. The program is known outside of NIST as the Office of Weights and Measures (OWM), a name that dates back to 1837 when the program was established. OWM sponsors the National Conference on Weights and Measures (NCWM), an organization of state weights and measures officials and representatives of industry, consumers, and federal agencies. NCWM develops uniform laws, regulations, and methods of practice that are published by NIST (www.nist.gov/ncwm). When these standards are adopted by regulatory agencies, they become mandatory. OWM administers the State Laboratory Program, which provides the basis for ensuring traceability of state weights and measures standards to NIST; the National Type Evaluation Program, which evaluates models of commercial weighing and measuring equipment to determine compliance with NIST Handbook 44; and the NCWM/NIST Training Program for weights and measures officials and state and industry metrologists.

\section{Contact:}

Gilbert M. Ugiansky

(301) 975-4004

email: owm@nist.gov

fax: (301) 926-0647

223 NIST North

www.nist.gov/owm

\section{INFORMATION SERVICES}

The Office of Information Services (OIS) maintains a comprehensive, international collection of information in scientific disciplines such as metrology, mathematics, physical sciences, computer science, and materials science. OIS staff serve the technical information needs of NIST scientists and engineers and communicate the results of NIST research to scientific and engineering communities worldwide.

OIS programs include selecting, acquiring, organizing, and disseminating primarily scientific and technical information in print and electronic forms. The NIST Research Library, with its specialized collection of approximately 200,000 volumes, including subscriptions to approximately 1,500 journals, microform collections, and electronic databases available on CD-ROMs or through online services, serves the entire NIST scientific and research community.
OIS can be reached on the Internet through the NIST Virtual Library (http:// nvl.nist.gov), a resource that features a selection of information resources available at the library, as well as pointers to other related information resources available through the Internet, including the World Wide Web.

To obtain further information about the NIST Research Library and the specialized reference services, online search services, and available databases, contact library reference staff at (301) 975-3052 or email: reflib@nist.gov.

\section{Contact:}

Paul Vassallo

(301) 975-2786

email:paul.vassallo@nist.gov

fax: (301) 869-8071

E106 Administration Building

http:/nvl.nist.gov 


\section{FACILITIES INDEX}

Acoustic Anechoic Chamber

Facility, 125

Advanced Insulation Facility, 50

Advanced Network Facility, 108

Calibrated Hot Box, 49

Center for Theoretical and

Computational Materials Science, 140

Computer and Network Security Facility, 108

Concentric Loop Antenna Systems, 96

Controlled Background Radiometric Facility, 160

Electromagnetic Anechoic Chamber, 96

Electron Paramagnetic Resonance Facility, 161

Fluid Flow Measurement and Research Facilities, 75

Ground Screen Antenna Range, 95

High-Resolution UV and Optical Spectroscopy Facility, 159

Integrated-Circuit Fabrication Laboratory, 97

Large-Scale Structures Testing Facility, 48

Large Environmental Chamber, * 48

Line Heat-Source Guarded Hot Plate, 49

Liquid-Nitrogen Flow Measurements, ${ }^{*} 75$

Low-Background Infrared Radiation Facility, 160

Magnetic Thin-Film Fabrication and Imaging Facility, 98

Magnetic Microstructure Measurement Facility, 159

Magnetic Engineering Research Facility, 141

Mass Standards Facility, 125

Materials Science X-ray Beamlines, 140

Medical-Industrial Radiation Facility, 160

Mobile Transient Reception/ Transmission System, 97

Mode-Stirred Chambers, 95

Molecular-Beam Epitaxy Facility, 94

National Advanced Manufacturing Testbed, 124

Near-Field Scanning Facility for Antenna Measurements, 98

Neutron Interferometer and optics Facility, 162
NIST Center for Neutron Research," 136

Powder Characterization and Processing Laboratory, 142

Radiopharmaceutical Standardization Laboratory, 162

Semiconductor Processing Laboratory, 93

Small-Angle X-ray Scattering Facility, ${ }^{*} 142$

Standard Transient//mpulsive Field Facility, 97

Synchrotron Ultraviolet Radiation Facility I11, 159

Transverse Electromagnetic Cell, 95

Tri-Directional Test Facility, 48

Uiltralow-Temperature Electronics Facility, 97

Wafer Probing Laboratory, 94

\section{SUBJECT INDEX}

\section{A}

AASHTO, Materials Reference

Laboratory, 42

absolute cryogenic radiometer, 88 , 160

ac

signals, generation of, 79

waveforms, 79, 87

accreditation

laboratories, testing and calibration, 165

Program, National Voluntary Laboratory, 165

ac-dc

thermal conversion measurements 88

voltage and current measurements, advanced, 79,87

acoustic(s)

anechoic chamber, facility, 125

emission

techniques, 116

waveform-based, 135

measurements

services, 125

temperature scale, 63

research, 115

resonators, 63

technology, flow measurements, 54 waveguides, 63

adaptive learning systems,

ATP focused program, 8

additives, compatibilizers, and

fillers, 134 adhesion, interfacial, 135

adsorbents

fundamental and applied properties of, 62

adsorption isotherm measurements, gases, 69

advanced

ceramics, precision machining research, 113

image display systems, 81

insulation facility, 50

manufacturing

Systems and Networking Testbed, 120

Testbed, National, 112, 118, 12

materials

precision machining research, 113

Program, 127

technologies, ATP projects, 21, 22

Network Technologies, division, 101

optical systems, 113

Processing Programs, division, 131

Technology Program

focused program descriptions, 8

overview, 6

programs and competitions, 8

project listing, 13

project sampler, 7

Proposal Preparation Kit, 12

proposing a focused program, 10

Welding Manufacturing System, 118

aerospace alloys, casting, 133, 134

agreement(s)

cooperative research and development, 35, 105, 167

facility use, 38

guest researcher, 35

air

conditioning, dynamic system, 44 quality and ventilation, 43

algorithm(s)

automation, reliability, 78

computational geometry, 106

image compression, 105

large-scale optimization, 104

mass spectral database, 66

mathematical and statistical problems, 104

numerical, high-performance computers, 103

signal processing, 58

statistical and neural network, 103

theoretical, 150

analytical

Chemistry, division, 69

infometrics, 73 analytical (cont.)

mass spectrometry for organics and biomolecules, 70

measurements, focusing cold neutrons for, 74 separation science methodology, 71 annealed fiber coil technology,

stable current sensors, 92 annealing, semiconductor wafers, 93 antenna

accuracy, 36

calibrations, 95, 96

characteristics, 98

diagnostics, 98

measurements, 87, 98

patterns, 95

Range, Ground-Screen, 95

systems, concentric loop, 96

APl thread gauges, measurement, 110 appearance

measurements for coated objects, 41 metrology, 42

application experts, enhancing capabilities of, ATP projects, 13 applied

computational chemistry, 56

Economics, division, 47

architecture

computer, 107

control, 113, 116

description languages, 119

reference model, manufacturing, 117 system, 103

artificial intelligence, selection of materials, 41

aspheres, measuring figure error, 113

assembly, materials

measurements, 128

ATM (asynchronous transfer mode)

network simulation and modeling, 101

network, testbed, 108

product interoperability and

standards conformance testing, 10 atmosphere

chemistry studies

high-resolution measurements, 157 use of laser pulses, 154

measurements, ambient, 72

research, 61

spectral studies, 153

thermodynamic data, 64

see also environment(al), ozone layer

atom(s)

cold, trapped, 150

highly ionized, research on, 149 
$\operatorname{atom}(s)($ cont.)

interferometry, 149

laser cooling and trapping of, 149

atomic

beam frequency standards, 156

clocks, next generation, 150

data. neutral atoms and ions, 159

-force microscope, calibrated, 110

Physics, division, 148

processes, fundamental, 61

-scale measuring machine, 110

spectra, measurement, 149

spectrometry, 69,70

spectroscopy, fundamental studies, 69

structure, 150

total energies, results, 147

atomization of steel, 133

automated

approaches; instrument control,

drift, and interference

corrections, 70

chemical analysis systems, 73

Computer Time Service, 163

conversion of machine-printed

documents to electronic form, 103

data entry from handprinted form images, 103

design and manufacturing systems, manipulating dynamic objects, 106

fingerprint classification, 103

generation of tests for specifications, formal methods, 99, 100

methods for mechanism generation, analysis, and reduction, 57

Production Technology, division, 113 sample preparation and sensing, 73

sample treatments, 70

welding, 118

automatic speech recognition technology, 102

automation

construction, 41, 44

electronic design, 81

laboratory technology and standards, 73

automotive

AutoStep, pilot project, 122

Composites Consortium, 135

manufacturing monitoring and control technologies,

ATP project, 12

measurements and standards, 36

parts, liquid composite molding, 135 product design, SIMA, 120

see also vehicle award, Malcolm Baldrige National Quality, 33

B

BACnet

Interoperability Testing Consortium, 37

standard, 36

Baldrige National Quality Program, 33

ballistic imaging systems, 106

barriers, trade, 166

beam stations, NSLS, 140

benchmark reference data, 147

bidirectional characterization, optical scatter, 154

biocatalyst development, industrial, 52

biomaterials

macromolecular structure, 52

measurement methods, 52

biomimetic materials, 53

biomolecular materials, 53

biomolecules

analytical mass spectrometry, 70

characterization and control, 53

determination of, 71

markers for health status, 70

bioprocess engineering

measurements, 52

bioreactor, desktop, ATP project, 7

biosensors

automated sample preparation, 73

biomimetic surfaces, 53

bioseparations, preparative, 53

biotechnology

applications, 53

ATP projects, 20

Center for Advanced Research in, 52,53

division, 52

health-related, ATP projects, 20

industrial and agricultural, ATP projects, 21

blackbody

and band-limited IR radiation, 88

cryogenic, 153, 160

heat-pipe, 152

large-area, development, 152

sources, 160

bone palliation, 162

Bose-Einstein condensates, 150, 158

bound coherent scattering lengths, measurement, 162

brachytherapy, intravascular, 162

breadboard heat pump, refrigerants and refrigeration cycles, 43 bridges and other large structures, technologies for, ATP projects, 18

brittle materials, mechanical properties, 129

broadband

integrated services digital network, 101

probes and sensors, calibration, 97

budget, 4

building(s)

and Fire Research

databases, 168

Laboratory, 40

codes and standards, 40

control

BACnet, consortia, 37

systems, 36,44

Environment, division, 43

heat transfer, 43

indoor air quality and ventilation, 43

Materials, division, 41

see also construction

C

calibration

and Research Laboratory,

Large-Scale Metrology, 112

laboratories, 165

Measurement Services, 168

methodologies, coordinate measuring machine, 111

Program, 168

services, 168

calorimetry, low-temperature heat capacity, facility, 64

camera, thermal imaging, 152

cancer therapy, clinical radiology, 161

candela, detector-based, 151

capacitance, fundamental standard, 88

capillary, electrophoresis automated sample preparation methods, 73

DNA detection, 52

mass spectrometry, 70

trace-level determination, 71

carotenoids in food and serum, 71

catalysts, NCNR studies, 139

catalysis and biocatalysis technologies,

ATP focused program, 9, 17

cement and concrete

Reference Laboratory (CCRL), 42

research, 41

Center for Advanced Research in

Biotechnology (CARB), 52, 53 ceramic(s)

advanced

Powder Characterization and

Processing Laboratory, 142

precision machining research, 113

ATP projects, 24

coatings, 127

databases

ceramic machinability, 128

Phase Diagrams for Ceramists, 128

Structural Ceramics, 128

division, 126

functional, 131

machining

Consortium, 37, 131

program, 131

mechanical properties, 129

phase equilibria diagrams, 36

powders, nanometer-scale, 7

processing

Characterization Consortium, 38, 132

research, 36, 132

certification

conformity assessment activities, 165

information, 166

chemical

analysis

NIST Center for Neutron

Research, 138, 139

with neutron beams, 74

equilibrium constants, 64

kinetics, 57, 64

measurements, improving

quality of, 61

microsensors, solid-state, 57

modeling, drug design and, ATP projects, 20

radicals, fundamental atomic and molecular processes, 61

reactions

dynamics, 154

pressure-dependent, 65

Science and Technology

Laboratory, 51

thermodynamics, 64

vapor deposition

materials processing, 55

reactions, 65

semiconductor processing, 94

chemistry

and chemical engineering,

ATP projects, 20

and Life Sciences Office, ATP, 17

ATP projects, 20

computational

applied, 56

program, 64

databases, 168

electroanalytical, 72 
chemistry (cont.)

in thermal reactors, flow and, 56 of materials processing, 55

WebBook, 65

chemometrics research, 61

chlorofluorocarbon research, 36, 66

chromatographic retention indices, analysis of natural gas, 62

chromatography

and electromigration techniques, 70

capillary, 71

gas, 71,72

liquid, 70,71

supercritical fluid, 71

clays, properties, 67

clocks

atomic

next generation, 150

NIST-7, 156

high-performance, noise

processes, 157

synchronized, hardware, 107

closed-loop

control, 56

manufacturing program, 113

coatings

appearance measurements, 41

ceramic, 127

diamond deposition and multilayer materials, ATP projects, 22

electrodeposited, ovaluation of methods used to optimize properties, 134

modeling appearance of, 42

organic, 42

Service Life Prediction

Consortium, 37, 42

steel, 41

cold

atoms, laser cooling and trapping, 149

neutrons

analytical measurements, 74

depth profiling, 138

prompt-gamma-ray activation analysis, 138

reflectometer with polarized

beam option, 137

source and guide hall, 136

trapping of polarized, 105

collaborative research, 3, 35

collision

-induced dissociation, analytical problems, 70

phenomena, ultracold neutral atom traps, 150 colloidal

mixtures, NCNR studies, 139

solutions, dynamics, 68

suspensions, studies, 67,143

combustion

chemical kinetic mechanisms, 57

chemistry, use of laser pulses, 154

data, measurement technology for benchmark spray, 54

polymer, research of, 3, 47

turbulent, models, 106

commerce

domestic, 165

electronic

in scientific and engineering data, 145

of component information, 81

of printed circuit assembly services, 82

of technical information, 44 STEP, 122

commercialization, N1ST technologies, 39, 167

Common-Criteria-based testing program, 101

complex

coupling, high-temperature reacting flows, 57

Form Metrology Laboratory, 110

reactions, 65

component-based software, ATP

focused program, 8,13

composite(s)

particles with enhanced magnetic and structural properties, growth, 55

polymer, 134

structures, manufacturing, ATP

focused program, 9, 18

compositional mapping, 61, 74

compression, image, 104

computational

algorithms, near-field optics, 150

chemistry, 64

fluid dynamics

capabilities, 75

large eddy simulation techniques, 45

metering research, 54

geometry, 104

materials research, 140

metrology of manufactured parts, 111

computer(s)

-aided design

semiconductor devices and packages, 84

sof tware, 121

STEP standard, 122 computer(s) (cont.)

-aided Manufacturing Engineering

Consortium (CAME), 37, 121

assisted tomography, 148

emergency response team, 108

graphics, techniques, 103

-integrated

construction, 44

knowledge system, construction materials and systems, 42

manufacturing, standards development, 120

massively parallel processing, 150

modern architecture, performance, 107

network security, statistical process control paradigm, 105

security

division, 100

technology, 100, 101, 108

simulation

air and contaminant transport, 43

formation dynamics and structure of gels, 67

measurement process, 111

thermodynamic and transport properties of fluids, 67

virus laboratory, 108

computing

and communications, high-

performance

information storage and interconnect systems, 107

Systems lntegration for

Manufacturing Applications, 120

parallel, 107

scientific, 106

concrete

frame structures, strengthening methodologies, 41

high-performance, 41, 42

condensed matter, 147

conformance testing

information technology, 100

STEP project, 123

conformity assessment

activities, 165, 166, 167

Systems Evaluation, National

Voluntary (NVCASE), 167

consortium

Automotive Composites, 135

BACnet Interoperability Testing, 37

Ceramic Machining, 37, 131

Ceramic Processing

Characterization, 38, 132

Coatings Service Life

Prediction, 37,42 consortium (cont.)

Computer-Aided Manufacturing Engineering, 37, 121

Enhanced Machine Controller, 37

electronic solders, 134

Environmentally Friendly New Flame Retardants, 37

Flowmeter lnstallation Effects, 37

Machine Tool Performance Models and Machine Data Repository, 38

Monolithic Microwave lntegrated Circuits, 37,86

National lndustrial lnformation Infrastructure Protocols, 122

National Storage Industry, 141

N1ST-EPRI Ultrasonic Flow Meter Testing Program, 37

North American 1ntegrated Services Digital Network Users' Forum, 37

Optical Properties of Materials, 37

Orthopedic Accelerated Wear Resistance, 37

PlantSTEP, Inc., 44, 120

constant(s)

elastic, resonance spectra, 135

fine-structure, determination of, 88

fundamental, data center, 145

optical, multilayer materials, 146

physical, redetermining, 72

rate, estimation of, 57,65

constraint representation, design tools, 121

construction

computer-integrated, 44

Materials and Systems Program (CONMAT), High-Performance, 41, 42

Materials Reference Laboratories (CMRL), 42

seismic standards, 40

see also building(s)

contaminant(s)

environmental, 71

gases

measuring in ultrapure materials, 72 measuring partial pressure of, 59

particle

formation, detection, 56

nucleation, simulation, 57

transport in buildings, 43

contract(s), research and

development, 35

controller(s)

enhanced machine, 37, 116, 119

real-time, software engineering, 119

cooperative research and

development agreements assistance, 167 
cooperative research and development agreements (cont.)

joint research efforts, 35

statistical engineering, 105

coordinate measuring machines, instruments, and systems calibration methodologies, 111

large-scale, standardization, artifact development, and calibration, 112

laser tracker, 112

measurement traceability, 36, 105

metrology, 111

temperature- and humidity-

controlled environment, 110

tolerance standards, 120

corrosion

detection and characterization, 55

Performance Database, NACE/NIST, 128

resistance of rapidly solidified nitrogenated steels, 134

coulometry, high-accuracy, 72

coupling coefficients of the weak interaction, 155

cryocooler(s), research and development, 68

cryoelectronics, nanoscale devices, 88

cryogenic(s)

current comparator

calibrating resistors, 78

precision electrical measurements, 78

flow measurement devices, calibration, 75

radiometry, 91, 152

temperatures, 68

cryptographic security, technology and standards, 100, 101

crystal

components, subsurface damage in single-, 114

Data Center, 128

diffraction techniques, 151

growth, mathematical modeling, 103

properties, 129

shapes, modeling three-dimensional, 141

structures, studies, 139

crystallography

analysis, 136

X-ray, 53

current measurements, advanced, 78,79

\section{D}

data

Center, Fundamental Constants, 145

chemical, 65

crystallographic, 128 data (cont.)

dictionaries, online, 81

Encryption Standard, 101

estimation

computational chemistry, 56

thermochemical and kinetic, 57

exchange, 120

fire, 45

for electronic structure

calculations, 147

machine-tool performance, 114

manufacturing, 121, 123

materials

characterization, 86

evaluated, 128

Measurement Services, 168

metals, 133

optical, storage, 92

polymer characterization, 130

process, 124

product, 81, 122, 145

Program, Standard Reference, 168

repository, 114

scientific and engineering, electronic commerce in, 145

sets, web service, 105

spectral, 153

spray combustion, 54

storage

digital, ATP focused program, 8, 13

ultrahigh density, 141

thermochemistry, $\mathrm{Si}-\mathrm{O}-\mathrm{H}$ and

Si-P-H, 57

thermodynamic, 64

time-series, statistical analysis of, 157

database(s)

adsorption isotherm measurements, 69

ceramic machinability, 128

fire data management, 45

hexapod metrology, 112

high- $\mathrm{T}_{\mathrm{C}}$ superconductivity, 128

indoor air quality performance, 43

NACE/NIST Corrosion Performance, 128

NIST/EPA/NIH Mass Spectral, 66

NIST Research Library, 169

optical constants, high-accuracy, 83

over computer networks,

dissemination of, 145

Phase Diagrams for Ceramists, 128

Physics Laboratory, 145

software errors, faults, and

failures, 99

Standard Reference Data

Program, 128, 168

structural ceramics, 128

thermochemical and kinetic properties, 65 daylight saving time, advanced alert, 163

deadweight standards, 115

decay-scheme parameters,

measurements, 162

degradation

chemical and physical mechanisms, 135

electric power, sources and presence, 80

mechanisms and methods, 41

dental

and medical materials, 127

ceramics, abrasive finishing and wear, 131

design

advanced, chemical measurements, 61

automation, electronic, 81

research, engineering, 121

detector(s)

characterizations, 91

fire protection, 45,46

infrared

characterizing, 153

long wavelength, 88

metrology, spectral radiometry, 152

photodiode, for radiometry, 146

technologies, characterizing

appearance, 42

$\mathrm{X}$-ray, 97

diagnostic(s)

DNA, tools for, A'TP focused program, 9, 19

for process control, online, 56

imaging, 162

low-temperature discharges, 80

predicting failure of electrical

insulating materials, 80

software, 99

dielectric(s)

materials and devices, 93

reliability, metrology, 84

research, 80

thin-film, 83

diffractometer

for residual stress, texture, and single-crystal (DARTS) studies, 136

high-performance, multiaxis, 150

neutron powder, high-resolution, 136

diffusion, oxidation, and annealing, 93

digital

data storage, ATP focused program, 8,13

display interfaces, 107

Library of Mathematical Functions, 104 digital (cont.)

signature

fingerprint biometrics, 36

standard, 101

video

in information networks, A'TP

focused program, 8, 14

Interoperability Testbed, 108

supercomputer, 81

technology development, 101

tools and management capabilities,

A'TP projects, 14

dilute-solution thermodynamics, 68

dimensional

measurement

capabilities, 110

coordinate measuring systems, 120

traceability, complex forms, 110

diode

high-frequency, capabilities, 88

lasers

frequency-stabilized, 159

high-performance, 157

semiconductor devices, 93

disabilities aids, 117

disaster response planning, 46

discharges

low-current dc Townsend, 80

low-temperature, 80

radio-frequency, 80

dispersion

and rheology, ceramic processing,

132

standards, 91

display(s)

and graphic image manipulation,

ATP projects, 16

flat-panel, metrology for, 81

information, light measurements,

151

quality, issues, 81

systems, advanced image, 81

technology systems, advanced, 107

DNA

chemistry, 52

diagnostics, tools for, ATP focused program, 9, 19

profiling, 52

sequencing technology, ATP project, 7

document conversion, automated,

103

domain-engineered geometries,

bulk and thin-film ferroelectric

materials, 93

dopant(s)

concentration profiles, evaluation, 93

profiles, two-dimensional, 83 
dosimetry

chemical, 155

electron paramagnetic resonance, 161

medical, 161

neutron, 156

NIST Center for Neutron Research, 139

radiation accident, 161

drug(s)

design and chemical modeling,

ATP projects, 20

of abuse in urine and hair, 71

drying, mechanism, 132

durability of construction materials and systems, 42

\section{E}

earthquake

engineering, National Earthquake

Hazards Reduction Program, 40, 48 simulation, Large-Scale Structures

Testing Facility, 48

system to predict spread of fires, 45

see also seismic

economic(s)

Applied, office, 47

Assessment Office, ATP, 12

sof tware tools for evaluating cost effectiveness of capital investments, 47

electrical

characterization of plasma parameters, 56

discharges, production of toxic byproducts, 80

insulators, dielectrics used as, 80

interconnect reliability, integrated circuits, 84

power systems

dielectrics used as electrical insulators, 80

metrology, 80

precision measurements, high-temperature superconductors, 78

properties of materials, non-invasive evaluation, 97

substitution, measurements, 152 systems, reliability and safety, 80 transport measurements of superconductors, 89

Electricity, division, 77

electroanalytical chemistry, inorganic, 72

electrodeposition techniques, metals processing, 133 electromagnetic

characterization of materials, 86

emission, radiated, 95

fields

division, 85

generation, 96

immunity measurements, 95

interference and compatibility, 87

noise, effects, 79

probes and sensors, evaluating impulse response, 97

Technology, division, 87

waves, mathematical modeling, 103

electromigration

and stress voidage, 128

reliability testing of magnetoresistive heads, 105

techniques, 70

electron(s)

accelerator, 160

and 0ptical Physics, division, 146

attachment cross sections for etching gases, 80

beam ion trap, 149

density of states in solids, 159

in solids, interactions, 147

Paramagnetic Resonance Facility, 161

spin-dependent contrast measurements in STM, 146

transfer processes, intra- and inter-protein, 52

electronic(s)

and Electrical Engineering Laboratory, 76

and electrical systems, new materials/manufacturing, ATP projects, 17

and optical systems, noise in, 157

ATP projects, 16, 17

commerce

in scientific and engineering data, 145

of component information, 81

of printed circuit assembly services, 82

of technical information, 44 STEP, 122

component representations, objectoriented, 82

databases, 168

design

automation, 81

Integrated Infrastructure for, 81

handbook, engineering problems and software applications, 120

information technology and, ATP, 8

Manufacturing, Integrated Infrastructure for, 82 electronic(s) (cont.)

marketplace, 145

packaging, interconnection and assembly, 128

product data, exchange, 81

structure

calculations, data for, 147

in matter, 150

systems, testing, 79

electrostatic discharges, measurement of fields radiated from, 97

elemental

analysis, 74

isotopic metrology, inorganic and, 69

ellipsometry, multiple wavelength, 94

energy conservation, buildings, 36 ,

$43,47,48,49$

engineering

design research, 121

measurements for near- and supercritical processes, 55

ontologies, design tools, 121

enhanced machine controller, 37 , 116,119

enthalpy

of adsorption

chlorinated trace constituents of natural gas, 62

clay and carbon adsorbents, 62

of combustion, 64

of formation, 64

environment(al)

atmospheric and chemometric research, 61

building, 43

chamber, large, 48

contaminants, 71

exposure of building materials, 42

Friendly New Flame Retardants

Consortium, 37

impact of gaseous dielectrics, 80

trace gases, 72

virtual, 119

see also atmosphere, ozone layer enzyme(s)

-catalyzed reaction project,

biothermodynamics, 52

characterization, 53

designer, 52

epitaxial growth, nanometer-scale

science, 146

epitaxy, kinetic-energy-enhanced, microscopic basis, 158 error(s)

analysis techniques, 113

correction codes, image compression, 105

sources, coordinate measuring machines, 111 etching, semiconductor processing,

94

evaluated data, materials, 128

experiment design, 105

EXPRESS, formal description

language, 123

extreme ultraviolet

microscopy, 148

optics, 146

\section{F}

face recognition, image-based systems, 103

facilities, use agreements, 38

Fastener Quality Act, 167

fast-pulse and waveform acquisition standards, research, 79

fiber optics

characteristics, 92

metrology, research, 91

sensors, 92

film, see thin-film

fine-structure constant, determination, 88

fingerprint classification automated, 36, 103

holographic storage, 107

finite-element modeling of complex physical and chemical processes, 68 fire(s)

-emulator/detector-evaluator, first generation, 46

detection and alarm, 45, 46

dynamics, 45

large, 45

measuring accurately, 46

oil-spill, 45

research

grants, 39

Information Service, 45

resistance of construction materials and systems, 42

Safety Engineering, division, 45

Science, division, 46

sensing, advanced, 46

service, law enforcement

standards, 77

suppression, 45, 46

flame(s)

extinguishers, 46

fundamental processes, 69

retardants, polymers, 47

Retardants Consortium,

Environmentally Friendly, 37

flammability, properties, 47 
flat-panel displays

metrology, 81

test methods, technology, and standards, 107

flow

and chemistry in thermal reactors, 56

-injection technology, optimization, 70

measurement

liquid-nitrogen, 75

research and standards, 54, 75

-meter

development of low-gas flow acoustic, 59

installation effects, consortium, 37

Testing Program, NIST-EPR1, 37

thermal mass, characterization, 59

reacting, simulation, 57

fluid(s)

and fluid mixtures, properties, 66 ,

$$
67,68
$$

flow

mathematical modeling, 103

measurement and research

facilities, 75

simulation, 68

software libraries, 107

grinding, chemical and

chemomechanical effects, 131

fluorescence, planar laser-induced, 56

fluorocarbon(s)

chemistry of, 56

plasmas, etching and chamber cleaning, 56

refrigerants, novel applications, 43

flux pinning in materials, examination, 129

foams, mathematical modeling, 103

focused ion beam, facility, 82

focused program (ATP)

adaptive leaming systems, 8

catalysis and biocatalysis

technologies, 9

component-based software, 8

descriptions, 8

digital

data storage, 8

video in information networks, 8

information infrastructure for healthcare, 9

manufacturing composite structures, 9

materials processing for heavy manufacturing, 9

microelectronics manufacturing infrastructure, 10

motor vehicle manufacturing technology, 10 focused program (ATP) (cont.)

photonics manufacturing, 9

premium power, 10

selective-membrane platforms, 9

technologies for the integration of

manufacturing applications, 9

tissue engineering, 9

tools for DNA diagnostics, 9

vapor compression refrigeration

technology, 10

force, measurement, 115

free radical(s)

damage to DNA, 52

kinetics, studies, 64

optical detection, 64

frequency

-domain

performance of sampling and digitizing systems, 79

techniques, optoelectronic measurement, 91

-stabilized lasers, 159

standards, 156

fundamental

and applied properties of adsorbents, 62

Constants Data Center, 145

physics, 139, 156

properties

for membrane separations, 63

of trace components of natural gas, 62

studies of atomic spectroscopy, 69

\section{G}

Gaseous Electronics Conference reference cell, 56, 80

gas(es)

analyzers for semiconductor process control, residual, 59

atmospheric, characterization, 61

chromatography, identifying organic compounds, 66

contaminant, measuring partial pressure of, 59

densities, measuring low, 59

flow acoustic flowmeter, low-, 59

-phase

species concentrations, 56 synthesis, nanoparticles, 55

pure, precise isotopic reference standards, 59

semiconductor processing, thermophysical properties, 63

thermophysical properties, 63

trace, analysis, 72

transport-property relationships, membrane separations, 63 gear involute artifacts,

measurement, 110

gels, properties, 67

geographic information systems

(GIS), 100

geometry, computational, 104

giant magnetoresistance

effect, magnetic multilayers, 129, 147

read-heads, 141

gigabit networks, instrumentation, 107

glass fiber materials, automotive applications, 135

global

Positioning System

GIS support, 100

satellite-based navigation system, 117

time transfer, 157

Standards Program, 166

warming, 160

GOES Time Code Service, 163

grants

fire research, 39

materials science and engineering, 39

precision measurement, 39

research, 39

Small Business lnnovation Research

Program, 39

Standard Reference Data, 39

graphic(s)

computer, techniques, 103

image manipulation, displays and, ATP projects, 16

scientific, 106

graphical multivariate data

exploration, chemical

measurements, 61

graphite-reinforced composites, marine and infrastructure applications, 135

green body characterization, ceramic processing, 132

Green's function library, 141

guest researcher agreements, 35

guided-wave microwave standards and measurements, 85

Guide to Available Mathematical Software, 104

\section{H}

halon fire suppressants, 46

handprinted forms, automated data entry from images, 103

hardness, standard test techniques, 105, 130

health

-care, information infrastructure, ATP focused program, 9, 14 health (cont.)

-related biotechnology,

ATP projects, 20

see also medical

hearing aids, development, 125

heating, dynamic building system, 44

heat transfer

measuring with calibrated

hot box, 49

research, 43,55

Henry's constants, dilute-solution thermodynamics, 68

hexapod

machine tools, 118

metrology, 112

high-performance

computing and communications

information storage and

interconnect systems, 107

Systems Integration for

Manufacturing Applications, 120

Construction Materials and

Systems Program, 41, 42

diode lasers, 157

sensors, infrared detectors, and

mixers, 88

Systems and Services, division, 106

high-speed

communications, optical fibers, 105

microelectronics, digital circuits, 86

networks, 101

optoelectronic measurements, 91

high-temperature

superconductors

applying to precision electrical measurements, 78

database, 128

electronics, 89

interfaces and electrical transport, 89

materials for wire and magnet

applications, 128

thermocouples, 58

holographic storage, 107

hotline(s)

European standards, 166

technical barriers to trade, 166

Hubble Space Telescope,

high-resolution spectrograph, 160

Human-Computer Interface

Technologies, 102

hurnidity measurement techniques, new generation, 59

hybrid fiber-coaxial systems, 101

hydrocarbons

decomposition in complex

mixtures, 65

polycyclic aromatic, 71

refrigerants, novel applications, 43

source of, 53 
hydrofluorocarbons,

thermochemistry, 57

hydrogen content in materials, 162

identity profiling, DNA, 52

imaging

analysis, computerized, 41

and measurement technology,

ATP projects, 23

-based measurement devices, 42

compression, 104

diagnostic, 162

display systems, advanced, 81

for magnetic recording technology, nanoprobe, 90

medical, tomography, 148

nuclear magnetic resonance, drying, 132

techniques, advanced, 148

visual, 42,103

immunity testing, electronic equipment, 95, 96, 97

immunoassay-based techniques, automated sample preparation, 73

indoor air quality and ventilation, 43 industrial

fellow agreements, 167

Partnerships Program, 167

process reactor simulations, 56

infometrics, analytical, 73

information

Assurance Partnership, National, 101

capacity improvements for transmission and distribution, ATP projects, 14

infrastructure

for healthcare, ATP focused program, 9, 14

Protocols Consortium, National Industrial, 122

networks, digital video, ATP focused program, 8,14

Program, Standards, 166

retrieval, search engines, 105

services, 169

standards-related, 166

storage and interconnect systems, 107 technology

and Electronics Office, ATP, 8, 13

ATP projects, 16

Laboratory, 99

visualization, 103

infrared

detectors

characterization, 160

Comparator Facility, 153

long wavelength, 88 infrared (cont.)

intelligent (cont.)

Radiation Facility, Low-Background, 153,160

radiometers, development, 160

spectral radiometry, 153

infrastructure

development technologies,

ATP projects, 14

for healthcare, information,

ATP focused program, 9, 14

microelectronics manufacturing,

ATP focused program, 10, 21

inorganic

and elemental isotopic metrology, 69

building materials, 41

compounds, thermodynamic data, 64

electroanalytical chemistry, 72

materials, crystallographic data, 128

inquiries, general, 3, 4

inspection system, in-process and post-process, 116

insulation

facility, advanced, 50

measuring thermal conductivity with hot-plate apparatus, 49

thermal performance of, 43

integrated circuit(s)

electrical interconnect reliability, 84

fabrication

infrastructure, 83

Laboratory, 97

Semiconductor Processing Laboratory, 93

incorporating ultrasmall metal tunnel junctions, 97

manufacturing processes, characterization, 84

measuring

features, 36

patterned layers, 111

metrology, 111

mixed-signal, testing, 79

new materials, ATP project, 7

next-generation, 83

ultra-large-scale, 105

see also semiconductor(s)

integrated infrastructure

for Electronics Design, project, 81

for Electronics Manufacturing, 82

integrated optics, metrology, 92

intellectual property, managing, 35, 167

intelligent

building mechanical systems, 44

machining of ceramics, 131

processing of materials, 132

systems

architecture, 117

automated welding, 118 systems (cont.)

component-based approach, 119

division, 116

RoboCrane, 118

vehicle systems, 117

interactions of cold,

trapped atoms, 150

interconnection, materials needs, 128

interconnect reliability, metrology, 84

interface(s)

and adhesion, measurement, 128

and networking, sensor, 114

integrating "smart" transducers, 36

NCNR studies, 139

program, operator, 119

properties of, 153

specifications for advanced

manufacturing systems, 120

standards, 118, 119

superconductor, 89

interfacial effects in polymer

blends, 134

international

Organization of Legal Metrology, 165

standardization activities, 166

System of Units, 145, 150, 151, 168

trade, standards-related policies and procedures, 165, 166

Internet

Commerce for Manufacturing project, 82

next-generation, 102

security, 101

see also World Wide Web

interoperable systems

BACnet, consortia, 37

North American 1SDN Users

Forum, 37

interoperability

system components, ATP projects, 14

testing

building controls, 36, 44

standard, development, 107

STEP, 123

inventions, NIST-patented, 39

inverse problems, 103

ion

cluster, mobility of, 158

implanter, semiconductor processing, 94

lithography, source, 149

/molecule reactions and clustering processes, kinetics and thermochemistry, 64

storage research, 156

trap technology, 70

lonizing Radiation, division, 155

irradiation facilities, 139
ISDN Users' Forum,

North American, 37

isotopic

metrology, inorganic and

elemental, 69

reference standards for pure gases, 59

\section{J}

JILA, 158

joining, cutting, and grinding,

ATP projects, 22

Joint Army/Navy/Air Force (JANAF) Tables, 64

Josephson

array

development, 87

device, 78

standards, fabrication, 97

-effect, voltage standards, 78, 87

junctions, high-temperature superconducting, 89

Journal of Research of the National Institute of Standards and Technology, 4

\section{K}

kinetic-energy-enhanced epitaxy, microscopic basis, 158

kinetics, chemical, 64

L

laboratory

accreditation

fastener testing, 167

Program, 165

automation technology and standards, 73

testing and calibration, 42, 165

language

process specification, 124

technology, spoken, 102

large-scale

manufacturing, intelligent systems integration testbed, 118

measurement, laser tracker, 112

Metrology Calibration and Research Laboratory, 112

laser(s)

cooling and trapping, 149

deposition of thin films, 158

diode, high-performance, 157

Doppler velocimetry, validation of flow meters, 54, 75

focusing of atom beams, 147

ionization of diatomic molecules in dense vapors, 149

isotope separation, 149 
laser(s) (cont.)

lead salt, 153

magnetic resonance, 157

optical techniques for temperature

and concentration measurements

in fires, 47

polarization of neutron beams, 155

pulses

femtosecond

sum frequency generation, 153

time-resolved infrared

spectroscopy, 154

observations, 154

radiation, fundamental atomic and molecular processes, 61

radiometry, measurement methods and standards, 90

scattering system, thin film, 158

spectroscopy, 149, 158

stabilized, 159

tracker, metrology, 112

ultraviolet, extreme, 160

vertical-cavity surface-emitting, 93

law enforcement standards, 77

layer(ed)

measuring pattemed, 111

structures, NCNR studies, 139

lead artifacts, measurement, 110

leap seconds, advanced notice, 163

length standards, sources, 157

library

Research, NIST, 169

virtual, NIST, 169

licenses, 39, 167

life-cycle costing, 47

lifeline systems, seismic performance, 40

light

measurements, 151

scattering

molecular mass characterization, 130

studies, 67, 153

surface observations, 62

linear systems, solution of large sparse, 104

line heat-source guarded hot plate, 49

liquefaction, techniques for determining, 41

liquid-nitrogen flow measurements, 75

lithography, X-ray, 113

low-flow standards, measurement, 59

low-temperature

discharges, chemical and physical processes, 80

plasmas, 148

refrigeration, advanced, 68

lumen, measurement accuracy, 151 luminescence spectral

radiometry, 151

\section{M}

machine

controller, enhanced, 116, 119

data repository, 114

tool performance models and machine data repository, 38, 114

tools, ATP projects, 22, 23

machining

ceramic, 131

Research Facility, Precision, 113

virtual, 114

macromolecules

biological structure and function, 53 molecular geometry of, NCNR

studies, 139

potential components of devices, 53

studies, fluid behavior, 67

magnet(ic)

Engineering Research, facility, 141

facility, 16

instruments, characterization, 90

levitation solubility instrument, 63

materials

mathematical modeling, 103

studies, 129, 155

microstructure, 147, 159

multilayers, investigations, 137

recording technology

ATP projects, 14

metrology, 89

nanoprobe imaging, 90

scanning micromagnetic

recording system, 89

resonance imaging, 155

scattering studies, 137

superconducting, 89

systems, NCNR studies, 139

-tesla, 78

Thin-Film Fabrication and 1maging Facility, 98

manufacturing

applications, technologies for integration of, ATP focused program, 9, 15

ATP projects, 23, 24

competitiveness, 25

composite structures, ATP focused program, 9, 18

Engineering

Laboratory, 109

tool kit, 37, 121

Extension Partnership

center locations, 28

overview, 25

success stories, 26 manufacturing (cont.)

heavy, materials processing, ATP focused program, 9, 21

infrastructure, microelectronics, ATP focused program, 10, 21 knowledge-based, ATP projects, $22,23,24$

net-shape, ATP projects, 21, 22 photonics, ATP focused program, 9 product data exchange standards, 122 program, closed-loop, 113

resource data, 123

simulation, software, 121

Systems integration, division, 120

technology, motor vehicle, ATP focused program, 10, 22

Testbed, National Advanced, $112,118,124$

manufactured parts

recognition, computational schemes, 104

three-dimensional, 111

mass

flow converters, 63

fundamental unit, 115

research, 115

Standards, Facility, 125

mass spectrometry

see spectrometry

material(s)

advanced technologies, ATP projects, 21, 22

and Manufacturing Office, ATP, 21, 23

brittle, mechanical properties, 129

building, organic, 41

characterization, electromagnetic, 86 construction, 42

databases, 168

handling, intelligent vehicle systems, 117

magnetic, 90

Measurement Services, 168

Optical Properties of, consortia, 37

processing

chemistry of, 55

for heavy manufacturing, ATP focused program, 9, 21 reactors, growth, 57

Program, Standard Reference, 168

Reliability, division, 126

science and engineering grants, 39

Laboratory, 126

structures, NCNR studies, 139

mathematical

and Computational Sciences, division, 103 mathematical (cont.)

functions, 104

modeling, 103

representations of concrete microstructures, 41

software, 104

Matrix Market, 104

measurement(s)

and Standards Laboratories, 35

of partial pressures and moisture, quantitative optical, 59

process

evaluation, 105

simulation, 111

services, 168

System, National, 168

technology for benchmark spray combustion data, 54

traceability, Standard Reference Materials Program, 168

uncertainty, 105, 145

mechanical properties,

brittle materials, 129

medical

and dental materials, 127

diagnostics, ionizing radiation, 155

dosimetry, 161

imaging

magnetic resonance, 155

tomography, 148

-Industrial Radiation Facility, 160

see also health

membrane(s)

platforms, selective, ATP focused program, 9

separations, fundamental properties, 63

mercury-containing dental alloys, hazards, 128

message passing interface, 107

metallic alloys, dendritic growth, software libraries, 107

metallurgical

facility, monitoring electrical properties of materials, 78

techniques, resistance standards, 77

Metallurgy, division, 126

metals

data and characterization, 133

deformation, 141

hydrogen in, NCNR studies, 139

processing, 133

Metric Program, 164

see also International System of Units

metrology

dielectric reliability, 84

electrical power systems, 80

fiber-optic, 91

flat-panel displays, 81 
metrology (cont.)

hexapod, 112

interconnect reliability, 84

isotopic, inorganic and elemental, 69

magnetic recording, 89

manufactured parts,

computational, 111

microwave and terahertz.

HTS devices, 89

modeling and simulation, 84

nanoelectronics, 82

optical characterization, 82

process and tool control, 84

scanning probe microscope, 83

silicon-on-insulator, 83

thin-film process, 83

micelles, properties, 67

microbeam analysis, 60

microcalorimeter, microwave power

measurements, 86

microeconomic analysis, 47

microelectromechanical systems

(MEMS), 61, 85, 97

microelectronic(s)

components, manufacture, 56

high-speed, 86

manufacturing

infrastructure, ATP focused program, 10,21

measurement procedures, 93

materials measurement and

standards issues, 128

packages, system-level thermal performance, 84

processing, chemistry of, 57

products, reliability, 84

programs, 77

microfluidics, 73

microform measurement, surface

finish and, 110

microhotplate designs, microsensors, 57

micromagnetic materials, modeling, 140

microphones, micromachined silicon, development, 125

microscopy

atomic-force, 83, 90, 106, 149

electron, 106

extreme ultraviolet, 148, 159

infrared, 159

magnetic

force, $90,98,147$

resonance force, 98

magneto-optic Kerr, 147

near-field scanning optical, 154

optical, 94, 106, 111, 115, 150

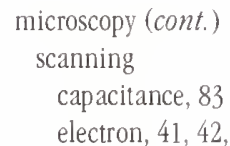

electron, 41, 42, 61, 105, 110, 111

electron with polarization

analysis, 106, 147, 159

near-field magneto-optic, 98

probe, $83,90,98,110,111$

tunneling, 58, 90, 146, 147, 158

X-ray, 148

microstructure(s)

and dynamics of frustrated

materials, 140

and magnetism, correlation, 146

atomic measurement techniques, 60

control, intelligent processing of

materials, 133

development, ceramic processing, 132

electronic and structural behavior, 82

interfacial, polymer composites, 134

magnetic, 147, 159

metals, 133, 135

stresses in brittle materials, 130

studies, 139

microwave

-digestion technology,

optimization, 70

guided-wave standards and measurements, 85

measurement, high-temperature superconductors, 89

mirror systems, multilayer, 113

mobility

of cluster ions, 158

outdoor, 117

model(ing)

aerosol, 57

appearance of coatings, 42

ATM network, 101

BEES, decision support system, 47

building envelope, heat, air, and moisture transfer, 43

cement and concrete structures, 41

chemical, 20, 65

CONTAM, air contamination, 43

coordinate measuring machines, errors, 111

design tools for process equipment, 56

disaster planning, 45

display characteristics using

Princeton Engine, 81

eddy simulation, fires, 45

error, testing electronic systems, 79

film systems, 131

finite-element, 68, 141

fire hazard and risk prediction, 45, 47

flammability properties, 47

fluid properties, 67,68 model(ing) (cont.)

fluid/solid-particle systems, 68

Henry's constants, 68

HVAC control system, 44

life-cycle costing, 47

Machine Tool Performance, consortia, 38

magnetic materials, 129

materials, 135,140

mathematical, 103

measurement process evaluation, 105

micromagnetic materials, 140

microstructure, cement pastes, 41

MOIST, prediction of moisture

transfer within building, 43

multivariate statistical, solution processes, 63

nanostructures, 150

numerical, dielectric materials and devices, 93

residual gas analyzers for semiconductor process control, 59

organometallic vapor-phase epitaxy, 68

optimization, 47

organic building materials, degradation, 41

primary pressure standards, 59

processes, 62, 121, 132, 133, 135

product, 121

regenerative cryocoolers, 69

semiconductor devices and packages, 84

smoke movement, 45

standard solder interconnect geometries, 140

turbulent combustion, 106

terrain, large-scale, 104

thermomechanical behavior of coatings, 127

thermophysical properties of fluid mixtures, 66,67

Wulffman, three-dimensional crystal shapes, 141

moisture

measurements, ceramic processing, 132

quantitative optical measurements, 59

transfer within building, model, 43 molecular

-beam epitaxy, 82, 94, 137

biology, facilities, 53

data, chemistry WebBook, 65

drag gauges, 59

dynamics

mathematical models, 103

particle nucleation and growth, 55 studies, 139 molecular (cont.)

kinetics and excitation, 159

mass characterization, polymers, 130

measuring machine (M-cubed), 110

processes, fundamental, 61

recognition technology, ATP project, 7

studies, equilibrium and non-equilibrium systems, 67

monolayers, self-assembled, 58

monolithic microwave integrated circuits (MMlCs), 37, 86

motor vehicle

see automotive, vehicle(s)

multilayer

magnetic processing, 129

materials, synthetic, production and characterization, 150

multimedia

and digital video, 101

test methods, technology, and standards, 107

mutation detection, methods and standards, 52

N

nanoelectronics

metrology for, 82

molecular measuring machine, 110

nanofabrication

source, electron beam ion trap, 149

with atom optics, 147

nanometrology, 82

nanoparticle formation, molecular dynamic simulations, 57

nanoprobe imaging, magnetic recording technology, 90

nanoscale

cryoelectronics, devices, 88

devices, research and metrology, 82

systems and metrologies, theory, 150 nanostructures

electronic properties, 146

fabrication of, 82

titanium thin films, production, 55 vapor-phase synthesis of, 55

nanotomography, X-ray, 148

nanotribology, magnetic hard disks, 129

national

Advanced Manufacturing Testbed, 112, 118, 124

Center for Standards and Certification lnformation, 166

Conference on Weights and Measures, 169

Earthquake Hazards Reduction Program, 40, 48 
national (cont)

Electronics Manufacturing Initiative, 82

Industrial Information Infrastructure Protocols Consortium, 122

Information Assurance Partnership, 101

Measurement System, 168

Quality Program, 33

Semiconductor Metrology Program, $\rightarrow$

Technology Roadmap for Semiconductors, 77, 83, 84

Transfer and Advancement Act, 165, 167

Type Evaluation Program, 169

Voluntary Laboratory Accreditation Program, 165

natural gas

properties of trace components, 62 systems, thermophysical properties, 66

near-critical processes, engineering measurements for supercritical and, 55

near-field

data, analysis of spherical, 87

measurements

photonic structures, 154

power, 96

optics, 150

scanning

characterization of antennas, 87

facility for antenna

measurements, 98

optical microscopy, 154

network(ing)

high-speed, 101

security, 101, 108

sensors, 114

standard interface, 36

synchronization, time transfer, 157

neutron(s)

activation analysis, 74, 138

beams, chemical analysis, 74

beta decay, 155, 156

cold, 74, 136

depth profiling, 74, 138

diffraction, properties of gels, micelles, and clays, 67

dosimetry, 156

-electron scattering length, 155, 162

interferometry, 139, 155, 162

lifetime, beam measurement, 156

phase contrast imaging, 162

physics, 139, 155

radiography, 139

reflectometers, 137

research, 136

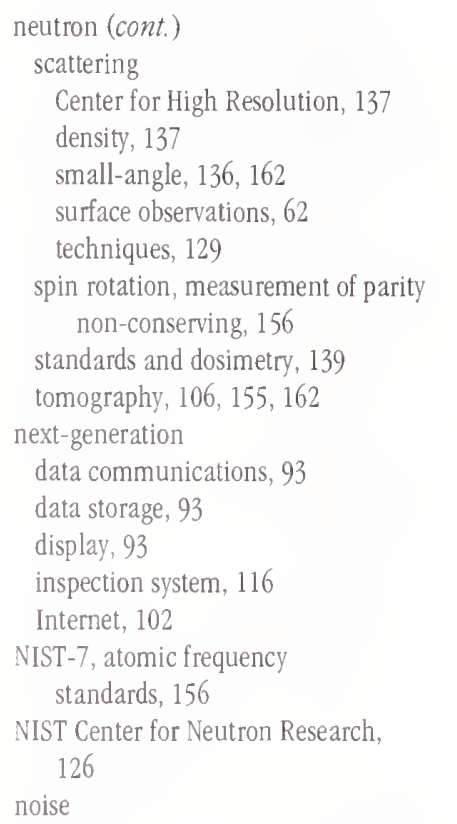

odorants, measurement in natural gas, 62

oil

production, technologies for offshore, ATP projects, 18

-spill fires, 45

online search services, NIST

Research Library, 169

on-wafer metrology, research and development, 86 open

architecture controllers, 116

systems architecture standards, 117, 118

operator interface, 119

optical

absorption, software libraries, 107

adsorption-based standard for measuring low gas densities, 59

cells, in-situ measurements, 55

-character recognition

image-based systems, 103

research, 107

in electronic and optical systems, 15

optoelectronic measurements, 91

processes in high-performance clocks, 157

temperature and figure measurements, radiometer, 86

non-destructive

evaluation methods

bulk and thin-film ferroelectric materials, 93

composites, 135

material-property and defect, 116

microstructure, 135

sensor development, 133

testing methods for structures, 41

non-disclosure arrangements, 167

North American Free Trade

Agreement, standards-related

aspects, 166

nuclear

magnetic resonance, 52, 143

medicine, radioactivity measurements, 162

reactors, neutron dosimetry, 156

numerical control program

verification, software, 121

\section{0}

object-oriented

electronic component representations, 82

finite-element modeling of composite materials, 141 numerical software design, 104 technologies, 44, 122 characterization metrology, 82

data storage, measurements, 92

detection, free radicals, 64

diagnostics, synthesis of nanoparticles, 55

/electro-optical components and systems, ATP projects, 17

fiber(s)

characteristics, 92

power, measurement services, 90

sensors, 92

Standard Reference Material, 91

filters, Standard Reference Material, 72

manipulation of atoms and molecules, 157

measurements

non-linear, 153

properties

materials, 159

of Materials Consortium, 37

of nanostructured materials, mapping, 154

radiation, measurement, 152 recording technology,

ATP projects, 13

reflectance, 106

scattering measurements, 153

systems

advanced, 113

noise in electronic and, 157

techniques

for trace-gas analysis, 72

high voltage testing, 80 partial pressures and moisture, 59

space-based applications, 113 optical (cont)

technology

appearance parameters, 42

division, 151

waveguide, planar geometries, 92

optics

atom

developing, 150

nanofabrication with, 147

extreme ultraviolet, 146

integrated, metrology, 92

optimization

and computational geometry, 104

design tools, 121

real-time, chemical processes, 153

optoelectronic(s)

division, 90

measurements, high-speed, 91

semiconductor devices, 93

sources and detectors

characterization, 90

temporal properties, 91

orbital eigen-values, elements, 147

$\operatorname{organic}(s)$

building materials, 41

compounds

analytical mass spectrometry, 70

Henry's constants, 68

thermodynamic data, 64

trace levels, 70, 71

interaction of pollutants with clay, 67

spectral "fingerprints," 66

organizational structure, NIST, 5

orifice pulse tube refrigerator,

cryocooler, 68

Orthopedic Accelerated Wear

Resistance Consortium, 37

osmometry, molecular mass

characterization, 130

oxidation, semiconductor wafers, 93

ozone layer, destruction of, 36,43 ,

$46,64,66,153$

see also atmosphere, environment

\section{$\mathrm{P}$}

packaging, electronic, 128

paint, Coatings Service Life

Prediction, consortia, 37

parallel computing, 107

partial differential equations,

103,104

particles (s)

charged, fundamental atomic and molecular processes, 61

dynamics, software libraries, 107

nucleation and growth, molecular dynamics, 55 
partnerships

industrial, 167

research, 35

technology, 167

patents, 39, 167

pattern formation in filled

polymers, 141

permeability measurements

bulk materials, 86

gases and gas mixtures, 63

permittivity measurements,

bulk materials, 86

pesticides, 71

pharmaceuticals, macromolecular structure, 52

phase

behavior in polymer blends, 134

composition, 143

contrast imaging, 155

diagrams

alloy, 134

for ceramic materials, 129

for ceramists, database, 128

shear effects, 134

equilibria

diagrams, 36

measurement, 63

measurements, 162

transition studies, 162

photodiode

detectors for radiometry, 146

metrology, solid-state, 152

photolithography

film thermal converter structures, 79

semiconductor wafers, 94

photometry, 151

photonic(s)

ATP projects, 16

devices, electronic and structural behavior, 82

information processing, test

methods, technology, and

standards, 107

manufacturing, ATP focused program, 9

structures, near-field measurements 154

Physical and Chemical Properties, division, 62

physics

databases, 168

Laboratory, 144

neutron, 155

plane waves, incident, 96

plant layout, software, 121 plasma(s)

diagnostics in tokamaks, 160

etching processes

low pressure, 56

chemical kinetic mechanisms, 57

fundamental processes, 69

low-temperature, 148

processing and chemistry

materials processing, 55

research, 80

semiconductors, 56

-spray research, 127

"plug-and-play"

compatibility, standard interfaces,

114,118

factory, 82

polarization-dependent loss and gain, optical communications, 92 pollution

atmospheric, 61

indoor, 43

see also atmosphere, environment

polychlorinated biphenyls, 71

polycyclic aromatic hydrocarbons, 71

polymer(s)

blends and processing, 3, 134

characterization, 130

combustion research, 3, 47

composites, 134

division, 126

filled, 141

-matrix composites, 41, 42

mathematical modeling, 103

potentiometry scanning, 90

powder

atomization processes, 134

characterization and processing, 142

diffraction data, 136

processing, 132

synthesis, 143

power

laser, measurement, 90

optical fiber, measurement, 90

premium, ATP focused program, 10,23

systems

dielectrics used, 80

metrology, electrical, 80

pre- and post-flight $\mathrm{X}$-ray

calibrations, 151

precision

electrical measurements, superconductors, 78

Engineering, division, 110

Machining Research Facility, 113

measurement grants, 39

$\mathrm{X}$-ray and gamma-ray spectroscopy, premium power, ATP focused program, 10, 23

pressure

-dependent chemical reactions, 65

quantitative optical measurements of partial, 59

vacuum, and low-flow standards, 59

Princeton Engine, video supercomputer, 81

printed wiring board, advanced manufacturing technologies, ATP project, 12

PRISE system, text search and retrieval, 102

probe(s)

broadband, calibration, 97

calibrations, 98

electromagnetic, evaluating impulse response, 97

proximal, fundamental atomic and molecular processes, 61

process(es)

analysis and spectroscopy standards and, 72

and tool control, metrology, 84

control, 116, 132, 133

online diagnostics, 56

data, 124

manufacturing, 113

measurements

division, 54

evaluation, 105

near- and supercritical, engineering measurements, 55

planning software, 121

polymer composites, 134

Specification Language, 124

surface dynamical, 61

processing

ceramic, 132

intelligent, 132

materials

chemistry of, 55

intelligent, 132

metals, 133

plasma, semiconductors, 56

polymers, 134

visual image, 103

product

data

exchange

electronic, 81

National Initiative, 145

standards, 122

management, software, 121

testing, activities, 165

production, System Engineering

Tool Kit, 121 prompt-gamma-ray activation analysis, chemical analysis, 74 proprietary measurements, 38 proteins (s)

folding, NMR measurements, 52 spectroelectrochemistry, measurement methods, 52 public domain prototype retrieval system, 102

public key infrastructure, computer security, 100

pulse(s)

and waveform acquisition standards, fast, 79

-echo techniques, 116

laser

femtosecond

sum frequency generation, 153

time-resolved infrared spectroscopy, 154

observations, 154

measurements, ultrashort, 93

radiolysis of aqueous solutions, 64

ultrashort laser, condensed phase chemistry, 154

a

quality

air, indoor, 43

assurance, Standard Reference

Materials, 168

construction materials, 42

measurement and data analysis, chemical measurements, 61 tools for, 72

control, methods, 155

measurement assurance, 155

Program, Baldrige National, 33

quantitative optical measurements of

partial pressures and moisture, 59 quantum

chemistry methods, 64

Hall effect, national unit of resistance, 78

physics

division, 158

fundamental questions, 162

principles, tests and demonstrations 162

processes, modeling, 150

quasicrystal structures with

icosahedral symmetries, display, 106

$\mathbf{R}$

radiant power, high-precision measurements, 153 
radiation

accident dosimetry, 161

continuous wave, laser sources and detectors, 90

effects and processing, 161

industrial, processing, 161

interactions with matter, 159

ionizing

measurements, 155, 161

processing, 155

quality assurance, 155

measuring unintentional emissions, 87

protection instruments, 156

ultraviolet, SURF, 159

radioactivity measurements, 36, 162

radiofrequency, radiation, biological effects, 96

radiography, industrial, 161

radioimmunotherapy, 162

radiology, clinical, 161

radiometry

cryogenic

absolute, 88, 160

high-accuracy, 91, 152

infrared

facility, 160

spectral, 153

laser, 90

luminescence-spectral, 151

near ultraviolet, 152

photodiode detectors for, 146

spectral, 152

thermal, 152

vacuum ultraviolet, 148

radionuclide

production, 161

measurements, 162

radiopharmaceuticals, 36, 162

radio stations WWV, WWVB, and

WWVH, 163

radon, entry and transport, 43

Raman spectroscopy, standards, 60

random processes, 103

rare-earth doped solid-state

waveguide lasers and amplifiers, 93

reacting flow simulation, 57

reactions

chemical, pressure-dependent, 65

dynamics, 154

reactor(s)

research, NIST Center for Neutron

$$
\text { Research, } 136
$$

thermal flow and chemistry in, 56

real-time

controllers, software engineering, 119

control system, 117

video processing, Princeton

Engine, 81 recording, magnetic, 89,90

reflectivity, dissipative

macrostructures, 97

reflectometry

in fiber, 91

neutron, 137

thin-film, 94

refrigerants, alternative, 36, 43, 63 ,

$$
66,153
$$

refrigeration

low-temperature, advanced, 68

machinery, 43

technology, vapor compression, ATP focused program, 10, 23

reliability

dielectrics in thin films, 84

electrical interconnect, 84

powder properties measurement techniques, 132

remote

manufacturing, 119

monitoring, 72

sensing, 152

research

and development

agreements, 35

contracts, 35

programs, 167

relationships, 167

and Technology Applications,

Program, 167

grants, 39

resistance standards and materials quantum Hall effect, 78

research, 77

retrieval

system, public domain prototype retrieval, 102

technology, 102

reverberating chambers, 95,97

risk management software, evaluation, 108

robots, RoboCrane, 118

Rockwell C hardness indenters, measurements, 110

role-based access control, first formal model, 99

roofing materials, $41,42,43$

roughness, Standard Reference Material, 110

\section{S}

sample(s)

automated

preparation and sensing, 73

research, 70

preparation, chromatographic and electrophoretic approaches, 71 sampling and digitized systems, time and frequency domain performance, 79

Sapphire Statistical Characterization and Risk Reduction Program, 115

satellite(s)

communications antennas, 36

determination of temperature of

Earth's surface and atmosphere, 160 optical characterization, 82

global positioning system, 117, 157

GOES, 163

scanning microscopy

see microscopy

scattering

Center for High Resolution Neutron Scattering, 137

inelastic, 137

light

molecular mass characterization, 130 studies, 67, 153

surface observations, 62

magnetic, studies, 137

measurements, optical, 153

optical, measurements, 153

reference instrument, multi-angle, 154

$\mathrm{X}$-ray, small-angle, 142

S-Check, instrumentation product, 107

scientific

computing, 106

visualization, 106

security technology

computer, 100, 101, 105, 108

law enforcement standards, 77

surveillance, intelligent vehicle, 117

seismic design and construction standards, 40,48

see also earthquake

selective-membrane platforms,

ATP focused program, 9

self-assembly

biomimetic materials, 53

monolayers, 58

semiconductor(s)

assessment of wafer materials and homoepitaxial overlayers, 151

chemical composition, NCNR studies, 139

devices

and packages, modeling and simulation, 84

materials, and fabrication, ATP projects, 16

dielectric reliability, 84

Electronics, division, 82

etching discharges, 80

interconnect reliability, 84

ion implantation, 77

process control, residual gas semiconductor(s) (conl.)

measurement and standards, measuring patterned layers on integrated circuits, 111

Metrology Program, national, 77, 128 microelectromechanical systems, 85 molecular-beam epitaxy, 82, 94

nanometrology, 82

optoelectronic devices, 93

plasma processing of, 56

process and tool control, 84 analyzers, 59

processing

equipment, effectiveness, 84

gases, thermophysical properties, 63

Laboratory, 93

low-temperature plasmas, properties, 148

reference material, 36

scanning probe microscopy, 83

silicon-on-insulator, 83

thin-film

process, 83

standards, 150

thermal process modeling, 84

see also integrated circuit(s)

sensing, automated sample

preparation and, 73

sensor(s)

-based process control, 116

broadband, calibration of, 97

characterizing plasmas, 56

electromagnetic, evaluating impulse response, 97

fast-response, 134

fire, 46

high-performance, 88

infrared, 68

interfaces and networking, 114

magnetic, 129

magnetoresistive, 89

materials, 155

micro-, solid-state chemical, 57

multianalyte measurements, 58

optical fiber, 92

process, 113, 132, 135

production-line, 135

smart, 36, 114

technology, 133

separation(s)

chemistries, microwave-digestion and flow-injection technologies, 70 processes

adsorbents, 62

alternative solvents, 62

use of membranes, 63 


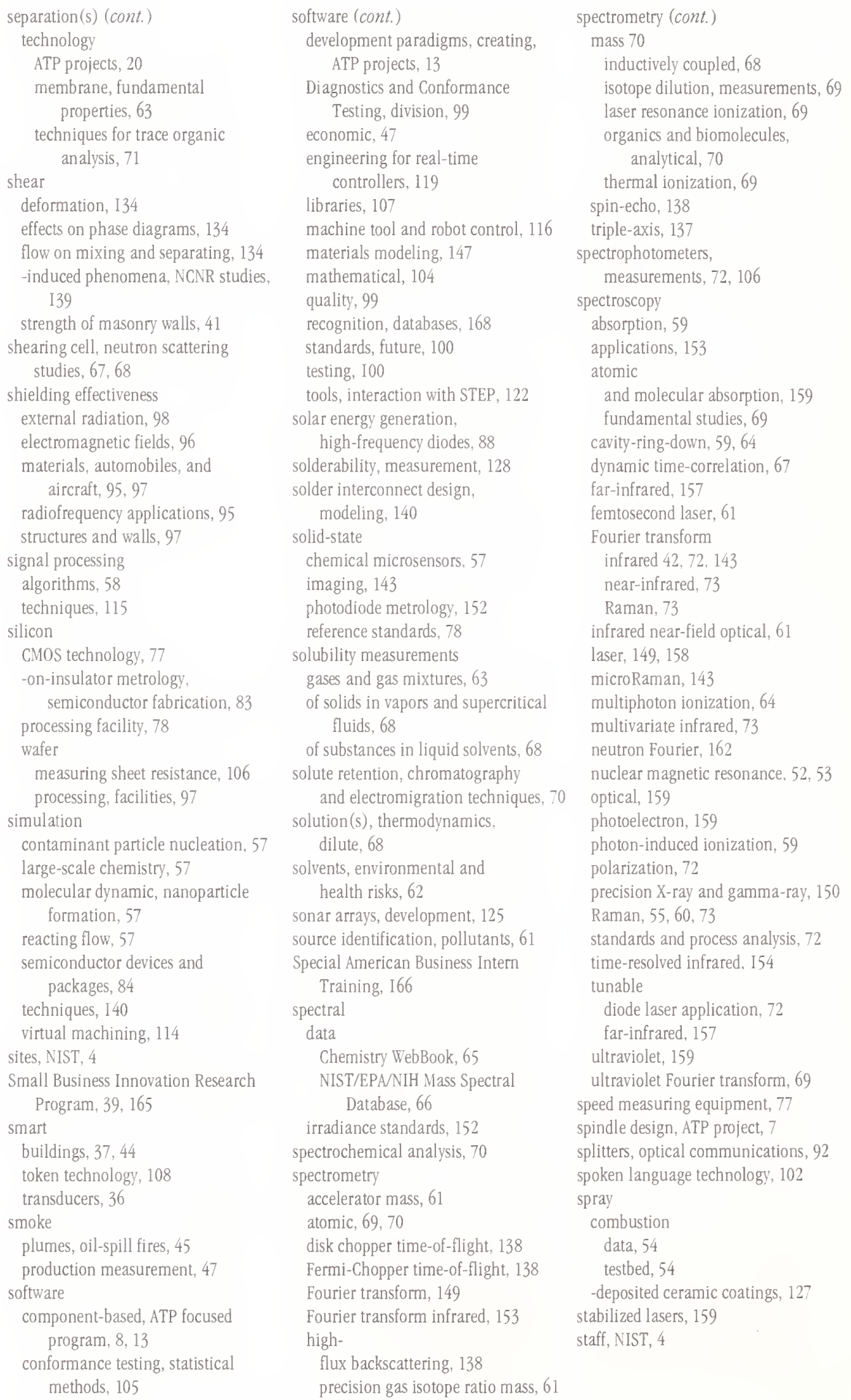

standard(s)

and Certification Information, National Center for, 166

capacitance, 88

Conformity Program, 167

Data Encryption, 101

Digital Signature, 101

experts at key embassies and missions, 166

fast pulse and waveform acquisition, 79

guided-wave microwave, 85

Information Program, 166

low-1low, 59

magnetic moment, 129

manufacturing, 120

organic building materials, 42

Policy, Interagency Committee on, 165,166

pressure, 59

product data exchange, 122

Program, Global, 166

Raman spectroscopy, 60

Reference Data

for semiconductor industry, 80

grants, 39

Program, 128, 168

Reference Materials Program, 168

-related information, 166

Secure Hash, 101

Services, Office of, 165

software, future, 100

Standards Activities Program,

Technical, 165

superconductor, 88

vacuum, 59

voltage

ac, 79

Josephson-effect, 78

voluntary, 165, 166

Standard Reference Material(s)

calorimetric, 64

ceramic processing, 132

coordinate measuring machines, 112 insulation, 43

law enforcement, 77

linewidth/pitch for photomasks, 111

magnetic materials, 129

metals processing, 133

optical

fibers, 91

filters, 72

retardance, 92

polymer characterization, 130

radiopharmaceutical, 162

roughness, $1 \mathrm{I} 0$

scanning electron microscopy, 110 
Standard Reference Material(s) (cont.) spectral range, 154

thermal performance of windows, 43 warelength calibration. 92 state

Laboratory Program, 169

weights and measures, 169

static analisis tools, Unravel. analyzing changes to $\mathrm{C}$ language source code, 99

statistical

analysis of time-series data, 157

Engineering

collaboration, 105

division. 105

steel

high-performance, 42

nitrogenated, corrosion resistance, 134

powders, atomization of 133

protective coatings for, 41

STEP

conformance and interoperability testing, 123

design information, 121

Sational Industrial Information Infrastructure Protocols

Consortium, 122

registry, 122

storage

data, 141

digital data

ATP focused program, 8, 13

test methods, technolog; ; and standards, $10^{\top}$

high-performance, 107

holographic, 107

information, $10^{-}$

optical data, 92

research, ion, 156

strength and ductility,

precast concrete structures, 40

stress(es)

and moisture in plastic packages, 128

in brittle materials.

microstructural, 130

voidage, 128

structural

control, 41

performance, 42

structure(s)

division, 40

electronic, data for, 147

in biological membranes, investigations, 154

large-scale testing facility, 48

photonic, near-field. 154

technologies for bridges and other

large, ATP projects, 18 substrate characterization, calibration of disc birefringence testers. 92

subsurface damage in single-crystal components, 114

sum frequency generation, non-linear measurements at interfaces, 153

superconductor(s)

high-temperature applving to precision electrical measurements, 78

database, 128

electronics, 89

materials for wire and magnet applications, 128

integrated circuits, fabrication, 97 interfaces and electrical transport, 89 quantum interference device magnetometer, 78, 98

standards and technology, 88

structure and magnetic

characterization, 129

systems and devices, ATP projects, 17

supercritical

fluid mixtures, thermophysical properties, 62

processes, engineering measurements for near- and, 55 surface (s)

and interface chemistry measurements, 143

and Microanalysis Science, division, 60

characterization, 159

dynamical processes, 61

modification, ATP projects, 21, 22

reactions, biomolecular processes, 53

texture measurement, standard, 110

surfactants, surface modifications of adsorbents, 62

synchronization, time transfer and network, 157

synchrotron radiation

resolution, 148

SURF, 159

synthesis of precise signals, 79

synthetic multilayers, production and characterization, 150

systems

and network security, 101

and Networking Testbed Advanced Manufacturing, 120

Integration for Manufacturing Applications (SIMAA), 44, 120, 123 intelligent, architecture, 117 manufacturing, 120

\section{T}

technical

barriers to trade, 166

Standards Activities Program, 165

technology

at a Glance, 4

integration of manufacturing applications, ATP focused program, 9, 15

licenses, 39

services, 164

transfer

and Advancement Act,

National, 165, 167

programs, 167

SIHLA, 120

telecommunications, fiber-optic metrology, 91

telephone systems, wireless, 36 terrain, modeling, 104

testbed(s)

Advanced Manufacturing Systems and Networking, 120

Advanced Welding Wanufacturing Ststem, 118

ATM network, 108

computer-integrated construction, 44

Digital Video Interoperability, 108

engineering design, 121

high-performance construction materials and systems, 42

intelligent systems integration, 118

National Advanced Manufacturing, $112,118,124$

next-generation inspection system, 116

outdoor mobility, 117

spray combustion, 54

testing and calibration

laboratories, 165

text search and retrieval, 102, 103

texture, determining, 135

theory, condensed matter, 147

thermal

analysis, materials selection and degradation, 41, 42

conductivity

building insulation materials, 49

plasma-spray coatings, 127

conversion measurements, ac-dc, 88 converters, special multijunction, 79 imaging camera, 152

performance

advanced insulation systems, 50

buildings, 48

walls, 49

windows, 43 thermal (cont.)

radiometry, 152

reactors, flow and chemistry in, 56

-spray-deposited ceramic

coatings, 127

voltage, 79

thermistor mounts, characterization, 86

thermochemistry data,

hydrofluorocarbons, 57

thermocouple(s)

high-temperature, 58

measuring temperatures in fire environments, 47

thermodynamic(s)

and transport properties of fluids and fluid mixtures, 67

chemical, 64

data, biotransformations, 52

dilute-solution, 68

thermometers

reference, wire and thin-film thermocouples, 59

transition-edge, 88

ultrasensitive, 88

thermophysical properties alternative refrigerants, 66

fluids and fluid mixtures, 67

gases, 63

natural gas systems, 66

semiconductor processing gases, 63 supercritical fluid mixtures, 62

thin film(s)

deposition, chamber, 146

fabrication

and Imaging Facility, 98

equipment, 89

process metrology, 83

images, STM, 158

laser deposition of, 158

magnetic, research facility, 159

measurements and standards, ceramics, 131

NCNR studies, 139

production facility, 150

reflectometry, semiconductor processing, 94

reliability, 84

standards, development, 150

time

and frequency

division, 156

services, 163

-domain

performance of sampling and digitizing converters, 79

techniques, optoelectronic measurements, 91 
time (cont.)

GOES satellites, 163

-resolved infrared spectroscopy, 154

-series data, statistical analysis, 157

Service, Automated Computer, 163

transfer and network

synchronization, 157

tissue engineering, ATP focused

program, 9, 19

tokamaks, plasma diagnostics, 160

tolerancing and metrology

research, 120

tomography

computer-assisted, 148

high flux X-ray, 106

neutron, 106, 155, 162

tool(s)

control, metrology, 84

for DNA diagnostics, ATP focused program, 9, 19

kit

Manufacturing Engineering, 37, 121

Production System Engineering, 121

topography, 115, 116

trace

components

microbeam analysis, 60

natural gas, properties of, 62

organic compounds, 70, 71

elements, detection, 149

-gas analysis, 72

impurities, sensing, 157

traceability

dimensional, 110

flow measurement, 54

ionizing radiation measurements, 155

measurement, SRM Program, 168

tracer gas methods, indoor pollutant concentrations, 43

trade agreements, standards-related aspects, 166

training

applied economics, 47

fire detection and alarm, 45

Special American Business

Intern, 166

weights and measures officials, 169

transfer mechanisms for

measurement traceability, 168

transport properties

molecular-level prediction, 63

of fluids and fluid mixtures, 67

transverse electromagnetic cells, 95

trapping

atoms, 149, 150

ions, 156

Type Evaluation Program,

National, 169
$\bar{U}$

\section{ultrasonic(s)}

characterization of materials, 135

Flow Meter Testing Program,

N1ST-EPR1, 37

non-contact, 135

non-linear, 135

research, 116

ultraviolet

laser, extreme, 160

microscopy, extreme, 159

radiation

biological effects, 152

SURF, 159

radiometry, near, 152

uncertainties, measurement, 73, 105 ,

$111,112,145,169$

user interface and

efficiency-enhancement

technologies, ATP projects, 15

V
vacuum
measurements, standards, 59
ultraviolet radiometry, 148
vapor
compression refrigeration
technology, ATP focused program,
10,23

-phase synthesis of nanostructures, 55

pressure measurements, 62

vector network analyzers, six-port, 85, 106

vehicle(s)

intelligent systems, 117

motor

control, intelligent systems, 117

manufacturing technology,

ATP focused program, 10, 22

technologies, ATP projects, 18

see also automobile

ventilation, buildings, 43, 44

vibration research, 115

video

display

terminals, emissions, 96

visual performance, 81

in information networks, digital,

ATP focused program, 8,14

Interoperability Testbed, Digital, 108

multimedia and digital, 101

processing, 81

Technology Laboratory, 81

tools and management capabilities, digital, ATP projects, 14 virtual

environments, 103, 119

inspection module, 114

library, N1ST, 169

machining and inspection, 38, 114

manufacturing environment, 114

reality

interfaces, 121

Modeling Language, 103

technology, NAMT, 124

viscoelasticity of polymers, 130

visual

image processing, 103

perception, 81

visualization

factory floor assembly lines, 103

information, 103

scientific, 106

three-dimensional, 103

vitamins in food and serum, 71

VLS1 Multikron clock chips, 107

volt(age)

high, testing, 80

measurements

ac-dc, advanced, 79

electrical characterization of plasma parameters, 56 ratio, 78

-meters, precision digital, 78

standards

ac, 79

Josephson array, 87

Josephson-effect, 78

voluntary

Laboratory Accreditation Program, 165

standards, 165, 166

\section{W}

wafer(s)

Probing Laboratory, 94

silicon-on-insulator, 83

waveform(s)

acquisition standards, time- and frequency-domain performance, 79

ac, synthesis, 79, 87

measurements, electrical characterization of plasma parameters, 56

waveguides, optical, 92

wavelength

calibration, SRM, 92

measurements, precise, 149, 150

mercury, precise isotope shifts, 160

standards, calibration of Hubble high-resolution spectrograph, 160 wavemeters

Fabry-Perot, 149

Fizeau, 148

wave propagation, 95, 135

Wear Resistance, Orthopedic Accelerated, consortium, 37

weights and measures

lab projects, 36

Measurement Services, 168

Metric Program, 164

National Conference on, 169

Program, 169

state standards, 169

Welding Manufacturing System Advanced, 118

wind

engineering capability, 46

load design standard, 41

windows, thermal performance, 43

wires, superconducting, 129

World Wide Web

electronic marketplace, 145

N1ST

and Your City, 5

in Your House, 5

programs and services, 4

Physics Laboratory databases, 145 servers, reference implementation of role-based access control, 99 service, reference data sets, 105 SRD database accessibility, 168 SRM catalog, 168 see also Internet

Wulffman, modeling threedimensional crystal shapes, 141

$\mathrm{X}$

$\mathrm{X}$-ray

absorption fine structure, 140 and gamma-ray spectroscopy, 150 beamlines, materials science, 140 detector

cryogenic device, 88 superior energy resolution and speed, 97

diffraction

imaging, 140

materials selection and degradation, 41

measurement capabilities, 131

microscopy, 148

nanotomography, 148

scattering, small-angle, 140, 142 technology, applications of, 151 topography, 115 
U.S. DEPARTMENT OF COMMERCE

William M. Daley, Secretary

Gary Bachula, Under Secretary for Technology

National Institute of Standards and Technology

Gaithersburg, Md. 20899-000 1

(301) $975-2000$

Boulder, Colo. 80303-3328

(303) $497-3000$

NIST Special Publication 858

July 1998 edition

Production Virginia Covahey, Susan Ford,

Gail Porter, Sharon Shaffer, and

Anne Enright Shepherd

A903 Administration Building

National Institute of Standards and Technology

Gaithersburg, Md. 20899-0001

(301) $975-2762$

Any mention of commercial products

is for information only; it does not

imply recommendation or

endorsement by the National Institute

of Standards and Technology nor does

it imply that the products mentioned

are necessarily the best available for

the purpose.

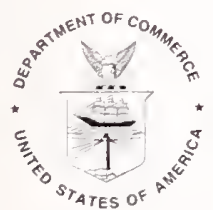




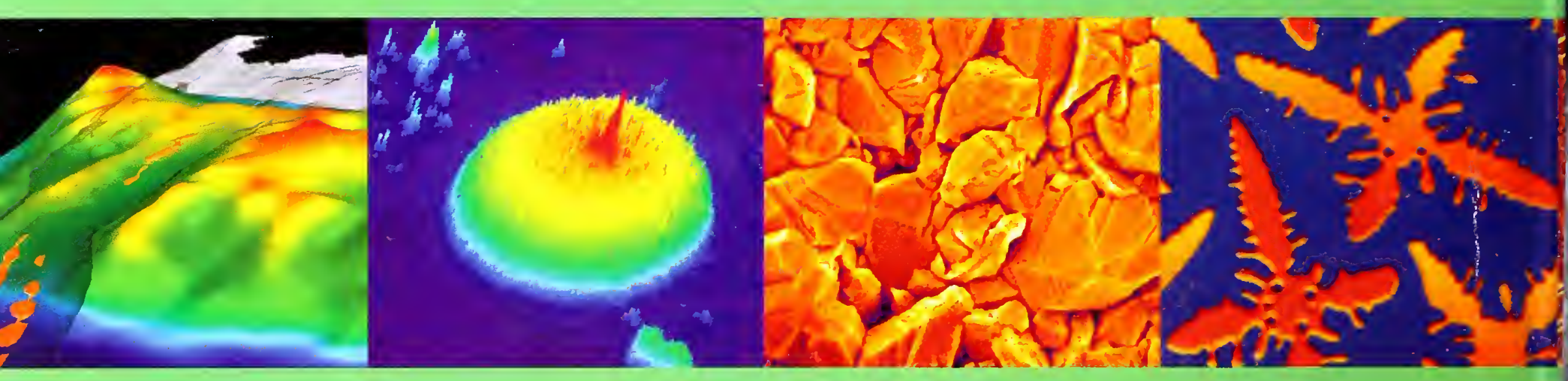

NGT 